\title{
Numerical Simulations for Enhanced Methane Recovery from Gas Hydrate Accumulations by Utilizing $\mathrm{CO} 2$ Sequestration
}

\author{
Prathyusha Sridhara
}

Follow this and additional works at: https://researchrepository.wvu.edu/etd

\author{
Recommended Citation \\ Sridhara, Prathyusha, "Numerical Simulations for Enhanced Methane Recovery from Gas Hydrate \\ Accumulations by Utilizing CO2 Sequestration" (2017). Graduate Theses, Dissertations, and Problem \\ Reports. 6708. \\ https://researchrepository.wvu.edu/etd/6708 \\ This Dissertation is protected by copyright and/or related rights. It has been brought to you by the The Research \\ Repository @ WVU with permission from the rights-holder(s). You are free to use this Dissertation in any way that is \\ permitted by the copyright and related rights legislation that applies to your use. For other uses you must obtain \\ permission from the rights-holder(s) directly, unless additional rights are indicated by a Creative Commons license \\ in the record and/ or on the work itself. This Dissertation has been accepted for inclusion in WVU Graduate Theses, \\ Dissertations, and Problem Reports collection by an authorized administrator of The Research Repository @ WVU. \\ For more information, please contact researchrepository@mail.wvu.edu.
}


Numerical simulations for enhanced methane recovery from gas hydrate accumulations by utilizing $\mathrm{CO}_{2}$ sequestration

\title{
Prathyusha Sridhara
}

\author{
Dissertation submitted \\ to the Benjamin M. Statler College of Engineering and Mineral Resources \\ at West Virginia University
in partial fulfillment of the requirements for the degree of
Doctor of Philosophy in
Chemical Engineering
Brian Anderson, Ph.D., Chair
Charter Stinespring, Ph.D.
Debangsu Bhattacharyya, Ph.D.
Ilkin Bilgesu, Ph.D.
Evgeniy Myshakin, Ph.D.
Wu Zhang, Ph.D.

Department of Chemical Engineering

Morgantown, West Virginia

2017

Keywords: Methane, $\mathrm{CO}_{2}, \mathrm{CO}_{2}$ sequestration, Class 2 hydrate accumulations, enhanced gas recovery, $\mathrm{CH}_{4}$ hydrates

Copyright 2017 Prathyusha Sridhara 


\section{Abstract \\ Numerical simulations for enhanced methane recovery from gas hydrate
accumulations by utilizing $\mathrm{CO}_{2}$ sequestration}

\section{Prathyusha Sridhara}

In 2013, the International Energy Outlook (EIA, 2013) projected that global energy demand will grow by 56\% between 2010 and 2040. Despite strong growth in renewable energy supplies, much of this growth is expected to be met by fossil fuels. Concerns ranging from greenhouse gas emissions and energy security are spawning new interests for other sources of energy including renewable and unconventional fossil fuel such as shale gas and oil as well as gas hydrates. The production methods as well as long-term reservoir behavior of gas hydrate deposits have been under extensive investigation. Reservoir simulators can be used to predict the production potentials of hydrate formations and to determine which technique results in enhanced gas recovery. In this work, a new simulation tool, Mix3HydrateResSim (Mix3HRS), which accounts for complex thermodynamics of multi-component hydrate phase comprised of varying hydrate solid crystal structure, is used to perform the $\mathrm{CO}_{2}$-assisted production technique simulations from $\mathrm{CH}_{4}$ hydrate accumulations. The simulator is one among very few reservoir simulators which can simulate the process of $\mathrm{CH}_{4}$ substitution by $\mathrm{CO}_{2}\left(\right.$ and $\left.\mathrm{N}_{2}\right)$ in the hydrate lattice.

Natural gas hydrate deposits around the globe are categorized into three different classes based on the characteristics of the geological sediments present in contact with the hydrate bearing deposits. Amongst these, the Class 2 hydrate accumulations predominantly confirmed in the permafrost and along seashore, are characterized by a mobile aqueous phase underneath a hydrate bearing sediment. The exploitation of such gas hydrate deposits results in release of large amounts of water due to the presence of permeable water-saturated sediments encompassing the hydrate deposits, thus lowering the produced gas rates. In this study, a suite of numerical simulation scenarios with varied complexity are considered which aimed at understanding the underlying changes in physical, thermodynamic and transport properties with change in pressure and temperature due to the presence of the simple $\mathrm{CO}_{2}$-hydrate and mixed hydrates (mainly $\mathrm{CH}_{4}-\mathrm{CO}_{2}$ hydrate and $\mathrm{CH}_{4}$ $\mathrm{CO}_{2}-\mathrm{N}_{2}$ hydrate) in the porous geologic media. These simulations on $\mathrm{CO}_{2} / \mathrm{CH}_{4}-\mathrm{CO}_{2}$ hydrate reservoirs provided a basic insight to formulate and interpret a novel technological approach.

This approach aims at prediction of enhanced gas production profiles from Class 2 hydrate accumulations by utilizing $\mathrm{CO}_{2}$ sequestration. The approach also offers a possibility to permanently store $\mathrm{CO}_{2}$ in the geologic formation to a greater extent compared to a direct injection of $\mathrm{CO}_{2}$ into gas hydrate sediments. The production technique implies a three-stage approach using one vertical well design. In Stage I, the $\mathrm{CO}_{2}$ is injected into the underlying aquifer. In Stage II, the well is shut in and injected $\mathrm{CO}_{2}$ is allowed to be converted into immobile $\mathrm{CO}_{2}$ hydrate. Finally, during Stage III, decomposition of $\mathrm{CH}_{4}$ hydrate is induced by the depressurization method. The gas production potential is estimated over 15 years. The results reveal that methane production is increased together with simultaneous reduction of concomitant water production rate comparing to a conventional Class 2 reservoir production. 


\section{Dedicated to my parents}




\section{Acknowledgement}

First and foremost, I'd like to express my deepest gratitude to Sri Ganapathi Sachchidananda Swamiji for His divine blessings and insightful messages. "Patience and perseverance are crucial for success"- this has been one of the most influential sayings of His on me and helped me to become goal-oriented.

I'd like to express my deepest gratitude to my research advisor, Dr. Brian Anderson for his constant support, remarkable guidance and encouragement. He has set himself as an example and shown me what a good scientist (and person) should be. I am also immensely indebted to Dr. Evgeniy Myshakin for his motivation and comprehensive advices throughout the research work. Their suggestions helped me to learn a great deal about scientific research and life in general. I'd like to thank Department of Chemical Engineering at WVU and also everyone in my dissertation committee members for their valuable suggestions and for providing unending inspiration.

I am immensely grateful to West Virginia University for providing me an opportunity to pursue my doctoral studies here in Morgantown. It also gave me a chance to explore the "wild and wonderful", and I take immense pleasure and pride in referring it as my second home and being a Mountaineer, I learnt from the people around here, that being kind and generous is an important virtue one should abide.

I'd like to thank my parents who have been my ultimate role models, who nurtured me to become a responsible independent individual and have always reminded me to dream and to achieve. I'm grateful to my grandparents, whose love and affection are with me in whatever I pursue. My sisters, who are also my best friends since childhood, I sincerely thank them for their endearing affection which lift up my spirits all the times. They were always by my side to lighten my mind in tough times and patted my back during my best moments. And my Uncles and Aunts, whose success journeys has always inspired and motivated me to become a better person in life.

I'm grateful to all those with whom I've associated and had the pleasure to work with during the project. Especially, Dr. Srinath Vengala, Dr. Taiwo Ajayi, Kelydra Walker and Matthew Tacker for their constant support and suggestions all through these years. I'd like to express my gratitude and sincere appreciation to Dr. Nagasree Garapati for her valuable inputs and timely suggestions. I'd also like to extend my gratitude to NETL for their financial assistance for this research project.

I'd like to extend my heartfelt gratitude to all my dearest friends because of whom this rollercoaster journey of mine till date has been extremely fun-filled and cheerful. I want to thank Manish Nandanwar, who has been a great friend and a phenomenal mentor and have helped and inspired me tremendously in all respects during the past five years. The best moments I've cherished at WVU happened with each and every one (Yashwanth, Murthy, Pradeep, Usha, Sujan, Mounica and Sarika) of the group "Friendship Is Ocean". They've always backed me up and cheered me all these years and never ceased believing in me.

Finally and most importantly, I'd like to express my sincere gratitude to my Motherland (India) for Her rich and diversified cultural heritage which made a profound impression upon me and taught me to respect, appreciate and always learn from the varied cultures around the world and thus make world a better place to live. 


\section{Table of Contents}

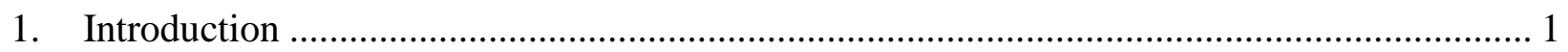

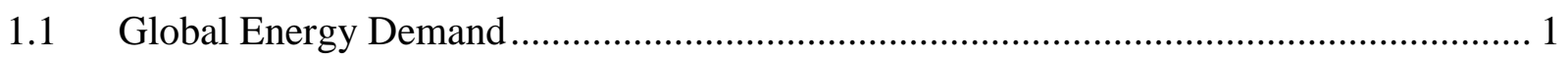

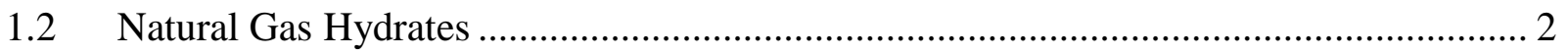

1.2.1 Overview and History .................................................................................... 2

1.2.2 Molecular Structures of Gas Hydrates.............................................................. 5

1.2.3. Phase equilibria of Gas Hydrates................................................................... 7

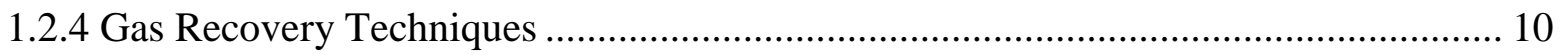

1.2.5 Natural Gas Hydrate accumulations .............................................................. 13

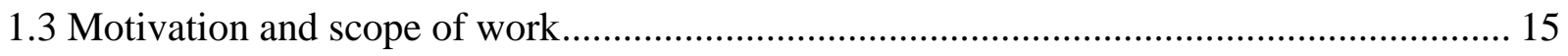

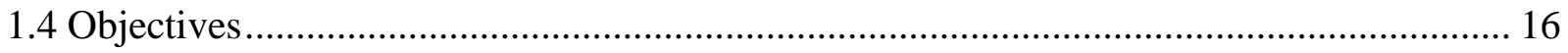

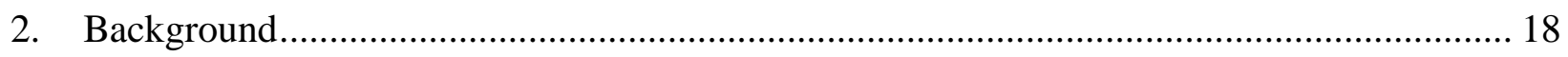

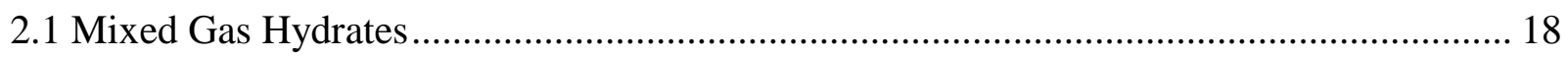

2.1.1 Experimentation for $\mathrm{CO}_{2}$ swapping .................................................... 18

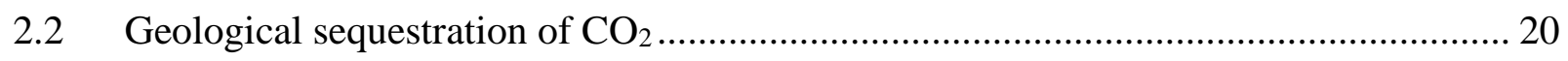

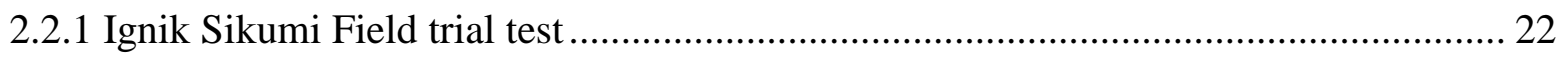

2.3 Class 2 Hydrate Accumulations ......................................................................... 25

2.4 Reservoir simulator - Mix3HydrateResSim ........................................................ 26

3. Suite of problems involving numerical simulations of Simple $\left(\mathrm{CO}_{2}\right.$ hydrate) and Mixed hydrate $\left(\mathrm{CH}_{4}-\mathrm{CO}_{2}\right.$ hydrates and $\mathrm{CH}_{4}-\mathrm{CO}_{2}-\mathrm{N}_{2}$ hydrates $)$ reservoirs .................................... 32

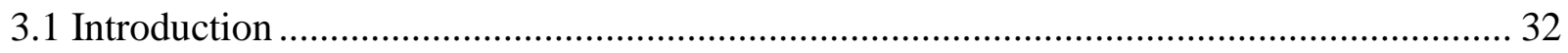

3.2 Problem 1: Dynamics of $\mathrm{CO}_{2}$ hydrate formation .................................................... 35

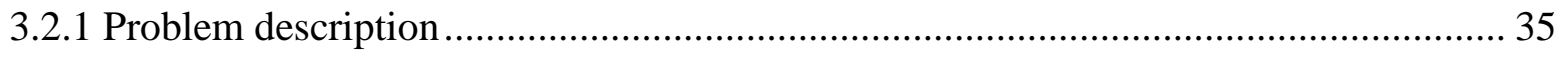

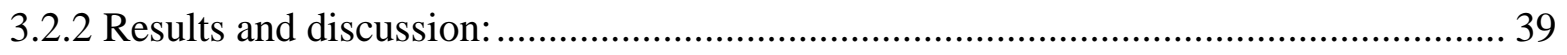


3.3 Problem 2: Dynamics of $\mathrm{CO}_{2}$ hydrate dissociation............................................... 42

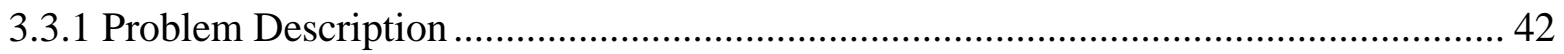

3.3.2 Case 1: $\mathrm{CO}_{2}$-hydrate dissoiation induced by thermal stimulation ........................... 42

3.3.3 Case 2: Hydrate dissociation by Depressurization ............................................. 44

3.4 Problem 3: Base case problem involving water $-\mathrm{CH}_{4}-\mathrm{CO}_{2}$ system .............................. 48

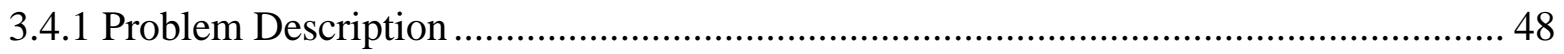

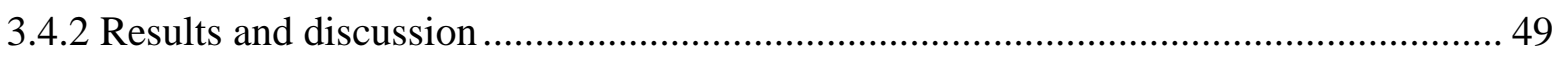

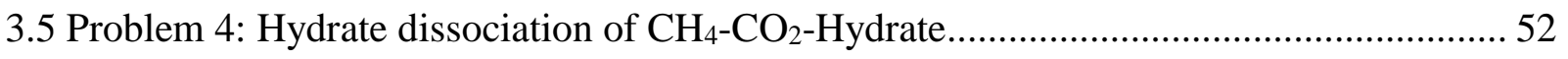

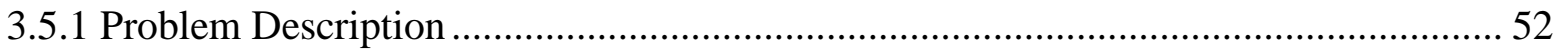

3.5.2 CASE 1: Hydrate dissociation by thermal stimulation......................................... 53

3.5.3 CASE 2: Depressurization Technique .......................................................... 55

3.6 Problem 5: Base case problem involving water $-\mathrm{CH}_{4}-\mathrm{CO}_{2}-\mathrm{N}_{2}$ system .......................... 58

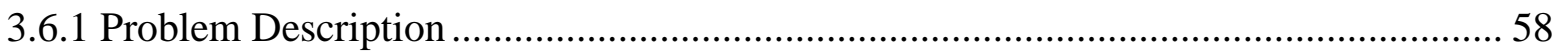

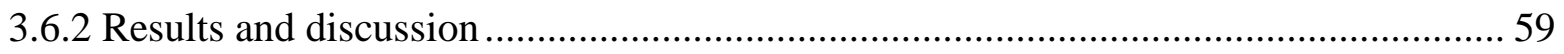

3.7 Problem 6 - Dynamics of Mixed hydrate $\left(\mathrm{CH}_{4}-\mathrm{CO}_{2}-\mathrm{N}_{2}\right.$ hydrate $)$ dissociation................ 64

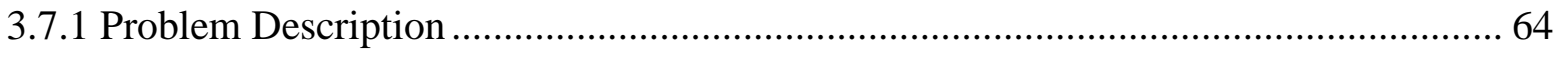

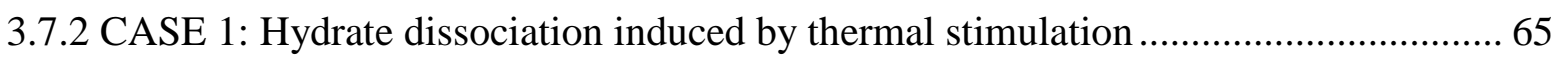

3.7.3 CASE 2: Hydrate dissociation induced by depressurization Technique .................... 67

3.8 Problem $7-\mathrm{CH}_{4}-\mathrm{CO}_{2}$ swapping conducted on an idealized five spot well system ...... 70

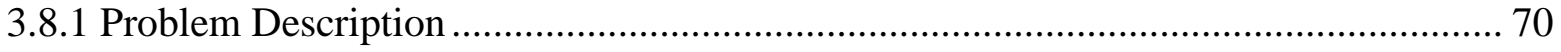

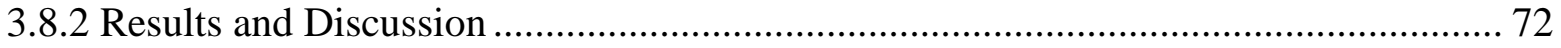

4. $\mathrm{CO}_{2}$ Sequestration and Enhanced $\mathrm{CH}_{4}$ recovery from Class 2 natural gas Hydrate

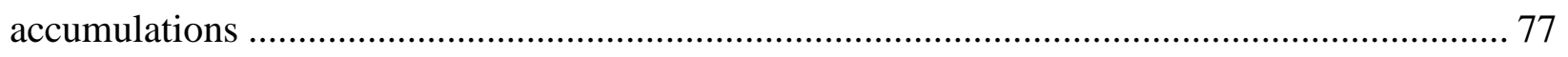

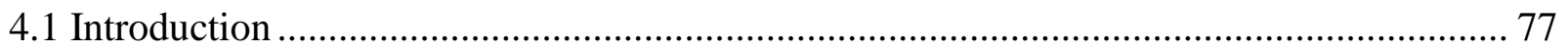

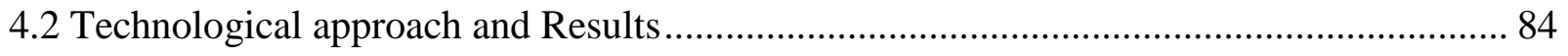




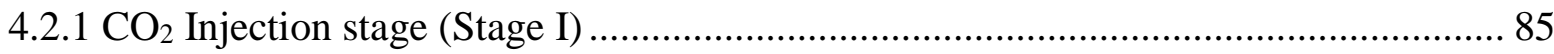

4.2.2 Equilibration stage (Stage II) .................................................................... 100

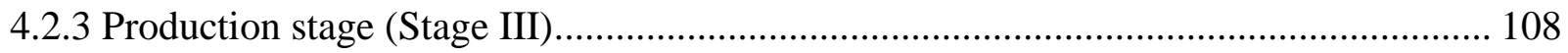

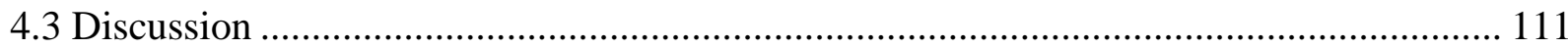

4.3.1 Effect of additional heat flux brought-in during Stages I and II to the CH4-hydrate

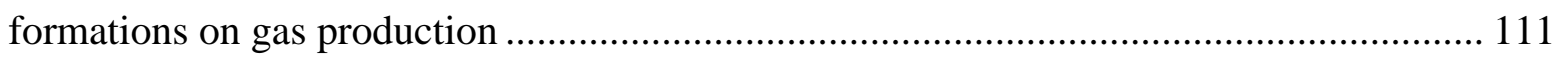

4.3.2 Effect of reduced water influx from the underlying aquifer to the $\mathrm{CH}_{4}$-hydrate

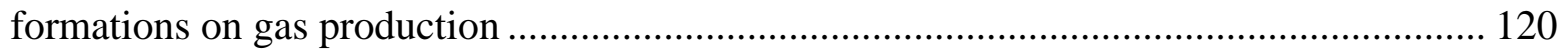

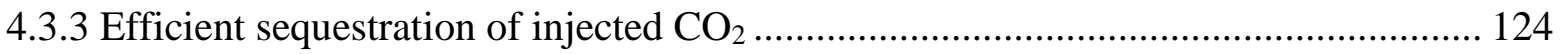

4.3.4 Enhanced gas recovery from $\mathrm{CH}_{4}$-hydrate accumulations ................................. 126

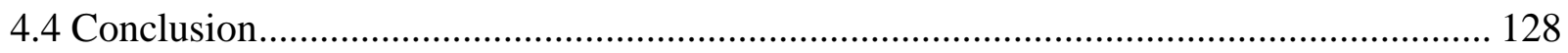

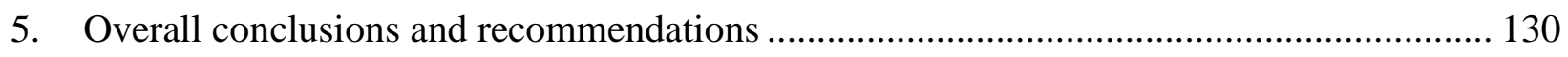

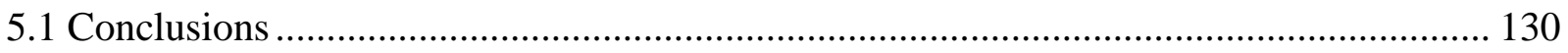

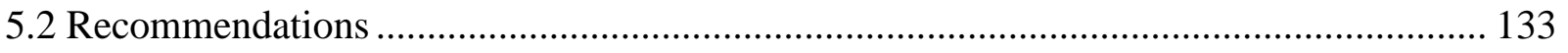

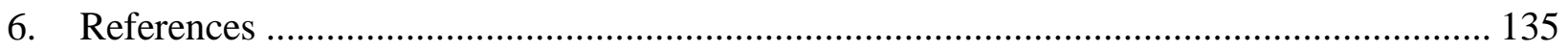




\section{List of Figures}

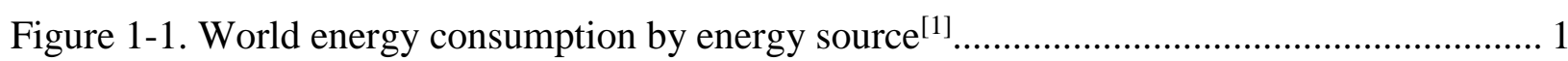

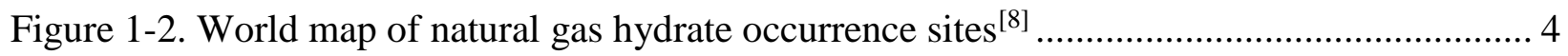

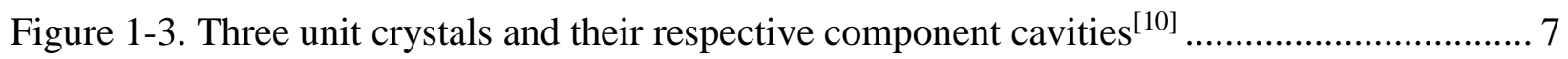

Figure 1-4. Phase equilibrium diagram for $\mathrm{CO}_{2}$ /water system, where I stands for ice, $\mathrm{L}_{\mathrm{w}}$ means liquid water, $\mathrm{V}$ designates gaseous $\mathrm{CO}_{2}, \mathrm{H}$ is $\mathrm{CO}_{2}$ hydrate, and $\mathrm{L}_{\mathrm{co} 2}$ is liquid $\mathrm{CO}_{2}$. Q1 and Q2 are quadruple points, $\mathrm{P} 1$ is the temperature required to initiate the $\mathrm{CO}_{2}$ hydrate formation in the

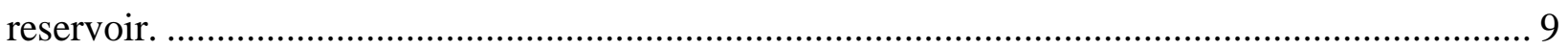

Figure 1-5. Methane Hydrate Stability Zones (a) Permafrost regions (b) Ocean floor ................. 10 Figure 1-6: Phase Diagram of $\mathrm{CH}_{4}$ Hydrate showing different recovery techniques.................... 12

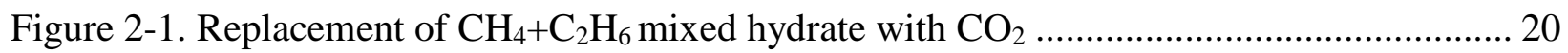

Figure 2-2. Conceptual representaion of the proposed exchange experiment (left side) and the

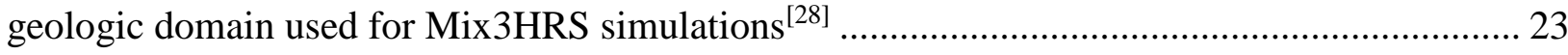

Figure 2-3. Vertical cross-sections of water saturation $\left(S_{\mathrm{w}}\right)$ distributions of reservoir models of

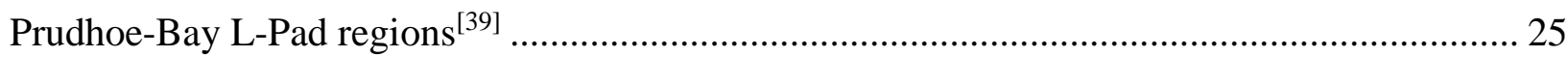

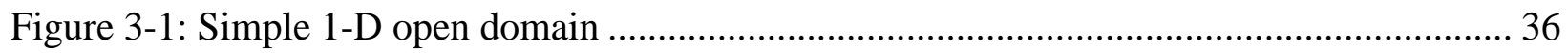

Figure 3-2. Phase equilibrium diagram for $\mathrm{CO}_{2}$ /water system, where I stands for ice, $\mathrm{L}_{\mathrm{w}}$ means liquid water, $\mathrm{V}$ designates gaseous $\mathrm{CO}_{2}, \mathrm{H}$ is $\mathrm{CO}_{2}$ hydrate, and $\mathrm{L}_{\mathrm{co} 2}$ is liquid $\mathrm{CO}_{2}$. Q1 and Q2 are quadrouple points, $\mathrm{P} 1$ is the temperature required to initiate the $\mathrm{CO}_{2}$ hydrate formation in the reservoir.

Figure 3-3. (a) Aqueous saturation, (b) hydrate saturation, (c) gas saturation, (d) temperature and (e) pressure distributions at different time periods

Figure 3-4 (a) Aqueous saturation, (b) hydrate saturation, (c) gas saturation and $(d)$ temperature distributions at different time periods 44 Figure 3-5. (a) Aqueous saturation, (b) hydrate saturation, (c) gas saturation and $(d)$ temperature distributions at different time periods 47

Figure 3-6: Schematic geological domain used for Problem 3. 48 Figure 3-7. Phase equilibrium diagram of $\mathrm{CH}_{4}-\mathrm{CO}_{2}-\mathrm{Hydrate}$ (with respective mole fractions of the guest molecules as 0.75 and 0.25 ). 
Figure 3-8. (a) Aqueous saturation, (b) hydrate saturation, (c) gas saturation and $(d)$ temperature

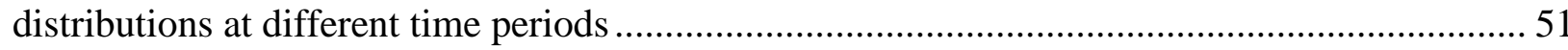

Figure 3-9: Schematic view of the grid used for this problem ........................................... 52

Figure 3-10. (a) Aqueous saturation, (b) hydrate saturation, (c) gas saturation, (d) temperature distributions and (e) Hydrate $\mathrm{CO}_{2}$ mole fractions at different time periods ............................. 55

Figure 3-11 (a) Aqueous saturation, (b) hydrate saturation, (c) gas saturation, (d) temperature distributions and (e) Hydrate $\mathrm{CO}_{2}$ mole fractions at different time periods ............................. 57

Figure 3-12. Schematic geological domain considered in the Problem 5................................. 58 Figure 3-13. Phase equilibrium diagram of $\mathrm{CH}_{4}-\mathrm{CO}_{2}-\mathrm{N}_{2}-\mathrm{Hydrate}$ (with respective mole fractions as $0.375,0.25$ and 0.375$)$ 59

Figure 3-14. Cumulative volumes of the $\mathrm{CH}_{4}, \mathrm{CO}_{2}$ and $\mathrm{N}_{2}$ released in the reservoir upon the mixed hydrate decomposition.....

Figure 3-15 (a) Aqueous saturation, (b) hydrate saturation, (c) gas saturation, (d) temperature distributions, (e) Hydrate $\mathrm{CO}_{2}$ mole fractions, (f) Hydrate $\mathrm{N}_{2}$ mole fractions at different and (g) pressure distributions time periods 63

Figure 3-16. Simple 1 D domain considered .... 64

Figure 3-17. (a) Aqueous saturation, (b) hydrate saturation, (c) gas saturation, (d) temperature distributions, (e) Hydrate $\mathrm{CO}_{2}$ mole fractions and (f) Hydrate $\mathrm{N}_{2}$ mole fractions at different time periods

Figure 3-18 (a) Aqueous saturation, (b) hydrate saturation, (c) gas saturation, (d) temperature distributions, (e) Hydrate $\mathrm{CO}_{2}$ mole fractions, (f) Hydrate $\mathrm{N}_{2}$ mole fractions at different and (g) pressure distributions time periods 69

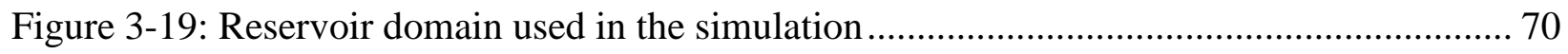

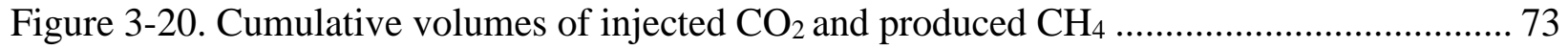

Figure 3-21. Reservoir conditions at the end of 30 days of production simulations .................. 75

Figure 3-22. Reservoir conditions at the end of 1 year of production simulations..................... 76

Figure 4-1. (a,b) Radial reservoir grid domain; (c) The 2D radial model used for simulations ... 80 Figure 4-2: Initial conditions of the domain (a) Hydrate saturation distribution $(b)$ Pressure (kPa) distribution $(c)$ Temperature $\left({ }^{\circ} \mathrm{C}\right)$ distribution 83 Figure 4-3. Graphs showing (i) Cumulative amount of $\mathrm{CO}_{2}$ injected (ii) Rate of $\mathrm{CO}_{2}$ injected .. 88 
Figure 4-4 Contour plots showing (a) pressure distribution ( $\mathrm{kPa}$ ), (b) temperature distribution $\left({ }^{\circ} \mathrm{C}\right),(\mathrm{c})$ gas saturation, and (the arrow indicates the distance at which hydrate formation evolves) d) water saturation after 170 days of injection.

Figure 4-5. Contour plots showing (a) pressure distribution ( $\mathrm{kPa}$ ), (b) temperature distribution $\left({ }^{\circ} \mathrm{C}\right),(\mathrm{c})$ gas saturation, and (the arrow indicates the distance at which hydrate formation evolves) d) water saturation after 110 days of injection.

Figure 4-6. Contour plots showing (a) pressure distribution ( $\mathrm{kPa})$, (b) temperature distribution $\left({ }^{\circ} \mathrm{C}\right),(\mathrm{c})$ gas saturation, and (the arrow indicates the distance at which hydrate formation evolves) d) water saturation after 240 days of injection. 95

Figure 4-7. Pressure profile in the element column next to the well-bore during Stage I. 97 Figure 4-8. Contour plots showing (a) pressure distribution (kPa), (b) temperature distribution $\left({ }^{\circ} \mathrm{C}\right)$, (c) gas saturation, and (the arrow indicates the distance at which hydrate formation evolves) d) water saturation after 145 days of injection. 98 Figure 4-9. Contour plots showing a) pressure distribution ( $\mathrm{kPa}), \mathrm{b})$ temperature distribution $\left({ }^{\circ} \mathrm{C}\right)$, c) $\mathrm{CO}_{2}$ gas saturation distribution d) $\mathrm{CO}_{2}$ hydrate saturation distribution after 2.5 years since the commencement of Stage II.

Figure 4-10. Contour plots showing a) pressure distribution $(\mathrm{kPa}), \mathrm{b})$ temperature distribution $\left({ }^{\circ} \mathrm{C}\right)$, c) $\mathrm{CO}_{2}$ gas saturation distribution d) $\mathrm{CO}_{2}$ hydrate saturation distribution after 3.5 years since the commencement of Stage II.

Figure 4-11. Contour plots showing a) pressure distribution $(\mathrm{kPa}), \mathrm{b})$ temperature distribution $\left({ }^{\circ} \mathrm{C}\right)$, c) $\mathrm{CO}_{2}$ gas saturation distribution d) $\mathrm{CO}_{2}$ hydrate saturation distribution after 8 years since the commencement of Stage II.

Figure 4-12. Effective permeability (aqueous) curve using power $n$ and $S_{\text {irrA }}$ in the Brooks-Corey relative permeability function (Table $4-1$ ). 105

Figure 4-13. Phase equilibrium diagrams for $\mathrm{CO}_{2} /$ water and $\mathrm{CH}_{4} /$ water systems, $\mathrm{A}$ and $\mathrm{B}$ designate the regions of $\mathrm{CO}_{2}$ hydrate stability and $\mathrm{CH} 4$ hydrate instability. 108 Figure 4-14. Gas production rates (dashed lines) and cumulative volume (solid lines) of gas produced for Cases 1-4. Time zero designates the onset of Stage III.

Figure 4-15. Heat flux across the upper boundary of hydrate zone during the Stage III for all the three cases. A positive sign means flow from the methane hydrate-bearing sand to overburden. 
Figure 4-16. Heat flux across the lower boundary of hydrate zone during the Stage I (dashed line), Stage II (dotted line) and Stage III (solid line) for Cases 1-4. A positive sign means flow from the aquifer to methane hydrate-bearing sand.

Figure 4-17. Temperature difference between the sub-layers in contact between the methane hydrate-bearing sand and the aquifer during the Stage III for Cases 1-4. Where $\mathrm{T}_{\mathrm{Z} 2}$ and $\mathrm{T}_{\mathrm{Z} 1}$ refers to the temperatures of the bottom sub-layer of the methane hydrate-bearing sand in contact with the top sub-layer of the underlying aquifer, respectively. 115 Figure 4-18. Hydrate saturation evolution profiles in the sub-layers present in the aquifer during the Stage III for Cases 2

Figure 4-19. Hydrate saturation and temperature distributions in Zones 1 and 2 during Stage III for Case 2 . 119 Figure 4-20. Cumulative heat flux across the lower boundary of hydrate zone during the Stage III for Cases 1-4. A positive sign means flow from the aquifer to the methane hydrate-bearing sand

Figure 4-21. Water production rates (dashed lines) and cumulative volume (solid lines) of water produced for Cases 1-4. Time zero designates the onset of Stage III 122 Figure 4-22. Water flux across the lower boundary of hydrate zone during the Stage III for Cases 1-4. A positive sign means flow from the aquifer to methane hydrate-bearing sand. 123 Figure 4-23. Water flux across the first $120 \mathrm{~m}$ of the lower boundary of hydrate zone during the Stage III for Cases 2 and-4. A positive sign means flow from the aquifer to methane hydratebearing sand 123

Figure 4-24. Water to gas ratio for all the cases (Cases 1-4) 124 Figure 4-25. Cumulative volumes of $\mathrm{CH}_{4}$ (Solid line) and $\mathrm{CO}_{2}$ (dashed line) for Cases 1-3 in the production stream. 125 


\section{List of Tables}

Table 1-1. Physical properties of ice and methane hydrate ................................................... 4

Table 2-1. Details of primary variables for different phases ................................................ 27

Table 3-1. Reservoir properties and pertinent model parameters .......................................... 38

Table 3-2. Various parameters used in the simulation......................................................... 71

Table 4-1. Various reservoir parameters used in the Stage 1 simulations ................................. 81

Table 4-2. Parameters used for Relative Permeability and Capillary Pressure ......................... 82

Table 4-3. Initial conditions used in the simulation.......................................................... 83

Table 4-4. The different case scenarios and the respective injection parameters ...................... 87

Table 4-5. The duration of stages for the Cases considered. The $\mathrm{CO}_{2}$ hydrate saturation numbers

are the saturation at the boundary around $\mathrm{CO}_{2}$ plume in the aquifer after Stage II.................. 107

Table 4-6. Physical parameters and initial conditions used in the calculation of Stefan number126

Table 4-7. Stefan numbers for Cases 1-4 ...................................................................... 127

Table 4-8. Total amount of $\mathrm{CH}_{4}$ stored in the reservoir, cumulative volumes of $\mathrm{CH}_{4}$ produced,

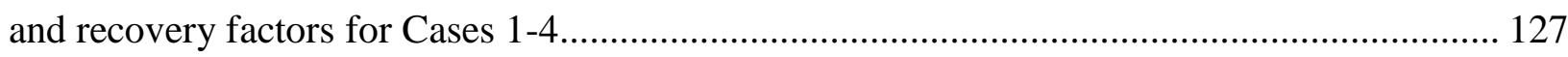




\section{Introduction}

\subsection{Global Energy Demand}

In the present day global scenario, rapid growth of the energy consumption has raised some stringent concerns over limited energy resources available, supply challenges and serious environmental impacts (global warming, climate change, etc.). The US Energy Information Administration's (EIA) recent survey predicted 48\% rise in the world energy consumption by $2040^{[1]}$. Figure 1-1 shows the energy consumption by energy source predicted till the year of 2040 , from which it is evident that, over the years, worldwide demand for natural gas and the global oil demand continues to grow until 2040. The projected coal consumption till the year 2040 remains relatively flat. On a percentage basis, renewable energy, followed by nuclear power grows the fastest over the projection period.

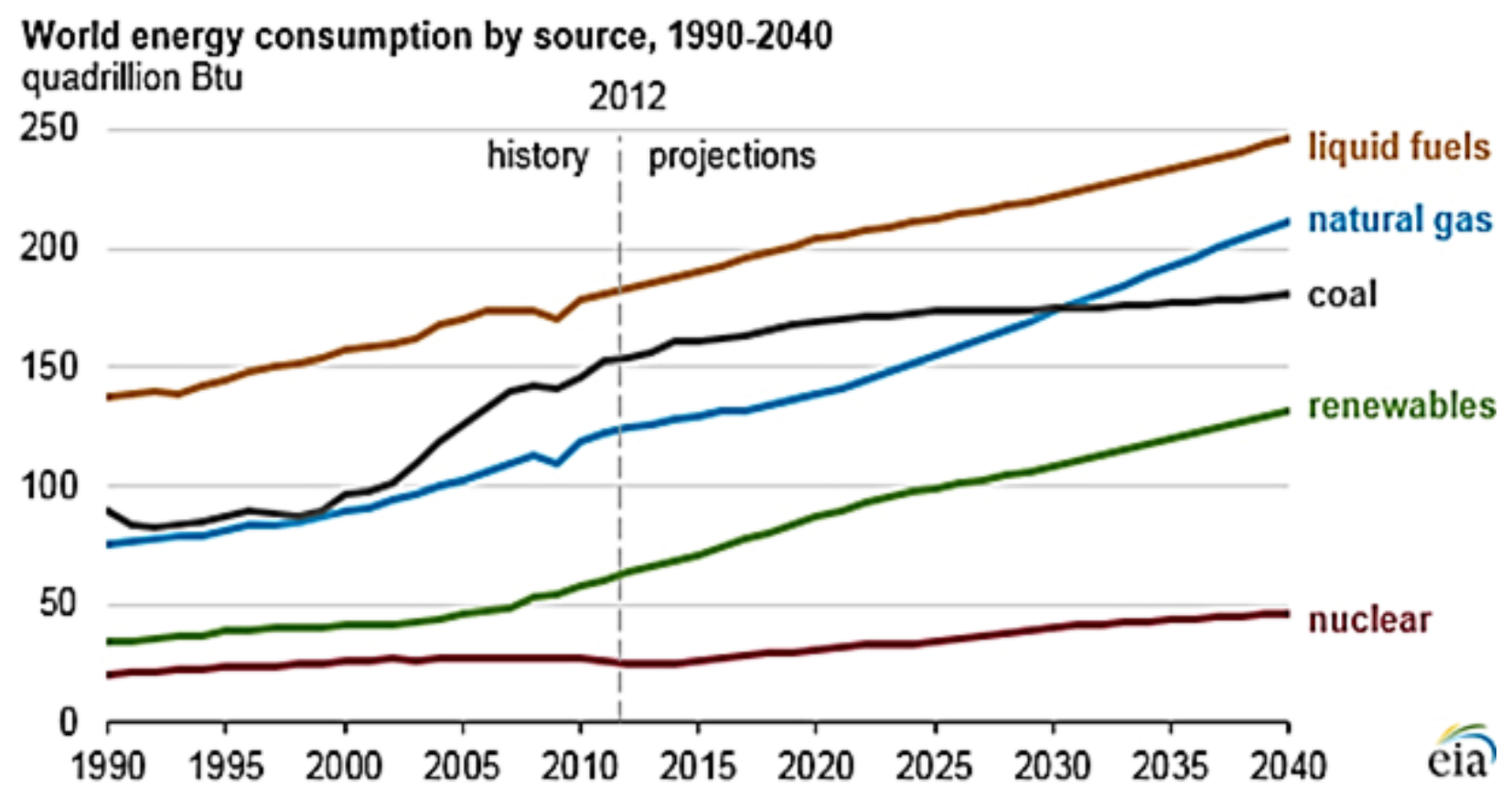

Figure 1-1. World energy consumption by energy source ${ }^{[1]}$ 
Despite strong growth in non-fossil fuels (renewable and nuclear power), much of this growth is expected to be met by fossil fuels (liquid fuels, natural gas and coal), which accounts for more than $75 \%$ of the primary energy demand. Rise in the supply of shale gas, tight gas and coalbed methane contribute to the proliferated consumption of natural gas. The growth of the demand for oil sector is primarily due to the lack of easy alternatives to oil in road freight, aviation and petrochemicals. Concerns about the greenhouse gas emissions owed to the sustained rise in the fossil fuel emissions spurred the new interests for other sources of energy including renewable and unconventional fossil fuel such as shale gas and oil as well as gas hydrates.

Among the various alternative fuel resources that are under extensive investigation currently, gas hydrate accumulations are projected as substantial future energy resource. In pre-1990 studies, estimates of the amount of methane trapped in global gas hydrate reserves varied by many orders of magnitude from $10^{5}$ trillion cubic feet (TCF; McIver, 1981) to $10^{8} \mathrm{TCF}$ (Trofimuk,1973) ${ }^{[2]}$. The estimate of GIP (gas-in-place, methane trapped in gas hydrates) in resource grade methane hydrates is $10^{4} \mathrm{TCF}$ (Boswell and Collet, 2011) ${ }^{[2]}$ which is nearly $35 \%$ more than the 2010 estimate for global natural gas reserves (nearly 6600 TCF; EIA, 2010) and nearly 100 times $^{[2]}$ greater than $^{2}$ the annual global gas consumption. The most promising about methane hydrates is decomposition of one volume of gas hydrate releases 164 volumes of natural gas at $1 \mathrm{~atm}$ and $273 \mathrm{~K}^{[2]}$. These are the primary factors which substantiate gas hydrates as a promising fuel resource.

\subsection{Natural Gas Hydrates}

\subsubsection{Overview and History}

Clathrate Hydrates or Gas Hydrates are non-stoichiometric, crystalline solids that consist of gas molecules (guests) encaged inside the lattices of hydrogen-bonded water molecules (host $)^{[3]}$.Usually, the guest molecules include methane, ethane, propane, carbon dioxide and 
nitrogen. Hydrates were first discovered by Sir Humphrey Davy (Davy,1811) ${ }^{[3]}$ in 1810, who noticed the formation of yellow precipitate (chlorine-hydrate) by passing chlorine through water at freezing temperatures. Later, existence of methane, ethane and propane hydrates first determined by Villard $(1888)^{[4]}$. Then the focus of the hydrate research moved on to measurement of the water to gas ratio in hydrates (hydration number), which still remains as a challenge to the scientific community till date. Circone et al. (2005) $)^{[5]}$ obtained hydration numbers from direct macroscopic measurements of the amount of gas released during hydrate decomposition. Later in mid-1930s, Hammerschmidt ${ }^{[6]}$ first discovered that formation of hydrates led to plugging of the pipeline at the operating temperatures greater than $273 \mathrm{~K}$. This spurred the scientific community to comprehend the thermodynamic conditions (phase equilibria) responsible for hydrate formation and dissociation. Henceforth, intensive research has been carried on to evaluate the technical challenges related to natural gas hydrate reservoirs.

First natural gas hydrate deposits were discovered in permafrost associated hydrate accumulations in Siberian permafrost deposits in $1964^{[7]}$. Hydrate deposits are prevalent worldwide in the sediments of continental margins and in the terrestrial regions with continuous permafrost where pressure and temperature conditions are favorable for hydrate formation. The abundant availability of gas hydrates around the globe makes it a promising option as a fuel resource. Figure 1-2 shows the worldwide known and inferred hydrate occurrence sites. 


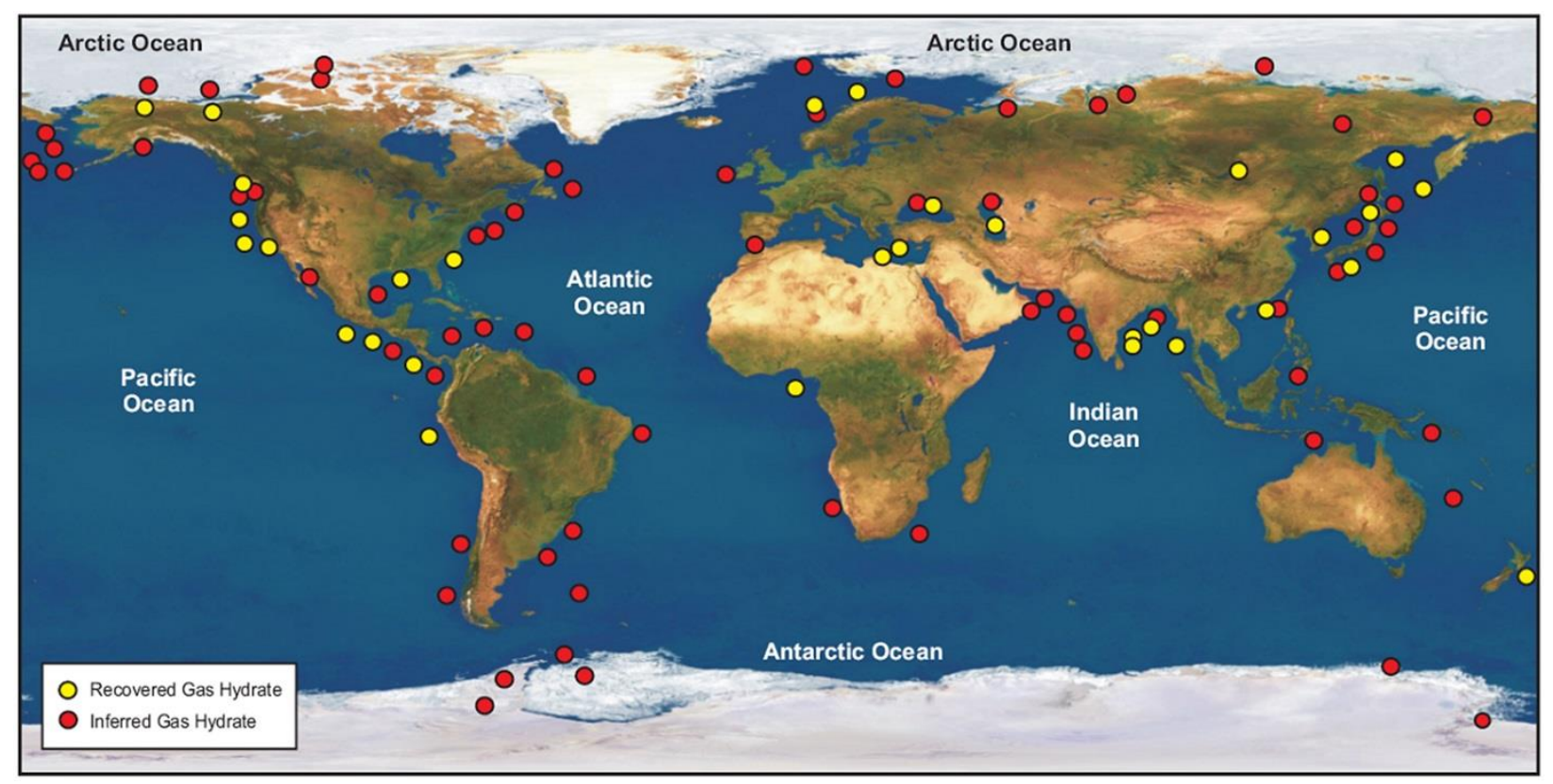

Figure 1-2. World map of natural gas hydrate occurrence sites ${ }^{[8]}$

Table 1-1. Physical properties of ice and methane hydrate

\begin{tabular}{|c|c|c|}
\hline Property & Ice & Hydrate \\
\hline Dielectric constant at 273 K & 94 & 58 \\
\hline Water molecule reorientation time at 273 K $(\mu \mathrm{sec})$ & 21 & 10 \\
\hline Isothermal Young's Modulus at 268 K (109 Pa) & 9.5 & 8.4 \\
\hline Poisson's ratio & 0.33 & 0.33 \\
\hline Bulk Modulus (272 K) & 8.8 & 5.6 \\
\hline Shear Modulus $(272 \mathrm{~K})$ & 3.9 & 2.4 \\
\hline Bulk Density (gm/cm $\left.{ }^{3}\right)$ & 0.916 & 0.912 \\
\hline Adiabatic Bulk Compressibility at 273 K, (10-11 Pa) & 12 & 14 \\
\hline Thermal Conductivity at $263 \mathrm{~K}(\mathrm{~W} / \mathrm{m}-\mathrm{K})$ & 2.25 & $0.49 \pm 0.02$ \\
\hline Heat of Fusion $(\mathrm{kJ} / \mathrm{mol})$ & 6 & 54 (measured) \\
\hline
\end{tabular}


On a molecular scale, gas hydrates contains mostly (nearly $85 \%{ }^{[3]}$ ) water; hence their structure and other mechanical properties resemble those of hexagonal ice $1 \mathrm{~h}$. The physical properties of ice and hydrate are listed out in Table 1-1.

\subsubsection{Molecular Structures of Gas Hydrates}

Natural gas hydrates are commonly found in three structures: structure I (sI), structure II (sII) and structure $\mathrm{H}(\mathrm{sH})$ hydrates. Structure I and structure II hydrates have cubic lattices whereas sH has a hexagonal structure. Structure I and structure II gas hydrates are abundantly found in nature. The structure of a gas hydrate depends on the size of guest molecule, size of the cages and number of the unit cells. Structure I hydrates consist of two cages which are differed by their size and structure: (1) pentagonal dodecahedron (12-sided polyhedron (denoted as $5^{12}$ ); small cage) (2) tetrakaidecahedron which consists of 12 pentagonal and 2 hexagonal faces (14-sided polyhedron $\left(5^{12} 6^{2}\right)$; large cages). The sI unit cell is body centered cubic lattice consists of 46 water molecules which forms 2 small cages and 6 large cages. The guest molecules having molecular diameter in the range of 4.2-6 $\AA$ such as $\mathrm{CH}_{4}, \mathrm{C}_{2} \mathrm{H}_{6}, \mathrm{CO}_{2}, \mathrm{H}_{2} \mathrm{~S}$ form Structure I.

Similarly, structure II also has two cages: (1) dodecahedron (12-sided polyhedron $\left(5^{12}\right)$; small cages) (2) hexakaidecahedron which has 12 pentagonal and 4 hexagonal faces (16-sided polyhedron $\left(5^{12} 6^{4}\right)$; large cages). The sI unit cell is face centered cubic lattice made up of 136 water molecules which forms 16 small cages and 8 large cages. The molecules of $\mathrm{d}<4.2 \AA$ (like $\mathrm{N}_{2}$ ) and also diameter in the range of 6-7 $\AA$ (like $\mathrm{C}_{3} \mathrm{H}_{8}$ or iso-butane) forms structure II.

Unlike the prior two structures, structure $\mathrm{H}$ unit cell has three cages of varied sizes: (1) dodecahedron (12-sided polyhedron $\left(5^{12}\right)$; small cages) (2) irregular dodecahedron has 3 square faces and 6 pentagonal along with 3 hexagonal faces $\left(\left(4^{3} 5^{6} 6^{3}\right)\right.$; medium cages) and (3) Icosahedron $\left(\left(5^{12} 6^{8}\right)\right.$; large cages). The larger molecules typically in the range of 7-9 $\AA$ (like iso-hexane) forms 
structure $\mathrm{H}$ when accompanied by smaller molecules like $\mathrm{CH}_{4}, \mathrm{H}_{2} \mathrm{~S}$, or $\mathrm{N}_{2}$. The $\mathrm{sH}$ unit cell encompasses a hexagonal lattice containing 34 water molecules that forms 3 small cages, 2 medium cages and one large cage.

Structure transitions take place with temperature variation is imposed on simple hydrates and with gas phase composition in mixed hydrates. The hydrate structure changes significantly on the addition of other guest molecules, for example though $\mathrm{CH}_{4}$ and $\mathrm{C}_{2} \mathrm{H}_{6}$ are each known to form sI hydrates as simple hydrates, but the Raman band frequencies for $\mathrm{C}_{2} \mathrm{H}_{6}$ obtained for various $\mathrm{CH}_{4}$ $\mathrm{C}_{2} \mathrm{H}_{6}$ mixed hydrate at $274.2 \mathrm{~K}$ indicate transformation of hydrate structure from sI to sII for particular gas composition of 72.2 and 75 mole $\%$ of $\mathrm{CH}_{4}$ in the vapor ${ }^{[9]}$. This structural change results in a variation of the hydration number and hence the gas concentration in hydrates. 


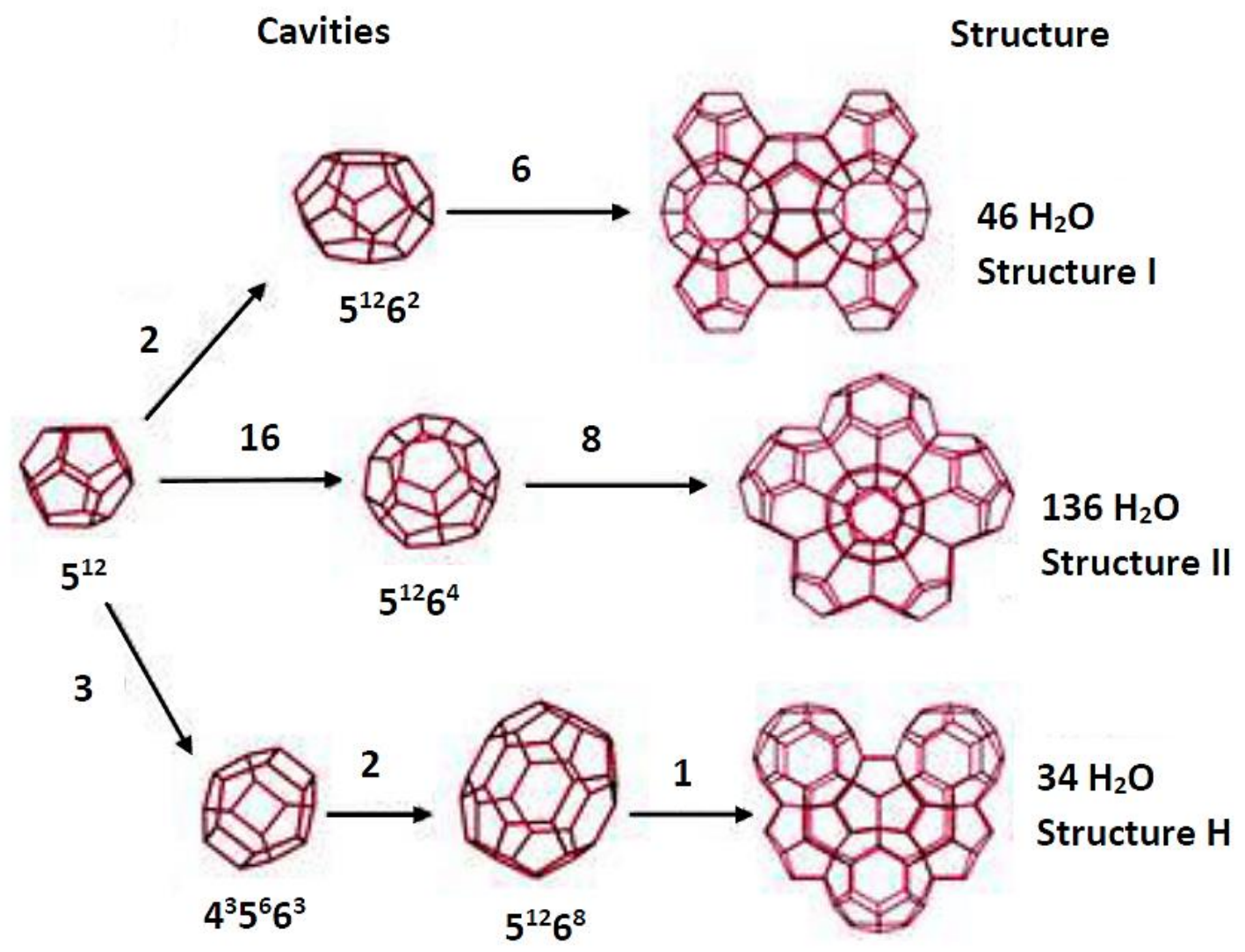

Figure 1-3. Three unit crystals and their respective component cavities ${ }^{[10]}$

\subsubsection{Phase equilibria of Gas Hydrates}

Gas clathrate hydrate formation is favored by 1) low temperatures 2) high pressures and 3) adequate availability of water and gas (guest compounds) molecules. The hydrate phase diagrams are the calculations of pressure and temperatures at which incipient hydrates form from gas (guest hydrocarbons) and free water. The typical pressure-temperature phase diagram for $\mathrm{CO}_{2} /$ water systems is shown in the Figure 1-4. The first quadruple point $\left(\mathrm{Q}_{1}\right)$ (Figure 1-4) indicates the thermodynamic conditions where four phases $\left(\mathrm{I}-\mathrm{L}_{\mathrm{w}}-\mathrm{H}-\mathrm{V}\right.$, ice-liquid water-hydrate-vapor) coexist. The first quadruple point temperature for all the hydrate formers is nearly $273 \mathrm{~K}$ but the corresponding pressure varies widely for different guest components. The gaseous compounds like 
pure methane or nitrogen doesn't have an upper bound for the line $\mathrm{L}_{\mathrm{w}}-\mathrm{H}-\mathrm{V}$ (denotes the equilibrium of three phases, liquid water-hydrate-vapor), which is due to their lower vapor-liquid critical points than the first quadruple point $\mathrm{Q}_{1}$. But for gases like $\mathrm{CO}_{2}$ (Figure 1-4) has an upper bound and there exists a second quadruple point where four phases $\left(\mathrm{L}_{\mathrm{w}}-\mathrm{H}-\mathrm{V}-\mathrm{L}_{\mathrm{G}}\right.$, liquid waterhydrate-vapor-liquid phase (of guest compound)) coexist. The lines $\mathrm{L}_{\mathrm{w}}-\mathrm{H}-\mathrm{V}$ and I-H-V (icehydrate-vapor) are the most common regions of interest for simple natural gas hydrates and the lines denote the thermodynamic conditions which mark the limit to the hydrate formation. In other words, hydrates remain stable in the region enclosed by the lines $\mathrm{L}_{\mathrm{w}}-\mathrm{H}-\mathrm{V}$ and $\mathrm{I}-\mathrm{H}-\mathrm{V}$. The extensive investigation of water/hydrocarbon phase diagram provide an insight to hydrate problems encountered during production, transportation, and processing of oil and natural gas. 


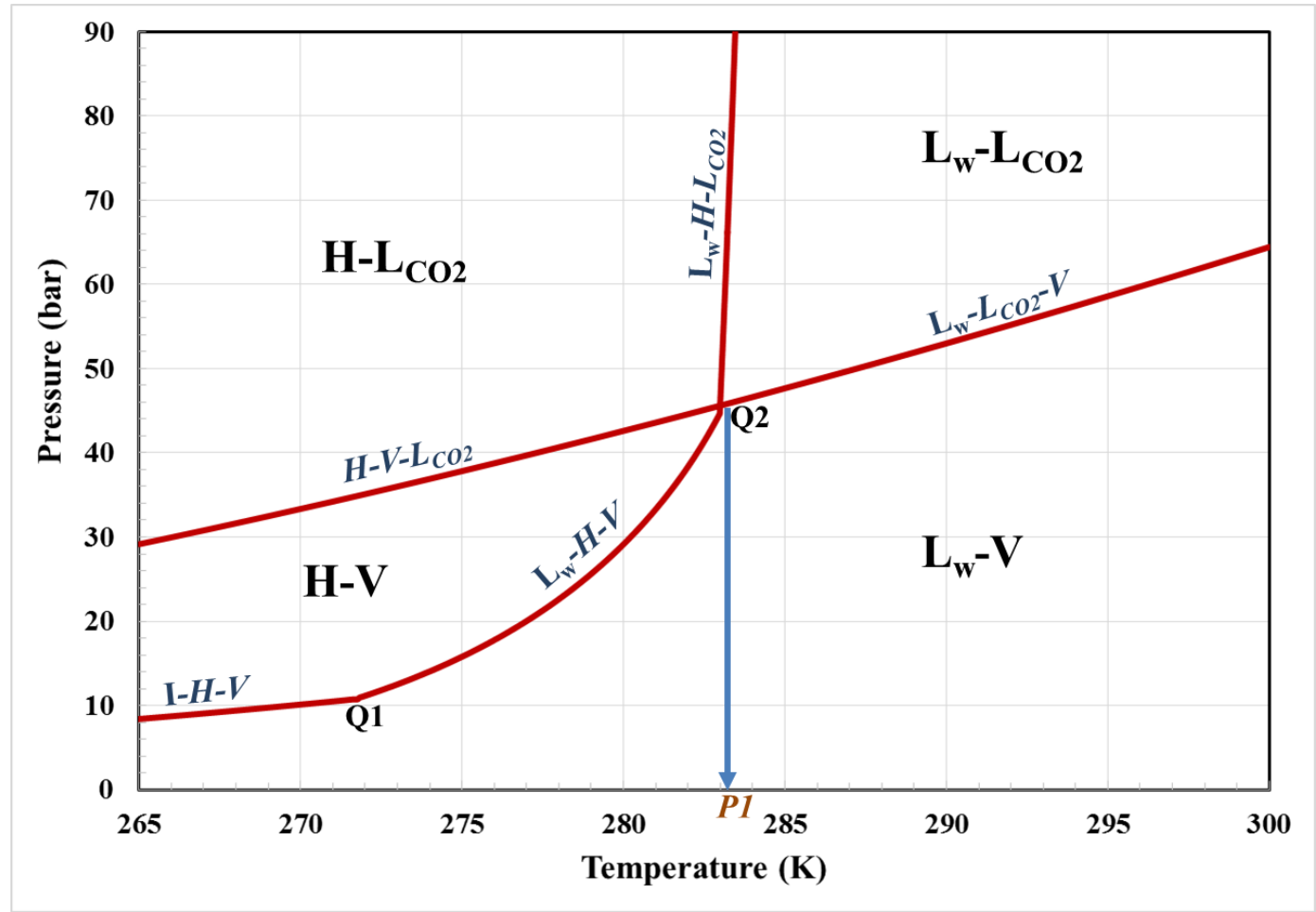

Figure 1-4. Phase equilibrium diagram for $\mathrm{CO}_{2}$ /water system, where I stands for ice, $\mathrm{L}_{\mathrm{w}}$ means liquid water, $\mathrm{V}$ designates gaseous $\mathrm{CO}_{2}, \mathrm{H}$ is $\mathrm{CO}_{2}$ hydrate, and $\mathrm{L}_{\mathrm{co} 2}$ is liquid $\mathrm{CO}_{2} . \mathrm{Q} 1$ and $\mathrm{Q} 2$ are quadruple points, $\mathrm{P} 1$ is the temperature required to initiate the $\mathrm{CO}_{2}$ hydrate formation in the reservoir.

As shown in the Figure 1-5, the solid blue line represents the phase boundary of the guest component (methane in this case) and the dashed line indicates the geo-thermal gradient curve. Hydrates are stable in the region bounded by the geothermal gradient curve and the phase boundary of methane-hydrates and is referred to Gas Hydrate Stability Zone (GHSZ). The thickness of the HSZ depends on the local geothermal conditions of the hydrate reserves. The hydrate reserves are typically stable at depths greater than $600 \mathrm{~m}$ in the ocean floor and at depths greater than $150 \mathrm{~m}$ at the permafrost regions ${ }^{[11]}$. The geothermal gradient controls the lower bound of HSZ, hence in the regions of high geothermal heat flow, the lower limit of HSZ may become shallower and vice 
versa i.e., the areas with low geothermal heat flow has thick hydrate stability zone (HSZ).
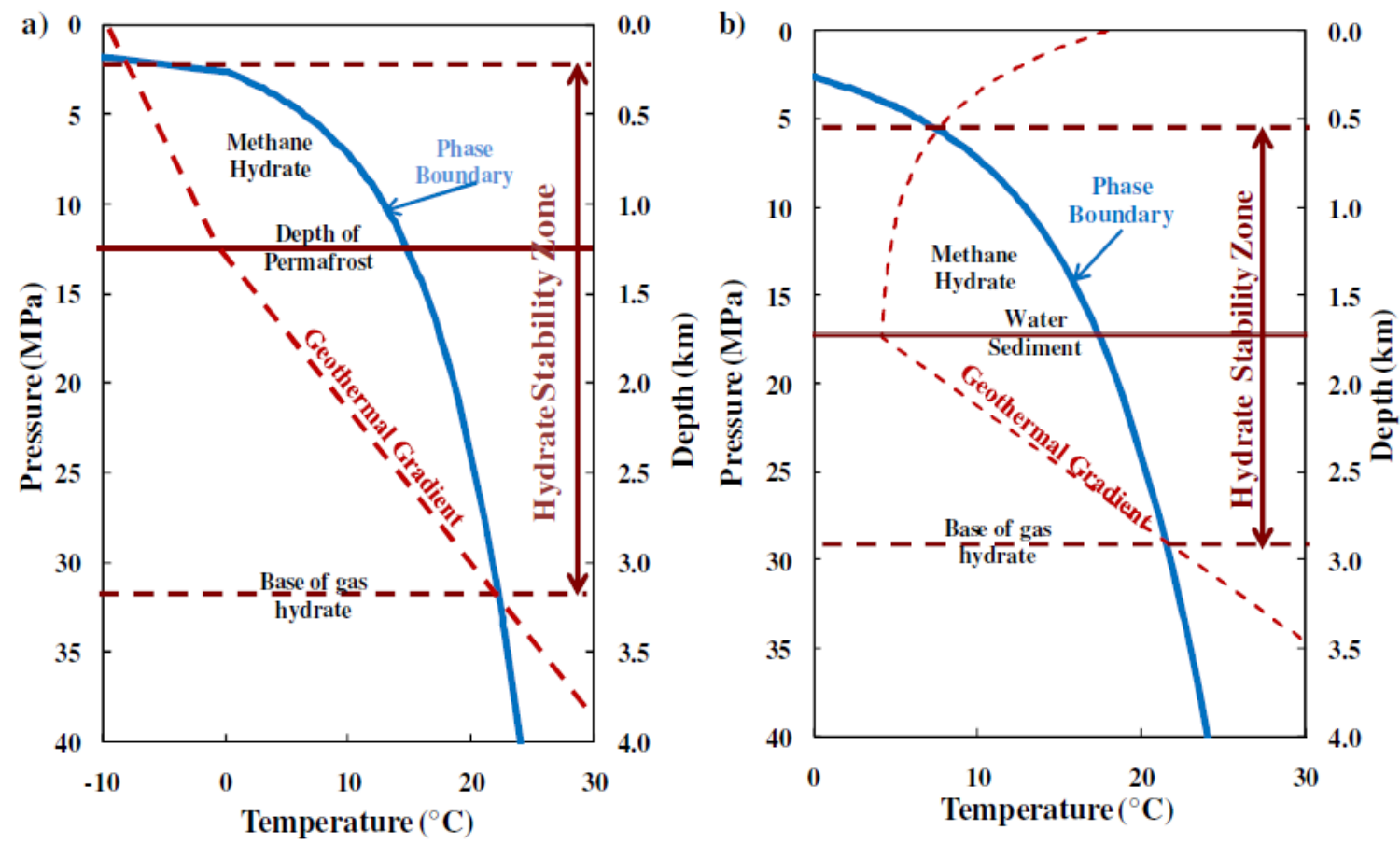

Figure 1-5. Methane Hydrate Stability Zones (a) Permafrost regions (b) Ocean floor

\subsubsection{Gas Recovery Techniques}

Currently there are various methods for recovering natural gas from hydrate reservoirs and new techniques are still developing. The most practical methods include thermal stimulation, depressurization and chemical inhibitor injection method. Thermal stimulation method involves warming of the hydrate formation settings by injection of hot fluid (like steam or hot brine) or potentially direct heating of the formation settings, hence the temperature of the formations increased beyond the hydrate stability region (Figure 1-6). Thermal stimulation is an energy intensive $^{[12]}$ technique, hence the endothermic nature of hydrate decomposition provides a major setback to this technique. The temperature lowering of the reservoir owed to the hydrate decomposition reactions necessitates more heat induction to keep the dissociation reaction progress in the reservoir. But, this technique provides a major benefit of preventing secondary 
hydrate formation which can lead to reduction of reservoir permeability. However, in terrestrial Arctic settings, this technique must be thoroughly monitored as it might sometime lead to permafrost thawing ${ }^{[13]}$.

Depressurization method involves lowering the pressure conditions below the equilibrium pressures, thus enabling the hydrates to dissociate, shown in Figure 1-6. Depressurization is more energy efficient than thermal stimulation method for which it is widely preferred and is considered to be the most economic technique ${ }^{[12]}$. The energy expenditure is very less and can be utilized to initiate dissociation of a large volume of gas hydrate relatively rapidly compared to other techniques. Apart from its multiple advantages, it holds few major shortcomings; 1) The endothermic reaction of hydrate dissociation tend to cooldown the reservoir which might result in ice formation or secondary hydrate formation, thus seriously affecting the reservoir rock permeability. 2) It results in the release of immense amount of water upon hydrate dissociation, thus leading to geologic subsidence. 3) The sensible heat in the hydrate sediments can barely offset the heat consumption by endothermic nature of hydrate decomposition process, which eventually slows down the dissociation process.

Chemical Inhibitor Injection involves injection of thermodynamic inhibitors like methanol, which shifts the hydrate phase-equilibrium to left, thus favoring the dissociation of hydrates (Figure 16). This method is not economical for two reasons: (1) Cost of the chemicals are likely to be expensive and (2) Highly permeable hydrate-bearing sands would be required to allow the easy flow of the injected fluid.

Thus each one of these methods hold their own limitations which can eventually lead to unintended environmental consequences. 


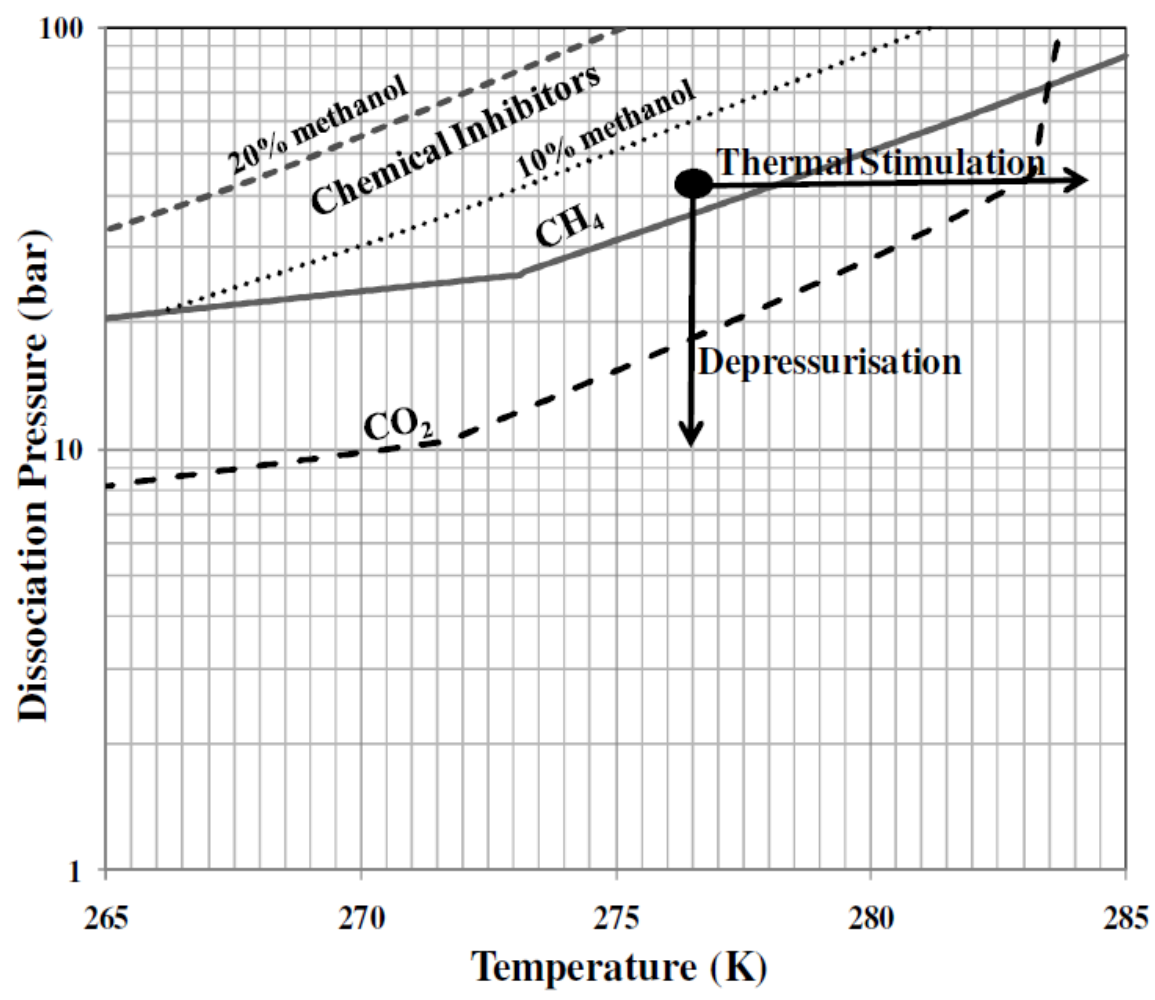

Figure 1-6: Phase Diagram of $\mathrm{CH}_{4}$ Hydrate showing different recovery techniques

A novel production technique was developed, which involves injection of $\mathrm{CO}_{2}$ into the hydrate formations, where $\mathrm{CH}_{4}$ in methane hydrate is swapped by $\mathrm{CO}_{2}$, thus serving the dual purpose of $\mathrm{CO}_{2}$ sequestration and production of methane. As shown in the Figure 1-6, it is evident that the equilibrium pressures for $\mathrm{CO}_{2}$ hydrate are lower than $\mathrm{CH}_{4}$ hydrates for temperatures below $285 \mathrm{~K}$, thus $\mathrm{CO}_{2}$ hydrate is more stable compared to that of $\mathrm{CH}_{4}$ hydrates for temperatures below $285 \mathrm{~K}$, hence it is thermodynamically possible to replace $\mathrm{CH}_{4}$ in the hydrate with $\mathrm{CO}_{2}$, thus producing $\mathrm{CH}_{4}$ in the gas phase. Another factor which makes the swapping feasible is the ability of $\mathrm{CO}_{2}$ to form hydrates, which has molecular structure similar to that of $\mathrm{CH}_{4}-\mathrm{Hydrate}$, thus maintaining the structural integrity even after the swapping. 


\subsubsection{Natural Gas Hydrate accumulations}

Natural gas hydrate deposits around the globe are categorized into different classes ${ }^{[14]}$ based on the characteristics of the geological deposits present in contact with the hydrate bearing deposits. Class 1 hydrate accumulations are characterized by a hydrate-bearing layer underlain by a twophase fluid zone with free gas interval. Generally, hydrate bearing interval exhibit very high hydrate saturations which eventually lead to permeability impairment of the reservoir rock. Hence, in this class, bottom of the relatively low effective permeability layer (hydrate-bearing layer) occurs above the bottom of permeable formation ${ }^{[15]}$ (free gas interval). This class is the most desirable exploitation site because of its hydrate thermodynamic proximity to the hydration equilibrium, which implies even small changes in the thermodynamic conditions initiate decomposition of clathrated hydrates. Amongst the various gas recovery techniques available so far, depressurization induced production ${ }^{[15]}$ from Class 1 accumulations lead to favorable gas production rates owed to couple of reasons; 1) the presence of highly permeable free gas present in proximity to the bottom of hydrate bearing layers, 2) the thermodynamic proximity of the hydrate bearing sediments to the hydration equilibrium. Class 1 deposits are found in some of the geological sediments in the Mackenzie Delta and Beaufort Sea ${ }^{[16]}$ in the Northwest Territories, Canada and the Mesoyakha field in Siberia, Russia ${ }^{[17]}$.

Class 2 accumulations comprise two layers similar to Class 1 accumulations but a mobile-aqueous layer with no free gas (e.g., aquifer) lying underneath a hydrate bearing geologic media. The presence of merely incompressible water saturated sand sediments suggests the depressurization technique as an attractive option to be employed as the presence of water assists in effective propagation of pressure front. Moreover, the high heat capacity of water acts as a heat source which assist the endothermic dissociation reactions of hydrate decomposition. Despite the 
favorable depressurization regime, the further study of Class 2 accumulations exposed few serious drawbacks due to the application of depressurization technique. First, the gas production rates are significantly affected due to competition to the gaseous phase provided by the presence of water at the wellbore. Second, the excessive water production can be uneconomical owing to higher lifting and water disposal costs. If depressurization-induced gas production is employed in such hydrate formation settings, the water phase fraction in the production stream represents up to $98 \%$ of the total produced mass ${ }^{[18]}$. To overcome this issue of proliferated water production, the studies proposed the application of combination of depressurization and thermal stimulation as well as implementation of multiple wells (like five spot configurations) to maximize produced gas rates ${ }^{[15]}$. Class 3 accumulations comprise single layer of hydrate-bearing geological settings sandwiched between highly impermeable shale layers. As these formations bounded by highly impermeable layers, depressurization technique doesn't lead to favorable gas production profiles, since the propagation of the pressure front will be slowed down owing to the presence of impermeable layer present in contact with the bottom of hydrate bearing layers. Hence, application of thermal stimulation technique results in enhanced gas production rates ${ }^{[15]}$. In Classes 2 and 3, the hydrate bearing interval may be situated well within the hydrate stability zone. Class 2 and 3 accumulations serves as less desirable exploitation sites compared to Class 1 deposits owing to several issues including thermodynamic proximity to hydration equilibrium, initial geologic conditions, environmental and economic considerations. Class 4 deposits $^{[19]}$ includes exclusively marine sediments in which mildly saturated hydrate deposits are observed without confining geologic strata. 


\subsection{Motivation and scope of work}

Amongst the four different gas hydrate accumulations that are present worldwide, Class 2 accumulations are the most prevalent hydrate settings that are usually the potential exploration targets. On a molecular scale, gas hydrates contain mostly (nearly $85 \%^{[3]}$ ) water, which results in release of large amounts of water upon hydrate dissociation. Particularly, exploitation of the Class 2 gas hydrate accumulations induced by the depressurization technique results in the production of significant volumes of water owing to the presence of highly permeable water saturated sand sediments (mobile water e.g., aquifer) in proximity to the hydrate bearing layers, thus lowering the produced gas rates. This undesirable volumes of produced water eventually results in geological subsidence which might lead to unintended ecological consequences. Therefore, the primary motivation of this work is to address the issue of proliferated water production from the Class 2 accumulations. In this work, it is accomplished by proposing a novel gas recovery technique for Class 2 accumulations which increases the gas production profoundly (by lowering the volumes of produced water) by utilizing $\mathrm{CO}_{2}$ sequestration. Over the years, $\mathrm{CO}_{2}$ capture and sequestration in deep saline aquifers has been under extensive investigation to reduce the emissions of the $\mathrm{CO}_{2}$ into the atmosphere. This concept is extended to this work where pure $\mathrm{CO}_{2}$ is utilized as the working fluid and incorporated a novel technique to permanently sequestrate the $\mathrm{CO}_{2}$ underground in one of its most stable forms $\left(\mathrm{CO}_{2}\right.$-hydrates/ $\mathrm{CH}_{4}-\mathrm{CO}_{2}$-hydrates $)$. The novel gas recovery technique proposed and implemented in this work, hence serves two purposes 1) enhanced gas recovery by lowering the volumes of produced water 2) $\mathrm{CO}_{2}$ sequestration into the underground geologic formation. The gas recovery technique implies a three stage approach which involves injection of $\mathrm{CO}_{2}$ into the mobile water (aquifer) underlying the $\mathrm{CH}_{4}$ hydrate bearing layer of the Class 2 accumulations, formation of immobile $\mathrm{CO}_{2}$ hydrate (thus trapping the greenhouse gas as a highly stable $\mathrm{CO}_{2}$ hydrate lattice) and finally, depressurization of the $\mathrm{CH}_{4}$ hydrate bearing layer. 
This technique also ensures maintaining the geological stability intact during the exploitation of Class 2 hydrate reserves.

\subsection{Objectives}

The overall objective of this study is to formulate and interpret a novel gas recovery technique which focused on enhanced gas production from Class 2 accumulations by utilizing $\mathrm{CO}_{2}$ sequestration. The detailed objectives are specified below:

1. To perform a suite of numerical simulations to comprehend the underlying changes in physical, thermodynamic and transport properties with change in pressure and temperature due to the presence of the simple $\mathrm{CO}_{2}$-hydrate and mixed hydrates (mainly $\mathrm{CH}_{4}-\mathrm{CO}_{2}$ hydrate and $\mathrm{CH}_{4}-\mathrm{CO}_{2}-\mathrm{N}_{2}$ hydrate) in the porous geologic media.

2. To study the $\mathrm{CO}_{2}$ injection and simultaneous depressurization of a natural gas hydrate reservoir by considering a five-spot well model.

3. To propose a stage-wise technological approach for successful implementation of a novel gas recovery technique which assists in lowering of the volumes of produced water (thus enhancing the gas production) from Class 2 accumulations by utilizing $\mathrm{CO}_{2}$-sequestration.

4. To perform sensitivity analysis on thermodynamic parameters such as pressure and temperature of the injected $\mathrm{CO}_{2}$ and also on the mode of injection (injection of $\mathrm{CO}_{2}$ using constant pressure or injection of $\mathrm{CO}_{2}$ using constant flow rate) that is to be employed during Stage I (the injection of $\mathrm{CO}_{2}$ stage).

5. To investigate the effect of equilibration of the reservoir on dynamics of $\mathrm{CO}_{2}$ hydrate formation.

6. To study the production potential of the Class 2 reservoirs by using depressurization. 
7. To understand the effect of reduced water influx from the underlying aquifer to the $\mathrm{CH}_{4}$ hydrate bearing layers on enhanced gas recovery.

8. To illustrate the concept of efficient sequestration of injected $\mathrm{CO}_{2}$.

9. To comprehend the various heat transfer mechanisms owed to the multiple thermodynamic processes taking place within the reservoir during all the stages of the proposed recovery technique. 


\section{Background}

\subsection{Mixed Gas Hydrates}

\subsubsection{Experimentation for $\mathrm{CO}_{2}$ swapping}

Swapping of $\mathrm{CH}_{4}$ by $\mathrm{CO}_{2}$ in natural gas hydrates was first proposed by Ohagaki et al. ${ }^{[20]}$ and then for ethane hydrate by Nakano et $\mathrm{al}^{[21]}$. Their experimental process involves injection of $\mathrm{CO}_{2}$ into an exploitation cave where in the thermodynamic conditions are well within the three phase coexisting region of the $\mathrm{CH}_{4}$ hydrate phase equilibrium curve. Their observations revealed that the mole fraction of $\mathrm{CH}_{4}$ in the gaseous phase starts to increase implying that $\mathrm{CH}_{4}$ in the hydrate cages are replaced by the injected $\mathrm{CO}_{2}$. Since then many experimental studies have been performed to comprehend the technicalities of this novel gas recovery technique $\left(\mathrm{CH}_{4}-\mathrm{CO}_{2}\right.$ technique). Hirohama et al. ${ }^{[2]}$ measured the recovery rate of methane from $\mathrm{CH}_{4}$ hydrate when it's soaked in liquid $\mathrm{CO}_{2}$. Later the focus shifted on to the study of thermodynamics of the swapping technique which might be affected by the varied porosity of the porous hydrate formation media wherein the conversion of $\mathrm{CH}_{4}$ hydrate to $\mathrm{CO}_{2}$ hydrate is expected to occur. Smith et al. ${ }^{[23]}$ performed calculations of the heat of dissociation of these hydrates $\left(\mathrm{CH}_{4}\right.$ hydrate and $\mathrm{CO}_{2}$ hydrate $)$ in porous media for any pore size distribution. Their results provided a basis to assess the thermodynamic feasibility of the conversion process $\left(\mathrm{CH}_{4}\right.$-hydrate to $\mathrm{CO}_{2}$ hydrate $)$ in a porous media. They concluded that replacement of methane by $\mathrm{CO}_{2}$ in the $\mathrm{CH}_{4}$ hydrate lattice is less thermodynamically favored for the sediments with very small pore sizes like clays.

The previous experimental studies did not address the issue of the kinetics of the $\mathrm{CH}_{4}-\mathrm{CO}_{2}$ swapping reaction. It was first attempted by Uchida et al. ${ }^{[24]}$ by using a Raman spectroscopic method and they confirmed the guest molecule swapping at the solid-gas interface. Further, a suite of experiments were conducted by McGrail et al ${ }^{[25]}$ which focused on directly measuring the rate 
of $\mathrm{CO}_{2}$ penetration into bulk $\mathrm{CH}_{4}$ hydrate. Their results indicated that swapping rates deeper into the gas hydrate are slow and moreover, the additional tortuosity imposed by the porous gas hydrate reservoir media would even lower down the exchange rates further by $1 / 2$ or $1 / 4$ of the rates calculated for bulk gas hydrates. Hence, they've conceptualized a new technique for Enhanced Gas Hydrate Recovery (EGHR) which involves injection of micro-emulsion (formed with $\mathrm{CO}_{2}$ and water) into the hydrate bearing sediments at a temperature greater than the equilibrium temperature of the methane which eventually results in decomposition of the enclathrated hydrates.

The recovery of $\mathrm{CH}_{4}$ from methane hydrates using $\mathrm{CO}_{2}$ was calculated to be around $64 \%$. This is due to the larger molecular diameter of $\mathrm{CO}_{2}$ (equal to the size of the small cage of structure I) compared to $\mathrm{CH}_{4}$ which allows them to replace the $\mathrm{CH}_{4}$ present only in the large cages, leaving the $\mathrm{CH}_{4}$ in the smaller cages remain intact. This was experimentally proven by Lee et al ${ }^{[26]}$ who employed MAS ${ }^{13} \mathrm{C}$ NMR technique to make the observations. Further, Park et al ${ }^{[27]}$ proposed the utilization of $\mathrm{N}_{2}$ and $\mathrm{CO}_{2}$ together for the recovery of $\mathrm{CH}_{4}$ from methane hydrates which resulted in improved recovery rate to $85 \%$, where $\mathrm{N}_{2}$ due to its small molecular diameter (similar to $\mathrm{CH}_{4}$ ) tends to replace the smaller cages while $\mathrm{CO}_{2}$ replaced the $\mathrm{CH}_{4}$ from the larger ones.

The swapping process of $\mathrm{CO}_{2}$ in $\mathrm{CH}_{4}+\mathrm{C}_{2} \mathrm{H}_{6}$ mixed hydrate (which forms structure II) was considered to study the replacement process. The replacement process results in structural transition from sII to structure I (sI) wherein most of the $\mathrm{CH}_{4}$ and $\mathrm{C}_{2} \mathrm{H}_{6}$ in small and large cages of the original structure (sII) are replaced by the injected $\mathrm{CO}_{2}$ (shown in Figure 2-1). 


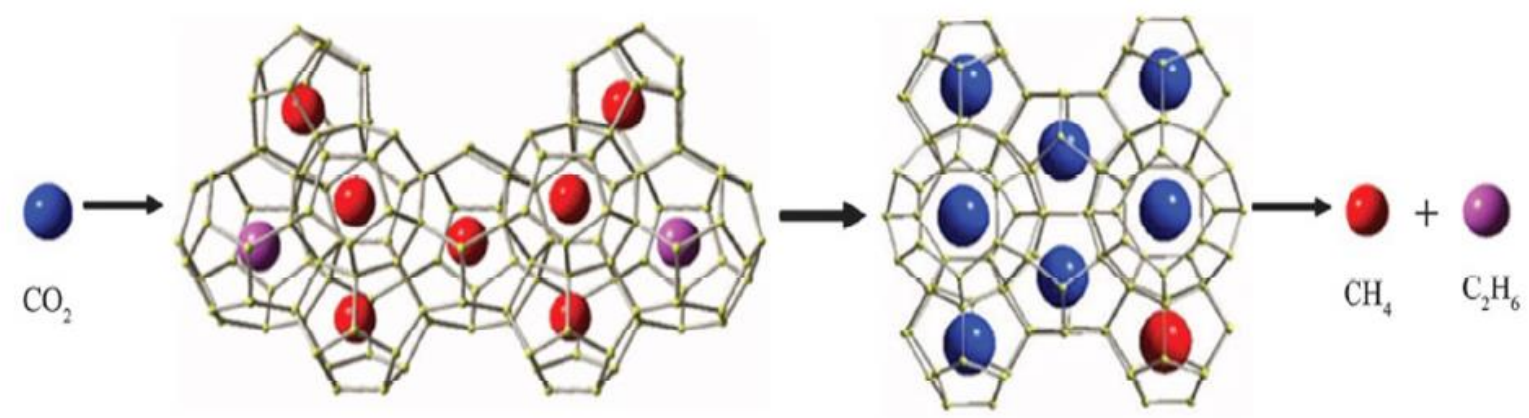

Figure 2-1. Replacement of $\mathrm{CH}_{4}+\mathrm{C}_{2} \mathrm{H}_{6}$ mixed hydrate with $\mathrm{CO}_{2}$

These experimental studies provided an insight for understanding the conversion process and henceforth, motivated further research in exploring this novel technique. Due to the expensive investment for the field-scale experiments and their related equipment, reservoir simulators were developed to determine the complexities of the swapping process. Mix3HydrateResSim(Mix3HRS) ${ }^{[28]}$ and STOMP-HYDT ${ }^{[29]}$ simulators are couple of simulators which can simulate the $\mathrm{CO}_{2}$ and $\mathrm{N}_{2}$ exchange process with methane present in $\mathrm{CH}_{4}$ hydrates.

\subsection{Geological sequestration of $\mathrm{CO}_{2}$}

Capture of $\mathrm{CO}_{2}$ and its long-term storage in the underground geological settings is a widely proposed approach to offset the alarming levels of $\mathrm{CO}_{2}$ in the atmosphere which is primarily produced from the fossil-fuel-burning power plants. Over the years, $\mathrm{CO}_{2}$ capture and sequestration (CCS) has been under extensive investigation to reduce the emissions of $\mathrm{CO}_{2}$ into the atmosphere. The geo-sequestration of $\mathrm{CO}_{2}$ involves injection of the greenhouse gas directly into the underground geological reservoirs (mainly hydrocarbon settings), whose geology (like highly impermeable caprock) assists in serving this technique as a quite attractive option. In the recent times, utilizing $\mathrm{CO}_{2}$ to extract geothermal energy has been under wide consideration. $\mathrm{CO}_{2}$ 
generated from power plants can be captured and utilized as a working fluid to recover geothermal heat from miles beneath the ground. Such a system serves two benefits, first, it captures the $\mathrm{CO}_{2}$ and keep it away from the atmosphere. Second, it is also estimated to be an economical pathway to utilize $\mathrm{CO}_{2}$ to fuel the generation of new power.

Although $\mathrm{CO}_{2}$ has been captured into the underground geological settings for decades to meet several purposes (like enhanced oil recovery), the long term secure storage of $\mathrm{CO}_{2}$ has remained as a challenging concept. Moreover, the intensive geo-sequestration might end up in aggressive fracturing of the geological formations, thus creating geological subsidence and lead to unintended environmental consequences. Natural gas hydrate formations serve as an attractive option to seal $\mathrm{CO}_{2}$ as gas hydrates. One such strategy which assists to sequestrate atmospheric $\mathrm{CO}_{2}$ was proposed by Ohgaki et al. ${ }^{[20]}$, is a novel gas hydrate recovery technique: " $\mathrm{CO}_{2}-\mathrm{CH}_{4}$ exchange in $\mathrm{CH}_{4}$ hydrates". This technique offers a dual purpose of enhanced $\mathrm{CH}_{4}$ gas production and simultaneous sequestration of the greenhouse gas as the most stable gas hydrate $\left(\right.$ as $\mathrm{CH}_{4}-\mathrm{CO}_{2}$-hydrate $\left.{ }^{[30]}\right)$. The feasibility of the swapping process is owed to the following reasons, 1) $\mathrm{CO}_{2}, \mathrm{CH}_{4}$ and even the mixtures of these gases form Structure 1 (sI) hydrate ${ }^{[3,31]}$. This structural similarity assists in maintaining the structural integrity even after swapping of $\mathrm{CH}_{4}$ by $\mathrm{CO}_{2}$ in the natural gas hydrate settings and hence no stiffness loss is observed at the sediment scale ${ }^{[32]}$. 2) $\mathrm{CO}_{2}$-hydrate is thermodynamically more stable than $\mathrm{CH}_{4}$-hydrate at temperatures below $283 \mathrm{~K}$ (shown in Figure 2.1), since the equilibrium pressures of the $\mathrm{CO}_{2}$-hydrate is lower than the $\mathrm{CH}_{4}$-hydrate at this condition $^{[33]}$.

Later, the experimental studies signified that injection of the mixture of $\mathrm{CO}_{2}$ and $\mathrm{N}_{2}$ gas into the natural gas hydrate settings would assist in enhancing the gas recovery by $85 \%$. During 2011 and 2012, the Ignik Sikumi, first field test for gas hydrate exchange trial within the Prudhoe Bay Unit 
(PBU) on the Alaska North Slope (ANS) was conducted by ConocoPhillips, in partnership with the U.S. Department of energy, the Japan Oil gas and Metals National Corporation and the U.S. Geological Survey ${ }^{[34]}$. The well log data obtained from a total of 90 wells located in proximity to the PBU L-Pad ${ }^{[35]}$ provided insight to determine the general occurrence of hydrates and the geologic structure. And the logs confirmed the presence of multiple gas hydrate bearing sand sediments in the Prudhoe Bay Unit. This field test concluded that $\mathrm{CO}_{2}-\mathrm{CH}_{4}$ swapping can be achieved successfully in natural gas hydrate reservoirs ${ }^{[34]}$ and hence asserted that $\mathrm{CO}_{2}$ trapping as a stable hydrate can be accomplished.

\subsubsection{Ignik Sikumi Field trial test}

The Ignik Sikumi field trial ${ }^{[34]}$ was conducted as a "huff and puff" design wherein a single vertical well was used as an injector at first and later as a producer. The trial consists of following stages 1) injection of mixture of $\mathrm{CO}_{2}(23 \%)+\mathrm{N}_{2}(77 \%)$ with minor amounts of chemical traces was done for 14 days; 2) After 14-day injection period, the well was shut-in for about 4.5 days; 3) jet-pumpassisted flow-back phase via depressurization for 30 day time period. During this phase, the bottom hole pressure was maintained at 3.5 MPa. Numerical simulations were performed to analyze the data obtained from the Ignik Sikumi \# 1 field trial test predicted my two approaches performed using two different simulators, which are STOMP-HYDT-KE and Mix3HRS. Numerical simulator STOMP-HYDT-KE can simulate formation, dissociation and guest-molecule exchange of mixed hydrates $\left(\mathrm{CH}_{4}-\mathrm{CO}_{2}-\mathrm{N}_{2}\right.$ hydrate $)$ via kinetic models and rate parameters, whereas Mix3HRS simulator predicts the mixed hydrate $\left(\mathrm{CH}_{4}-\mathrm{CO}_{2}-\mathrm{N}_{2}\right.$ hydrate $)$ dissociation and formation reactions by equilibrium model. Both the approaches used a 2-dimensional radial domain wherein heterogeneity was imposed vertically, but constant petrophysical properties was assumed radially from the Ignik Sikumi \# 1 well. The schematic of the geological domain used in the numerical 
simulations performed by Mix3HRS simulator is shown in Figure 2-3 (similar domain was used in the other approach as well but with different grid discretization).

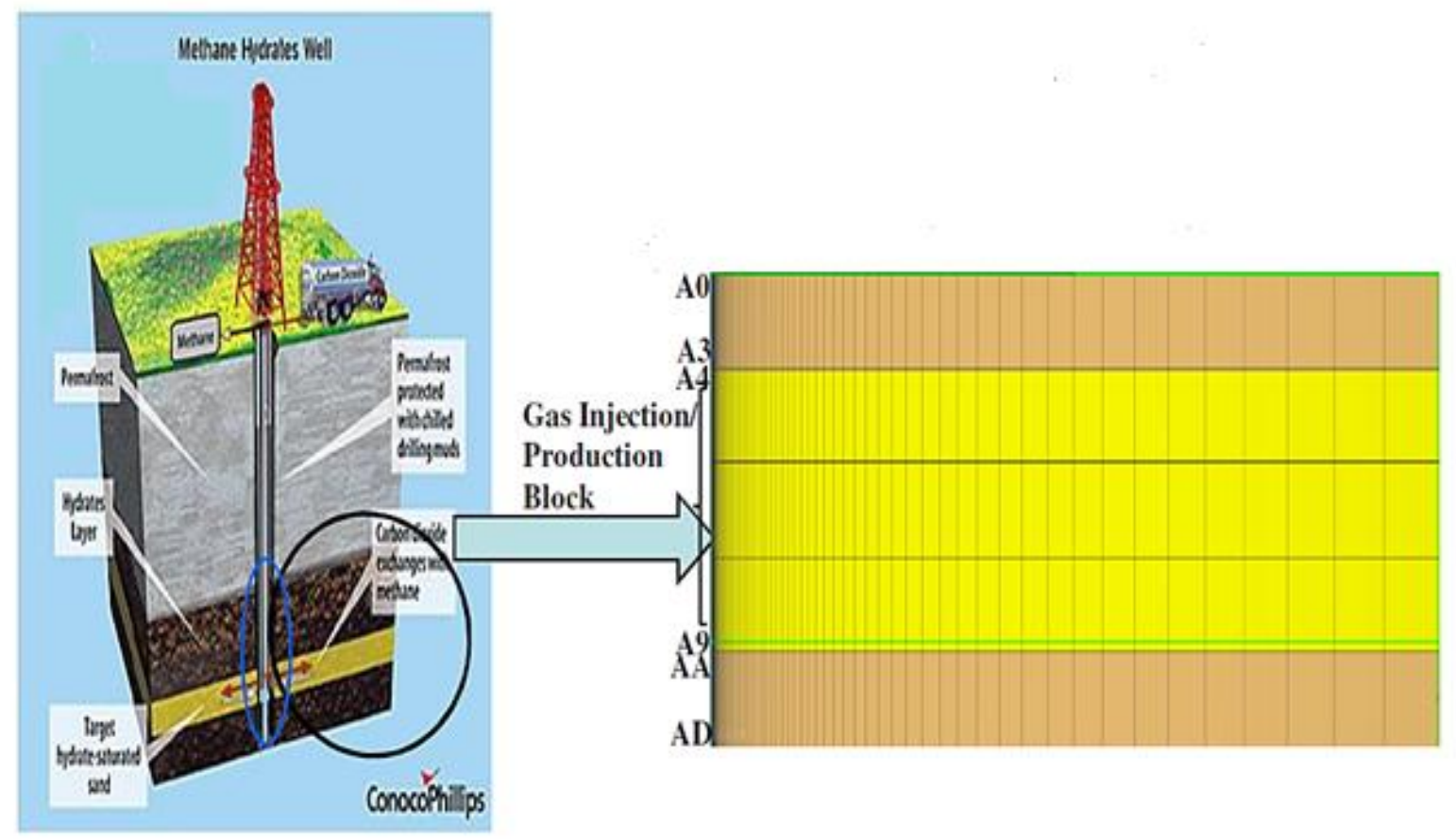

Figure 2-2. Conceptual representaion of the proposed exchange experiment (left side) and the geologic domain used for Mix3HRS simulations ${ }^{[28]}$

The results obtained from both the approaches indicated good agreement with the field data. It was deduced from the injection simulations performed via kinetic model (STOMP-HYDT-KE simulator) that the gas molecular exchange rates in the field test are slower than those inferred from laboratory experimental settings owed to the reasons including $\mathrm{CO}_{2}$ hydrate formation (with the free water available), ice accumulation, etc. In the field test, during the 30 day flow back phase, along with produced gas and water, the produced stream was observed with $2.6 \%$ volume of sand. The production of sand was attributed to the significant rise in flow potential owed to the rise in the permeability, thus resulting in the hydrate being pulled into the wellbore and hence 
decomposing in the wellbore (thus increased produced gas and water profiles are also observed along with sand production). Mix3HRS code was modified accordingly to account for the sand production during the flow back phase of the field trial. The gas production profiles of $\mathrm{CH}_{4}, \mathrm{CO}_{2}$ and $\mathrm{N}_{2}$ were monitored throughout the flow back phase and it was observed that the volume fraction of $\mathrm{N}_{2}$ in the production stream was higher than $\mathrm{CO}_{2}$ owing to the instability of the $\mathrm{N}_{2}$ hydrate at the prevailing conditions. $\mathrm{CO}_{2}$ hydrate being more stable at lower pressure conditions resulted in lower $\mathrm{CO}_{2}$ gas production during the flow back phase. Some of the major findings from the field test are listed below:

- Swapping of $\mathrm{CH}_{4}$ by $\mathrm{CO}_{2}$ in methane hydrates is feasible in natural gas hydrate accumulations

- The injection of appropriate gaseous phase mixtures (of $\mathrm{CO}_{2}$ and $\mathrm{N}_{2}$ ) as opposed to pure $\mathrm{CO}_{2}$ injection which leads to the permeability impairment of the reservoir rock is deduced to be beneficial for successful $\mathrm{CO}_{2}-\mathrm{CH}_{4}$ swapping.

- Complexities such as production of sand and water during the gas hydrate production spurred the scientific community to develop more aggressive experimental and numerical modeling capabilities.

- The field trial confirmed that $\mathrm{CO}_{2}$ was preferentially sequestered in the reservoir compared to $\mathrm{N}_{2}$ due to the virtue of $\mathrm{CO}_{2}$ forming stable hydrates unlike $\mathrm{N}_{2}$. 


\subsection{Class 2 Hydrate Accumulations}

Class 2 hydrate accumulations are characterized by a Hydrate-Bearing Layer (HBL) underlain by a water saturated sand zone (mobile water). Class 2 deposits are widely found around the globe in both permafrost ${ }^{[36]}$ and ocean settings ${ }^{[37]}$ and it is estimated that these deposits are the most prevalent deposits among the various hydrate formation settings that are potential exploration targets ${ }^{[19]}$. The well-logs of L-Pad and Ignik-Sikumi wells drilled in Prudhoe Bay L-Pad region of Alaska North Slope indicate the presence of hydrate-water contact ${ }^{[34]}$ at a depth of $685 \mathrm{~m}$ (shown in Figure 2-3). Also, the short-term field tests conducted at the geologic deposits of the Mallik Site, in the Mackenzie Delta, Northwest Territories, Canada, indicated that hydrate deposits fall under the category of class $2^{[38]}$ accumulations.

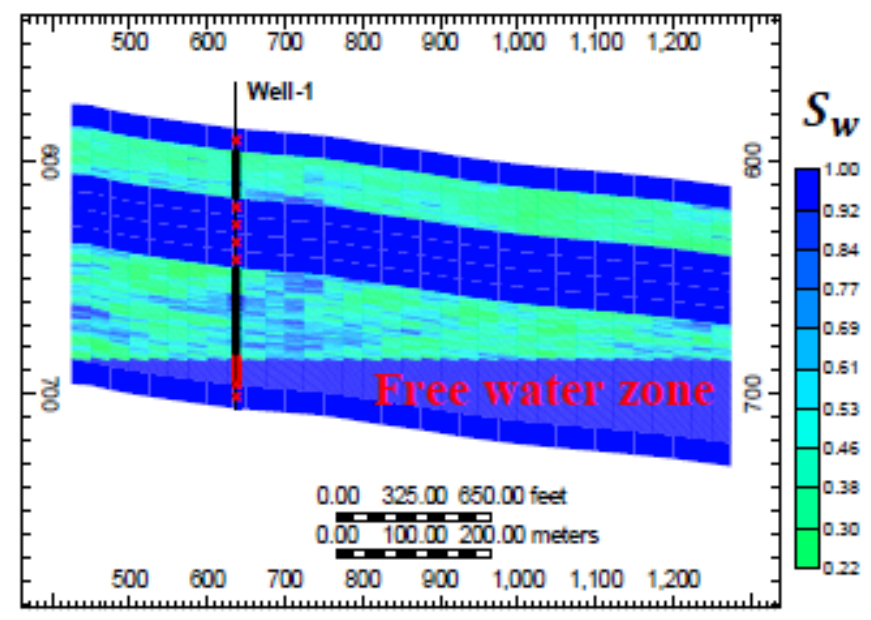

Figure 2-3. Vertical cross-sections of water saturation $\left(S_{\mathrm{w}}\right)$ distributions of reservoir models of Prudhoe-Bay L-Pad regions ${ }^{[39]}$

In this type of hydrate accumulations, the bottom of the hydrate bearing layer (HBL) is situated within or at the proximity to the bottom of the Hydrate Stability Zone (HSZ). The proximity of the bottom of the HBL to the base of the Hydrate Stability Zone (which is characterized by the maximum possible equilibrium temperature at the prevailing pressures) augments the gas 
productivity of the formation matrix because of higher sensible heat of the deposits owing to the higher temperatures.

Depressurization of these hydrate accumulations eventually produce high gas rates due to the presence of an aquifer which is in proximity with the hydrate formations. The reason for high subsequent gas rates is the incompressible behavior of water, which assists in effective propagation of pressure front, thus resulting in the rapid dissociation of hydrates present at hydrate-water boundary. Moreover, the high heat capacity of water acts as a heat source which assist the endothermic dissociation reactions of hydrate decomposition. However, the presence of an aquifer poses a phenomenal drawback of huge water production and needs to be looked into to achieve significant gas recovery rate. The excessive release of water in the production stream eventually impedes the gas flow rates due to higher saturation of aqueous phase observed around the well bore which decreases the permeability of the gas phase (the relative permeability of the gas near the well-bore decreases). Additionally, the excessive water production can be uneconomical owing to higher lifting and water disposal costs.

\subsection{Reservoir simulator - Mix3HydrateResSim}

As the gas hydrate research is intensified among the coordinated national research programs, various reservoir simulators emerged over the past decade. In comparison to field-scale experiments, use of reservoir simulators are considered to be more economical. The different reservoir simulators that are available are CMG STARS ${ }^{[40]}$, HydrateResSim ${ }^{[41]}$, MH-21 HYDRES $^{[42]}$, STOMP-HYD ${ }^{[29]}$, TOUGH+HYDRATE ${ }^{[43]}$. Amongst these simulators, HydrateResSim (HRS) is the only open-source code available for public through the National Energy Technology Laboratories (NETL). HRS includes equilibrium and kinetic models of nonisothermal formation and dissociation of simple $\mathrm{CH}_{4}$-hydrate. It accounts for five components 
$\left(\mathrm{CH}_{4}, \mathrm{H}_{2} \mathrm{O}\right.$, hydrate, inhibitors and a heat pseudo-component) distributed among four phases (gas, liquid, ice and hydrate).

Later, HRS has been modified ${ }^{[28]}$ to include the equilibrium model which accounts for formation and dissociation of ternary hydrates $\left(\mathrm{CH}_{4}-\mathrm{CO}_{2}-\mathrm{N}_{2}\right.$ hydrate $)$ which is called as the Mix3HydrateResSim (Mix3HRS) ${ }^{[28]}$. Mix3HRS allows distribution of six components $\left(\mathrm{CH}_{4}, \mathrm{CO}_{2}\right.$, $\mathrm{N}_{2}, \mathrm{H}_{2} \mathrm{O}$, water-soluble inhibitors and a heat pseudo-component) among four possible phases (gas, liquid, ice, and hydrate). The multiphase system is described as primary variables in the code. These primary variables fully describes the state of the system and they keep changing throughout the simulation owing to the changes in thermodynamic states of the system.

Table 2-1. Details of primary variables for different phases

\begin{tabular}{|c|c|c|c|c|c|}
\hline Phase & $\begin{array}{c}\text { Primary } \\
\text { Variable 1 }\end{array}$ & $\begin{array}{c}\text { Primary } \\
\text { Variable 2 }\end{array}$ & $\begin{array}{c}\text { Primary } \\
\text { Variable 3 }\end{array}$ & $\begin{array}{c}\text { Primary } \\
\text { Variable 4 }\end{array}$ & $\begin{array}{c}\text { Primary } \\
\text { Variable 5 }\end{array}$ \\
\hline 1 Phase Aqu & P & X_mA & $\mathrm{T}$ & X_cA & X_nA \\
1 Phase Gas & P_gas & Y_mG & $\mathrm{T}$ & Y_cG & Y_nG \\
2 Phases AqG & P_gas & S_aqu & $\mathrm{T}$ & Xmol_cG & Xmol_nG \\
2 Phases AqH & P & S_aqu & $\mathrm{T}$ & Xmol_cH & Xmol_nH \\
2 Phases IcG & P_gas & S_ice & $\mathrm{T}$ & Xmol_cG & Xmol_nG \\
2 Phases IcH & P & S_ice & $\mathrm{T}$ & Xmol_cH & Xmol_nH \\
3 Phases AGH & S_gas & S_aqu & $\mathrm{T}$ & Xmol_cH & Xmol_nH \\
3 Phases AIG & P_gas & S_aqu & S_gas & Xmol_cG & Xmol_nG \\
3 Phases AIH & P & S_aqu & S_ice & Xmol_cH & Xmol_nH \\
3 Phases IGH & S_gas & S_ice & T & Xmol_cH & Xmol_nH \\
4 Phases Qup & S_gas & S_aqu & S_ice & Xmol_cH & Xmol_nH \\
2 Phases GsH & P_gas & S_gas & T & Xmol_cH & Xmol_nH \\
\hline
\end{tabular}

Where the possible primary variables are: $P x$ (for phase Aqu)-Pressure(Pa); $P x$ (for phase Gas)Gas Pressure $(\mathrm{Pa}) ; T x$, temperature $(\mathrm{C}) ; X \_m A$, mass fraction of $\mathrm{CH}_{4}$ dissolved in Aqueous phase; $X \_c A$, mass fraction of $\mathrm{CO}_{2}$ dissolved in Aqueous phase; $X \_n A$, mass fraction of $\mathrm{N}_{2}$ dissolved in Aqueous phase; $X m o l \_m G$, mole fraction of $\mathrm{CH}_{4}$ dissolved in Gas phase; $X m o l \_c G$, mole fraction of $\mathrm{CO}_{2}$ dissolved in Gas phase; Xmol_nG, mole fraction of $\mathrm{N}_{2}$ dissolved in Gas phase; Xmol_cH, 
mole fraction of $\mathrm{CO}_{2}$ dissolved in Hydrate phase; $X m o l \_n H$, mole fraction of $\mathrm{N}_{2}$ dissolved in Hydrate phase; $S \_a q u$, liquid saturation; $S \_g a s$, Gas Saturation; $S \_i c e$, Ice saturation.

The mass and energy balances in each volume element into which the simulation grid domain is discretized in space using the integral finite difference method as:

$$
\int \frac{d}{d t} \int_{V n} M^{k} d v=\int_{\tau_{n}} F^{k} \cdot n d \tau+\int_{V_{n}} q^{k} d V
$$

where,

$V, V n$ are volume, volume of subdomain $\mathrm{n}\left[\mathrm{m}^{3}\right]$

$M^{k}$ Mass accumulation term of component $k\left[\mathrm{~kg} \mathrm{~m}^{-3}\right]$

$\Gamma, \Gamma_{n}$ surface area, surface area of subdomain $\mathrm{n}\left[\mathrm{m}^{2}\right]$

$F^{k}$ Darcy flow vector of component $k\left[\mathrm{~kg} \mathrm{~m}^{-2} \mathrm{~s}^{-1}\right]$

$n$ inward unit normal vector

$q^{k}$ source/sink term of component $k\left[\mathrm{~kg} \mathrm{~m}^{-3} \mathrm{~s}^{-1}\right]$

$t$ Time [s]

Under equilibrium, the mass accumulation term is given by:

$$
M^{k}=\sum_{\beta=A, G, I} \varnothing S_{\beta} \rho_{\beta} X_{\beta}^{k}, k=w, m, G, i
$$

where,

$\Phi$ Porosity

$S \beta$ saturation of phase $\beta$

$\rho_{\beta}$ density of phase $\beta[\mathrm{kg} \mathrm{m}-3]$

$X_{\beta}^{k}$ mass fraction of component $k$ in phase $\beta[\mathrm{kg} / \mathrm{kg}]$ 
whereas the heat accumulation term encompasses the contributions from all the phases and the reservoir rock matrix, and is calculated as

$$
M^{k}=(1-\emptyset) \rho_{R} C_{R} T \sum_{\beta=A, G, I} \varnothing S_{\beta} \rho_{\beta} U_{\beta}+Q_{\text {diss }}
$$

where

$Q_{\text {diss }}=\emptyset \rho_{H} \Delta S_{H} \Delta H^{0}$

$\rho_{R} \quad$ rock density $\left[\mathrm{kg} \mathrm{m}^{-3}\right]$

$C_{R} \quad$ heat capacity of the dry rock $\left[\mathrm{J} \mathrm{kg}^{-1} \mathrm{~K}^{-1}\right]$

$U_{\beta} \quad$ specific internal energy of phase $\beta\left[\mathrm{J} \mathrm{kg}^{-1}\right]$

$\triangle S H$ change in the hydrate saturation over the current time step

$\Delta U H$ specific enthalpy of hydrate dissociation/formation $\left[\mathrm{J} \mathrm{kg}^{-1}\right]$

The flux term from the Eq-2.1, encompasses the mass and heat flux profiles. The mass fluxes includes contributions from aqueous and gaseous phases, and are given by

$$
F^{k}=\sum_{\beta=A, G} F_{\beta}^{k}
$$

The phase flux for the aqueous phase is given by Darcy's law as:

$F_{A}=K \frac{K_{r A} \rho_{A}}{\mu_{A}}\left(\Delta P_{A}-\rho_{A} \boldsymbol{g}\right)$

where

$k \quad$ rock intrinsic permeability $\left[\mathrm{m}^{2}\right]$

$k_{r A}$ relative permeability of the aqueous phase

$\mu_{A} \quad$ viscosity of the aqueous phase [Pa.s]

$P_{A} \quad$ pressure of the aqueous phase $[\mathrm{Pa}]$ 
g gravitational acceleration vector $\left[\mathrm{m} \mathrm{s}^{-2}\right]$

For the gaseous phase, the flux consists of advection and diffusion terms, and is defined as:

$$
F_{G}^{k}=-k_{0}\left(1+\frac{b}{P_{G}}\right) \frac{k_{r G} \rho_{G}}{\mu_{G}} X_{G}^{k}\left(\Delta P_{G}-\rho_{G} \boldsymbol{g}\right)+\boldsymbol{J}_{G}^{k}
$$

where

$k_{0} \quad$ absolute permeability at large gas pressures $(=k)\left[\mathrm{m}^{2}\right]$

$b \quad$ Klinkenberg [1941] $b$-factor accounting for gas slippage effects [Pa]

$k_{r G} \quad$ relative permeability of the gaseous phase [dimensionless]

$\mu_{G} \quad$ viscosity of the gaseous phase $[\mathrm{Pa} \mathrm{s}]$ and

$J_{G}^{k} \quad$ is the diffusive mass flux of component $k$ in the gas phase $\left[\mathrm{kg} \mathrm{m}^{-2} \mathrm{~s}^{-1}\right]$

The heat flux encompasses conduction, convection and radiative heat transfer contributions and is given by

$$
F^{h}=-\left[(1-\emptyset) K_{R}+\emptyset\left(S_{H} K_{H}+S_{I} K_{I}+S_{A} K_{A}+S_{G} K_{G}\right)\right] \Delta T+f_{\sigma} \sigma_{0} \Delta T^{4}+\sum_{\beta=A, G} h_{\beta} F_{\beta}
$$

where

$K_{R}$ thermal conductivity of the rock $\left[\mathrm{W} \mathrm{m} \mathrm{m}^{-1} \mathrm{~K}^{-1}\right]$

$K_{\beta}$ thermal conductivity of phase $\beta \equiv \mathrm{A}, \mathrm{G}, \mathrm{H}, \mathrm{I}\left[\mathrm{W} \mathrm{m}{ }^{-1} \mathrm{~K}^{-1}\right]$

$h_{\beta}$ specific enthalpy of phase $\beta \equiv \mathrm{A}, \mathrm{G}, \mathrm{H}, \mathrm{I}\left[\mathrm{J} \mathrm{kg}^{-1}\right]$

$f_{\sigma}$ radiance emittance factor

$\sigma_{0}$ Stefan-Boltzmann constant $\left[5.6687 \times 10-8 \mathrm{~J} \mathrm{~m}^{-2} \mathrm{~K}^{-4}\right]$.

The phase equilibrium data for the mixed hydrate $\left(\mathrm{CH}_{4}-\mathrm{CO}_{2}-\mathrm{N}_{2}\right.$ hydrate $)$ obtained using cell potential $^{[44]}$ code is incorporated in to Mix 3 HRS in a tabular form and a tri-linear interpolation is 
used to interpolate data at given conditions. The phase equilibrium is given as input to the code (Mix3HRS) in two data files.

$$
\mathrm{Teq}=\mathrm{f}\left(\mathrm{P}, \mathrm{yCO}_{2}, \mathrm{yCH}_{4}\right) \& \mathrm{Peq}=\mathrm{g}\left(\mathrm{T}, \mathrm{yCO}_{2}, \mathrm{yCH}_{4}\right)
$$

Where, $T$ is temperature $\left({ }^{0} \mathrm{C}\right), P$ is pressure $(\mathrm{Pa}), y \mathrm{CO}_{2}$ is $\mathrm{CO}_{2}$ composition in gas phase and $y \mathrm{CH}_{4}$ is $\mathrm{CH}_{4}$ composition in gas phase.

The continuum equations (Mass and energy balance equation) are discretized in space using the integral finite difference method (IFD) and by forward first-order finite difference and a fully implicit approach in time. This time discretization results in a set of coupled non-linear algebraic equations obtained for each volume element. These equations completely define the state of the flow system at a time level and are solved by Newton/Raphson iteration.

All the numerical simulations that are discussed in the following chapters (Chapters $3 \& 4$ ) are performed using the Mix3HRS simulator as it is one among very few reservoir simulators which can simulate the process of $\mathrm{CH}_{4}$ substitution by $\mathrm{CO}_{2}\left(\right.$ and $\left.\mathrm{N}_{2}\right)$ in the hydrate lattice. 


\section{Suite of problems involving numerical simulations of Simple $\left(\mathrm{CO}_{2}\right.$ hydrate) and Mixed hydrate $\left(\mathrm{CH}_{4}-\mathrm{CO}_{2}\right.$ hydrates and $\mathrm{CH}_{4}-\mathrm{CO}_{2}-\mathrm{N}_{2}$ hydrates) reservoirs}

\subsection{Introduction}

Over the years, various numerical simulators were developed worldwide with a common goal of predicting the dynamics and production potential of $\mathrm{CH}_{4}$ from gas hydrate reservoirs by investigating different gas recovery techniques. National Energy Technology Laboratory (NETL) and U.S Geological Survey (USGS) designed an "International code comparison project ${ }^{[45,46] \text { " in }}$ 2008, which was first of its kind. The project aimed at scrutinizing the unanimity among various

gas hydrate reservoir simulators. As a part of it, several problems were formulated ${ }^{[45,46]}$ (by the U.S.D.O.E. and USGS) which were intended to comprehend the dynamics of $\mathrm{CH}_{4}$-hydrate reservoirs and to understand the efficacy of various production techniques which have been under extensive investigation for decades. The code comparison project encompasses seven problems of varied complexity comprising of simple cases as a start off and with the increased complexity as the project proceeds. The numerical simulators involved in the project were STOMP, HydrateResSim, TOUGH-Fx/Hydrate, CMG STARS, MH21, and a code from Houston whose focus was primarily the $\mathrm{CH}_{4}$-hydrate reservoirs.

This part of the thesis aims at understanding the underlying changes in physical, thermodynamic and transport properties with change in pressure and temperature due to the presence of the simple $\mathrm{CO}_{2}$-hydrate and mixed hydrates (mainly $\mathrm{CH}_{4}-\mathrm{CO}_{2}$ hydrate and $\mathrm{CH}_{4}-\mathrm{CO}_{2}-\mathrm{N}_{2}$ hydrate) in the porous geologic media. In this chapter, similar to the 'International code comparison project', design suite of problems involving varied complexity are focused but unlike the code comparison project which was focused on simple $\mathrm{CH}_{4}$-hydrate reservoirs, here mixed hydrate reservoirs are 
studied. There are couple of factors which served as motivation to work on the dynamics of mixed gas-hydrate reservoirs. First, to investigate the novel production technique which is " $\mathrm{CH}_{4}-\mathrm{CO}_{2}$ swapping" for which the basic study of mixed hydrate reservoirs is of paramount requirement. This recovery technique was implemented in the Ignik Sikumi ${ }^{[34]}$, the first field trial test for gas hydrate swapping technique. Second, MIX3HRS is one among very few ${ }^{[28]}$ simulators around the globe which has the capability to perform the mixed hydrate reservoir simulations. Hence, consideration of various problems featuring the complexities of the mixed hydrate reservoirs will serve as a basis for future formulation of 'code comparison project for mixed hydrate reservoirs'.

This project starts with the study of simple $\mathrm{CO}_{2}$-hydrate reservoirs, to gain a basic insight on how Pressure/Temperature change affects the $\mathrm{CO}_{2}$-hydrate formation and dissociation phenomena. The suboceanic sequestration of $\mathrm{CO}_{2}$ has been the most preferred storage option for $\mathrm{CO}_{2}$ due to the formation of $\mathrm{CO}_{2}$ hydrates underneath the deep sea floor ${ }^{[47]}$. Hence, as a start off its necessary to study the dynamics of $\mathrm{CO}_{2}$-hydrate formation in the sediment pores which enable the trapping of $\mathrm{CO}_{2}$ in the form of $\mathrm{CO}_{2}$ hydrates and thus, assists in preserving the ecological balance. In this project, Problems $1 \& 2$ deal with the $\mathrm{CO}_{2}$-hydrate formation and dissociation respectively. Problem 2 deals with two different cases investigating the couple of well-established production techniques (depressurization and thermal stimulation) to recover gas from hydrate reservoir settings. Further, Problem 3 serves as a base case problem which aims at investigating the numerical simulation of multifluid flow and heat transport processes for water- $\mathrm{CH}_{4}-\mathrm{CO}_{2}$ system outside the stability region of gas hydrate formation. Problem 4 is intended to study the dissociation behavior of $\mathrm{CH}_{4}-\mathrm{CO}_{2}$-hydrates present in a reservoir by employing two different production techniques (depressurization and thermal stimulation). These problems assists in understanding the reservoir behavior of $\mathrm{CH}_{4}-\mathrm{CO}_{2}$ swapping technique. Another difference 
between these two problems (Problems 3 and 4) is the model grid system considered for each problem, Problem 3 dealt with 1D cartesian domain, whereas Problem 4 considered radial cylindrical grid, which helps to study the effect of fine discretization of the grid.

These problems are followed by Problems $5 \& 6$, which are quite similar to the previous two problems except for the presence of $\mathrm{CH}_{4}-\mathrm{CO}_{2}-\mathrm{N}_{2}$ hydrates in the reservoir. These two problems study the mechanics of the dissociation reaction of mixed hydrates. Finally, Problem 7 deals with the $\mathrm{CO}_{2}$ injection and simultaneous depressurization of a natural gas hydrate reservoir by considering a five-spot well model. The favorable thermodynamics of $\mathrm{CO}_{2}$ over $\mathrm{CH}_{4}$ hydrates can be utilized to produce natural gas from the formation settings. Hence, the objective of Problem 7 is to study the pros and cons of employing this $\mathrm{CH}_{4}-\mathrm{CO}_{2}$ swapping technique efficiently.

For all the numerical simulation scenarios considered in this chapter, the reservoir domains are considered either as homogenous 1D or 2D cartesian/radial cylindrical domains. The initial conditions (reservoir pressure and temperature) of each problem is based on the compositions of $\mathrm{CH}_{4}, \mathrm{CO}_{2}$ and $\mathrm{N}_{2}$ in the mixed hydrates present initially in the reservoir. In all the problems, the reservoir rock has homogeneous and isotropic properties. As the simulation proceeds on, the temporal changes of reservoir properties are monitored. Each of these problems are discussed in detail in the following sections. 


\subsection{Problem 1: Dynamics of $\mathrm{CO}_{2}$ hydrate formation}

\subsubsection{Problem description}

This problem involves a base case model which simulates the formation of $\mathrm{CO}_{2}$-hydrate in a porous geological media. The detailed understanding of dynamics of $\mathrm{CO}_{2}$-hydrate formation in highly permeable water-saturated sand reservoirs (particularly Class 2 accumulations) assists in exploring one of the novel options of geological $\mathrm{CO}_{2}$-sequestration which involves a unique way of sealing the greenhouse gas as highly stable $\mathrm{CO}_{2}$-hydrates. In this problem, $\mathrm{CO}_{2}$-hydrate formation is enabled by injecting $\mathrm{CO}_{2}$ into water-saturated sands.

The model involves a horizontal one-dimensional spatial domain. The domain is finely discretized into 30 grid blocks of $0.05 \mathrm{~m}$ each which extends out $1.5 \mathrm{~m}$ laterally (shown in the Figure 3-1). This problem uses a fine gridding of a small domain simialr to the problem 3 of code comaprison project $^{[45]}$, which assists to explore the fine-scale effects of hydrate formation closer to the well. The domain is considered to be non-closed system which imples that the gas is injected into the reservoir at the boundary (at $x=0$, the origin). The lateral boundaries are taken as impermeable for both heat and mass transfer. 


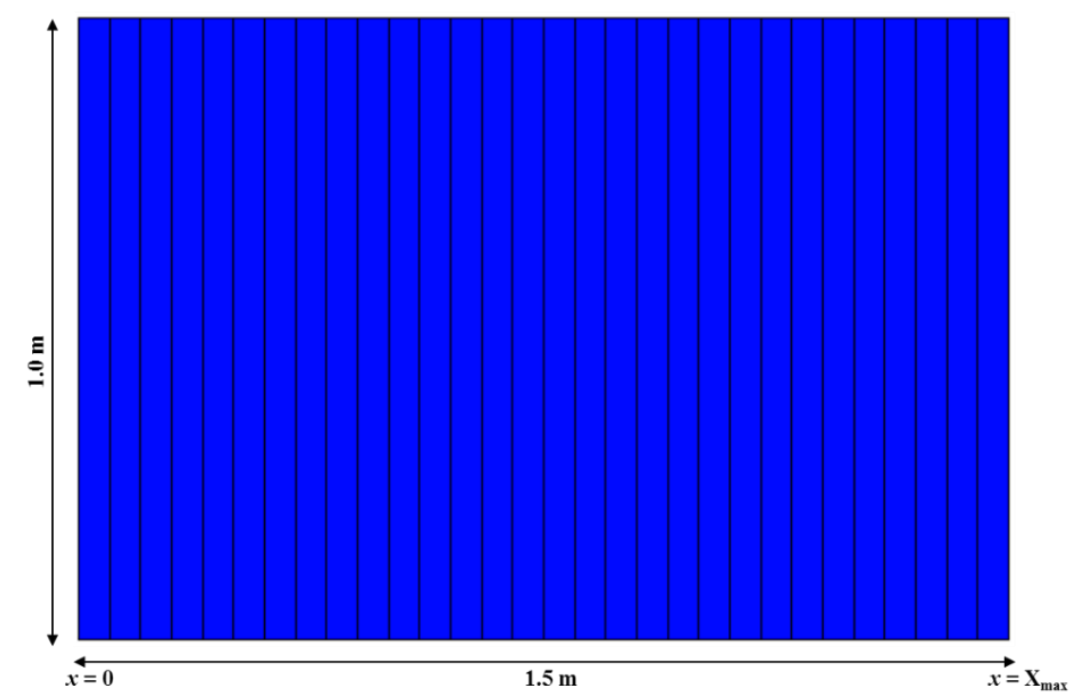

Figure 3-1: Simple 1-D open domain

\section{Initial conditions}

The domain is considered to be at a pressure and temperature of $6.5 \mathrm{MPa}$ and $5{ }^{\circ} \mathrm{C}$ respectively with a single phase aqueous conditions. The block at $x=0$ (the boundary) is considered as a pure gas (mole fraction of $\mathrm{CO}_{2}, X_{\text {molCO2 }}=1.0$ ) well element with pressure and temperature as $9.5 \mathrm{MPa}$ and $15^{\circ} \mathrm{C}$ respectively. The reason for selecting the respective temperature condition for the injection element can be explained from the Figure 3-2. The Figure 3-2 displays the $\mathrm{CO}_{2}$-hydrate equilibrium curve which indicates that for pressures greater than 4.5 MPa, the temperature of the injected fluid has to be greater than $10.5^{\circ} \mathrm{C}$ to prevent the hydrate formation. Hence, temperature value greater than $10.5^{\circ} \mathrm{C}$ is picked to avoid the wellbore plugging and allow the smooth penetration of $\mathrm{CO}_{2}$ gas plume. The geophysical properties of the domain are listed in the Table 3.1. 


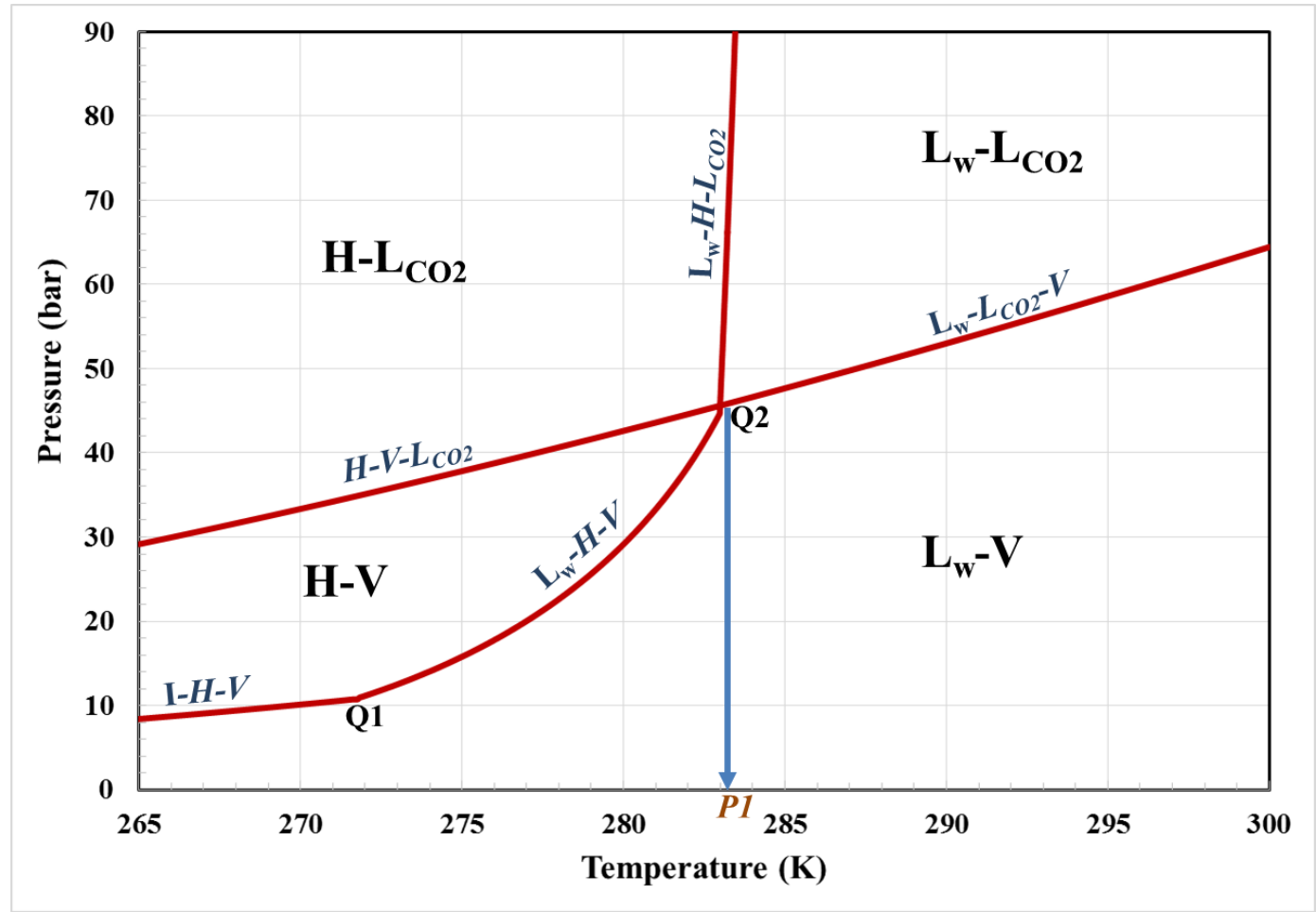

Figure 3-2. Phase equilibrium diagram for $\mathrm{CO}_{2} /$ water system, where I stands for ice, $\mathrm{L}_{\mathrm{w}}$ means liquid water, $\mathrm{V}$ designates gaseous $\mathrm{CO}_{2}, \mathrm{H}$ is $\mathrm{CO}_{2}$ hydrate, and $\mathrm{L}_{\mathrm{c} 2}$ is liquid $\mathrm{CO}_{2}$. Q1 and Q2 are quadrouple points, $\mathrm{P} 1$ is the temperature required to initiate the $\mathrm{CO}_{2}$ hydrate formation in the reservoir. 
Table 3-1. Reservoir properties and pertinent model parameters

\begin{tabular}{|c|c|}
\hline PARAMETERS & VALUE USED \\
\hline Porosity & 0.3 \\
\hline Intrinsic permeability, $m D$ & $10^{3}$ \\
\hline Bulk Density, $\mathrm{kg} / \mathrm{m}^{3}$ & 2650 \\
\hline Dry Thermal Conductivity, $W / m K$ & 2.0 \\
\hline Wet Thermal Conductivity, $W / m K$ & 2.18 \\
\hline Grain Specific heat, $J / \mathrm{kg} K$ & 750 \\
\hline Pore Compressibility, $\mathrm{Pa}^{-1}$ & $5 \times 10^{-10}$ \\
\hline $\begin{array}{l}\text { Capillary pressure model, } \\
\text { Van Genuchten }\end{array}$ & $P_{c a p}=-P\left[\left(S^{*}\right)^{-1 / \lambda}-1\right]^{1-\lambda} \quad S^{*}=\frac{\left(S_{A}-S_{i r A}\right)}{\left(S_{\max A}-S_{i r A}\right)}$ \\
\hline$\lambda^{[28]}$ & 0.45 \\
\hline$S_{\max A}$ & 1.0 \\
\hline $\mathrm{P}_{\max }, \mathrm{Pa}^{[28]}$ & $1.25 \times 10^{4}$ \\
\hline Irreducible aqueous saturation & 0.14 \\
\hline $\begin{array}{c}\text { Relative permeability, } \\
\text { Modified Stone 3-phase model }{ }^{[49]}\end{array}$ & $\begin{array}{c}k_{r A}=\left(S_{A}^{*}\right)^{n A} ; k_{r G}=\left(S_{G}^{*}\right)^{n G} \\
S_{A}^{*}=\frac{\left(S_{A}-S_{i r A}\right)}{\left(1-S_{i r A}\right)} ; S_{G}^{*}=\frac{\left(S_{G}-S_{i r G}\right)}{\left(1-S_{i r G}\right)}\end{array}$ \\
\hline$n^{[50]}$ & 3 \\
\hline Irreducible gas saturation, $S_{i r G}{ }^{[50]}$ & 0.001 \\
\hline Irreducible aqueous saturation, $S_{i r A}$ & 0.15 \\
\hline
\end{tabular}




\subsubsection{Results and discussion:}

The changes in the reservoir conditions due to formation of the $\mathrm{CO}_{2}$ hydrate are shown in the Figure 3-3. As the $\mathrm{CO}_{2}$ is injected in to the water-saturated sand domain, the gas saturation escalates, so does the temperature of the reservoir (refer to Figure 3-3(c) and $(d)$ ). From the gas saturation profiles (Figure 3-3(c)), the propagation of gas forward towards the rear end of the domain is observed. At the end of initial 12 hours, the gas propagation is till $1.1 \mathrm{~m}$ which keeps moving ahead with time and by day 3 the $\mathrm{CO}_{2}$ plume reaches the other end of the domain. Temperature profiles (shown in Figure 3-3(d)) indicate a rise in the temperature which is observed to be consistent with the $\mathrm{CO}_{2}$ plume propagation. As the plume propagates, the rise in temperature during the initial time period (till day 3 ) is exclusively due to two factors, 1) the specific enthalpy of the injected fluid; as the temperature of the injected $\mathrm{CO}_{2}$ is higher than the reservoir temperature, it leads to an increment in the temperature of the reservoir as the injection of the fluid is carried on. 2) the exothermic nature of dissolution of $\mathrm{CO}_{2}$ in water $\left(\mathrm{CO}_{2}(\mathrm{gas}) \rightarrow \mathrm{CO}_{2}(\mathrm{aq}) ; \mathrm{Q}=-19.4\right.$ $\mathrm{kJ} / \mathrm{mol}^{[51]}$ for pure water at $15^{\circ} \mathrm{C}$ ). As there is no surrounding strata available in this geological domain to enable the heat transfer, the temperature of the domain remains to be higher than the initial temperature of the domain.

From the temperature profiles (Figure 3-3(d)), it is seen that by the day 4, there is temperature drop (compared to the initial days) in the elements closer to the wellbore. The temperature drop is induced in the reservoir to lower down the temperature conditions below the second quadruple point to initialize the $\mathrm{CO}_{2}$ hydrate formation. From the hydrate saturation profiles (Figure 3-3 $(d)$ ), it is observed that hydrate saturation starts to build up from day 3 and the saturation keeps on increasing with time. The aqueous saturation displayed in the Figure 3-3(a) drops down as the gas plume propagates, and finally (by the end of day 5) goes to a very small value (to the order of $10^{-}$ 
$\left.{ }^{4}\right)$ in the elements closer to the wellbore. The lowering of water saturation in the initial elements to a very small value by day 4 and 5 indicates the water converting from aqueous phase to hydrate phase. Upon running the simulation further, it is implicit that hydrate saturation of $\mathrm{CO}_{2}$ reaches much higher value, thus leading to permeability impairment of the reservoir.

Hence, it can be concluded from this problem that $\mathrm{CO}_{2}$ capture and its storage as stable $\mathrm{CO}_{2}$ hydrates underneath the ocean sediments or in the aquifers present underlying the natural gas hydrate formations (Class 2 accumulations) can be considered as a viable option. 


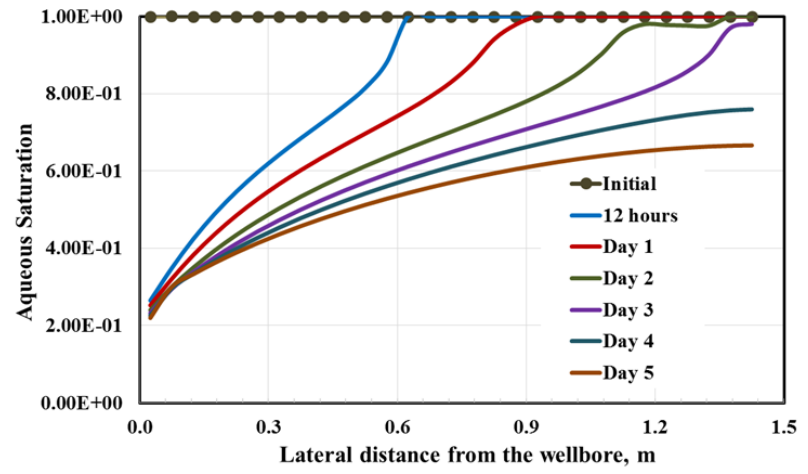

(a)

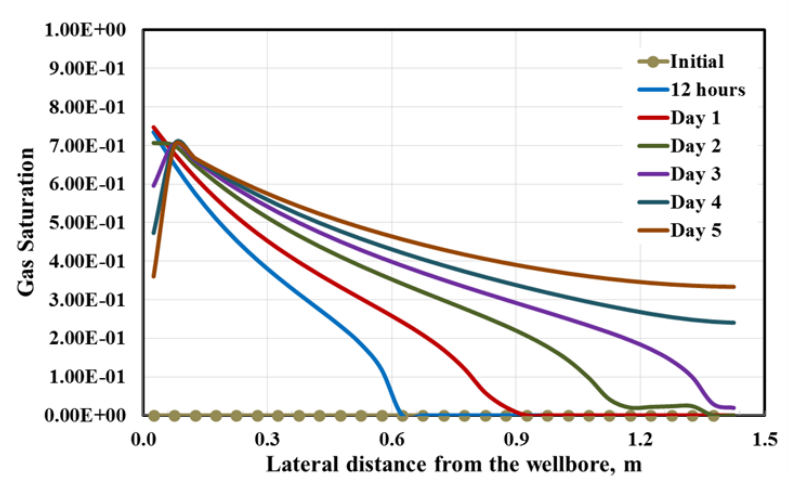

(c)

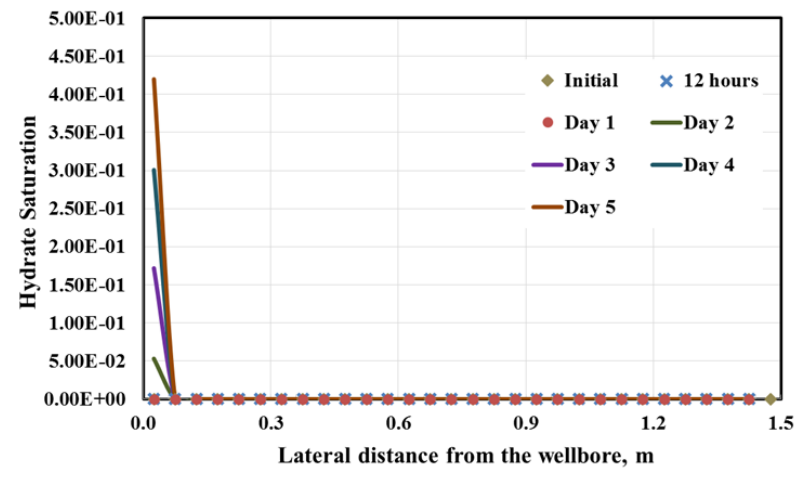

(b)

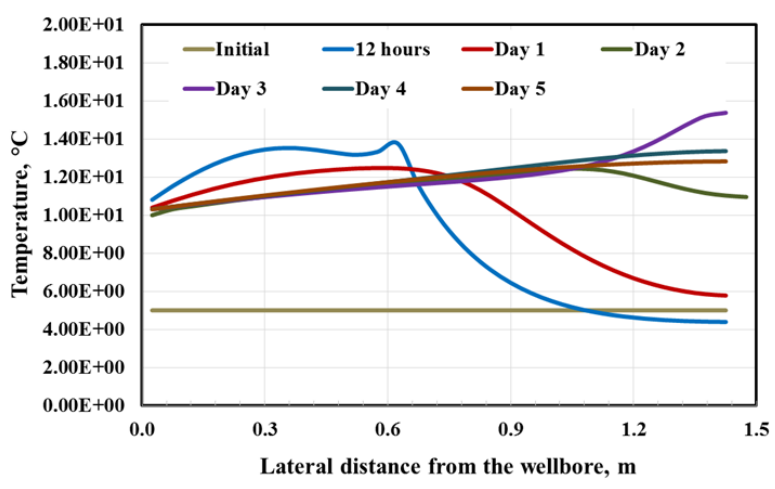

(d)

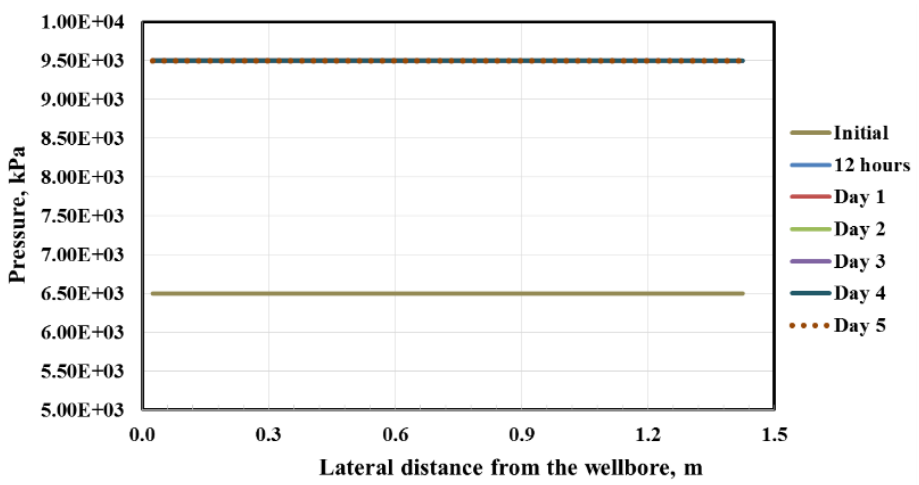

Figure 3-3. (a) Aqueous saturation, (b) hydrate saturation, (c) gas saturation, $(d)$ temperature and (e) pressure distributions at different time periods 


\subsection{Problem 2: Dynamics of $\mathrm{CO}_{2}$ hydrate dissociation}

\subsubsection{Problem Description}

The intent of this problem is to study the $\mathrm{CO}_{2}$-hydrate dissociation in a reservoir when it is subjected to different gas hydrate recovery techniques (like thermal stimulation and depresurization). Similar to the previous problem, a horizontal one dimensional open domain is considered in this problem as well. In this problem, the non-closed system indicates that gas is produced from the reservoir at the boundary (at $x=0$, the origin). The domain descritization is exactly similar to the previous problem (Figure 3-1). This problem facilitates an option to explore the fine-scale effects of hydrate dissociation in an open system.

\section{Initial conditions}

The reservoir is considered to be a two-phase system involving aqueous and hydrate phases with hydrate saturation of 0.5 (hence $S_{A q}=0.5$ ). The entire domain is maintained at a pressure and temperature of $6.5 \mathrm{MPa}$ and $5^{\circ} \mathrm{C}$ which are inside the $\mathrm{CO}_{2}$-hydrate stability zone (refer to the Figure 3-2). The geophysical properties used in this problem are same as the problem 1 listed in Table 1 . The conditions at the boundary element are specified based on the production technique involved which are discussed in detail below. The two technniques, thermal stimulation and depresurization are explained in detail as different cases below.

\subsubsection{Case 1: $\mathrm{CO}_{2}$-hydrate dissoiation induced by thermal stimulation}

In this case of hydrate dissociation by thermal stimulation, the block at $\mathrm{x}=0$ (the boundary) is considered to be an aqueous phase with a temperature of $25^{\circ} \mathrm{C}$. 


\section{Results and discussion:}

As the injection of hot water commences, the temperature of the reservoir starts to go up, thus decomposing the stable $\mathrm{CO}_{2}$-hydrates initially present in the reservoir. The Figure 3-4(d) displays the temperature change of the reservoir as the hot water in injected. The temperature front clearly moves ahead with time and so does the hydrate dissociation front (refer to Figure 3-4 (b)). From the phase diagram of $\mathrm{CO}_{2}$-hydrate (Figure 3.2), it is evident that as the temperature goes higher than $10.5^{\circ} \mathrm{C}$ (point P1), the hydrates tend to move outside the stability region and thus dissociate. And this can be confirmed from the gas and hydrate saturation profiles (Figure 3-4 (c) and $(d)$ ) that the hydrate dissociation front is extended out till the distance where the temperature is higher than $10.5^{\circ} \mathrm{C}$. 


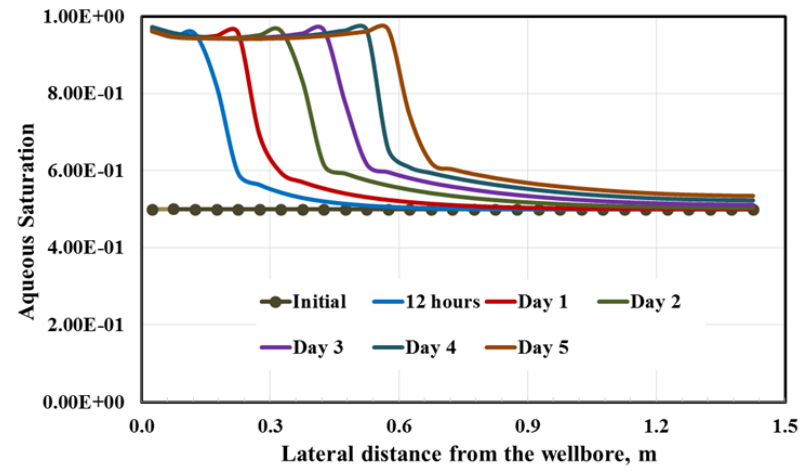

(a)

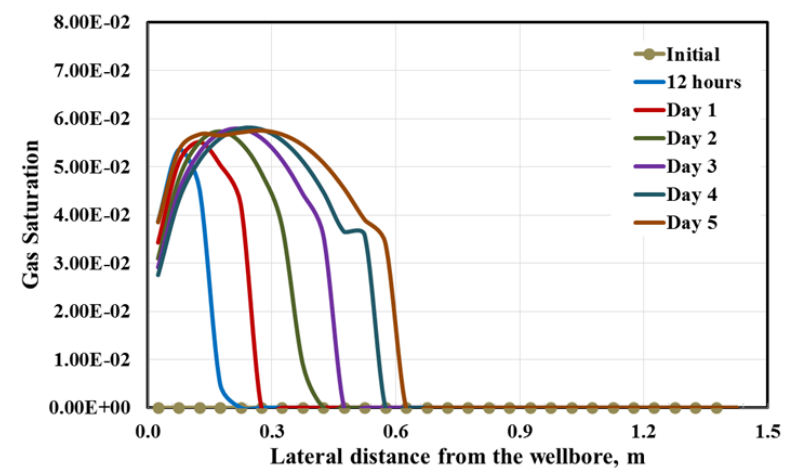

(c)

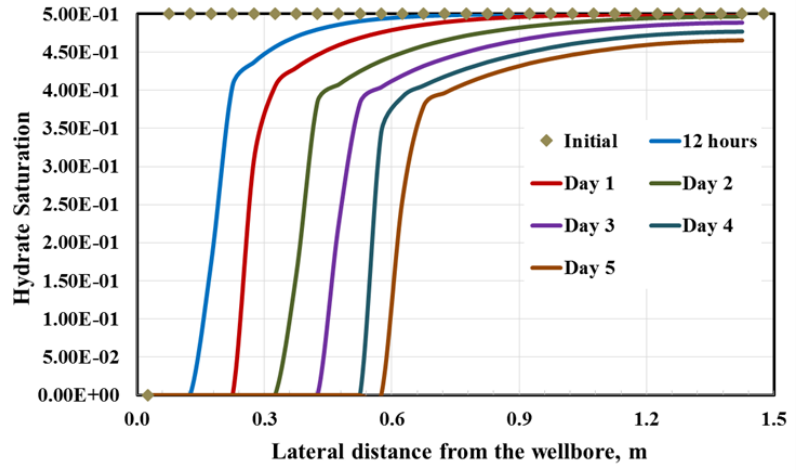

(b)

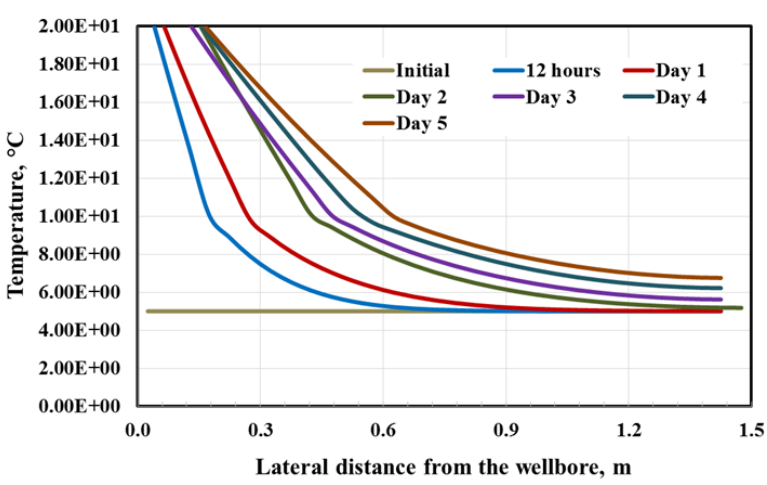

(d)

Figure 3-4 (a) Aqueous saturation, (b) hydrate saturation, (c) gas saturation and $(d)$ temperature distributions at different time periods

From the aqueous saturation profiles (Figure 3-4 (a)), it is evident that at the end of $1.5 \mathrm{~m}$ there is a little rise in the aqueous saturation. The reason for a minimal rise in the latter grid blocks is the flow of dissociated water from the initial elements (grid blocks present at $\mathrm{x}=0$ ) to the rear end elements.

\subsubsection{Case 2: Hydrate dissociation by Depressurization}

The same domain mentioned in the case 1 is used for this case also. In this case, the hydrate dissociation is induced by depressurizing the domain. The depressurization is induced at the origin 
to a pressure little above the first quadruple point (1.2 MPa), to avoid the ice formation in the reservoir. Initially, the block at $x=0$ (the boundary) is considered to be an aqueous phase held at a pressure of 1.5 MPa.

\section{Results and discussion}

We can observe from pressure profile (Figure 3-5(e)) that due to depressurization, the pressure of the entire domain decreases to1.5 $\mathrm{MPa}$. As the pressure depletes in the reservoir, from saturation profiles (Figure 3-5 (a), (b) and (c)) it is clear that the commencement of hydrate dissociation is observed. But contrary to thermal stimulation, here the hydrates present in the entire domain are dissociated by the end of first 12 hours of simulation, which justifies that depressurization technique is more efficient method for hydrate decomposition compared to thermal stimulation method.

From the gas saturation profile ((Figure 3-5 (c)), we can observe that there is high gas saturation at the initial blocks, but later on, gas saturation at those blocks have been decreased. This can be explained from the fact that due to mass transfer, the aqueous saturation of those blocks increases and also there might be movement of gas towards the farther end of the domain, thus increasing the gas saturation at the farther blocks. From the temperature profile (Figure 3-5 $(d)$ ), we can observe that the temperature of the domain decreased drastically (initially temperature is $5{ }^{\circ} \mathrm{C}$, which is reduced nearly to $1.7^{\circ} \mathrm{C}$ ) during the dissociation. This is due to the endothermic nature of $\mathrm{CO}_{2}$ hydrate dissociation reaction $\left(\mathrm{CO}_{2} \cdot n \mathrm{H}_{2} \mathrm{O}(\mathrm{s})=\mathrm{CO}_{2}(\mathrm{~g})+n \mathrm{H}_{2} \mathrm{O}\right.$ is found to vary from $(63.6 \pm 1.8) \mathrm{kJ} \cdot \mathrm{mol}^{-1}$ to $\left.(57.7 \pm 1.8) \mathrm{kJ} \cdot \mathrm{mol}^{-1}\right)^{[52]}$ during depressurization. 


\section{Conclusion:}

The results from the cases $1 \& 2$ indicate that decomposition of hydrates is efficient when depressurization technique is employed compared thermal stimulation method. As the hydrate dissociation induced by depressurization is driven by heat transfer and pressure difference, the hydrate dissociation is proliferated. But the sensible heat in the hydrate sediments can barely offset the heat consumption by endothermic nature of hydrate decomposition process, which eventually slows down the dissociation process. Whereas for the thermal stimulation, as there is a constant source of warm-water injection, the heat efficiency is pronounced compared to the other method. 


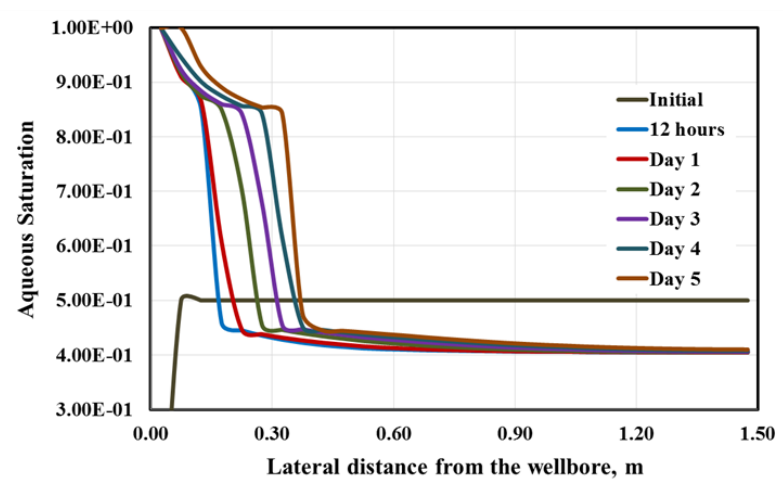

(a)

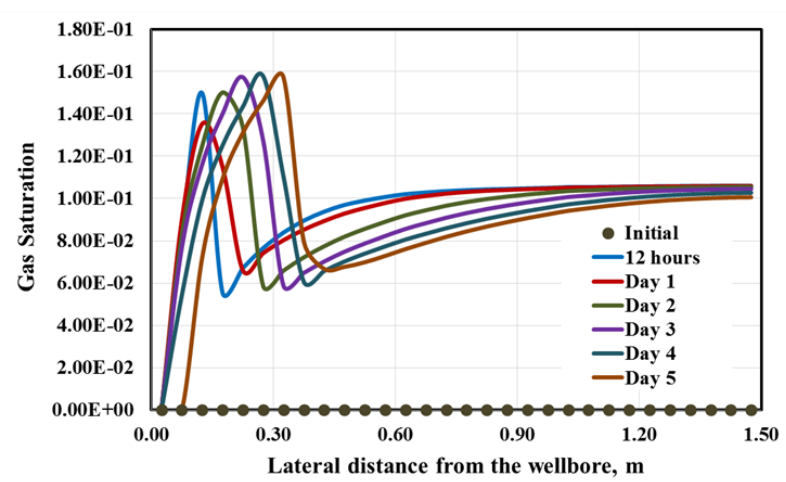

(c)

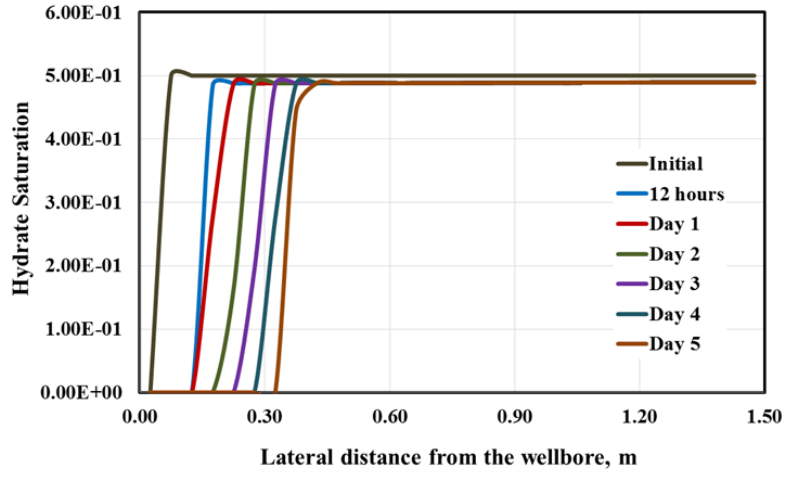

(b)

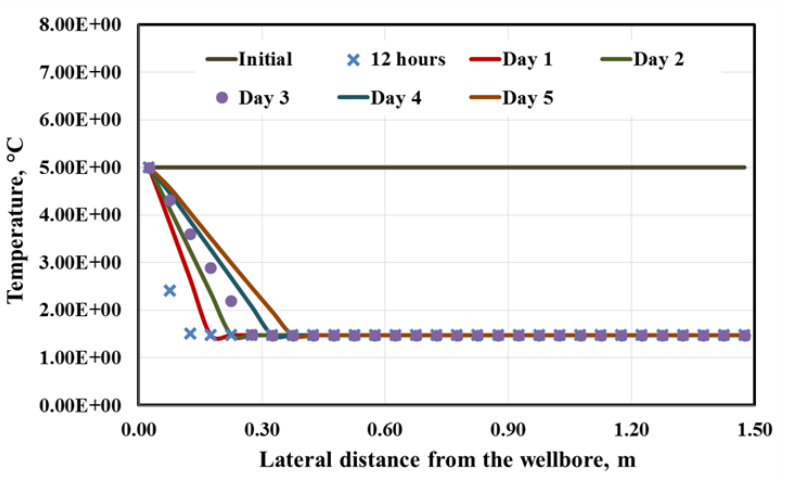

(d)

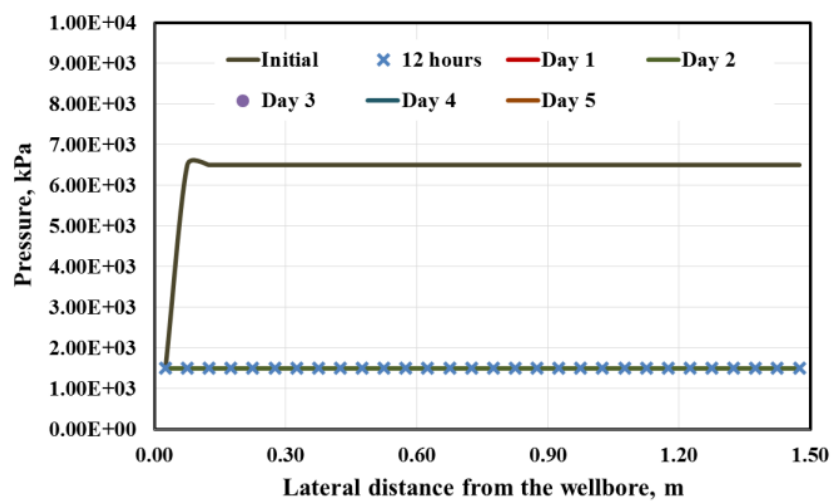

Figure 3-5. (a) Aqueous saturation, (b) hydrate saturation, (c) gas saturation and $(d)$ temperature distributions at different time periods 


\subsection{Problem 3: Base case problem involving water- $\mathrm{CH}_{4}-\mathrm{CO}_{2}$ system}

\subsubsection{Problem Description}

This problem and the following one focuses on the mixed gas hydrates (paricularly on $\mathrm{CH}_{4}-\mathrm{CO}_{2}$ hydrate). Problem 3 holds the similar motive and the domian descritization as that of problem $2^{[45]}$ of International code comparison project. In this problem, one half of the domain is initialized with aqueous-hydrate conditions, whereas, the other half of the domain is initialized with gas-aqueous conditions. This is formulated as a base case problem designed to study the multifluid flow and heat transport across the porous geologic media. The domain used in this problem is one dimensional spatial horizontal domain which is $20 \mathrm{~m}$ long. It is discretized using uniformly spaced 1-m wide grid blocks (shown in Figure 3-6).

\section{Initial Conditions}

The first half of the domain is maintianed at a pressure and temperature of $3.8 \mathrm{MPa}$ and $3.5^{\circ} \mathrm{C}$ and is initialized with two phase (aqueous and hydrate), two component $\left(\mathrm{CH}_{4}, \mathrm{CO}_{2}\right)$ system. The respective phase saturations and component mole fraction values are as mentioned in Figure 3.6. The second half is held at a pressure and temperature of $2.7 \mathrm{MPa}$ and $25^{\circ} \mathrm{C}$. This half of the domain is initialized with gas-aqueous conditions. The percentage of $\mathrm{CO}_{2}$ mole fraction in the hydrates is considered as $25 \%$.

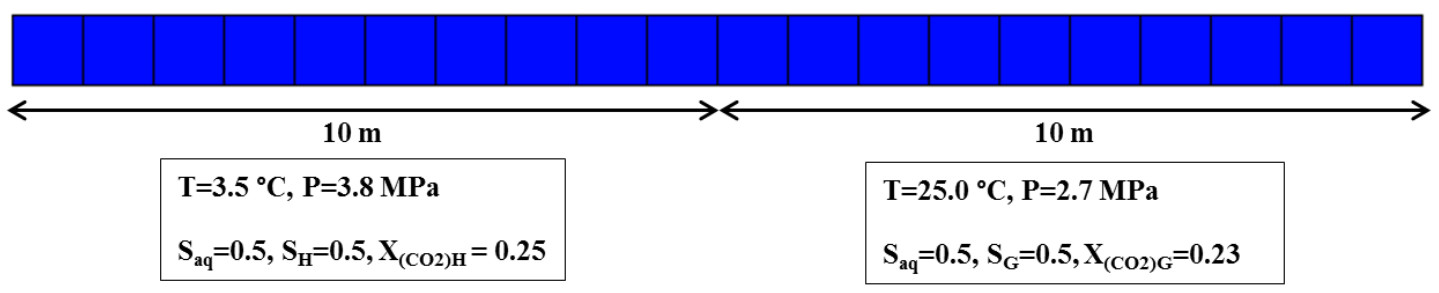

Figure 3-6: Schematic geological domain used for Problem 3 


\subsubsection{Results and discussion}

Hydrates present in the first half of the domain dissociates in response to in-situ thermal stimulation initialized due to the reservoir conditions pertained to the domain-half present with gas-aqueous conditions (second half of the domain). After 1000 day time period, the temperature (nearly $6^{\circ} \mathrm{C}$ ) is observed (refer to Figure 3-8(d)) to drop down lower than equilibrium temperature (Figure 3-7), thus allowing the formation of hydrates in the second half of the domain as well. Figure 3-8 $(f)$ shows temporal changes of the mole fraction of $\mathrm{CO}_{2}$ in the mixed hydrates present in the domain. It is evident from the simulation results that the hydrates present in the first half of the domain hasn't dissociated completely leading to the fact that $\mathrm{CH}_{4}-\mathrm{CO}_{2}$-hydrate being the most stable $^{[30]}$ form hydrates needs much higher temperature influx (if the thermal stimulation method is imposed to dissociate hydrates) for the mixed hydrates to dissociate. 


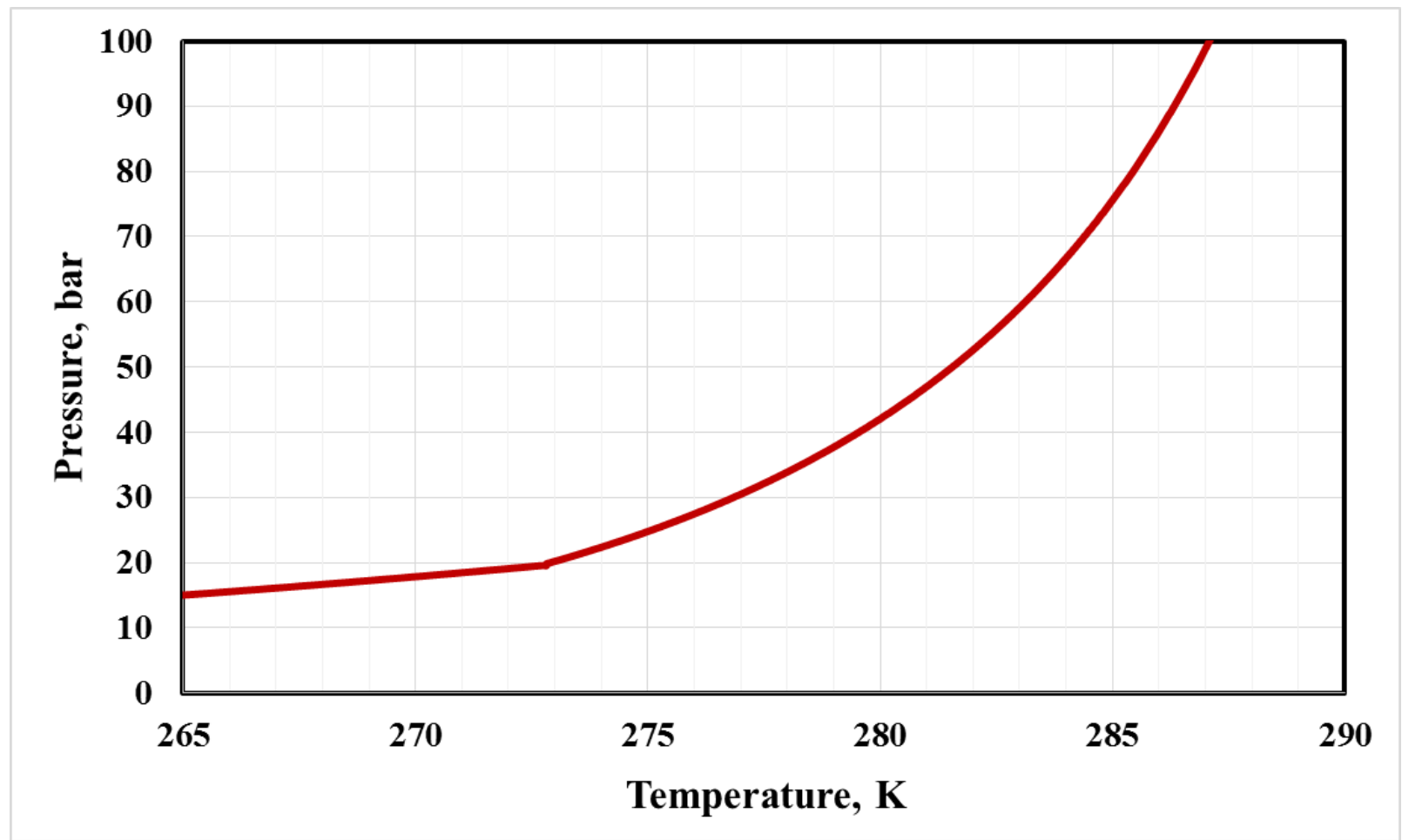

Figure 3-7. Phase equilibrium diagram of $\mathrm{CH}_{4}-\mathrm{CO}_{2}-\mathrm{Hydrate}$ (with respective mole fractions of the guest molecules as 0.75 and 0.25 )

Moreover, from pressure distribution plots (Figure 3-8 $(e)$ ), it is clear that the pressure in the first half of the domain by the end of 10,000 day starts to escalate implying the formation of $\mathrm{CH}_{4}-\mathrm{CO}_{2}$ hydrate, which tends to increase the reservoir pressure). Compared to the initial distribution of reservoir pressure, the pressure at the end of 10,000 day tends to increase in the entire domain indicating it's relation to the increase in mixed hydrate saturation. Similarly, the gas and aqueous saturation profiles seem to follow the trends which are consistent with the P/T conditions of the reservoir. 


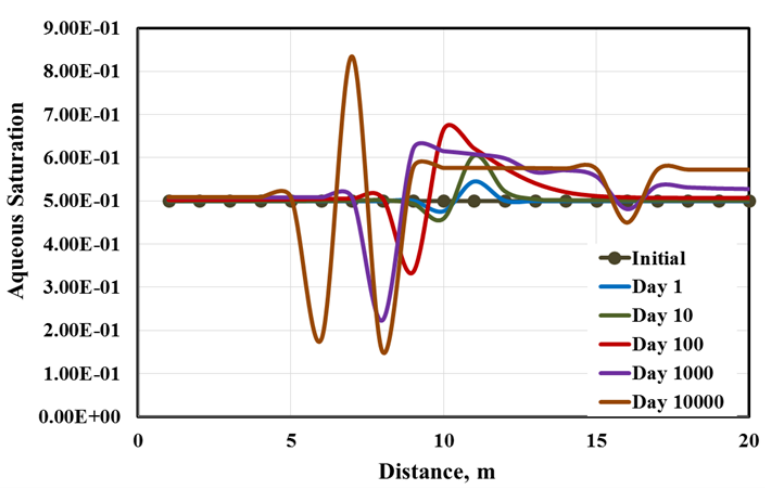

(a)

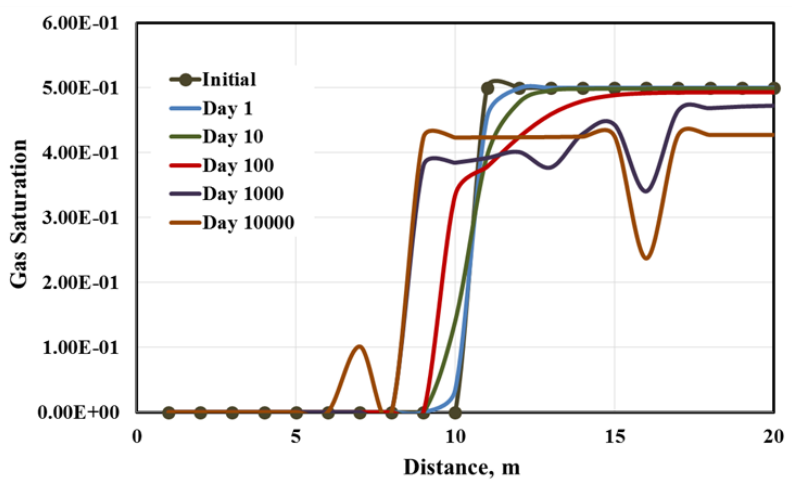

(c)

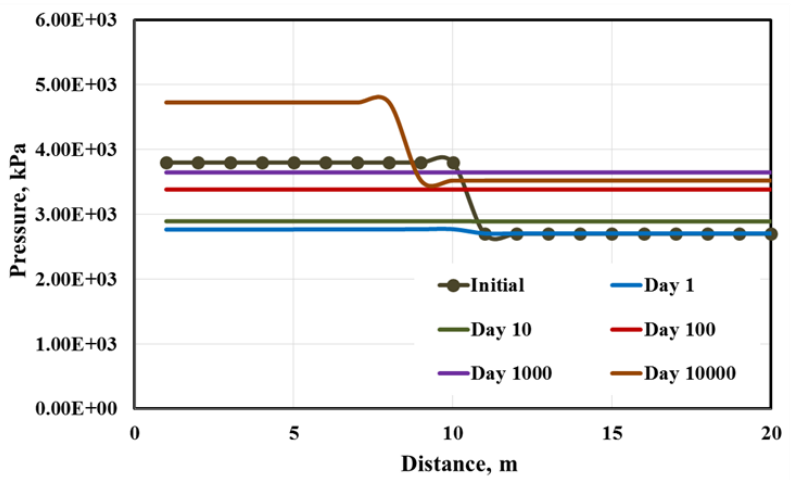

(e)

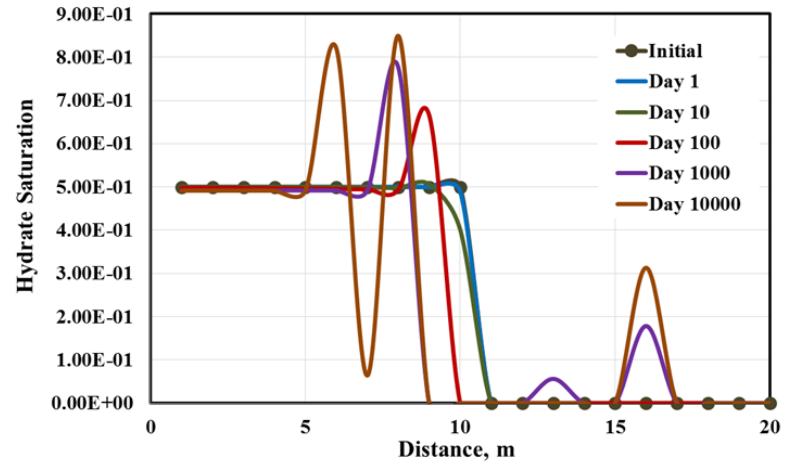

(b)

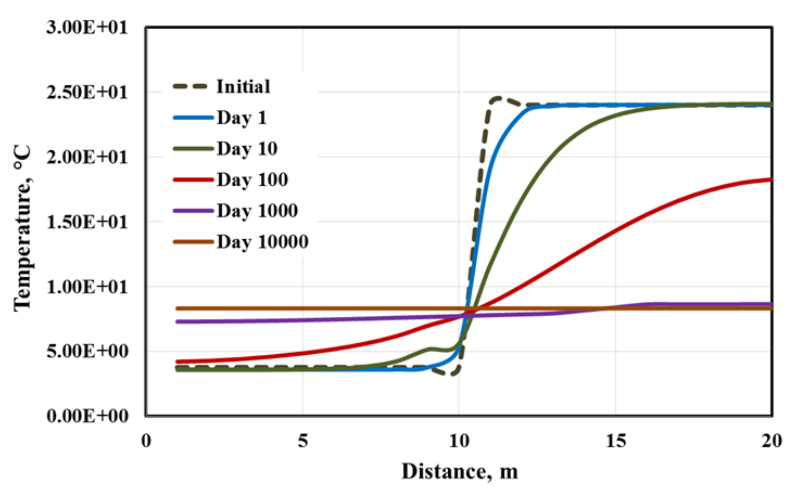

(d)

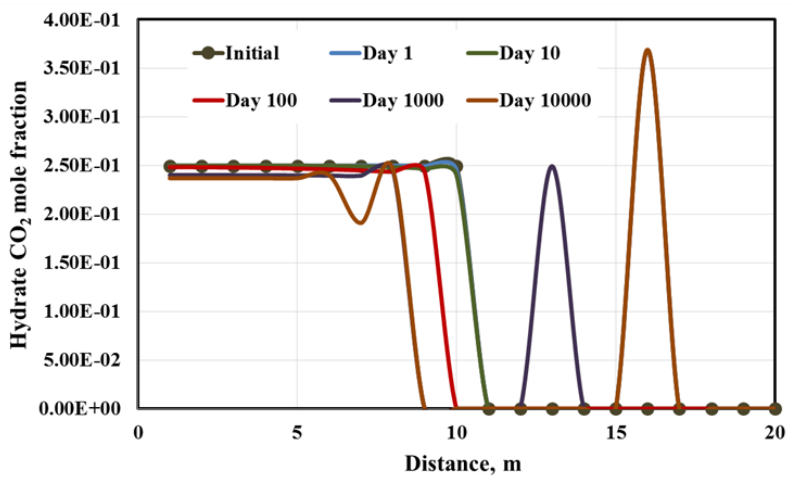

(f)

Figure 3-8. (a) Aqueous saturation, (b) hydrate saturation, (c) gas saturation and $(d)$ temperature distributions at different time periods 


\subsection{Problem 4: Hydrate dissociation of $\mathrm{CH}_{4}-\mathrm{CO}_{2}-\mathrm{Hydrate}$}

\subsubsection{Problem Description}

In this Problem, dissociation of mixed hydrates in a radial cylindrical grid system is studied by implementing both the techniques, thermal stimulation and depressurization. Here, both the techniques are dealt as two seprarate cases. The basis for considering the grid discretization performed in this problem is problem $4^{[45]}$ of International code comparison project. A fine discritization of the grid is employed to comprehend the mass and heat transport properties in a radial domain. A 2D radial domain of $1000 \mathrm{~m} \times 1 \mathrm{~m}$ is considered (shown in figure 3-9). The domain is discritized into 1500 grid blocks, amongst which 1000 cells are split with a $\Delta \mathrm{r}=0.02 \mathrm{~m}$ and the next 500 radial grids are logarithmically discretized starting from $r=20 \mathrm{~m}$ to $r_{\max }=1000$ m.

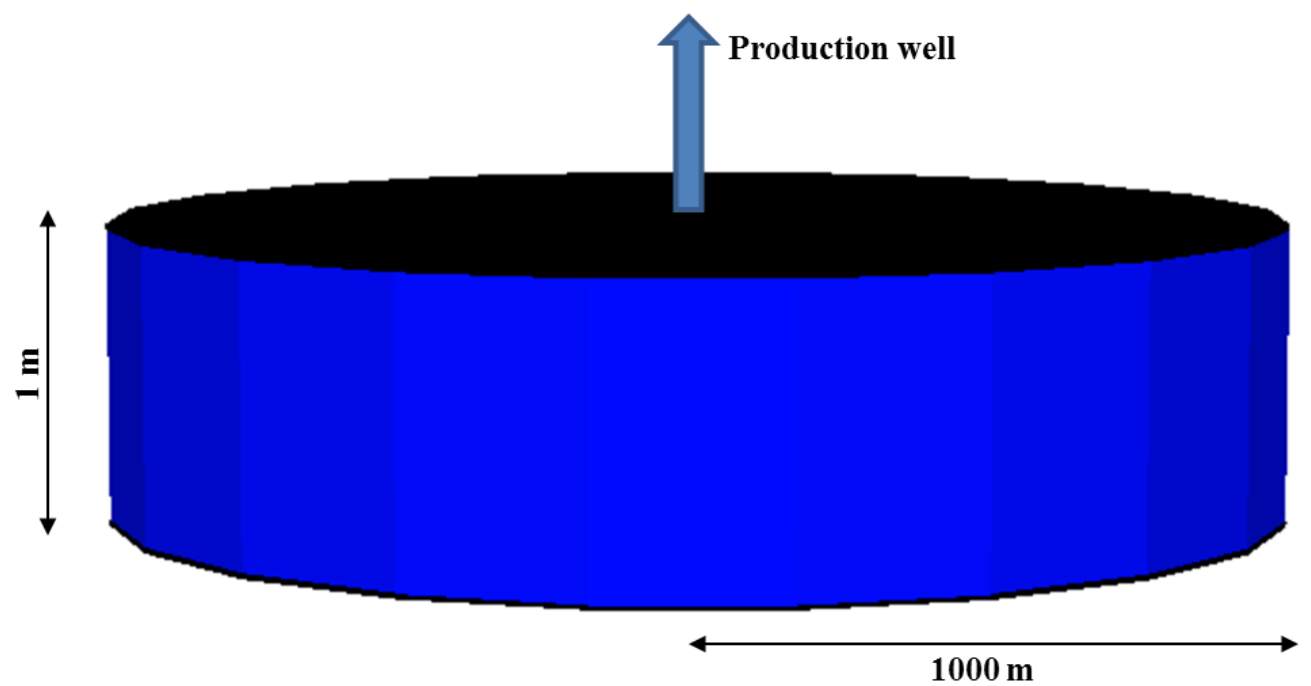

Figure 3-9: Schematic view of the grid used for this problem 


\section{Initial conditions}

The reservoir is considered to be a two-phase system involving aqueous and hydrate phases with hydrate saturation as 0.5 (hence $S_{A q}=0.5$ ). The mole fraction of $\mathrm{CO}_{2}$ in the mixed hydrate $\left(\mathrm{CH}_{4}\right.$ $\mathrm{CO}_{2}$-hydrate) is considered as 0.25 . The entire domain is maintained at a pressure and temperature of 6.5 $\mathrm{MPa}$ and $5^{\circ} \mathrm{C}$ which are inside the $\mathrm{CH}_{4}-\mathrm{CO}_{2}$-hydrate stability zone (refer to the Figure 3-7). The petrophysical physical properties used in this problem are same as the problem 1 listed in Table 1 . The $P / T$ conditions of the wellbore element (the boundary element) is chosen accordingly on the basis of production technique implemented. The two technniques, thermal stimulation and depresurization are dealt as different cases below.

\subsubsection{CASE 1: Hydrate dissociation by thermal stimulation}

In this case, initially, the block at $x=0$ (the boundary) is considered to be an aqueous phase with a temperature of $12{ }^{\circ} \mathrm{C}$ and pressure to be same as reservoir pressure which is $6.5 \mathrm{MPa}$.

\section{Results and discussion}

As the simultion commences, the warm water starts to penetrate in the domain, thus initiating the dissociation of mixed hydrates $\left(\mathrm{CH}_{4}-\mathrm{CO}_{2}\right.$-hydrate $)$ which can be noticed from the hydrate saturation profiles (3-10(b)). The hydrate saturation front is observed to be consistent with temperature front. From the phase equilibrium data plotted in Figure 3-7, for the pressure of 6.5 $\mathrm{MPa}$, the respective hydrate equilibrium temperautre is $10.5^{\circ} \mathrm{C}$, hence, the hydrate dissociation is observed in the elements where in the respective temperature is greater than the equilibrium temperature. But as the thermal stimulation uses only the heat influx as the primary driving force for hydrate decomposition, the dissociation front by the end of 50 days reached around $1.5 \mathrm{~m}$. From the gas saturation profile, it is clear that the hydrate dissociation to gas and water is extended 
only till the first few blocks which are in proximity to the well-block element. The Figure 3-10 (e) displays the change in the mole fraction of $\mathrm{CO}_{2}$ present in the mixed hydrate as the thermal stimulation is employed. It can be observed from the Figure 3-10(e), that as the hydrate dissociation front propagates ahead, the $\mathrm{CO}_{2}$ mole fraction in the hydrate decreases indicating the movement of $\mathrm{CO}_{2}$ from hydrate phase to gas phase.

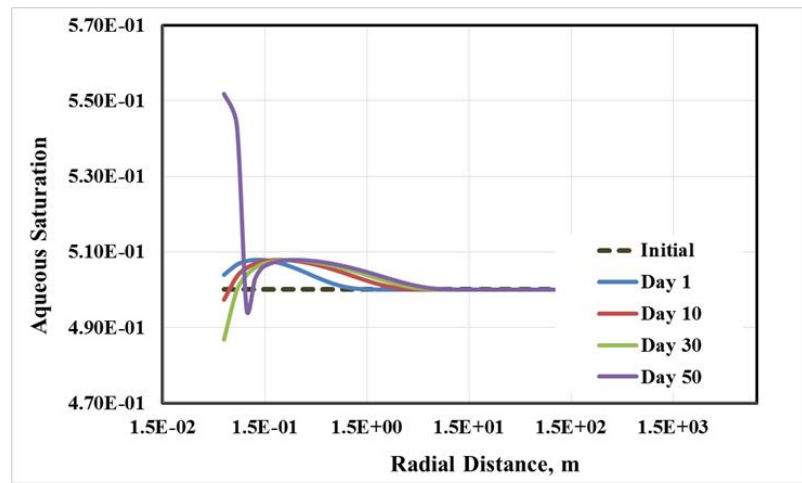

(a)

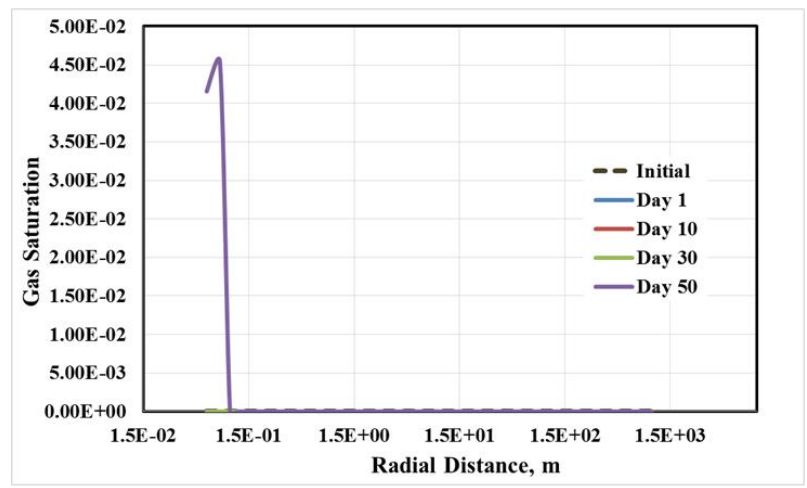

(c)

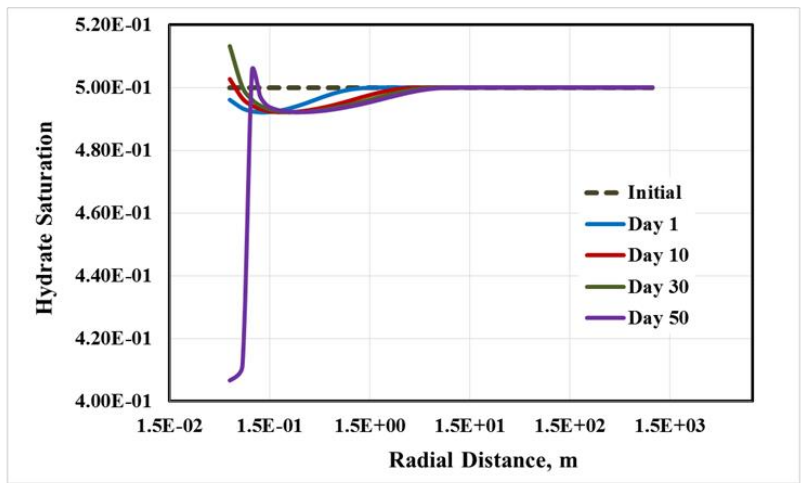

(b)

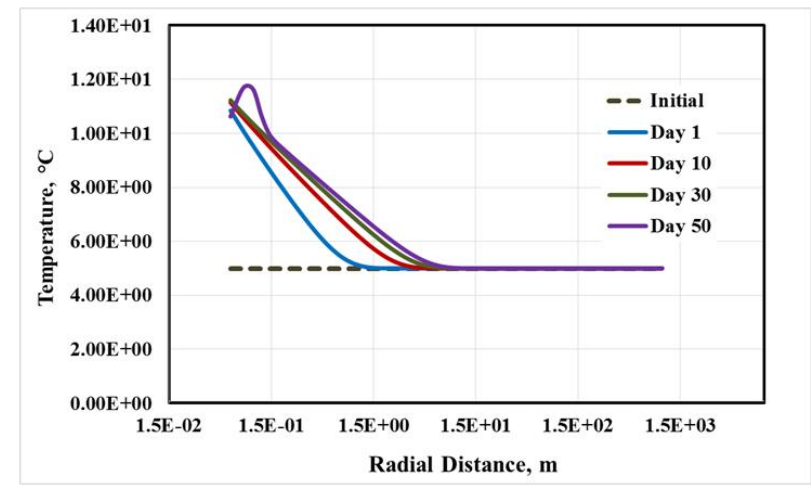

(d) 


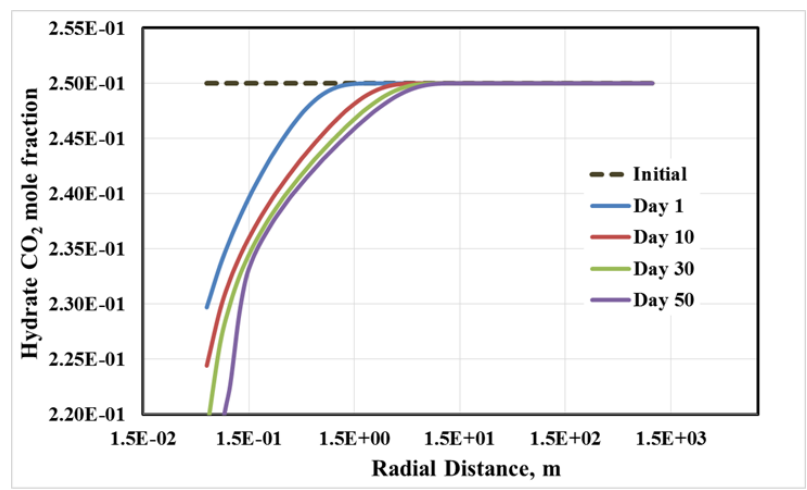

(e)

Figure 3-10. (a) Aqueous saturation, (b) hydrate saturation, (c) gas saturation, (d) temperature distributions and (e) Hydrate $\mathrm{CO}_{2}$ mole fractions at different time periods

\subsubsection{CASE 2: Depressurization Technique}

In this case, initially, the block at $\mathrm{x}=0$ (the boundary) is considered to be an aqueous phase with a pressure of 2.8 $\mathrm{MPa}$, which is greater than the quadruple point (2.0 MPa, refer to the Figure 3-7) so as to avoid formation of ice, which leads to permeability impairment of the reservoir rock.

\section{Results and discussion}

The distributions of various reservoir parameters plotted in the Figure 3-11 indicate the depressurization technique is leads to effective hydrate decomposition. The reservoir pressure has to be lower than $3.5 \mathrm{MPa}$ as the equilibrium pressure of the mixed hydrate at $5^{\circ} \mathrm{C}$ is $3.5 \mathrm{MPa}$ (refer to Figure 3-7). The pressure front displayed in the Figure 3-11 (e) indicates that the pressure drop in the reservoir to a pressure $2.5 \mathrm{MPa}$ provoked the dissociation of hydrates, thus producing gas and water saturations in the domain. The temperature profiles (Figure 3-11 (d)) show that a temperature drop down is observed in the blocks in which the hydrates have dissociated. This is due to the endothermic nature of hydrate dissociation reaction. This effect of lowering of reservoir 
temperature occasionally results in the formation of ice in the reservoir, thus hampering the reservoir permeability, which is a major drawback of the depressurization technique.

From the phase saturation profiles (Figures 3-11 (a), (b) and (c)), a noticeable fluctuation is observed which is owed to the numerical issues caused by the fine discretization of the grid. The phase saturation profiles seem to comply with the P/T changes in the reservoir. The pressure changes lead to the dissociation of hydrates, thus lowering the hydrate saturation in the domain (Figure 3-11 (b)), which eventually increased the gas and water saturations (Figures 3-11 (a) and (c)). 


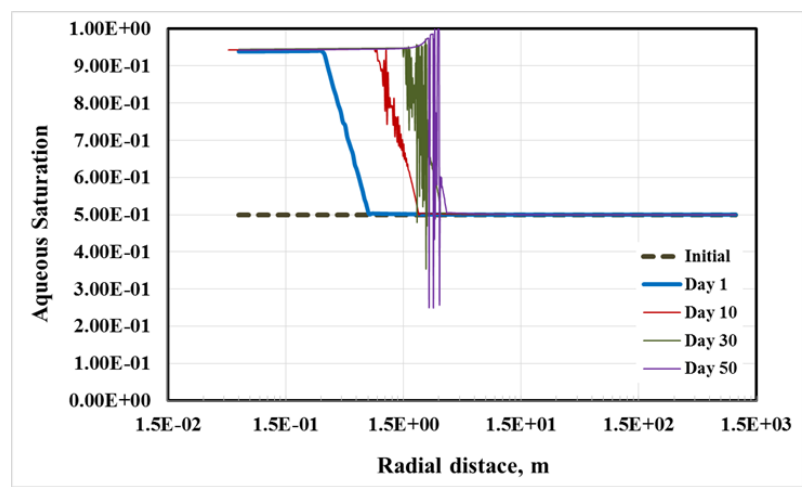

(a)

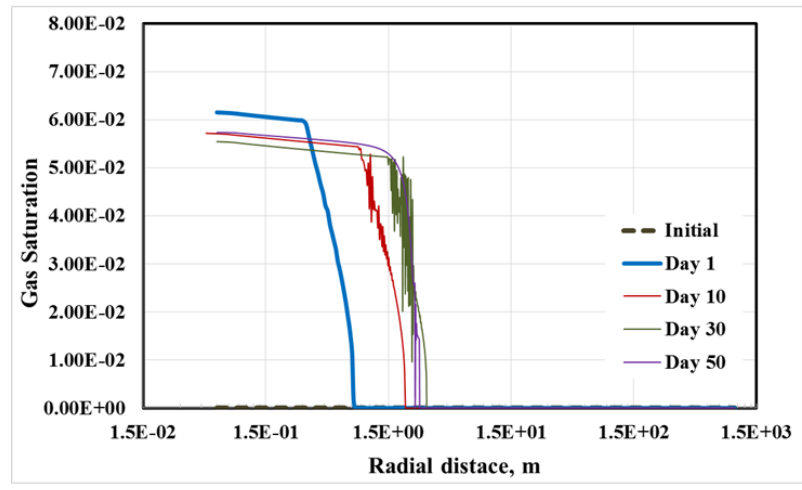

(c)

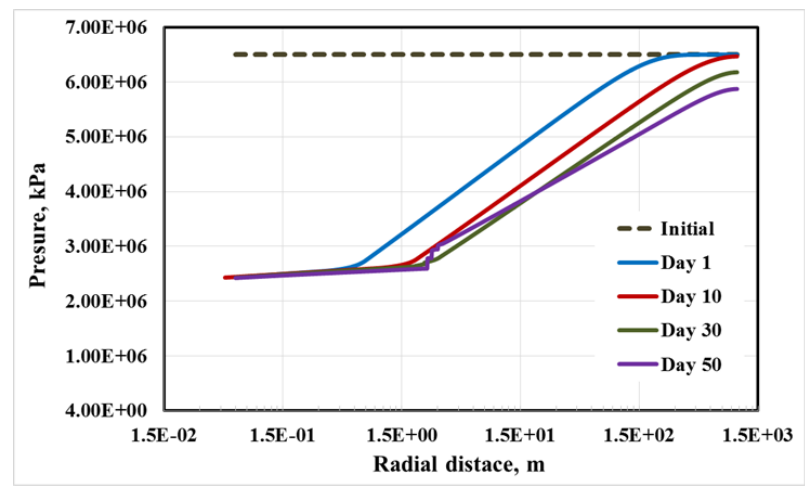

(e)

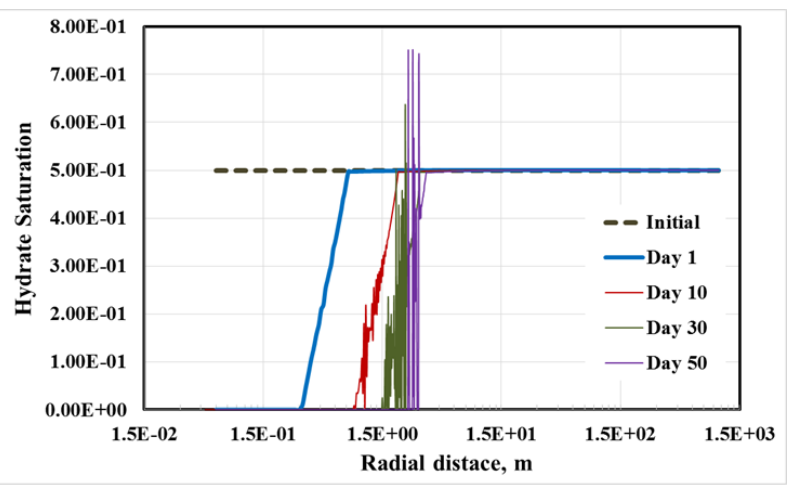

(b)

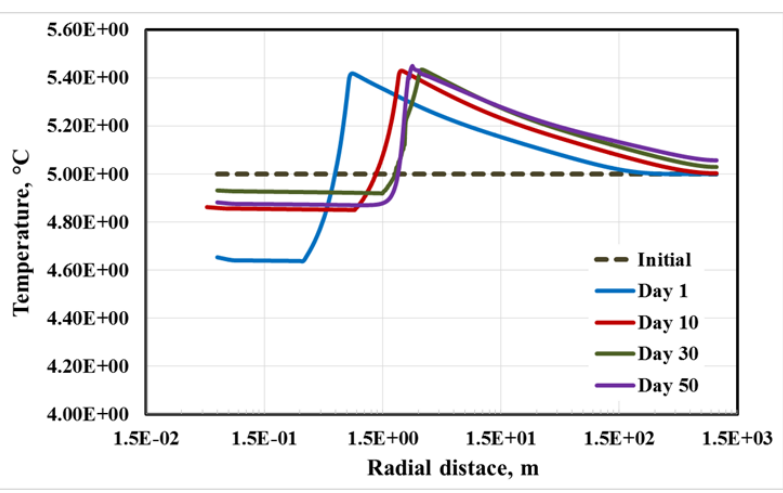

(d)

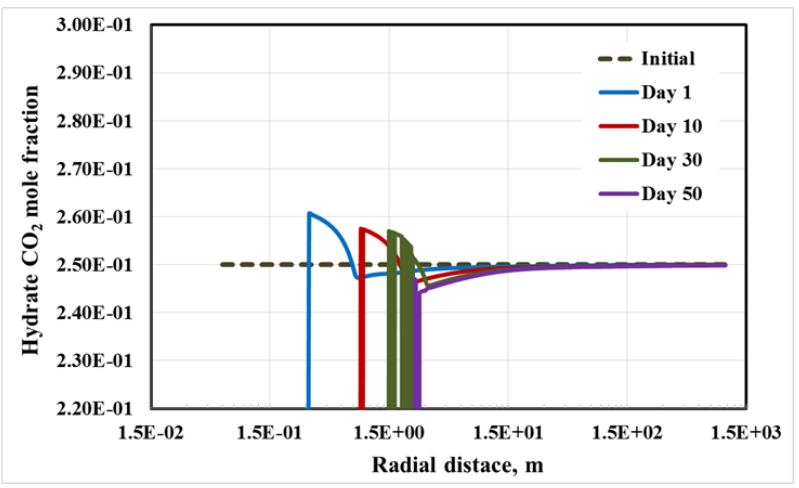

(f)

Figure 3-11 (a) Aqueous saturation, (b) hydrate saturation, (c) gas saturation, (d) temperature distributions and (e) Hydrate $\mathrm{CO}_{2}$ mole fractions at different time periods 


\subsection{Problem 5: Base case problem involving water- $\mathrm{CH}_{4}-\mathrm{CO}_{2}-\mathrm{N}_{2}$ system}

\subsubsection{Problem Description}

This problem uses the same motive and grid discritization as the problem 3 . The major difference between these two problems is the consideration of ternary hydrates $\left(\mathrm{CH}_{4}-\mathrm{CO}_{2}-\mathrm{N}_{2}\right.$ hydrate $)$ in this problem. Hydrates dissociation is induced due to thermal stimulation provided from the second half of the domain. This is designed to comprehend the heat transport and multifluid flow across the permeable formation matirx. The hydrate dissociation of a ternary gas system is simulated using an equilibrium model. Reservor comprises of four components $\left(\mathrm{CH}_{4}, \mathrm{CO} 2, \mathrm{~N} 2\right.$ and water) and three phase system. The first half of the domain is considered to be in hydrate phase $\left(\mathrm{CH}_{4}-\right.$ $\mathrm{CO}_{2}-\mathrm{N}_{2}$ hydrate) in which the mole fractions of $\mathrm{CO}_{2}$ and $\mathrm{N}_{2}$ are 0.25 and 0.375 respectively.

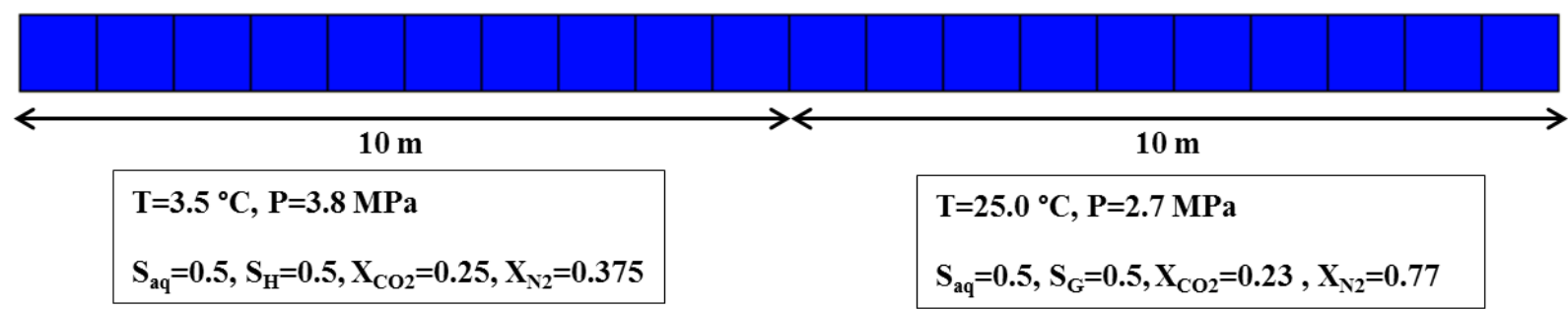

Figure 3-12. Schematic geological domain considered in the Problem 5

\section{Initial Conditions:}

The first half of the domain is maintianed at a pressure and temperature of $3.8 \mathrm{MPa}$ and $3.5^{\circ} \mathrm{C}$ and is initialized with two phase (aqueous and hydrate), three component $\left(\mathrm{CH}_{4}, \mathrm{CO}_{2}, \mathrm{~N}_{2}\right)$ system. The saturations of both the phases are assigned as 0.5 . The mole fractions of $\mathrm{CH}_{4}, \mathrm{CO}_{2}, \mathrm{~N}_{2}$ in the mixed gas hydrates are considered to be $0.375,0.25$ and 0.375 respectively. The phase saturations and component mole fraction values are as mentioned in Figure 3-12. The second half is held at a pressure and temperature of $2.7 \mathrm{MPa}$ and $25^{\circ} \mathrm{C}$. This half of the domain is initialized with gas- 
aqueous conditions. The molar fractions of $\mathrm{CO}_{2}$ and $\mathrm{N}_{2}$ in the gaseous phase present in the second half of the domain is considered as 0.23 and 0.77 respectively, the same fractional compositions of $\mathrm{CO}_{2}$ and $\mathrm{N}_{2}$ were used in the Ignik Sikumi field trial test ${ }^{[34]}$.

\subsubsection{Results and discussion}

The hydrate decomposition in the first half of the domain is initiated by thermal stimulation and as the heat transfer from the second half of the domain takes place across the porous geologic media due to phase advection, the hydrate decomposition is noticed. Figure 3-13 shows the volumes of each gas released upon the decomposition of hydrates.

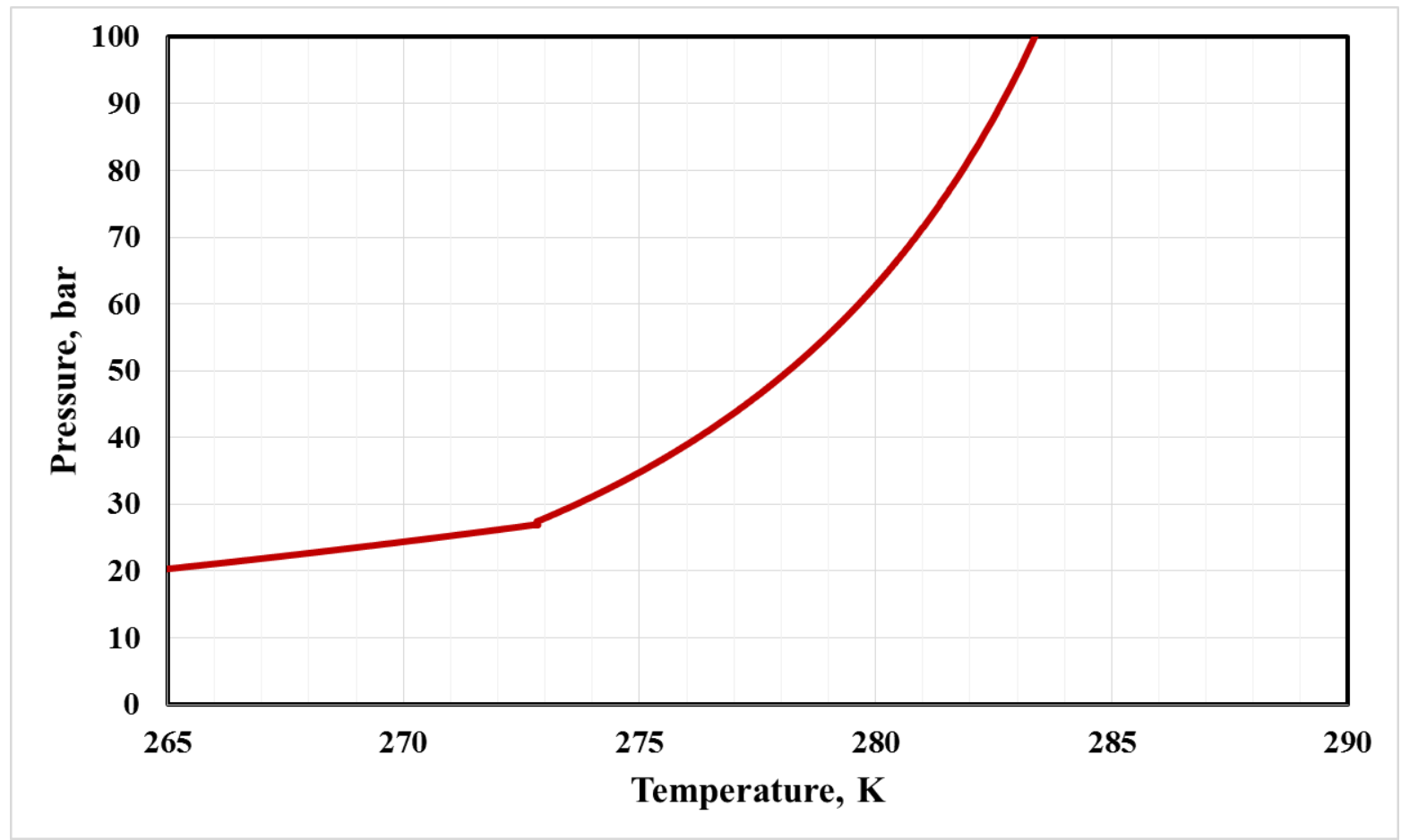

Figure 3-13. Phase equilibrium diagram of $\mathrm{CH}_{4}-\mathrm{CO}_{2}-\mathrm{N}_{2}-\mathrm{Hydrate}$ (with respective mole fractions as $0.375,0.25$ and 0.375$)$ 
The plots in the Figure 3-15 indicate that by the end of 100 days, the hydrate dissociation is pertained only the region present at the center of the domain (the elements present in the vicinity of the second half of the domain). A noticeable fluctuation in all the phase saturation profiles (the Figure 3-15 (a), (b) and (c)) is observed at the later time period (at the end of day 1000 and day $10,000)$ of the simulation run owing to the pressure disturbances leading to the hydrate formation and dissociation in every alternate element present in the domain.

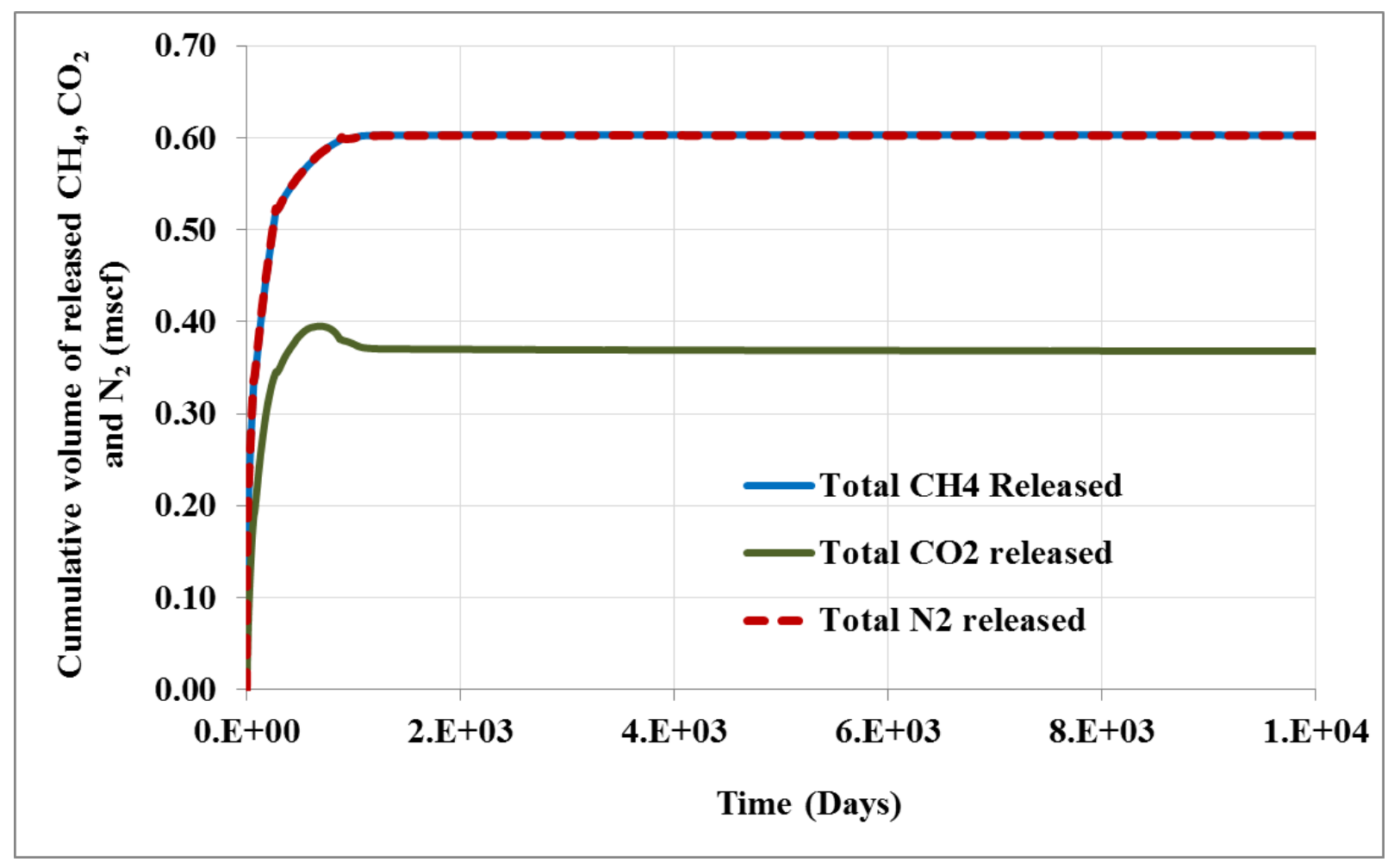

Figure 3-14. Cumulative volumes of the $\mathrm{CH}_{4}, \mathrm{CO}_{2}$ and $\mathrm{N}_{2}$ released in the reservoir upon the mixed hydrate decomposition

The temperature profiles (Figure 3-15(d)) indicate that the thermal equilibrium is reached in the domain by the end of day 10,000. The pressure profiles (Figure 3-15 $(g)$ ) provide couple of notable 
insights. First, the equilibrium in pressure conditions is reached by the end of day 100. Second, as the simulation proceeds, there is a rise in the pressure of the first half of the domain, which lead to the fluctuations in the phase saturation conditions. The increase in the hydrate saturation in one element lead to the dissociation in its next element, this phenomenon happened in a series of elements sequentially and thus ended up with a fluctuating pattern of the phase saturation profiles. In the hydrate saturation profiles (Figure 3-15 (b)) it can be seen that, in some of the elements the saturation value is as high as 0.85 , this sometimes result in the permeability impairment of the reservoir.

The gas saturation and the aqueous saturation profiles (Figure 3-15 (a) and (c)) are observed to be consistent with the hydrate saturation profiles. The elements in which hydrates have dissociated, the gas and aqueous saturations are very high in the respective elements, but for the elements in which hydrate formation took place, the gas saturation is nearly zero. The Figure 3-15 (e) and $(f)$ show that the trend of mole fractions of $\mathrm{CO}_{2}$ and $\mathrm{N}_{2}$ in the hydrates with time comply with the hydrate saturation profiles. 


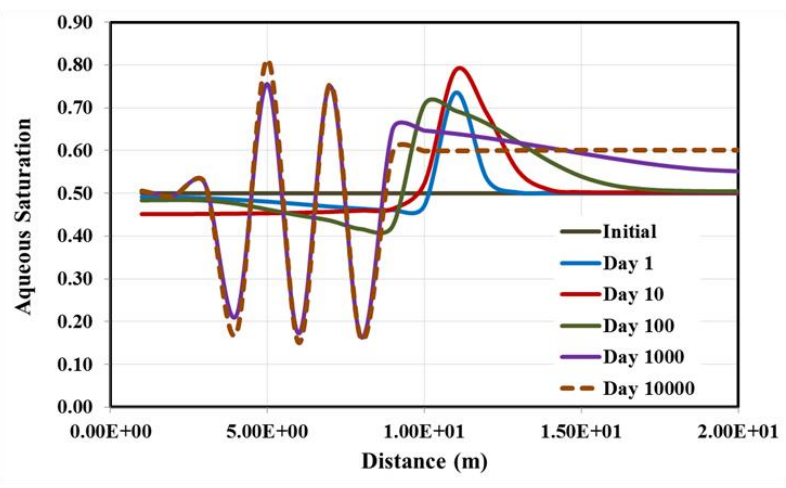

(a)

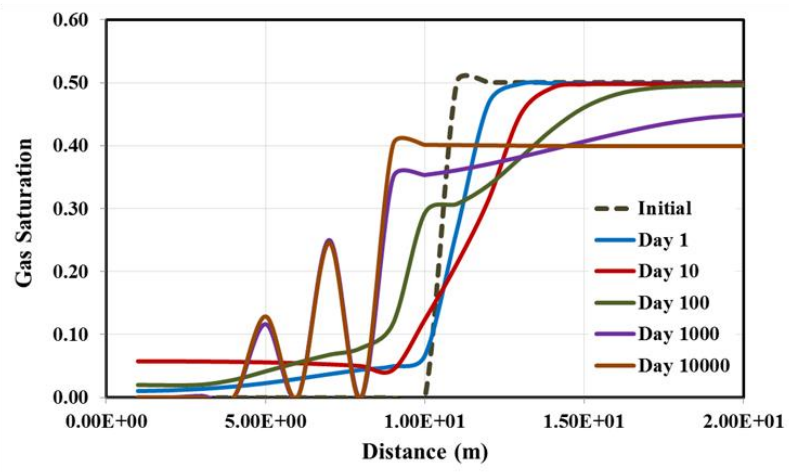

(c)

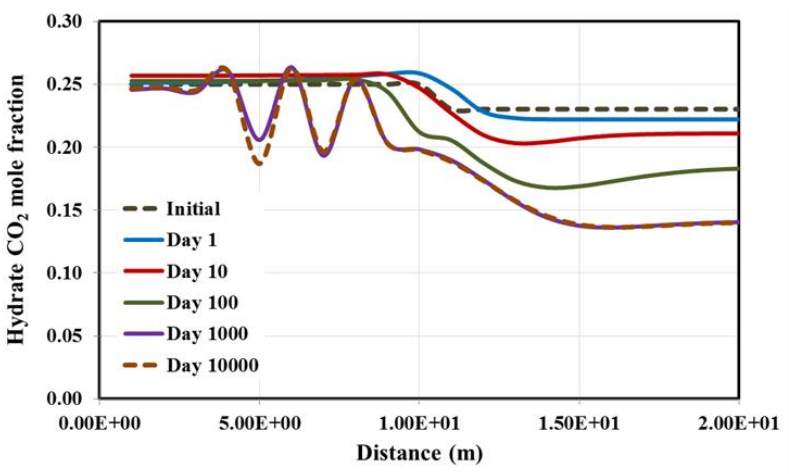

(e)

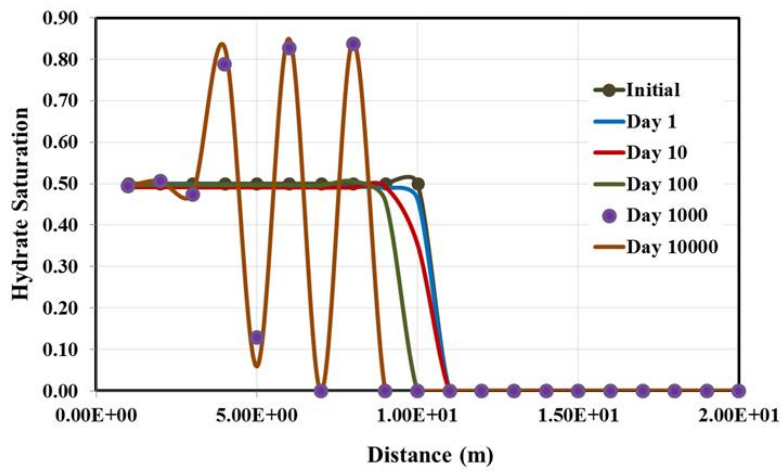

(b)

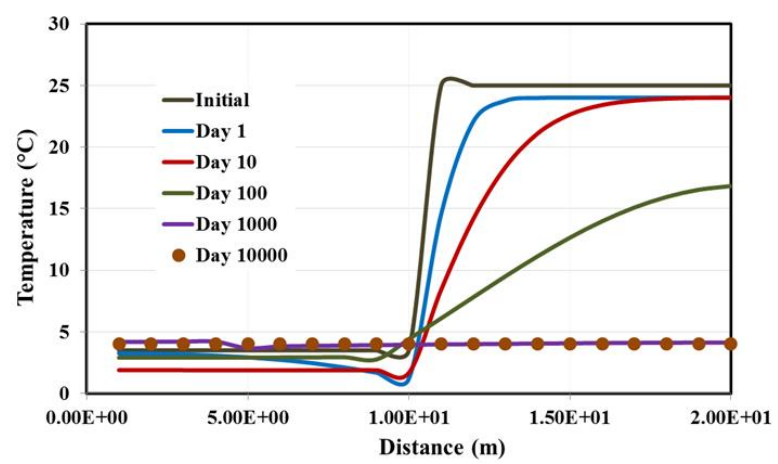

(d)

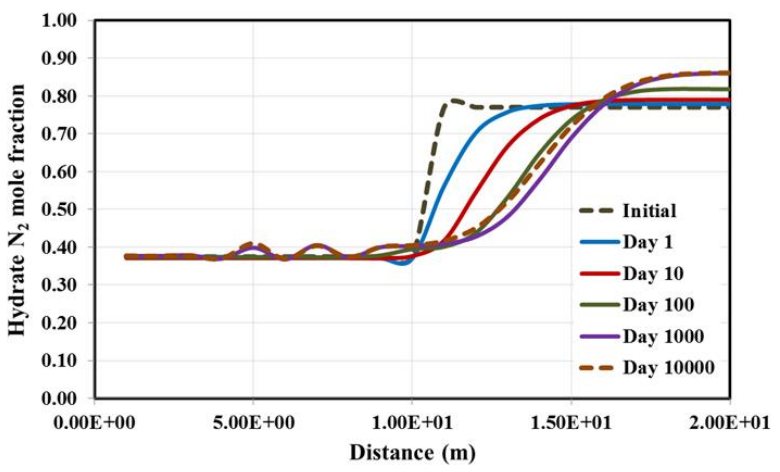

(f) 


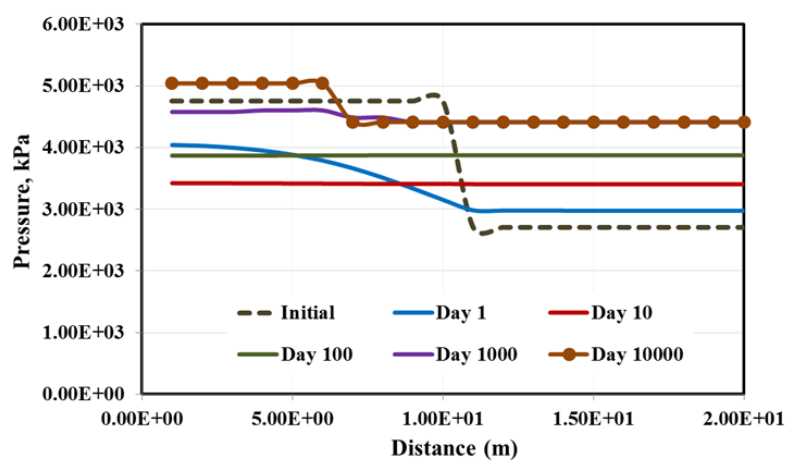

(g)

Figure 3-15 (a) Aqueous saturation, (b) hydrate saturation, (c) gas saturation, (d) temperature distributions, (e) Hydrate $\mathrm{CO}_{2}$ mole fractions, (f) Hydrate $\mathrm{N}_{2}$ mole fractions at different and (g) pressure distributions time periods 


\subsection{Problem 6 - Dynamics of Mixed hydrate $\left(\mathrm{CH}_{4}-\mathrm{CO}_{2}-\mathrm{N}_{2}\right.$ hydrate $)$ dissociation}

\subsubsection{Problem Description}

In this problem, hydrate dissociation of mixed hydrate $\left(\mathrm{CH}_{4}-\mathrm{CO}_{2}-\mathrm{N}_{2}\right.$ hydrate $)$ is studied considering a horizontal 1D cartesian domain. Both the gas recovery techniques, thermal stimulation and depressurization are considered as two seprarate cases in this problem. The domain is finely discretized into 30 grid blocks of $0.05 \mathrm{~m}$ each which extends out to a length of $1.5 \mathrm{~m}$. The domain is considered to be an open system. It implies that the reservoir conditions are disturbed (either employing lower pressure conditions or injection of warm water) by imposing the conditions at the boundary (at $x=0$, the origin).

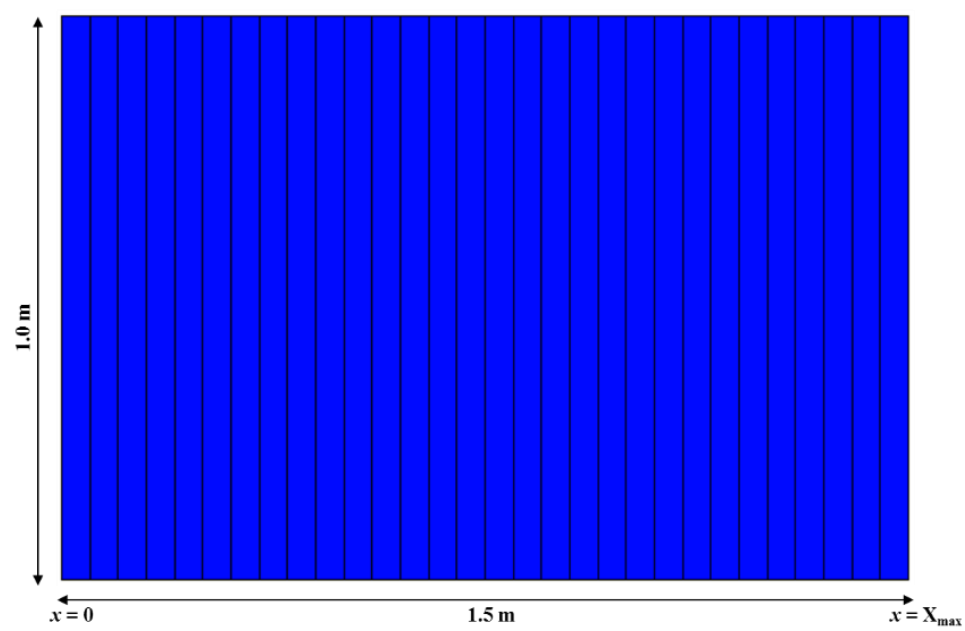

Figure 3-16. Simple 1 D domain considered

\section{Initial Conditions}

The reservoir is considered to be maintained at a pore pressure of $6.5 \mathrm{MPa}$ and temperature of 5 ${ }^{\circ} \mathrm{C}$ which fall within the equilibrium conditions of $\mathrm{CH}_{4}-\mathrm{CO}_{2}-\mathrm{N}_{2}$ hydrates with the mole fractions as $0.375,0.25,0.375$ of $\mathrm{CH}_{4}, \mathrm{CO}_{2}, \mathrm{~N}_{2}$ respectively. The domain is assigned to be a two-phase system involving aqueous and hydrate phases with saturation of hydrate $\left(S_{H}\right)$ as 0.5 (hence 
$\left.S_{A q}=0.5\right)$. The pertinent petrophysical properties used in this problem is same as listed in the Table 3.1. The $P / T$ conditions of the wellbore element (the boundary element) is chosen accordingly on the basis of production technique employed. The two technniques, thermal stimulation and depresurization are explained in detail as different cases below.

\subsubsection{CASE 1: Hydrate dissociation induced by thermal stimulation}

In this case of hydrate dissociation by thermal stimulation, initially, the block at $x=0$ (the boundary) is considered to be an aqueous phase with a temperature of $25^{\circ} \mathrm{C}$.

\section{Results and Discussion}

The injection of warm water (temperature $25^{\circ} \mathrm{C}$ ) propels the decomposition of clathrated mixed hydrates present in the vicinity of the wellbore element. It can be followed from the Figure 3-17 that as the temperature front (Figure 3-17 $(d)$ ) propagates, the hydrate dissociation front moves ahead as well (seen in the hydrate saturation profile, Figure 3-17 $(b)$ ). The hydrate saturation distribution imply that as the $\mathrm{P} / \mathrm{T}$ conditions move out of the stability region, the mixed hydrates tend to decompose and produce the gas/water saturation in the domain. From the Figure 3-13, we can see that the initially the reservoir conditions are inside the stability conditions, but as the warm water $\left(25^{\circ} \mathrm{C}\right)$ gets in contact with the hydrates present in the porous media, the hydrates tend to move out of their stability region, thus releasing gas and water. The Figures 3-17 (e) and $(f)$, displays the mole fractional changes pertained to $\mathrm{CO}_{2}$ and $\mathrm{N}_{2}$ compositions in the mixed gas hydrate system respectively.

The gas and aqueous saturation profiles (Figures 3-17 (a) and $(c)$ ) agree with the trend of the propagation of dissociation front. The rise in the aqueous and gas saturation values can be observed in the elements in which the hydrate dissociation have taken place. 


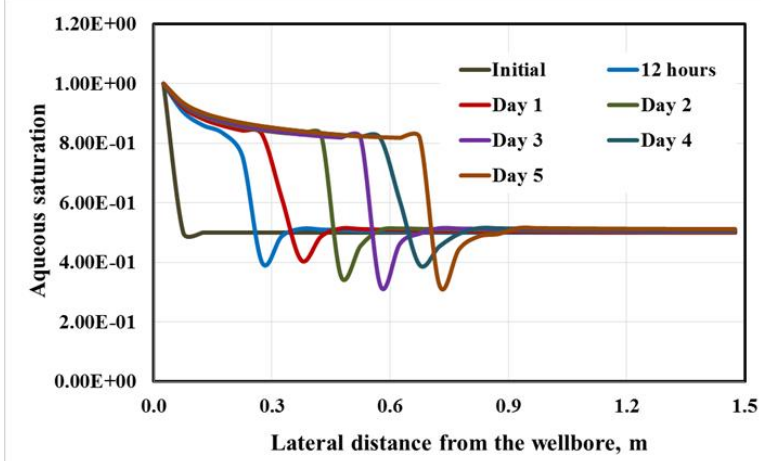

(a)

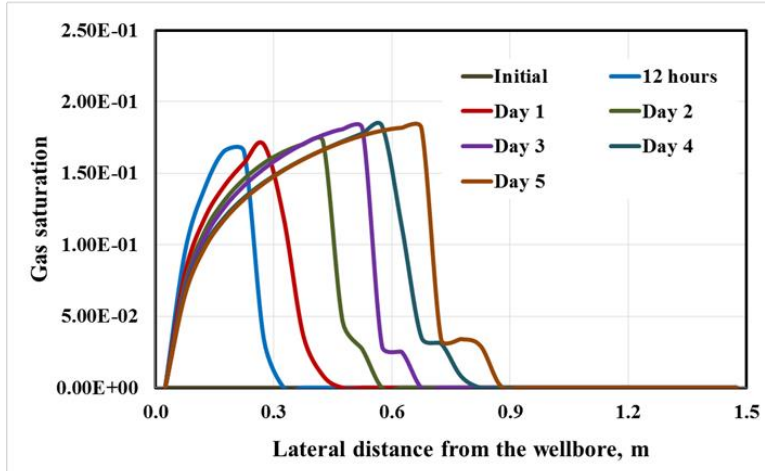

(c)

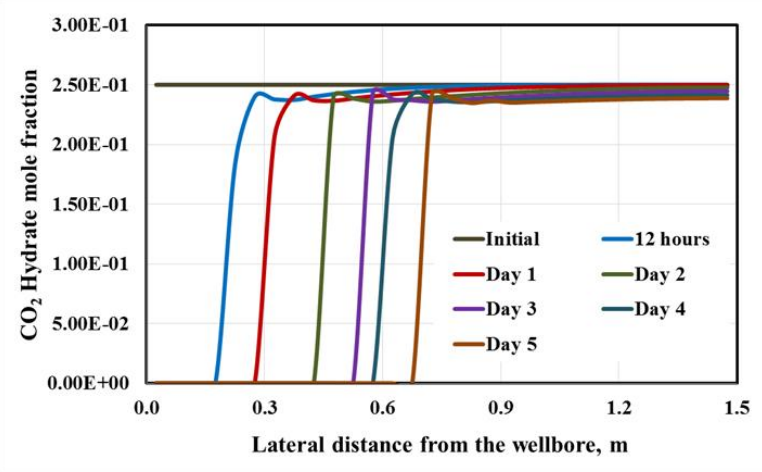

(e)

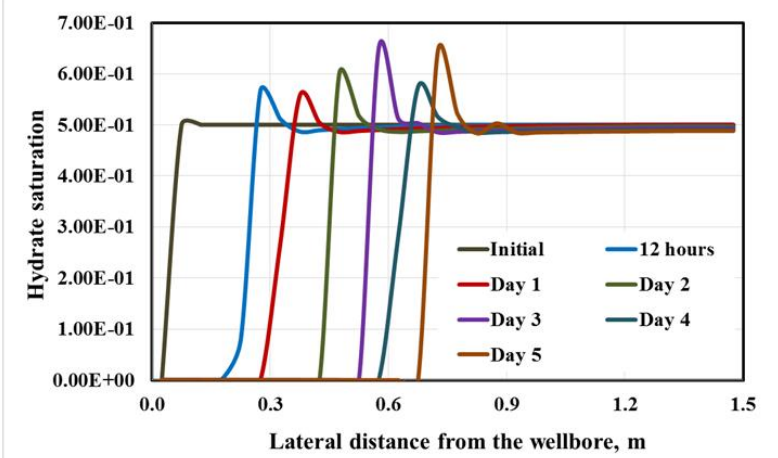

(b)

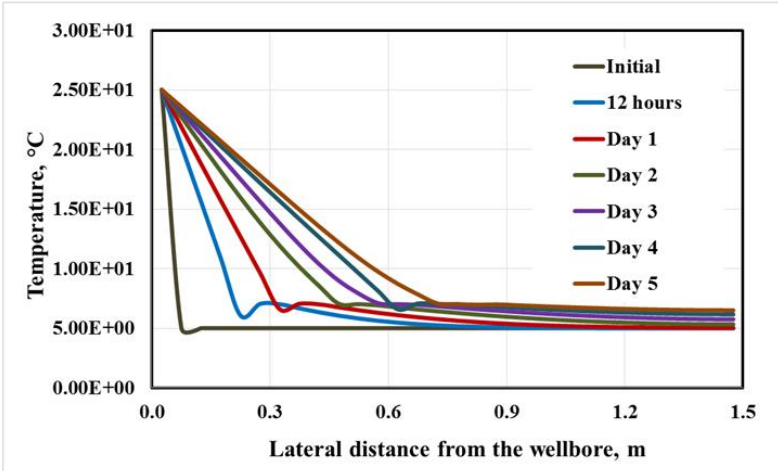

(d)

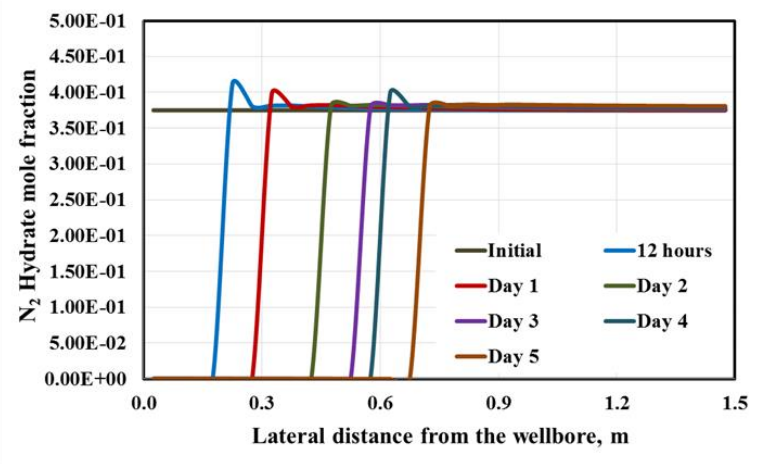

(f)

Figure 3-17. (a) Aqueous saturation, (b) hydrate saturation, (c) gas saturation, (d) temperature distributions, (e) Hydrate $\mathrm{CO}_{2}$ mole fractions and (f) Hydrate $\mathrm{N}_{2}$ mole fractions at different time periods 


\subsubsection{CASE 2: Hydrate dissociation induced by depressurization Technique}

In this case, the mixed hydrate dissociation is induced by depressurizing the domain. The gridding of the domain considered in this case remains same as the previous case (Case 1). The block at $x=0$ (the boundary) is considered to be an aqueous phase with a pressure of $2.8 \mathrm{MPa}$, which depressurizes the domain. The bottom-hole pressure is selected so as to avoid the ice formation in the domain.

\section{Results and discussion}

The results displayed in Figure 3-18 compared with the results of the previous case (gas recovery induced by thermal stimulation) show that depressurization is a more efficient technology to be employed to expedite the hydrate decomposition reaction process. In the Figure 3-18 (c), gas saturation profiles displays that the mixed hydrates present in the entire domain are decomposed by the end of first 12 hours, thus building up the gas saturation in the domain. The gas saturation profiles comply with the $P / T$ changes in the domain as the simulation proceeds on. The pressure front profiles (Figure 3-18 $(g)$ ) show that the pore pressure of the domain is lowered down to the bottom hole pressure by the end of 12 hours of the simulation, thus producing the gas saturation in the domain 3-18 (c). Owing to the endothermic nature of hydrate decomposition, the temperature of the domain (Figure 3-18 $(d)$ ) goes down compared to the initial reservoir temperature. 


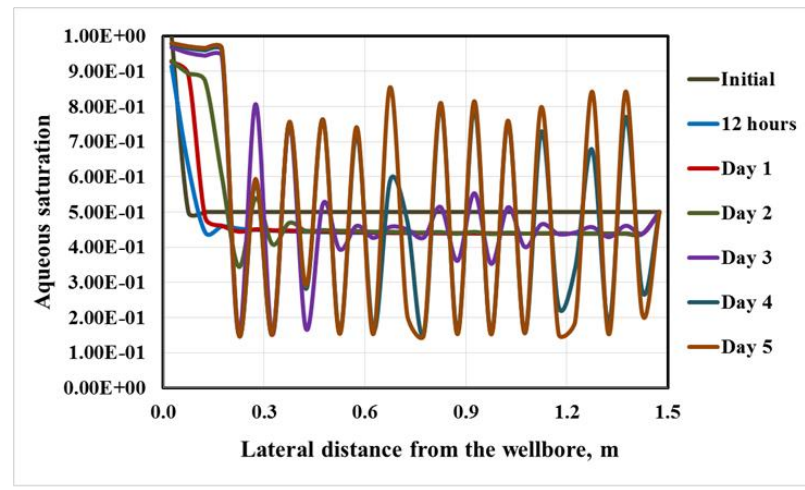

(a)

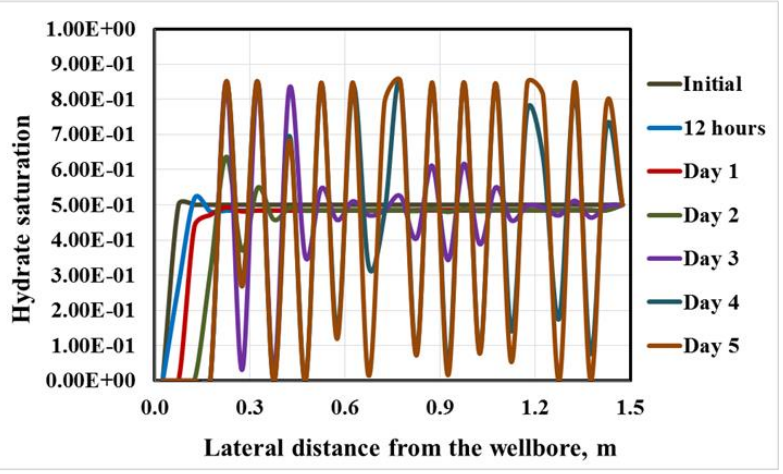

(b)

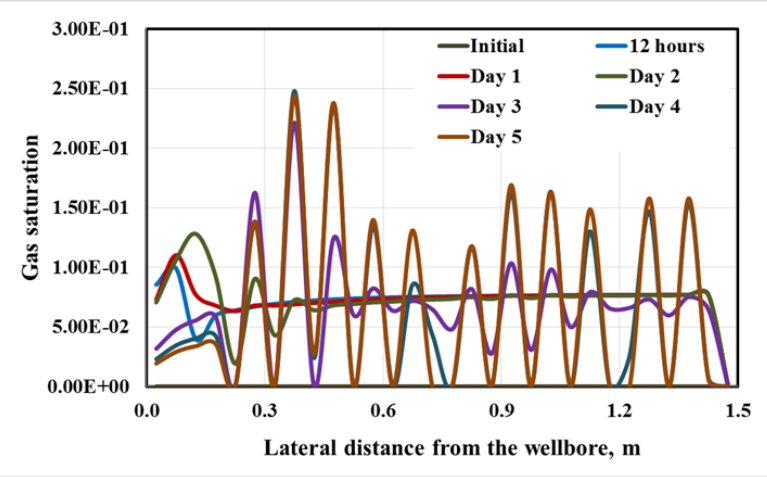

(c)

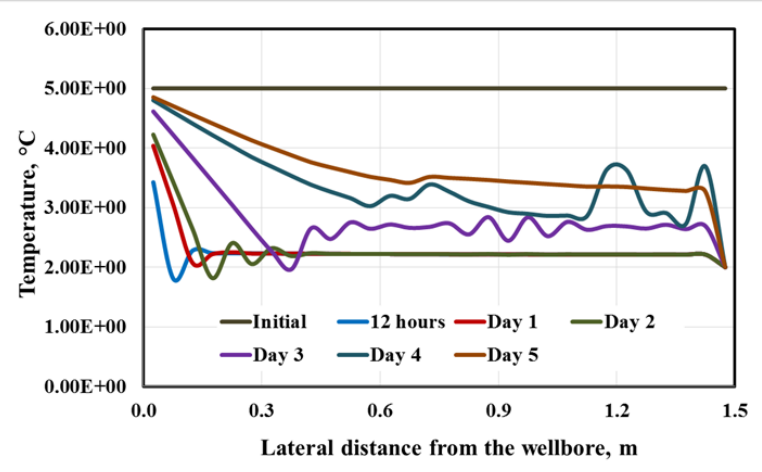

(d) 


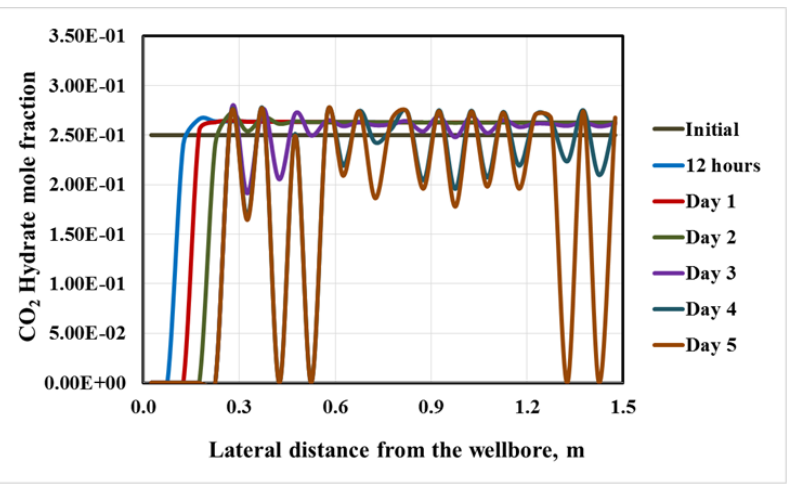

(e)

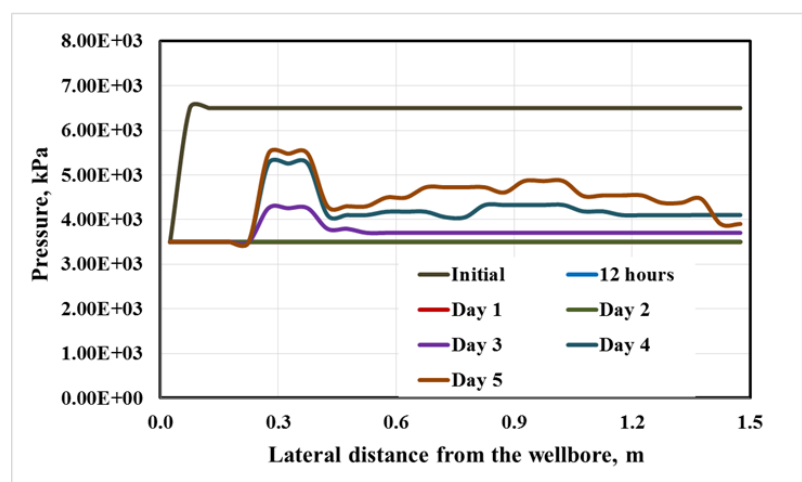

(g)

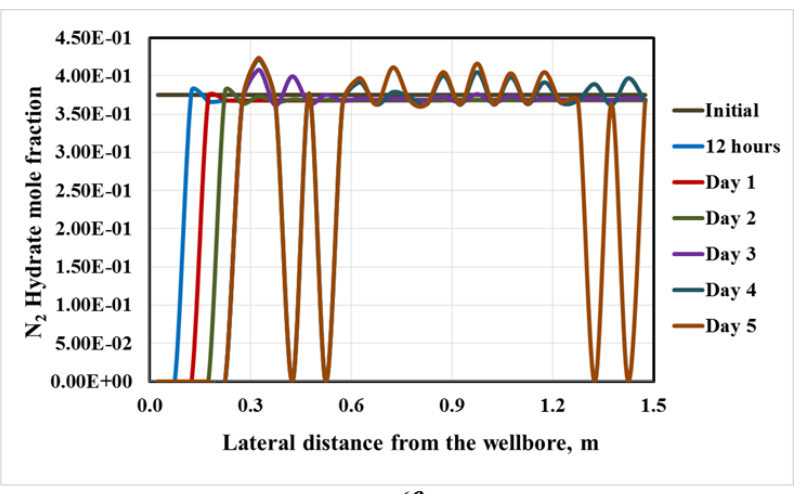

$(f)$

Figure 3-18 (a) Aqueous saturation, (b) hydrate saturation, (c) gas saturation, (d) temperature distributions, (e) Hydrate $\mathrm{CO}_{2}$ mole fractions, (f) Hydrate $\mathrm{N}_{2}$ mole fractions at different and (g) pressure distributions time periods

We can observe the fluctuations in the profiles of the various reservoir conditions. From the Figure 3-18 $(g)$, it is clear that by the end of day 2 , there is a mild pressure disturbance arose in the domain, which is mainly due to the formation of mixed hydrates (Figure 3-18 $(b)$ ) in every alternate element. As the hydrate saturation increases as high as 0.8 , the pressure also tend to increase eventually. The hydrate formation, lead to the temperature rise in its next elements, thus leading to the decomposition of hydrate in that particular element. Thus arising a fluctuated gas and aqueous saturation profiles as well (refer to Figure 3-18 (a) and (c)). 


\subsection{Problem 7 - $\mathrm{CH}_{4}-\mathrm{CO}_{2}$ swapping conducted on an idealized five spot well system}

\subsubsection{Problem Description}

The intent of this problem is to investigate the challenges for production of natural gas hydrate accumulations involving injection of $\mathrm{CO}_{2}$ and depressurization performed using a five-spot well model. In this simulation, the reservoir domain is considered to be one-quarter of the 1-m thick five-spot well with outer well spacing of $20 \mathrm{~m}$. A 10×10 Cartesian domain is used with size of each volume element equal to $1 \mathrm{~m}$ (shown in Figure 3-19). An Injection well is considered at left side lower corner $(0,0)$ of the reservoir and the right side upper corner $(10,10)$ is considered to be the production well.

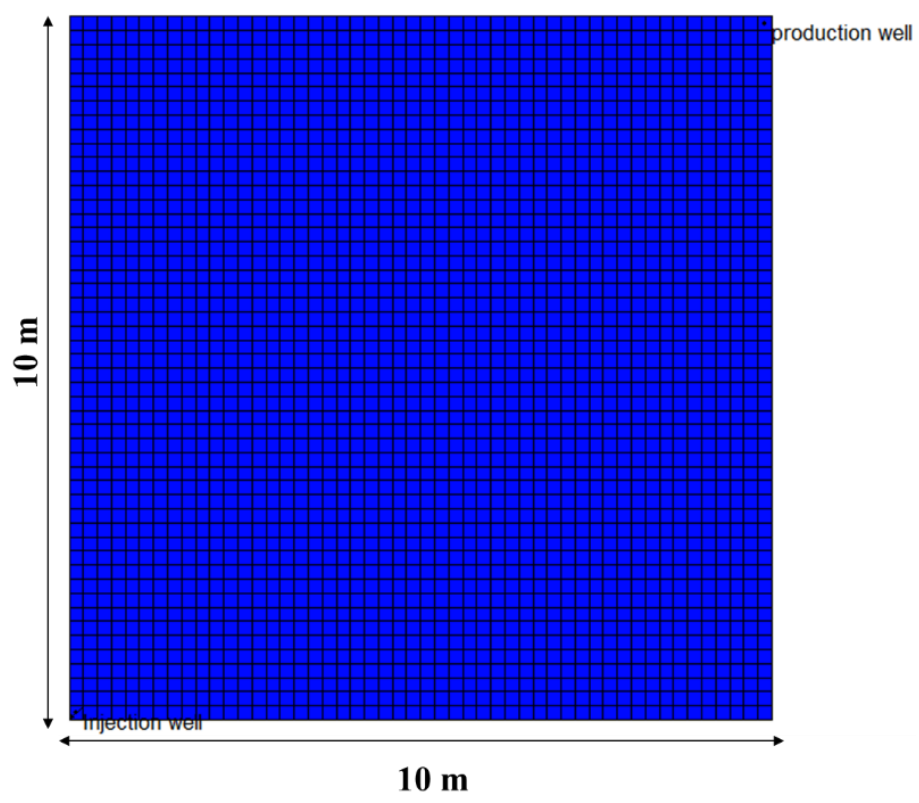

Figure 3-19: Reservoir domain used in the simulation

\section{Initial Conditions}

Permeability of the domain is considered as $1 \mathrm{D}$. The domain is modeled as geologic formations with a high hydrate saturations. Initially, the reservoir domain is modeled to be at $6 \mathrm{MPa}, 5^{\circ} \mathrm{C}$ with 
a pure $\mathrm{CH}_{4}$ hydrate saturation of 0.7 and aqueous saturation of 0.3 . Before, the commencement of $\mathrm{CO}_{2}$ injection, to increases the permeability of the formation matrix, the domain was depressurized initially using both the wells to a bottom-hole pressure of $3 \mathrm{MPa}$. The endothermic nature of hydrate decomposition mechanism reduces the temperature of the domain to $1.5^{\circ} \mathrm{C}$, thus producing gas saturation in the domain. Both the wells, production and injection wells are modeled using surface boundary condition. During the production simulations, pure gaseous $\mathrm{CO}_{2}$ is injected at a pressure of $4 \mathrm{MPa}$ and $25^{\circ} \mathrm{C}$ into the domain through the boundary surfaces which represents the center injection well. The production well is modeled as a constant pressure boundary surface maintained at $3 \mathrm{MPa}$. The simulation was run for 1 year time period. All the pertinent geophysical properties of the geologic media are as mentioned in the following table (Table 3-2). The relative permeability and capillary pressure values are assigned as shown in the Table 3-1.

Table 3-2. Various parameters used in the simulation

\begin{tabular}{|c|c|}
\hline PARAMETERS & VALUE USED \\
\hline Porosity $^{[53]}$ & 0.35 \\
\hline Intrinsic permeability $^{[53]}, \mathrm{mD}$ & $10^{3}$ \\
\hline Bulk Density, $\mathrm{Kg} / \mathrm{m}^{3}$ & 2650 \\
\hline Dry Thermal Conductivity & \\
\hline Wet Thermal Conductivity, $\mathrm{W} / \mathrm{W} / \mathrm{K}^{\mathrm{K}} \mathrm{K}$ & 2.0 \\
\hline Grain Specific heat $^{[53]}, \mathrm{J}^{\mathrm{kg}} \mathrm{K}$ & 2.18 \\
\hline Pore Compressibility $^{[53]}, \mathrm{Pa}^{-1}$ & 700 \\
\hline
\end{tabular}




\subsubsection{Results and Discussion}

At an injection pressure of $4 \mathrm{MPa}$, the total amount of injected $\mathrm{CO}_{2}$ is 13.178 tonne and produced 2.7 tonne of $\mathrm{CH}_{4}$ gas, which represents around $40 \%$ of the initial $\mathrm{CH}_{4}$ present in the system. Figure 3-20 displays the cumulative amount of $\mathrm{CO}_{2}$ injected and the amount of $\mathrm{CH}_{4}$ produced.

The commencement of $\mathrm{CO}_{2}$ injection leads to increase in the pressure around the injection well. The Figure 3-21 displays the distributions of various reservoir properties at the end of 30 days of production simulations. The temperature around the injection well also increases (till $12^{\circ} \mathrm{C}$ ) owing to the exothermic nature of mixed hydrate $\left(\mathrm{CH}_{4}-\mathrm{CO}_{2}\right.$-hydrate) formation reaction (enthalpy of $\mathrm{CO}_{2}$ hydrate formation is from -57.7 to $-63.6 \mathrm{~kJ} / \mathrm{mol}^{[52]}$ while enthalpy of methane hydrate decomposition is from 52.7 to $\left.55.4 \mathrm{~kJ} / \mathrm{mol}^{[54]}\right)$. The temperature rise around the injection wellbore is consistent with the rise in the hydrate saturation around the injection well implying the formation of mixed hydrates upon injection of $\mathrm{CO}_{2}$ into the formations. The rise in the molar concentration of $\mathrm{CO}_{2}$ in mixed hydrates (formed near the injection well) up till 0.2 (displayed in the Figure 3-21) confirms the swapping of $\mathrm{CH}_{4}$ with $\mathrm{CO}_{2}$ in the initially present pure $\mathrm{CH}_{4}$ hydrate lattices. The gas saturation contours displayed in Figure 3-21 indicates that the gas saturation closer to the injection well is high due to injection of gaseous $\mathrm{CO}_{2}$ and similarly at the proximity of production well due to the continuous dissociation of $\mathrm{CH}_{4}$ hydrates. 


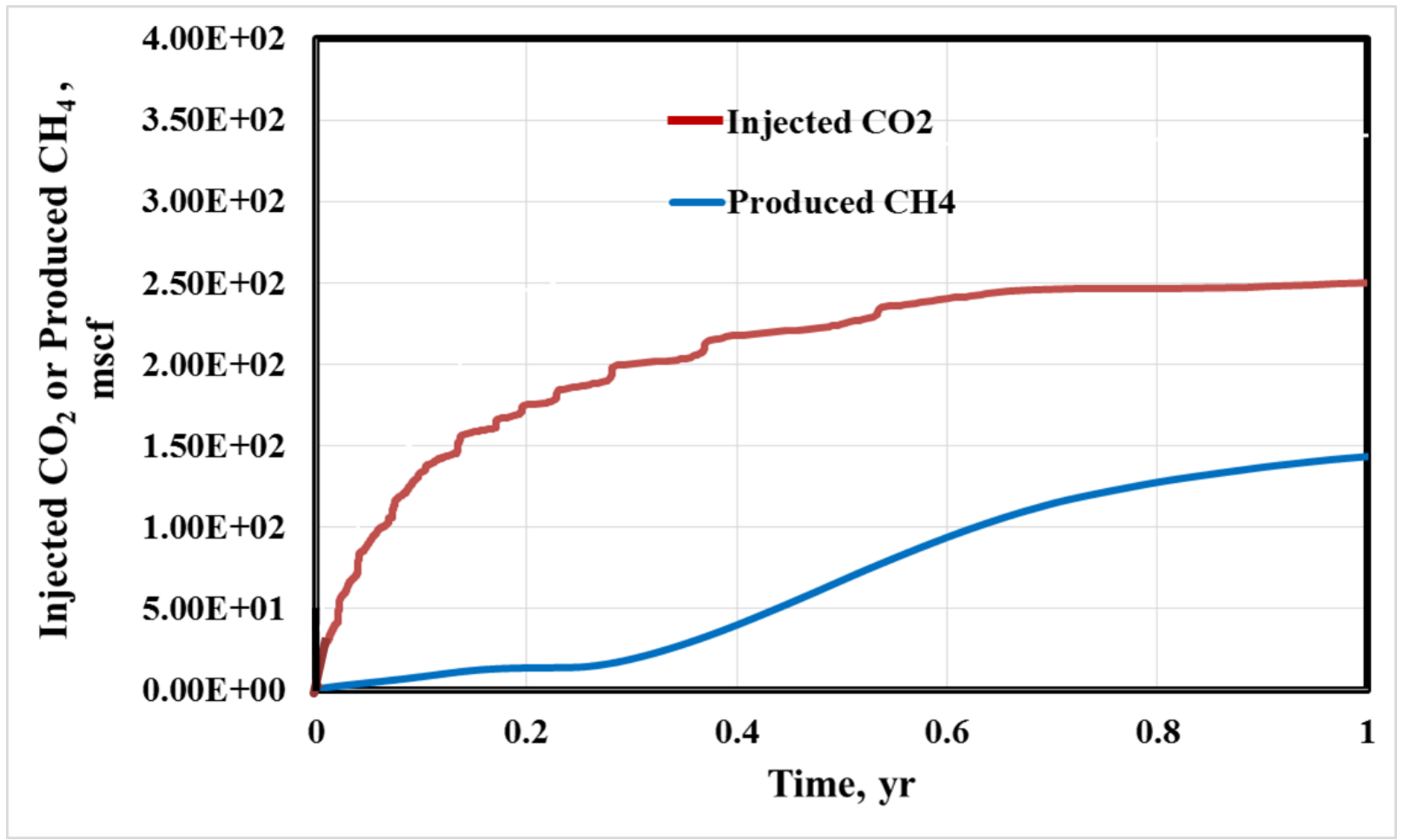

Figure 3-20. Cumulative volumes of injected $\mathrm{CO}_{2}$ and produced $\mathrm{CH}_{4}$

The following contours displayed in Figure 3-22 indicates the distributions at the end of 1 year of production simulation. Compared to the prior simulation results (Figure 3-21), we can observe a rise in the extent of hydrate saturation increment indicating the formation of mixed hydrate. Even the molar concentrations of $\mathrm{CO}_{2}$ in the hydrates fortify the claim of increased mixed hydrate saturation in the domain. The changes in the P/T conditions remains to be consistent with the observations deduced so far. 

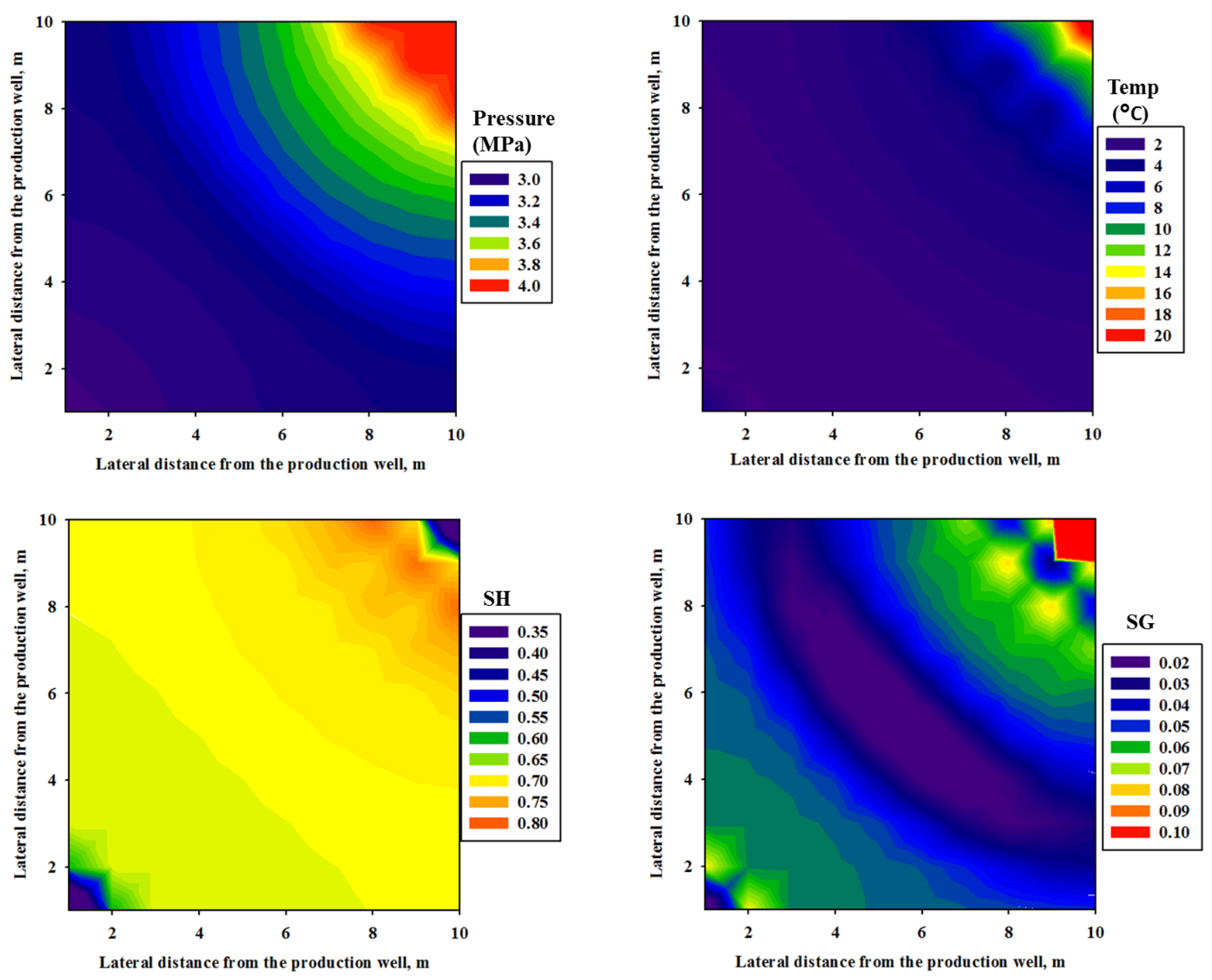


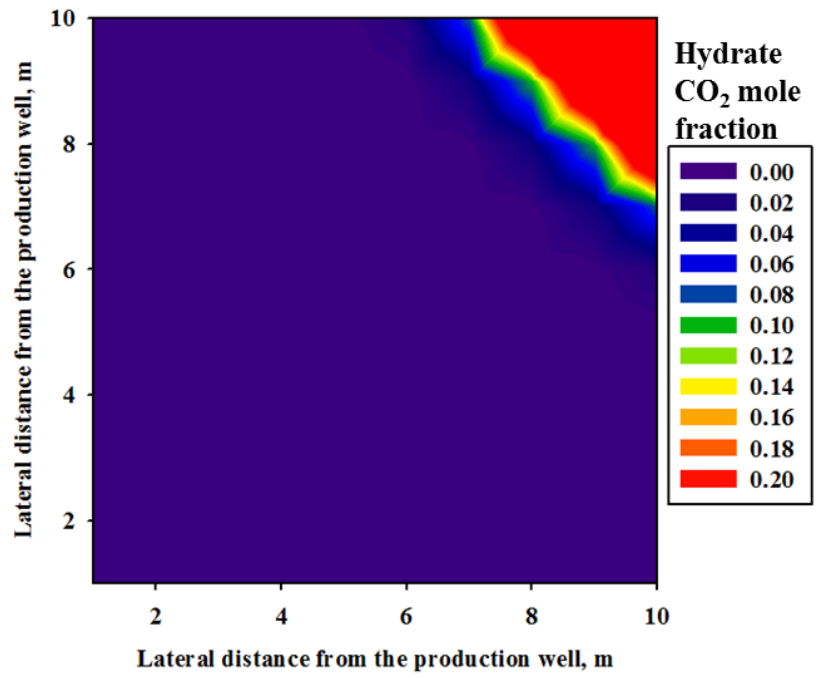

Figure 3-21. Reservoir conditions at the end of 30 days of production simulations
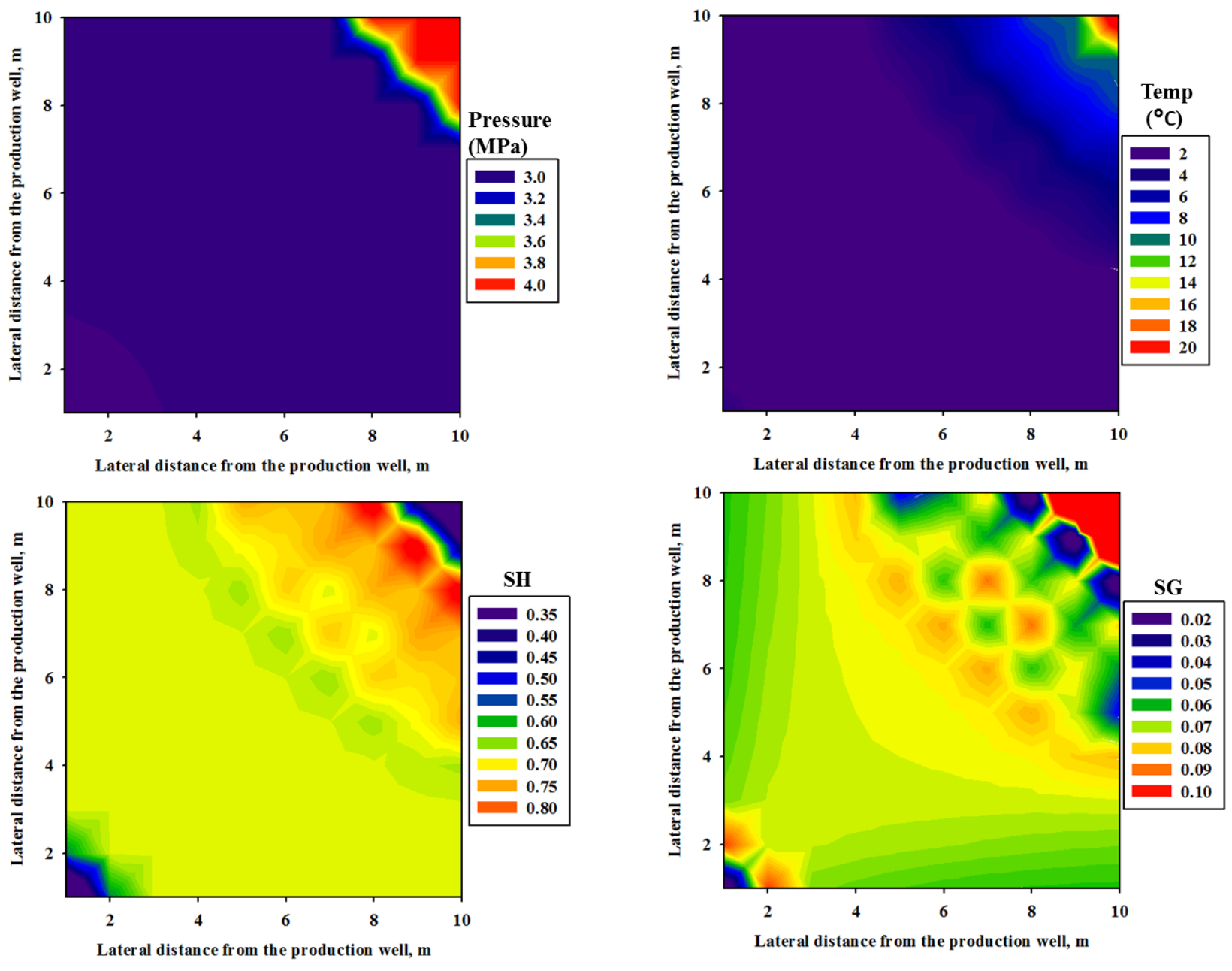


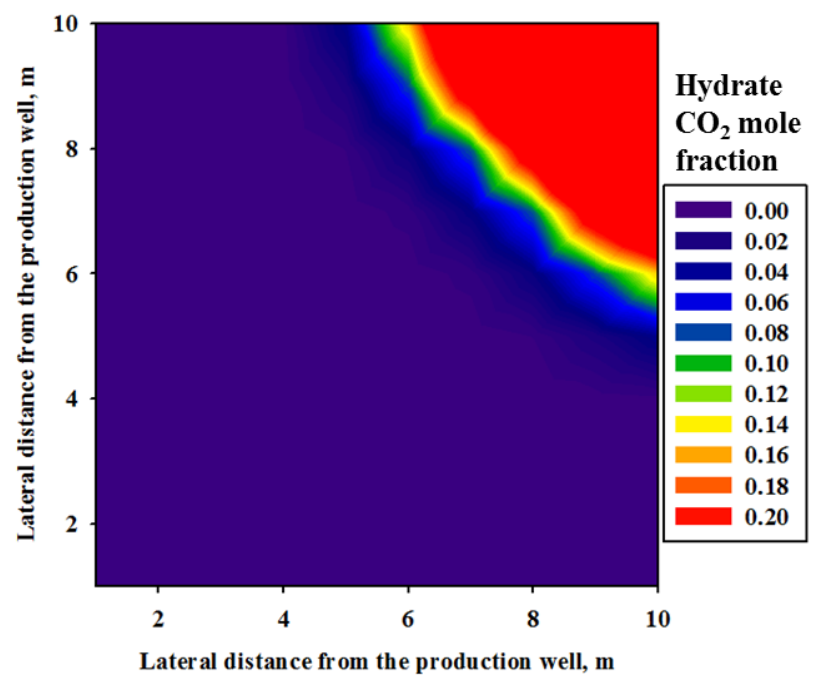

Figure 3-22. Reservoir conditions at the end of 1 year of production simulations

These seven numerical simulations on $\mathrm{CO}_{2} / \mathrm{CH}_{4}-\mathrm{CO}_{2}$ hydrate reservoirs provided a basic insight to formulate and interpret a novel technological approach, which is explained in detail in the following Chapter. This novel approach aims at prediction of enhanced gas production profiles from Class 2 hydrate accumulations by utilizing $\mathrm{CO}_{2}$ sequestration. 


\section{4. $\mathrm{CO}_{2}$ Sequestration and Enhanced $\mathrm{CH}_{4}$ recovery from Class 2 natural gas Hydrate accumulations}

\subsection{Introduction}

Capture of $\mathrm{CO}_{2}$ and its long-term storage in the underground geological settings is a widely proposed approach to offset the alarming levels of $\mathrm{CO}_{2}$ in the atmosphere which is primarily produced from the fossil-fuel-burning power plants. Natural gas hydrate formations serve as an attractive option to seal $\mathrm{CO}_{2}$ as gas hydrates. One such strategy which assists to sequestrate atmospheric $\mathrm{CO}_{2}$ was proposed by Ohgaki et al. ${ }^{[20]}$, is a novel gas hydrate recovery technique: " $\mathrm{CO}_{2}-\mathrm{CH}_{4}$ exchange in $\mathrm{CH}_{4}$-hydrates". This technique offers a dual purpose of enhanced $\mathrm{CH}_{4}$ gas production and simultaneous sequestration of the greenhouse gas as the most stable gas hydrate (as $\mathrm{CH}_{4}-\mathrm{CO}_{2}$-hydrate ${ }^{[30]}$ ). The feasibility of the swapping process is owed to the following reasons, 1) $\mathrm{CO}_{2}, \mathrm{CH}_{4}$ and even the mixtures of these gases form Structure 1 (sI) hydrate ${ }^{[3,31]}$. This structural similarity assists in maintaining the structural integrity even after swapping of $\mathrm{CH}_{4}$ by $\mathrm{CO}_{2}$ in the natural gas hydrate settings and hence no stiffness loss is observed at the sediment scale ${ }^{[32]}$. 2) $\mathrm{CO}_{2}$-hydrate is thermodynamically more stable than $\mathrm{CH}_{4}$-hydrate at temperatures below $283 \mathrm{~K}$, since the equilibrium pressures of the $\mathrm{CO}_{2}$-hydrate is lower than the $\mathrm{CH}_{4}$-hydrate at this condition $^{[33]}$.

Methods for recovering natural gas from hydrate accumulations are various. The most practical methods include depressurization, thermal stimulation and chemical inhibitor injection method. Depressurization is the most energy efficient method for which it is widely preferred and is considered to be the most economic technique. Exploitation of the hydrate accumulations induced by the depressurization technique results in commingled gas and water flow in the production stream due to the decomposition of hydrate lattice. On a molecular scale, gas hydrates contains 
mostly (nearly $85 \%^{[3]}$ ) water, which results in release of large amounts of water upon hydrate dissociation.

This work utilizes the above mentioned advantages of the $\mathrm{CO}_{2}$-hydrates and combines it to overcome the shortcomings of the exploitation of Class 2 natural gas hydrate accumulations, which is one among the three different gas hydrate accumulations present around the world. Class 2 accumulations consist of two layers in which a mobile-aqueous layer (e.g., an aquifer) present underneath a hydrate bearing geologic media. Exploitation of these geological settings often results in the release of vast volumes of water, thus affecting the gas production rates and eventually leading to an uneconomical exploitation site.

This work aims at maximizing the gas production (by lowering the water production) from Class 2 hydrate accumulations implemented by the $\mathrm{CO}_{2}$-assisted technique. The production technique involves a three-stage approach using one-well design, which serves as an injector in the first stage and as a producer in the third stage. In first stage, $\mathrm{CO}_{2}$ is injected into the mobile aqueous phase and the $\mathrm{CO}_{2}$ plume propagation is allowed. As the injection goes on, the temporal changes of the reservoir parameters (like pressure, temperature, saturations, etc.) are monitored. These thermodynamic parameters ( $P / T$ conditions) eventually hit a favorable regime of the hydrate equilibrium curve during Stage II, which is an equilibration stage. In this Stage II, the initiation and evolution of the $\mathrm{CO}_{2}$-hydrate formation is witnessed in the reservoir. When the suitable impermeable $\mathrm{CO}_{2}$-hydrate is observed across the methane hydrate-water boundary, the commencement of production stage (Stage III) takes place. It involves the depressurization of the $\mathrm{CH}_{4}$-hydrate bearing deposits to predict the gas and water production profiles over the 15 year time-period. Further, the depressurization of conventional Class 2 hydrate accumulations is 
considered to compare with enhanced gas production predicted by the $\mathrm{CO}_{2}$-assisted technique due to better water management.

\section{Geometry and Stratigraphic units}

The reservoir flow-simulation model considered in this work is axisymmetric representing a cylindrical domain suitable to study radial flow near the vertical well ${ }^{[55]}$ (Figure 4-1c, red arrow). Taking an advantage of the symmetry, the reservoir was simplified into a $2 \mathrm{D}$ model as a vertical cross-section along its radius. Figure 1a shows the 2D model used in the simulation with the vertical well completed at the center of the axis. The radial grid extends out to $500 \mathrm{~m}$ which is logarithmically distributed into 75 grid blocks with the lowest $r_{w e l l}=0.11 \mathrm{~m}$ and largest $r_{x}=475 \mathrm{~m}$ ensuring fine discretization around the wellbore. The total thickness of the reservoir domain is 40 $\mathrm{m}$. It consists of the sand sediment $(20 \mathrm{~m})$ bounded at the top and bottom by shale deposits $(10 \mathrm{~m}$ each). The sand formation layer is split between the hydrate-bearing zone (13 m, Zone 1 in Figure 4-1c) and the water-bearing zone (7 m, Zone 2 in Figure 4-1c) represents typical Class 2 hydrate

accumulation $^{[15]}$.In the vertical direction the over- and under-burden are discretized into sub-layers of $2 \mathrm{~m}$ thickness and the hydrate-bearing and water-bearing sands have sub-layers of $1 \mathrm{~m}$ thickness. The top and bottom boundaries of the reservoir are set at fixed temperature conditions providing heat influx into the formation with no mass flow allowed. The lateral boundaries are taken as impermeable for both heat and mass transfer. A vertical wellbore of radius $0.11 \mathrm{~m}$ is completed through the sand zones (Figure 4-1c). 


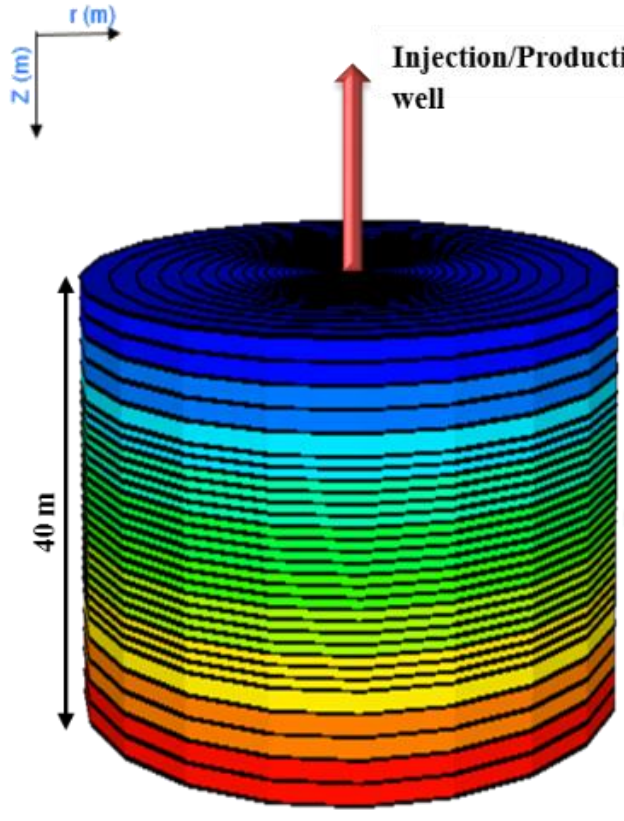

(a)

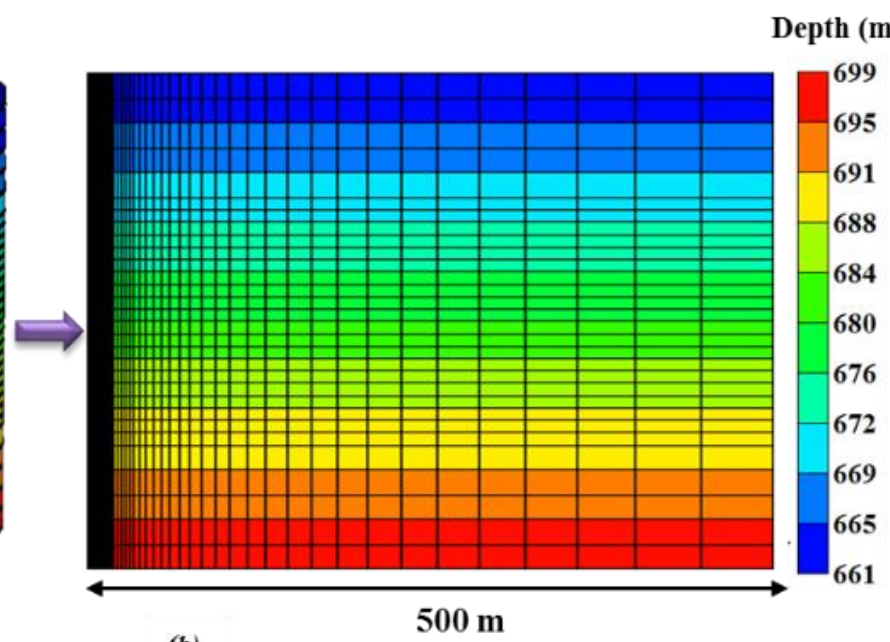

(b)
$500 \mathrm{~m}$

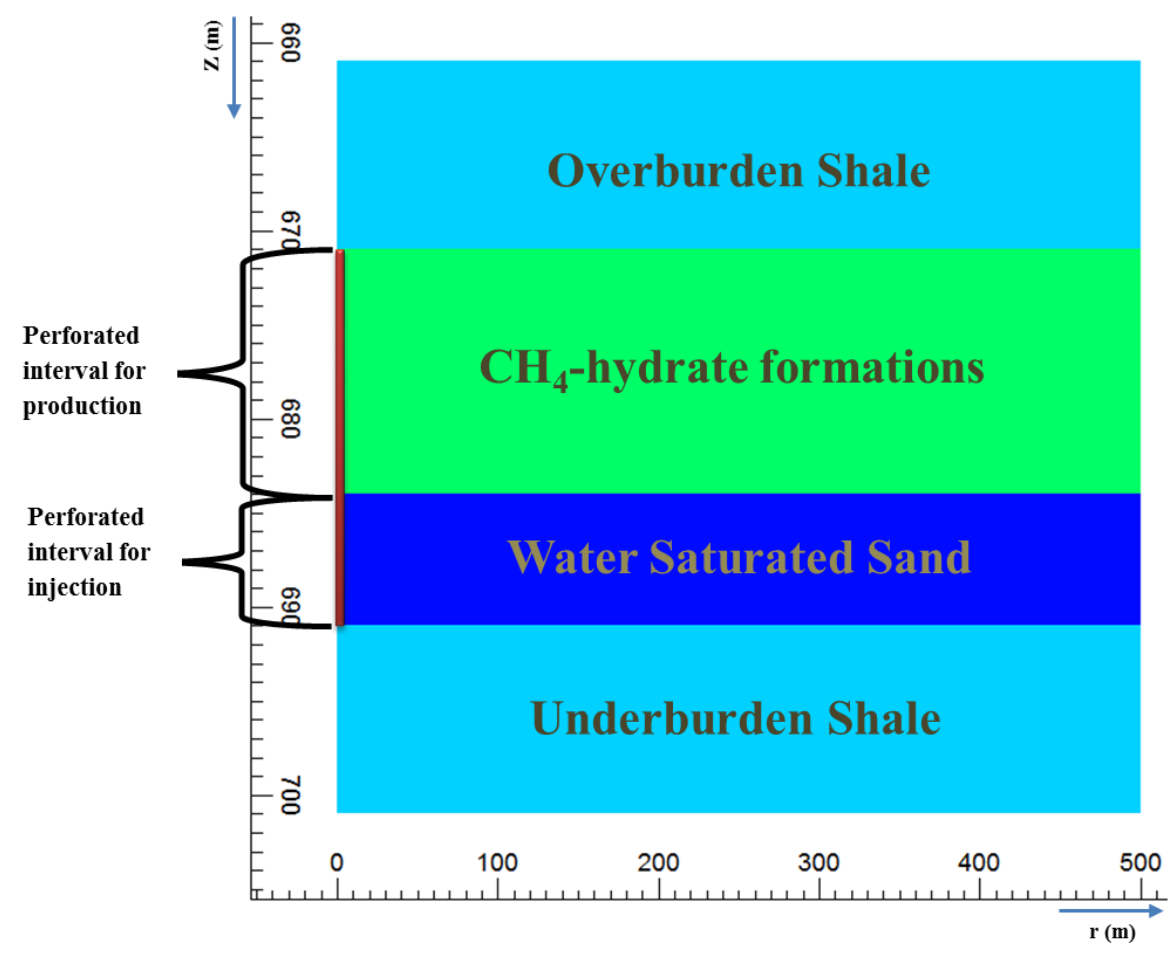

(c)

Figure 4-1. (a,b) Radial reservoir grid domain; (c) The 2D radial model used for simulations 


\section{Reservoir model properties}

The $\mathrm{CH}_{4}$-hydrate layer (Zone 1) extends from $673 \mathrm{~m}$ to $685 \mathrm{~m}$ (beneath the earth surface). The hydrate-water contact is considered at a depth of $685 \mathrm{~m}(2248 \mathrm{ft})$ to model the stratigraphic distributions of Prudhoe Bay L-Pad region of Alaska North Slope ${ }^{[34]}$. The geological deposits are assumed to be sandstone formations underneath the permafrost with high hydrate saturations. The reservoir properites used in this simulation corresponds to the field data available for North slope Alaska region ${ }^{[56]}$. Homogeneous distribution of various reservoir parameters like intrinsic permeability, rock porosity, irreducible water saturation, etc. is considered in the simulations. The values of pertinent petro-physical parameters are tabulated below (Table 4-1). Relative permeability values are calculated using the Brooks and Corey ${ }^{[57]}$ correlations and capillary pressure values are calculated using Van Genuchten ${ }^{[48]}$ function as mentioned in the Table 4-2.

Table 4-1. Various reservoir parameters used in the Stage 1 simulations

\begin{tabular}{|c|c|}
\hline Parameters & Values Used \\
\hline \multirow{2}{*}{ Rock Grain Density (kg/m³) } & Zones 1 and 2 - 2600 \\
\hline & Shale- 2600 \\
\hline \multirow{2}{*}{ Porosity (\%) } & Zones 1 and 2- 35 \\
\hline & Shale- 10 \\
\hline \multirow{3}{*}{ Intrinsic Permeability (mD) } & Zone 1 - 0 \\
\hline & Zone 2 - 1000 \\
\hline & Shale- 0 \\
\hline \multirow{2}{*}{ Rock grain specific heat $\left(\mathrm{J} / \mathrm{kg}^{\circ} \mathrm{C}\right)$} & Zones 1 and $2-1000$ \\
\hline & Shale - 1000 \\
\hline \multirow{2}{*}{ Thermal conductivity (W/m K) } & Hydrate -3.1 \\
\hline & Shale - 3.1 \\
\hline Pore Compressibility $\left(\mathbf{P a}^{-1}\right)$ & $5.0 \times 10^{-10}$ \\
\hline
\end{tabular}


Table 4-2. Parameters used for Relative Permeability and Capillary Pressure

\begin{tabular}{|c|c|}
\hline Relative Permeability & $\begin{array}{l}\text { Brooks and Corey } \\
k_{r A}=\left(S_{A}^{*}\right)^{n} ; k_{r G}=\left(S_{G}^{*}\right)^{n} \\
S_{A}^{*}=\frac{\left(S_{A}-S_{i r A}\right)}{\left(1-S_{i r A}\right)} ; S_{G}^{*}=\frac{\left(S_{G}-S_{i r G}\right)}{\left(1-S_{i r G}\right)}\end{array}$ \\
\hline $\begin{array}{l}\text { Irreducible water saturation, } \\
S_{\text {irA }}\end{array}$ & 0.10 \\
\hline $\begin{array}{l}\text { Irreducible gas saturation, } \\
\text { SirG }_{\mathrm{i}}^{[50]}\end{array}$ & 0.001 \\
\hline $\mathbf{n}^{[50]}$ & 3 \\
\hline Capillary Pressure & $\begin{array}{l}\text { Van Genuchten Function } \\
P_{c a p}=-P\left[\left(S^{*}\right)^{-1 / \lambda}-1\right]^{\lambda} S^{*}=\frac{\left(S_{A}-S_{i r A}\right)}{\left(S_{\max A}-S_{i r A}\right)}\end{array}$ \\
\hline $\begin{array}{l}\text { Irreducible water saturation, } \\
\text { S irA }\end{array}$ & 0.09 \\
\hline$\lambda^{[28]}$ & 0.45 \\
\hline$S_{\operatorname{maxA}}$ & 1 \\
\hline$P_{\max }, \mathrm{Pa}^{[28]}$ & $1.25 \times 10^{4}$ \\
\hline
\end{tabular}

\section{Initial conditions}

Initial pore pressure of the system is assumed to follow hydrostatic pressure distribution ${ }^{[58]}$. Temperature of the reservoir is assigned based on the local geothermal gradient $\left(0.033{ }^{\circ} \mathrm{C} / \mathrm{m}\right)^{[56]}$ of the North Slope Alaska region. Figure 4-2 displays the initial distributions of hydrate saturation, pressure and temperature. Respective initial conditions of the model are given in the Table 4-3. $\mathrm{CH}_{4}$-hydrate (Zone 1) formations are modeled as a two-phase system with aqueous phase in equilibrium with hydrate phase. The mobile-water region (Zone 2) and shale deposits are considered as pure aqueous phase. 


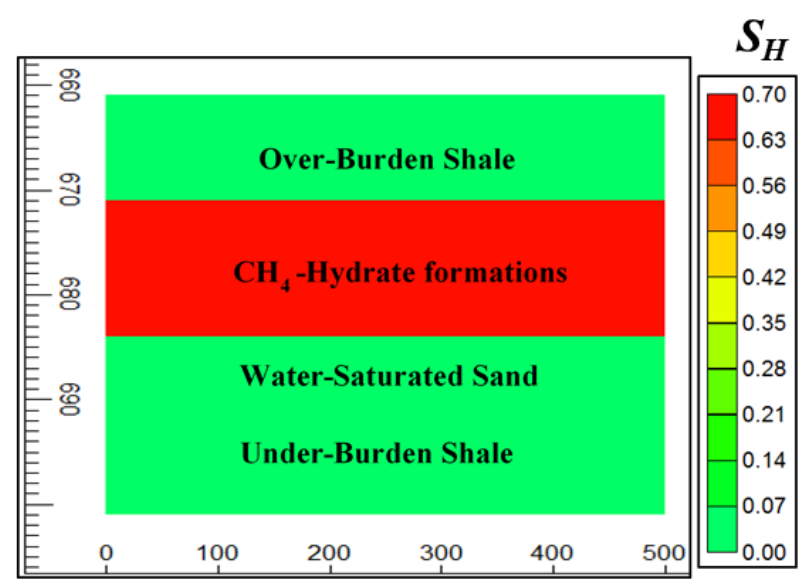

(a)

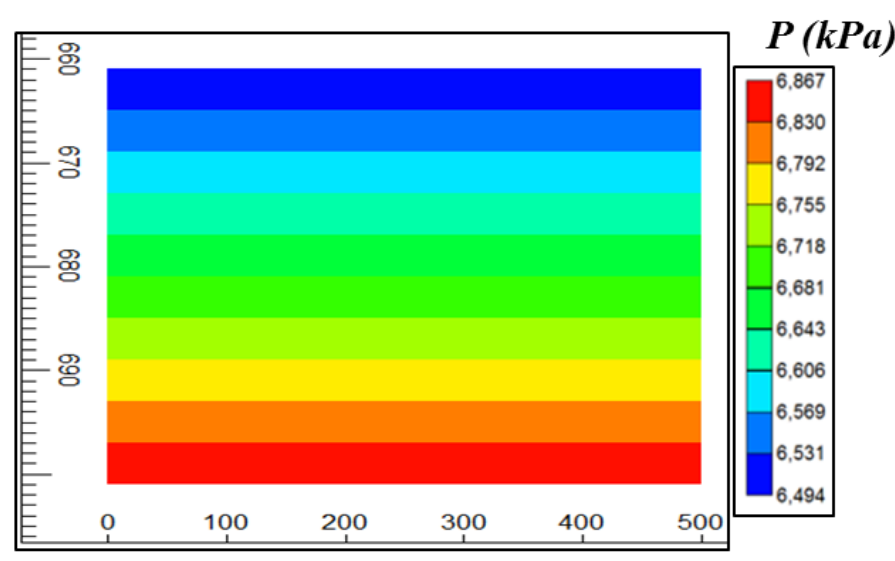

(b)

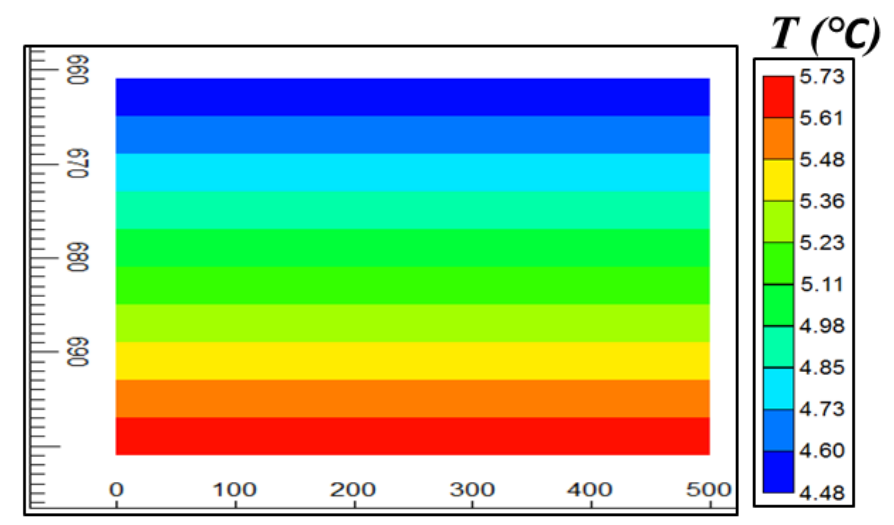

(c)

Figure 4-2: Initial conditions of the domain $(a)$ Hydrate saturation distribution $(b)$

Pressure $(\mathrm{kPa})$ distribution $(c)$ Temperature $\left({ }^{\circ} \mathrm{C}\right)$ distribution

Table 4-3. Initial conditions used in the simulation

\begin{tabular}{|l|l|l|}
\hline $\begin{array}{l}\text { Zone } 1 \\
\text { (Hydrate formations) }\end{array}$ & Hydrate Saturation, $\mathbf{S}_{\mathbf{h}}$ & $\mathbf{0 . 7 0}$ \\
\cline { 2 - 3 } & Water Saturation, $\mathbf{S}_{\mathbf{w}}$ & 0.30 \\
\hline $\begin{array}{l}\text { Zone 2 } \\
\text { (free water beneath the } \\
\text { hydrate deposits) }\end{array}$ & Water Saturation, $\mathbf{S}_{\mathbf{w}}$ & 1.00 \\
\hline Gas saturation $\mathbf{S}_{\mathbf{g}}$ ) in Zone 1 and 2 & 0.00 \\
\hline Reservoir Pressure distribution & Hydrostatic-Pressure \\
\hline Geo-thermal gradient ${ }^{[56]}$ & $0.033^{\circ} \mathrm{C} / \mathrm{m}$ \\
\hline
\end{tabular}




\subsection{Technological approach and Results}

The approach consists of three stages and is conducted as a 'huff and puff' style, where a single vertical wellbore is used as an injector in the first stage and later as a producer in the third stage. During the Stage I, the wellbore is perforated throughout the Zone 2 to inject pure $\mathrm{CO}_{2}$ into the water-bearing sand sediments (Zone 2, Figure 1c). For this stage, different case scenarios are considered to investigate two different modes of injection; injection of $\mathrm{CO}_{2}$ using constant pressure and injection of $\mathrm{CO}_{2}$ using constant flow rate. The case scenario which results in an extended propagation of $\mathrm{CO}_{2}$ plume in the aquifer without increasing the reservoir pore pressure beyond fracture initiation pressure of the in-situ hydrate formation settings is selected for further simulations (next stages; Stage II and Stage III) to be performed. In all these various case scenarios, injection is continued till the onset of $\mathrm{CO}_{2}$-hydrate is observed at the advancing front of the injected fluid in the Zone 2 and is considered as the end of Stage I. At Stage II, the wellbore is shut-in and the system is allowed to reach a thermal equilibrium with the surrounding layers, thus bringing the thermodynamic conditions of Zone 2 into the $\mathrm{CO}_{2}$-hydrate stability regime, to induce and maintain the $\mathrm{CO}_{2}$-hydrate formation reaction. In the Stage III, the dissociation of $\mathrm{CH}_{4}$-hydrates present in the Zone 1 is initiated by depressurization method using the well interval perforated throughout the Zone 1(shown in Figure 1c). The production benefits from the additional heat supplied to the reservoir during first two stages (exothermic nature of gas dissolution in water and $\mathrm{CO}_{2}$ hydrate formation reaction) which increases the temperatures of the formation matrix. Hence, along with depressurization, this method uses an in-situ thermal stimulation which helps in pronounced release of gas from the $\mathrm{CH}_{4}$-hydrate accumulations. The stages are described in detail in the following sections. 


\subsection{1 $\mathrm{CO}_{2}$ Injection stage (Stage I)}

Injection of $\mathrm{CO}_{2}$ into the water saturated sand zone of the Class 2 gas hydrate accumulations can be achieved by Injecting $\mathrm{CO}_{2}$ using constant pressure or using constant flow rate. Each of these modes of injection hold inherent advantages and disadvantages. The primary goal of this stage is to allow maximum penetration of $\mathrm{CO}_{2}$ plume into the confined aquifer without surpassing the formation parting pressure of the hydrate formation matrix. Hence, different are considered with an intention to determine the best mode of injection that has to be employed for the desirable results (which is extended penetration of injected $\mathrm{CO}_{2}$ plume) to be achieved by the end of the Stage I. The best case scenario (the case scenario which results in the maximum migration of $\mathrm{CO}_{2}$ plume) is considered as for next Stages. Both the injection modes (Injection using of $\mathrm{CO}_{2}$ constant pressure and injection of $\mathrm{CO}_{2}$ using constant flow rate) are discussed in detail in the following sections.

\section{Injection of $\mathrm{CO}_{2}$ at constant pressure}

In most of the operational scenarios, injection pressure should be maximized to ensure the highest possible injection rate that does not exceed the formation parting pressure associated with fracturing of the storage formation, therefore a constant pressure boundary is preferred ${ }^{[59]}$. The well grid element is modeled as a fixed pressure boundary condition with a gas phase. In 2012, during the Ignik-Sikumi field test, ConocoPhilips conducted the step rate test to measure the Formation Parting Pressure (FPP) of the in situ hydrate sediments located in the Prudhoe Bay Unit on the Alaska North Slope. The FPP value was calculated to be $9.86 \mathrm{MPa}^{[34]}$. Hence, the injection pressure that is intended to be employed must be maintained lower than the FPP value. In this section, three different case scenarios are considered with different injection pressures (two cases dealt with injection pressures less than FPP value (9.86 MPa) and other case studied the injection 
pressure greater than FPP value) to comprehend the effect of injection pressure on the plume propagation in the aquifer. The different case scenarios considered in this section are listed out in the Table 4-4.

Similarly, selection of an appropriate temperature of the injection fluid is of utmost importance. The reason is, if the temperature of the inflow is lower than $10.5^{\circ} \mathrm{C}^{[60]}$, the thermodynamic conditions fall within the $\mathrm{CO}_{2}$-hydrate equilibrium conditions. Hence, as the $\mathrm{CO}_{2}$ inflow into the water saturated sand zone commences, the hydrates start building up around the wellbore, thus arising an issue of well-bore plugging. On the contrary, if the temperature of the fluid is high enough (greater than $20^{\circ} \mathrm{C}$ ), the time expended (during Stage II) to cool down the reservoir and to initiate $\mathrm{CO}_{2}$ hydrate formation will be huge, thus making the technique impractical. Hence, performing the sensitive analysis on the temperature and pressure of injected fluid is of paramount requirement.

In all the simulations using injection at constant pressure (Case Scenario \# 1-3), impact of only injection pressures are discussed. The injection temperature is maintained at $20^{\circ} \mathrm{C}$ for all the cases because any temperatures lower than $20^{\circ} \mathrm{C}$ resulted in the earlier formation of $\mathrm{CO}_{2}$ hydrate at the advancing front, which is undesirable. Hence, the lower injection temperatures aren't discussed here. But for the case scenario \# 4 where injection at constant flow rate is studied, the lowest possible temperature is considered, since it resulted in favorable results 1) minimal increase in the reservoir temperature upon injection of $\mathrm{CO}_{2}$ compared to rest of the three cases and 2) extension of $\mathrm{CO}_{2}$ plume propagation is similar to that of other cases. Hence, higher injection temperatures and flow rates aren't discussed here. 
Table 4-4. The different case scenarios and the respective injection parameters

\begin{tabular}{|l|l|l|}
\hline Injection at constant Pressure & Injection Pressure $(\mathrm{MPa})$ & Injection Temperature $\left({ }^{\circ} \mathrm{C}\right)$ \\
\hline Case Scenario \# 1 & 7.5 & 20 \\
\hline Case Scenario \# 2 & 9.5 & 20 \\
\hline Case Scenario \# 3 & 11.5 & 20 \\
\hline Injection at constant flow rate & $\begin{array}{l}\text { Injection Flow rate } \\
\text { (metric ton/ day) }\end{array}$ & Injection Temperature $\left({ }^{\circ} \mathrm{C}\right)$ \\
\hline Case Scenario \# 4 & 165 & 13 \\
\hline
\end{tabular}

\section{Case Scenario \# 1: Injection of $\mathrm{CO}_{2}$ using constant pressure set at 7.5 MPa}

The injection of $\mathrm{CO}_{2}$ is carried out for 165 days and then it is shut-down when an onset of hydrate formation is observed at the advancing front of $\mathrm{CO}_{2}$-plume propagation in the aquifer of the reservoir. As the pure $\mathrm{CO}_{2}$ is injected into the water-saturated sand zone of the reservoir, the injection rate decreases sharply and is lowered down to zero eventually (refer to Figure 4-3) indicating that the reservoir is pressurized upon the injection. The injection rate of $\mathrm{CO}_{2}$ and cumulative amount of $\mathrm{CO}_{2}$ injected into the reservoir is shown in the Figure 4-3. 


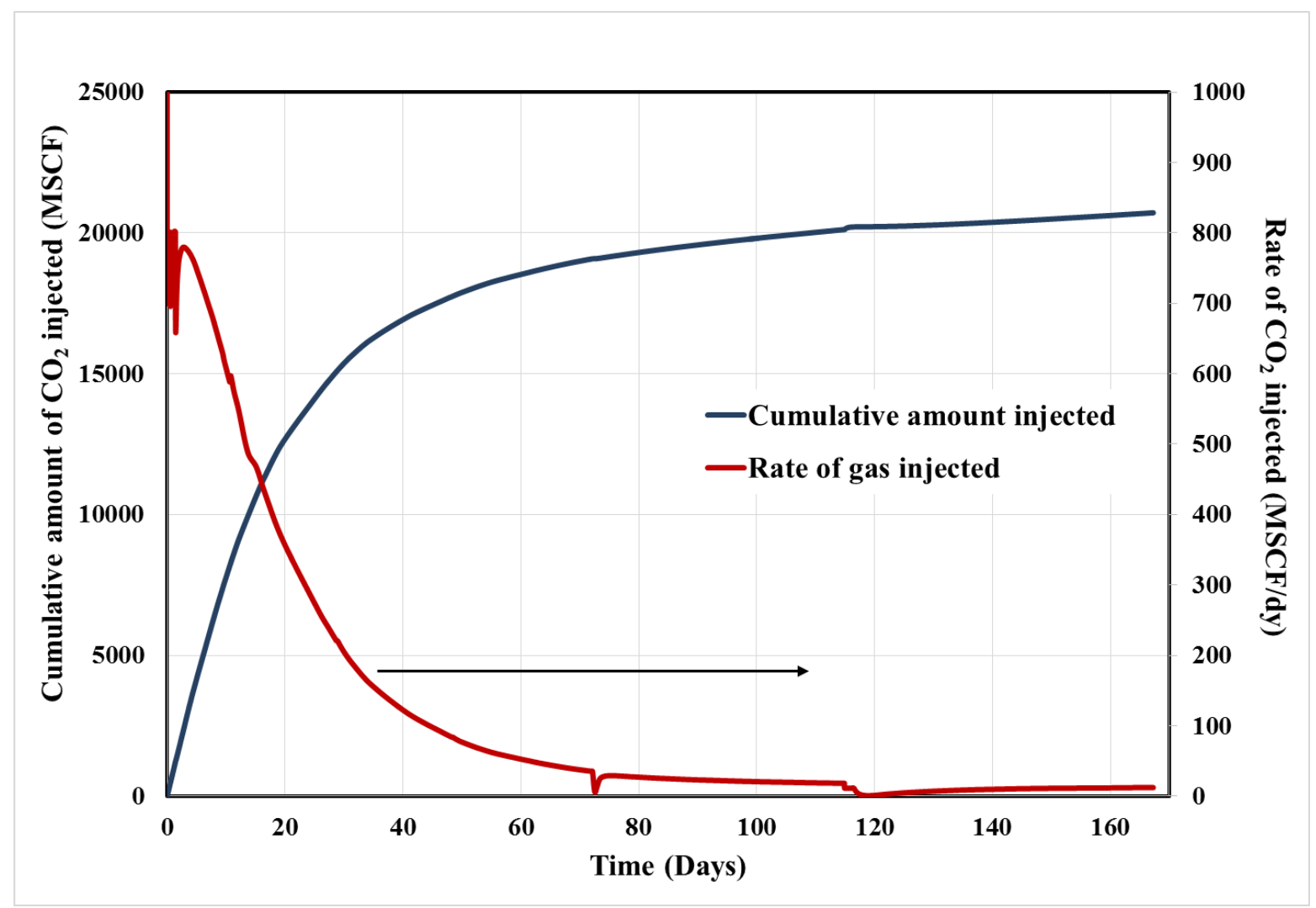

Figure 4-3. Graphs showing (i) Cumulative amount of $\mathrm{CO}_{2}$ injected (ii) Rate of $\mathrm{CO}_{2}$ injected

Figure 4-4 displays the pressure, temperature, $\mathrm{CO}_{2}$ gas and water saturation distributions at the end of Stage I. To get a clear picture of the distribution profiles around the well, the domains displayed are truncated to a length of $150 \mathrm{~m}$. As the $\mathrm{CO}_{2}$ is injected, the plume displaces water, thus increasing the gas saturation in the domain to 0.5 (Figure $4-4$ (c)) in the vicinity of the wellbore. As the domain is pressurized due to injection (Figure 4-4 (a)), the partial pressure of the gas goes higher than the reservoir pressure. It results in the onset of the gas phase in the system which eventually remains in equilibrium with the aqueous phase. Figure 4-4 (b) shows that there is a rise in the temperature of the reservoir corresponding to the $\mathrm{CO}_{2}$ gas saturation advance. The reason for the temperature rise is due to two thermodynamic processes: (1) the specific enthalpy 
of injected $\mathrm{CO}_{2}$; (2) exothermic nature of $\mathrm{CO}_{2}$ dissolution in water $\left(\mathrm{CO}_{2}(\mathrm{gas}) \rightarrow \mathrm{CO}_{2}(\mathrm{aq}) ; \mathrm{Q}=\right.$ $19.4 \mathrm{~kJ} / \mathrm{mol}^{[51]}$ for pure water at $\left.15^{\circ} \mathrm{C}\right)$. Because of the heat exchange with the surrounding strata, we can observe that the temperature declines as the $\mathrm{CO}_{2}$ plume propagates in the reservoir (Figure 4-4 (b)). In order to enable $\mathrm{CO}_{2}$ hydrate formation in the gas plume spread out region of the aquifer, the temperature should drop below $10-10.5{ }^{\circ} \mathrm{C}$ at the pressure range of $7-8 \mathrm{MPa}$ as shown in the phase diagram in Figure 3.2 (point P1).

Since there is no hydrate formed yet, the aqueous saturation is calculated simply from the relation $\mathrm{S}_{\mathrm{w}}=1-\mathrm{S}_{\mathrm{G}}$. From all the contours (Figure 4-4), it is evident that the penetration of $\mathrm{CO}_{2}$ is till 85 $\mathrm{m}$ of the domain during the 165 days of injection. At the end of 165 days of injection, trace of $\mathrm{CO}_{2}$ hydrate is observed after at a radial distance of $85 \mathrm{~m}$ from the center, the injection is then shutdown. This marks the end of the Stage I and commencement of Stage II. 


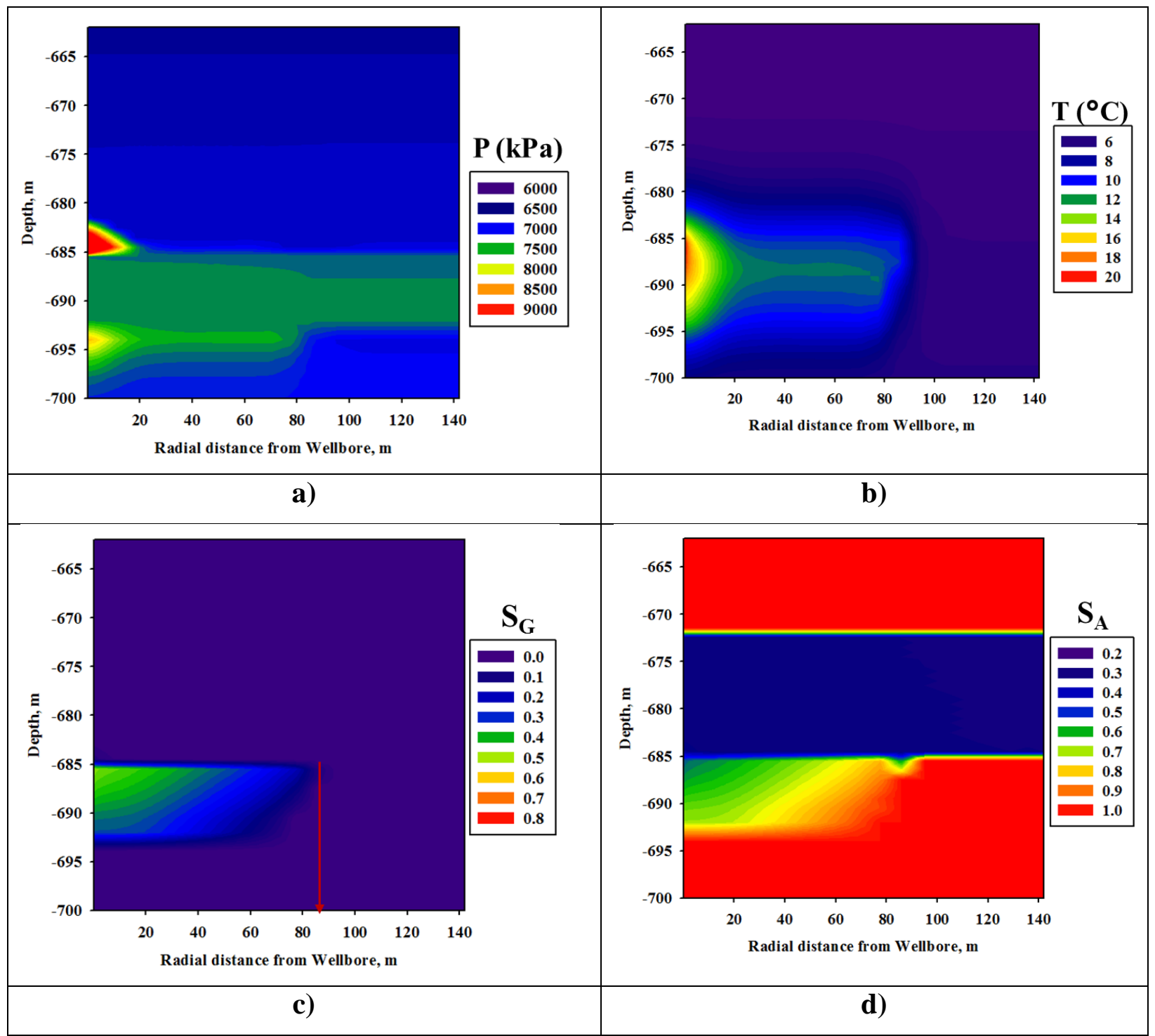

Figure 4-4 Contour plots showing (a) pressure distribution ( $\mathrm{kPa})$, (b) temperature distribution $\left({ }^{\circ} \mathrm{C}\right),(\mathrm{c})$ gas saturation, and (the arrow indicates the distance at which hydrate formation evolves) d) water saturation after 170 days of injection. 


\section{Case Scenario \# 2: Injection of $\mathrm{CO}_{2}$ using constant pressure set at $9.5 \mathrm{MPa}$}

The well is modeled as a fixed boundary condition with a gas phase at pressure and temperature of $9.5 \mathrm{MPa}$ and $20^{\circ} \mathrm{C}$ respectively. The injection pressure is higher than the previous case scenario (Case scenario \# 1) but the temperature value is assigned to be the same. The increased injection pressure expedited the plume migration in the aquifer compared to the previous case i.e., the plume reached the first $85 \mathrm{~m}$ of the water saturated sand zone in 110 days since the injection commencement, unlike the previous case for which the Stage I lasted for 165 days (and the extent of plume propagation is recorded to be same as the current one). The distributions of the pressure, temperature, $\mathrm{CO}_{2}$ gas and water saturation at the end of 110 days of injection (refer to Figure 4-5) exhibits a similar trend as that of the case scenario \# 1. The increase in injection pressure also led to the increased gas saturation in the domain (i.e., $S_{g}=1.0$ ) (Figure 4-5 (c)) around the wellbore, which is significantly higher than the Case scenario \# 1 (in which the gas saturation around the well is around 0.5). From the gas saturation profiles, it can be concluded that increased injection pressure tend to push the water away from the wellbore, thus escalating the saturation of gas around wellbore to be 1.0. As observed in the previous case scenario, Figure 4-5 (b) also shows that there is an increase in the temperature of the reservoir which complies with the $\mathrm{CO}_{2}$ plume advancement. From these observations it can be concluded that increasing the injection pressure by 2 MPa pace up the penetration of $\mathrm{CO}_{2}$ plume in the aquifer but it holds no significant effect on extent of $\mathrm{CO}_{2}$ plume migration. Hence, another case scenario (the following one, case scenario \# 3) investigates a much higher injection pressure (11.5 MPa) to study its effect on extension of plume propagation in the water saturated sands. 


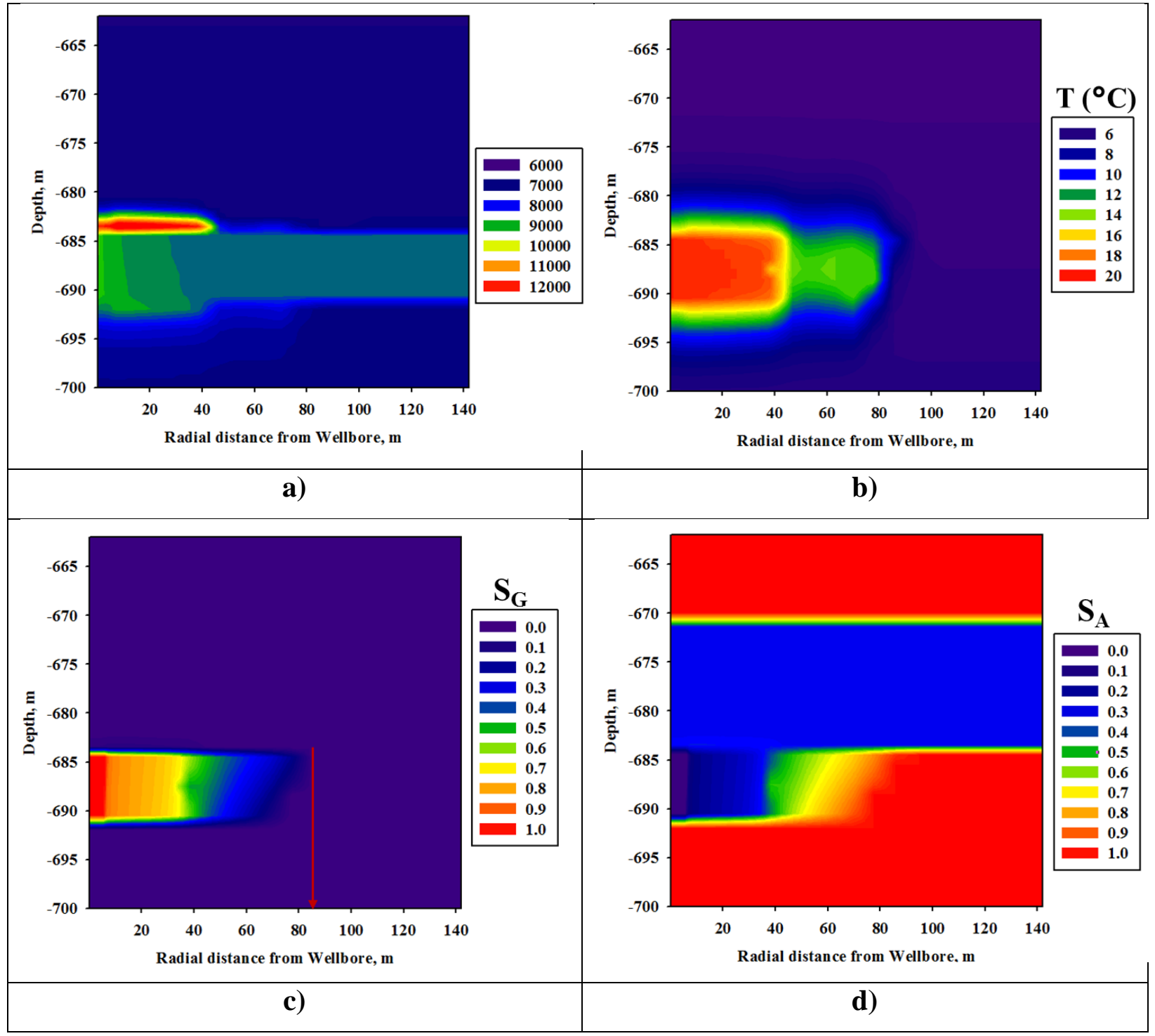

Figure 4-5. Contour plots showing (a) pressure distribution ( $\mathrm{kPa})$, (b) temperature distribution $\left({ }^{\circ} \mathrm{C}\right),(\mathrm{c})$ gas saturation, and (the arrow indicates the distance at which hydrate formation evolves) d) water saturation after 110 days of injection 


\section{Case Scenario \# 3: Injection of $\mathrm{CO}_{2}$ using constant pressure set at $11.5 \mathrm{MPa}$}

The injection pressure (11.5 MPa) employed in this case scenario is much above the FPP of the in-situ hydrate formation settings of the North Alaska Slope, but this injection pressure value is considered to study the effect of increased injection pressure value. Clearly, imposing such a high injection pressure doubled the amount of $\mathrm{CO}_{2}$ fluid injected into the reservoir settings compared to the previous cases, since the contours depict much extended penetration of $\mathrm{CO}_{2}$ in the reservoir. The distributions of the pressure, temperature, $\mathrm{CO}_{2}$ gas and water saturation at the end of 240 days of injection (refer to Figure 4-6) show a similar trend as that of the case scenario \# 1. The increased injection rate led to an enhanced penetration of the injected fluid plume as shown in Figure 4-6. The increased gas injection pressure resulted in increasing the gas saturation in the domain to 0.8 (Figure 4-6 (c)) around the wellbore, which is notably higher than the Case scenario \# 1 (in which the gas saturation around the well is around 0.5). Similar to the previous two case scenarios, Figure 4-6 (b) also shows that there is a rise in the temperature of the reservoir which is quite consistent to the $\mathrm{CO}_{2}$ plume advancement. It is evident that the gas penetration is till $135 \mathrm{~m}$ of the domain by the end of 240 days of injection. Hence, it can be established that, as the injection pressure is increased, it increases the extent of gas plume advancement in the aquifer. Consequently, it helps in the release of vast of amounts of energy which is owed to the exothermic nature of $\mathrm{CO}_{2}$ dissolution in water. The extended penetration of $\mathrm{CO}_{2}$ plume offers greater sequestration of $\mathrm{CO}_{2}$ and also it beholds an additional benefit of larger warmer region exposure to the $\mathrm{CH}_{4} \mathrm{Hydrate}$ formations, which assists in pronounced dissociation of $\mathrm{CH}_{4}$ hydrates in the Stage III. Besides its various advantages, this case scenario (the Case scenario \# 3) cannot be considered in the upcoming Stages (II and III) due to its significant pressure buildup around the wellbore which can initiate the fractures in the reservoir rocks and thus affecting the geological stability of the formation settings. 
All these three cases concluded that injection using constant pressure boundary lowers the injection rate (injection rate goes to zero) eventually after certain period which significantly affects the extent of $\mathrm{CO}_{2}$ plume migration in the aquifer. The major drawback employing this mode of injection is that the unavailability of the injected fluid after certain period of time insists on using high temperature injection fluid for extended plume propagation which serves as a major setback during the Stage 2. This issue of injection rate lowering can be overcome by using another mode of injection which is injection using constant flow rate. This mode of injection is investigated in detail in the next section. 


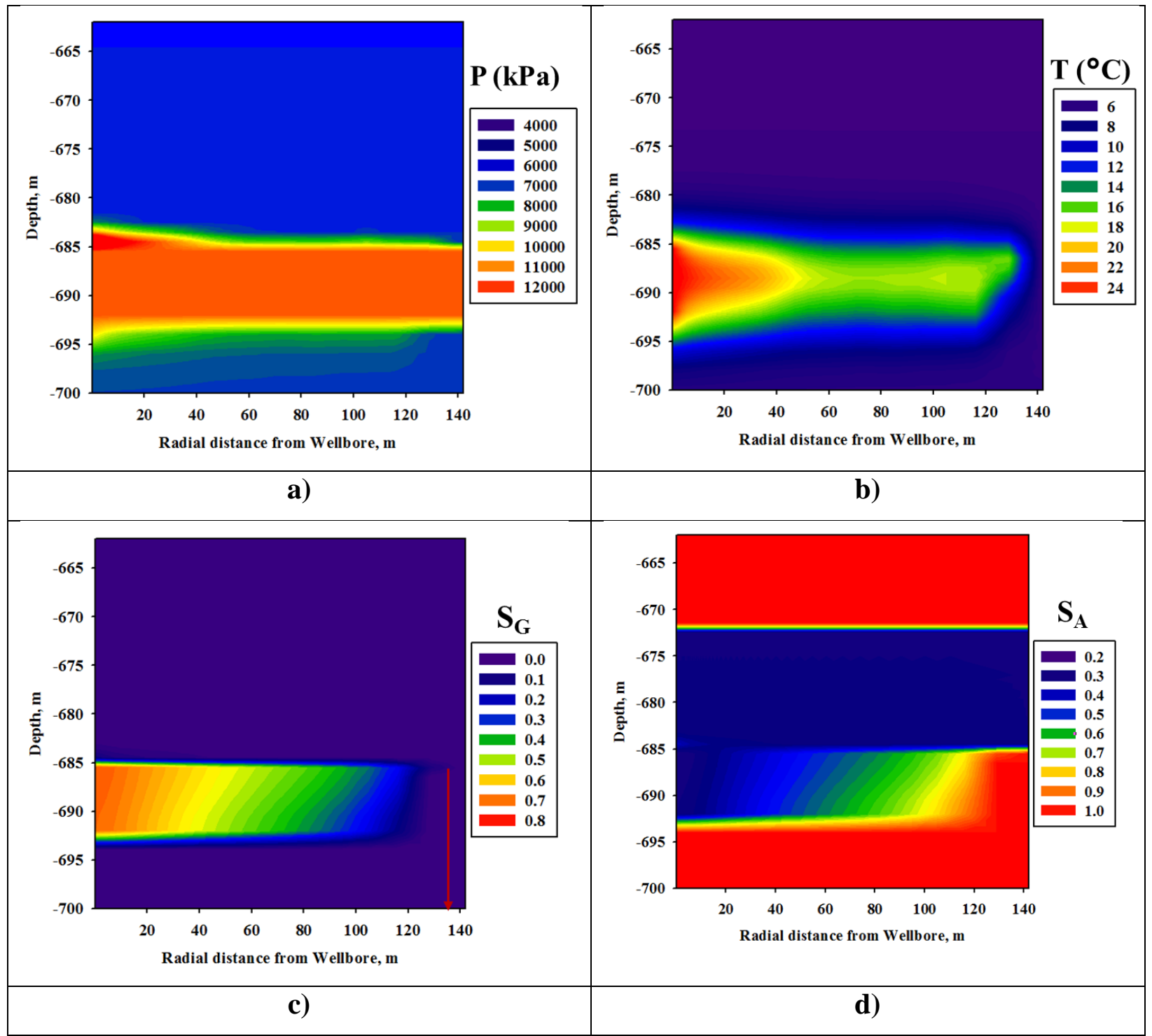

Figure 4-6. Contour plots showing (a) pressure distribution (kPa), (b) temperature distribution $\left({ }^{\circ} \mathrm{C}\right),(\mathrm{c})$ gas saturation, and (the arrow indicates the distance at which hydrate formation evolves) d) water saturation after 240 days of injection 


\section{Injection using constant flow rate}

\section{Case Scenario \# 4: Injection of $\mathrm{CO}_{2}$ using constant flow rate - 162 metric ton/day}

Pure $\mathrm{CO}_{2}$ is injected at a constant flow rate of 162 metric ton/day ( $82 \times 10^{3} \mathrm{ST} \mathrm{m}^{3} /$ day $)$ and with the specific enthalpy of $-252.5 \mathrm{~kJ} / \mathrm{kg}$ (approx. $13^{\circ} \mathrm{C}$ ). The advantage this mode of injection beholds is that as the constant rate condition is imposed on the inflow, it ensures the continuous flow of $\mathrm{CO}_{2}$ into the reservoir. This allows to select lower temperature ranges (closer to the $10.5^{\circ} \mathrm{C}$ ) of the injected $\mathrm{CO}_{2}$ which assists in expediting the cooling process of the reservoir during the Stage II, thus assisting in early emergence of $\mathrm{CO}_{2}$ hydrates. This is the reason for considering the lowest possible temperature of the injected fluid which is $13^{\circ} \mathrm{C}$ (closer to the $10.5^{\circ} \mathrm{C}$ ). Figure $4-7$ shows the pressure build up around the wellbore during the Stage I. Hence, in our simulations, the injection flow rate is selected such that the pressure build up around the wellbore remains lower than fracture initiation pressure of the in-situ hydrate formation settings $\left(9.86 \mathrm{MPa}^{[34]}\right)$.

The temperature of the injected $\mathrm{CO}_{2}$ must be greater than $10.5^{\circ} \mathrm{C}^{[60]}$ to ensure that no $\mathrm{CO}_{2}$-hydrate forms around the wellbore during injection (Stage I) which might lower the gas permeability in the reservoir and thus avoids the plugging of $\mathrm{CO}_{2}$ plume propagation pathways in the underlying aquifer. During the 145 days of injection period, 23,490 metric tons of $\mathrm{CO}_{2}$ is injected. 


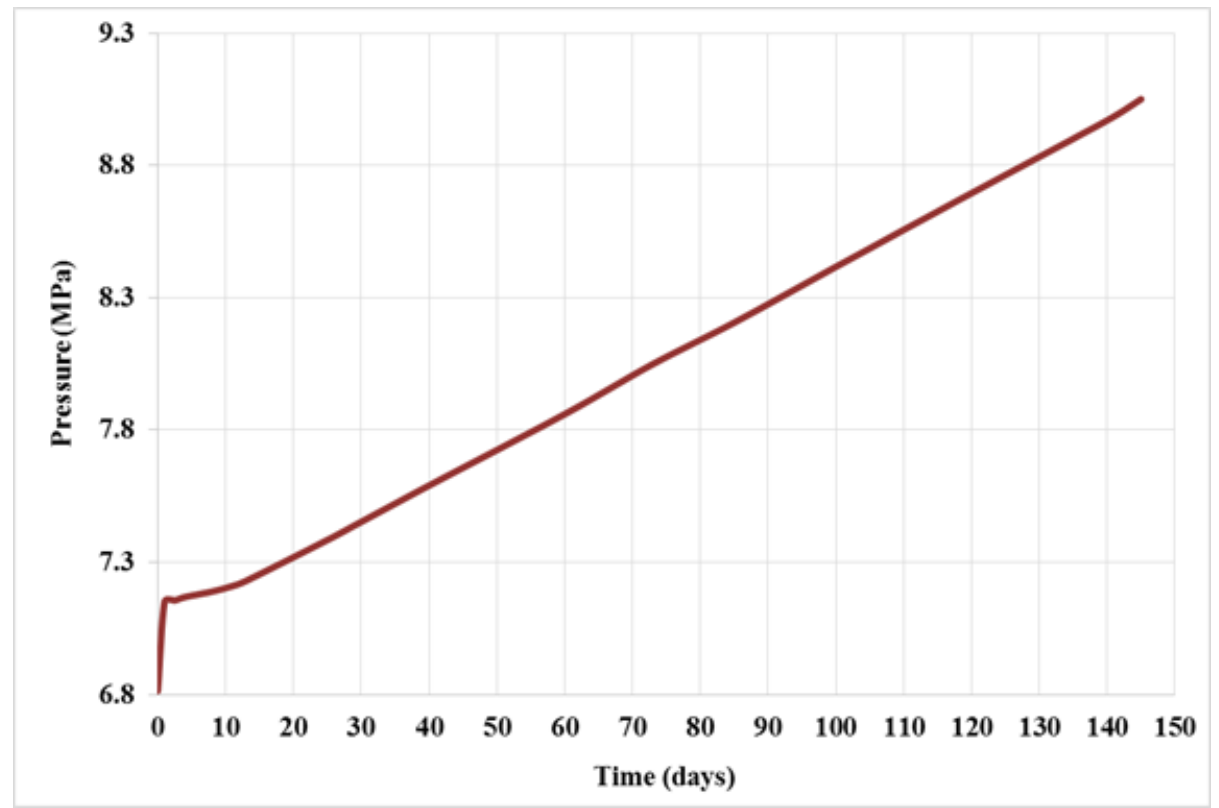

Figure 4-7. Pressure profile in the element column next to the well-bore during Stage I.

The distribution of the reservoir parameters (pressure, temperature, $\mathrm{CO}_{2}$ gas and water saturation) at the end of 165 days (after this time period, $\mathrm{CO}_{2}$ hydrate formation is observed at the advancing front of plume propagation) of injection is displayed in the Figure 4-8. Similar observations as that of the previous case scenarios can be noticed in this case as well. The flow rate 162 metric ton/day corresponds to the injection pressure of 7.5 MPa, hence the extent of the penetration of $\mathrm{CO}_{2}$ and the respective temperature and pressure increase in the domain is similar to the Case Scenario \# 1. The onset of $\mathrm{CO}_{2}$-hydrate formation observed after 165 days at a radial distance of $85 \mathrm{~m}$ indicates the end of Stage I and the injection well is then shut off. By this time, the pressure buildup around the wellbore is around $9 \mathrm{MPa}$ (shown in Figure 4-7), hence any further injection might end up exceeding the fracture initiation pressure. Moreover, hydrate formation prevents further flow of the fluid to the rear end of the reservoir as it starts to lower down the permeability of aquifer. 


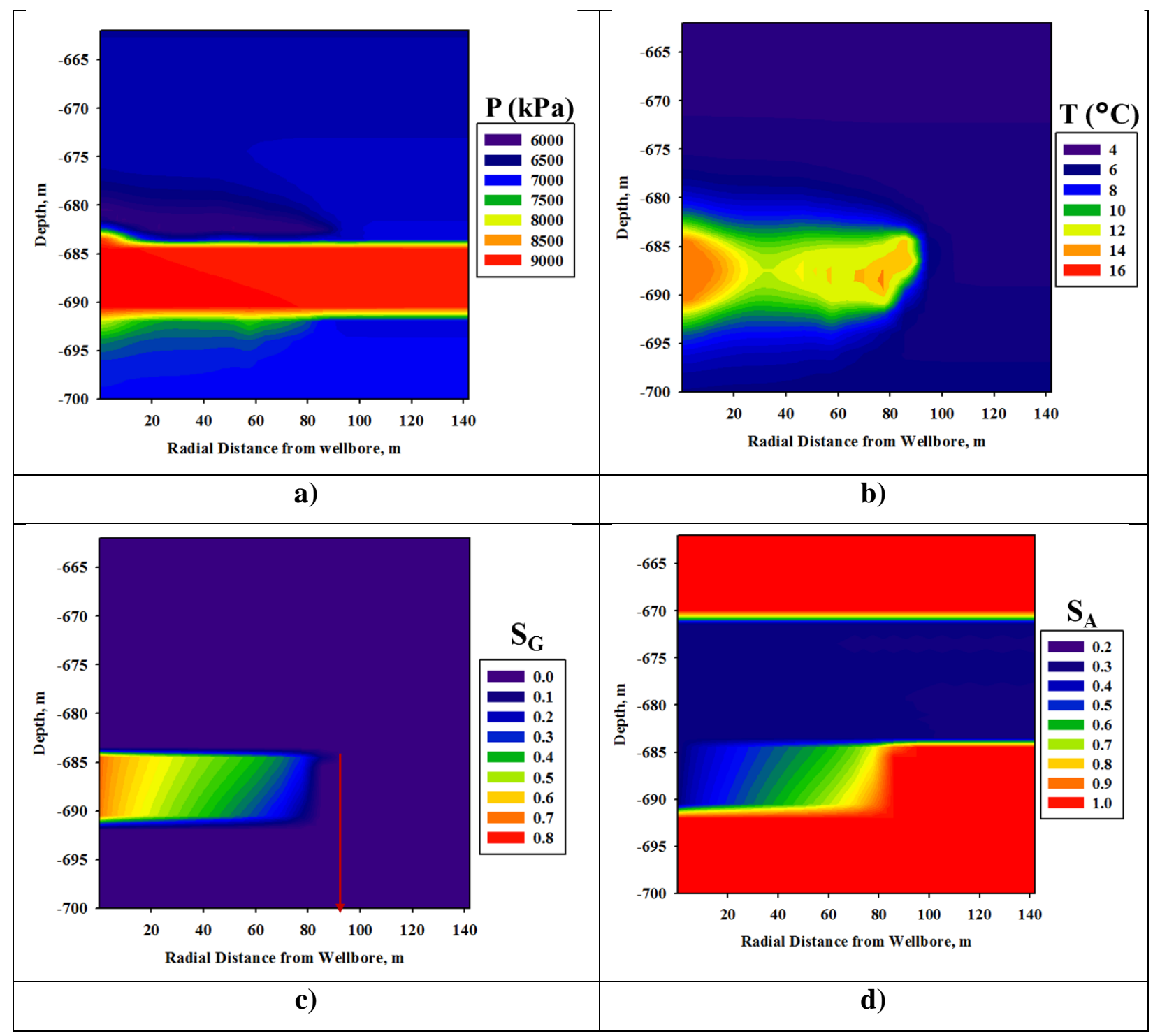

Figure 4-8. Contour plots showing (a) pressure distribution ( $\mathrm{kPa})$, (b) temperature distribution $\left({ }^{\circ} \mathrm{C}\right),(\mathrm{c})$ gas saturation, and (the arrow indicates the distance at which hydrate formation evolves) d) water saturation after 145 days of injection.

The Case scenario \# 4 is considered to be the best case which results in the most desirable reservoir conditions by the completion of Stage I. The desirable results noticed from this case are 1) the maximum pressure buildup in this case is still less than the FPP, hence reservoir integrity is maintained, 2) the temperature rise in the reservoir is the least compared to rest of the case scenarios, and finally 3) the gaseous plume extension in the water saturated sands is almost same 
as the first two case scenarios. Hence, the results obtained from this case (Case scenario \# 4) serves as initial conditions for the next stages. The Stage II is explained in detail in the following section. 


\subsubsection{Equilibration stage (Stage II)}

This stage is intended to lower down the temperature of the Zone 2 in order to enable the $\mathrm{CO}_{2}$ hydrate formation. The injection of $\mathrm{CO}_{2}$ is shut-down during the equilibration period and as the top and bottom-most boundaries are maintained at constant temperature conditions, the temperature of the water-saturated sand zone decreases eventually to conserve the energy of the system. The over-burden and under-burden shale acts as heat sink, thus promoting the heat transfer efficiently from water-saturated sand zone.

Figure 4-9 shows the conditions of the reservoir at the end of 2.5 years of equilibration. From the contours of hydrate saturation (Figure 4-9(d)), it is observed that $\mathrm{CO}_{2}$-hydrates start forming at the top and bottom boundaries of the Zone 2. The temperature contours (Figure 4-9(b)) show that the temperature of this region is decreased to hydrate equilibrium temperature, thus promoting hydrate formation. These observations are interrelated and can be comprehended from the fact that these regions being closer to the heat sinks (in fact, the bottom boundary of the Zone 2 is in direct contact with the under-burden shale formations), promotes an efficient heat transfer, which expedites the process of temperature reduction in these regions, eventually enabling the $\mathrm{CO}_{2}$-hydrate formation. The gas saturation distribution (refer to Figure 4-9(c)) indicates that its value decreased owing to the reason that $\mathrm{CO}_{2}$ is moving from gaseous phase to hydrate phase.

The following Figure 4-10 shows the conditions of the reservoir at the end of 3.5 years of equilibration. We can observe from the contours of $\mathrm{CO}_{2}$ hydrate saturation (refer to Figure 4-10 (d)) that the saturation of the $\mathrm{CO}_{2}$ hydrate phase has increased in the domain owing to the temperature drop (Figure 4-10 (b)) attained in the domain. Further decrease in the $\mathrm{CO}_{2}$ gas saturation in the reservoir (refer to Figure 4-10 (c)) explains the occurrence of phase transition from gas phase to hydrate phase as the $P / T$ conditions fall into the $\mathrm{CO}_{2}$ hydrate equilibrium 
conditions. Pressure profile indicates a noticeable increase in the pressure at the top and bottom boundaries of the Zone 2, where the $\mathrm{CO}_{2}$ hydrate formation is prominent, the pressure increment is owed to increased hydrate saturation in these regions. As the duration of equilibration increases, the temperature of the Zone 2 further goes down which results in substantial rise of hydrate saturation to a value as high as 0.9 as displayed in Figure 4-11, which shows the conditions of the reservoir at the end of 8 years of equilibration.

From the temperature contours displayed in the Figure 4-11 (b), it is evident that as the equilibration stage prolongs, the heat released from the Zone 2 (due to hydrate formation) sinks into the surroundings of the Zone 2 resulting in the temperature increase of the $\mathrm{CH}_{4}$-hydrate region. The lowering of the temperature value led to significant hydrate formation (Figure 4-11 $(d)$ ), which led to the increase of the pressure in the same region where $\mathrm{CO}_{2}$ hydrate saturation is as high as 0.9 .

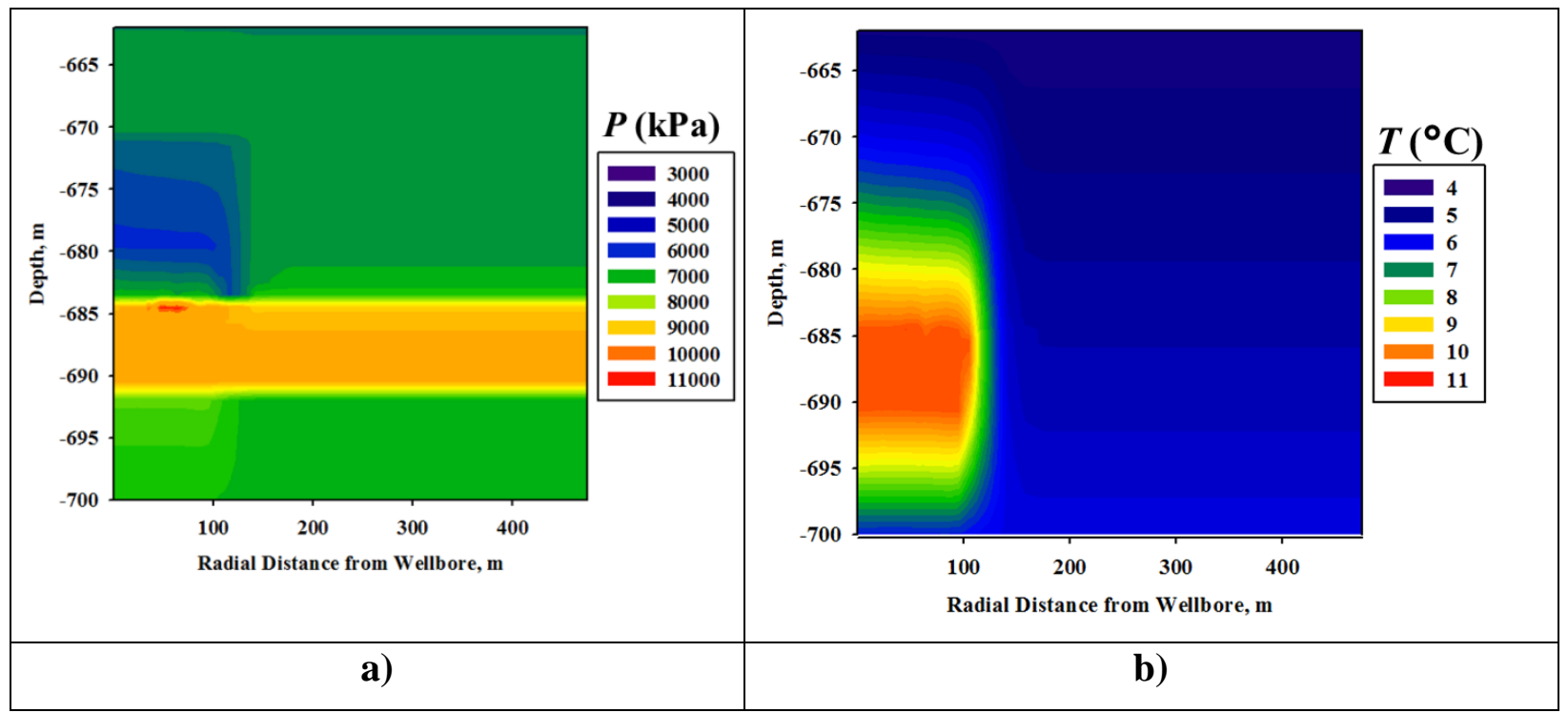




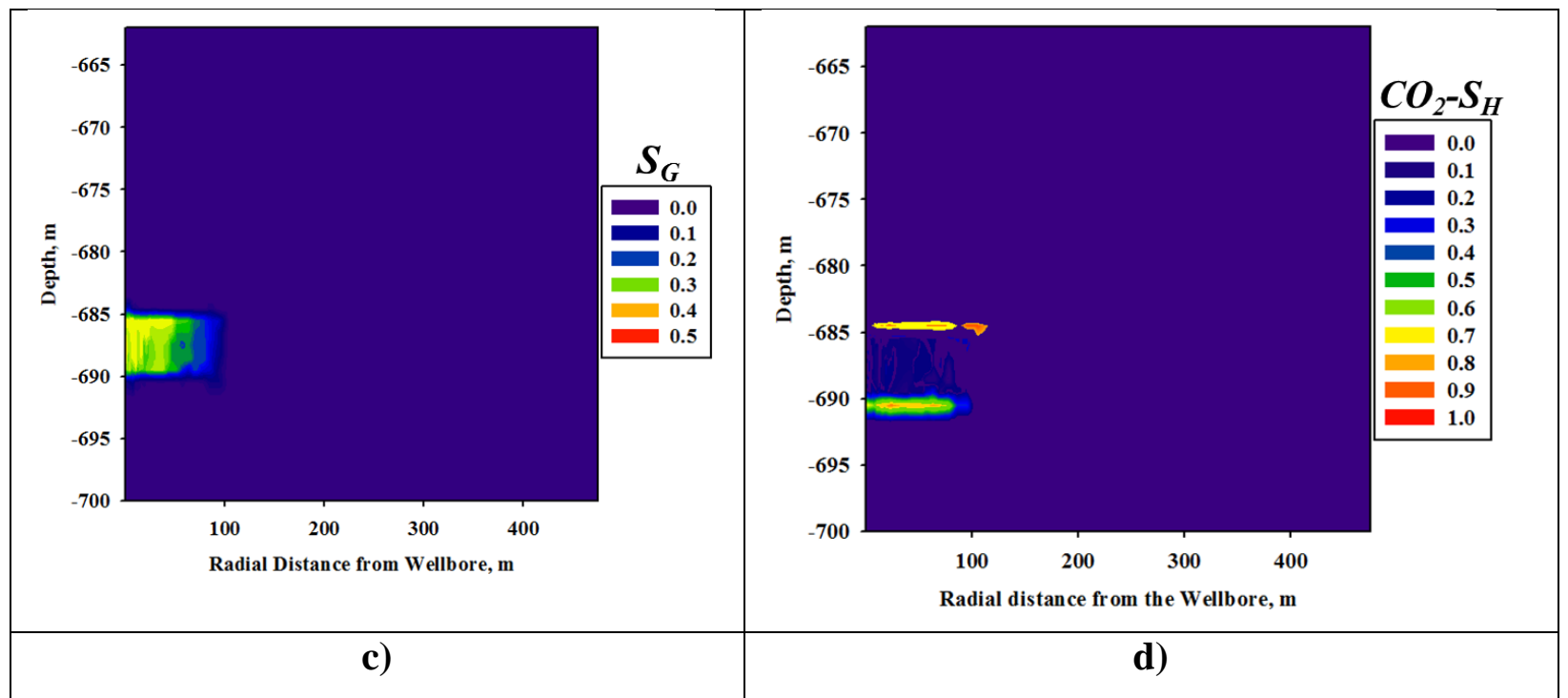

Figure 4-9. Contour plots showing a) pressure distribution $(\mathrm{kPa}), \mathrm{b})$ temperature distribution $\left({ }^{\circ} \mathrm{C}\right)$, c) $\mathrm{CO}_{2}$ gas saturation distribution d) $\mathrm{CO}_{2}$ hydrate saturation distribution after 2.5 years since the commencement of Stage II.

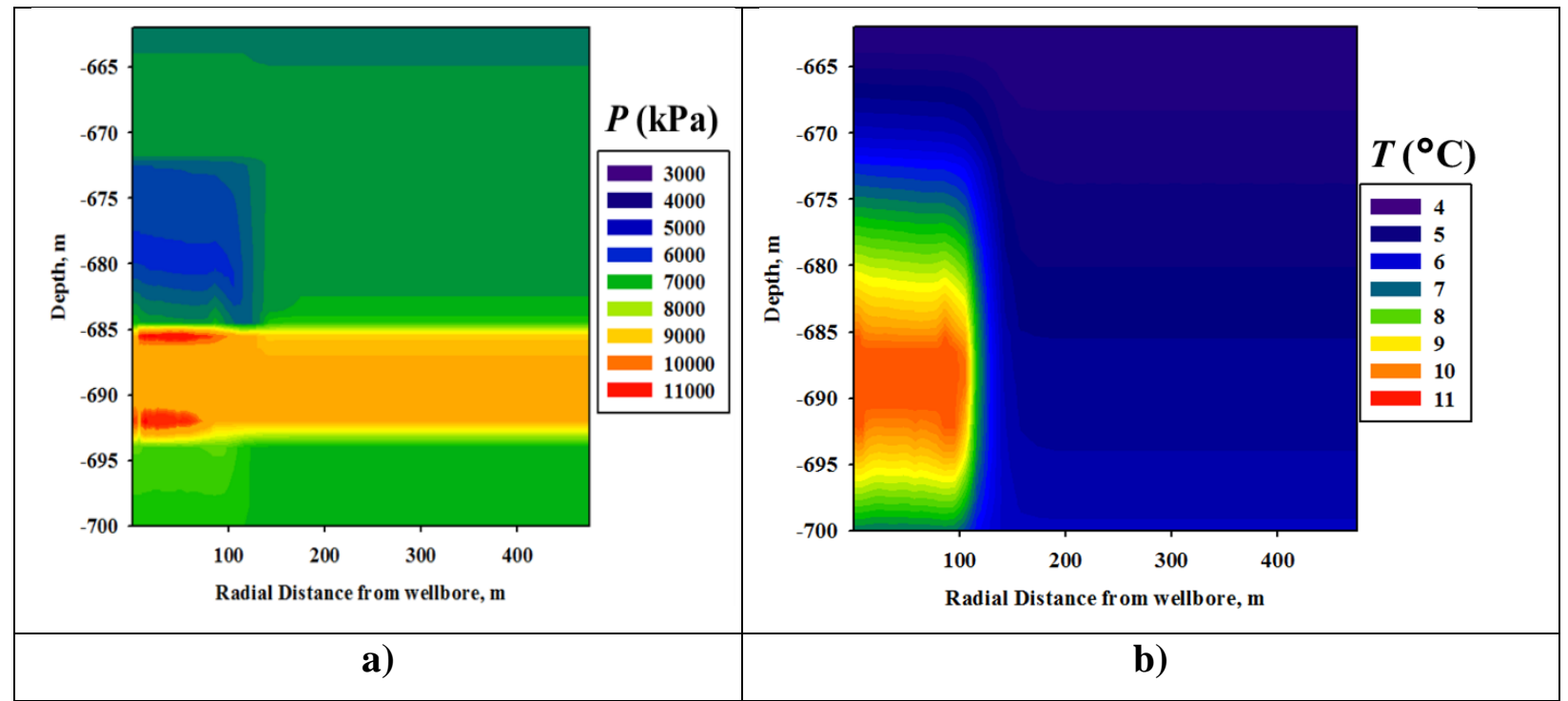




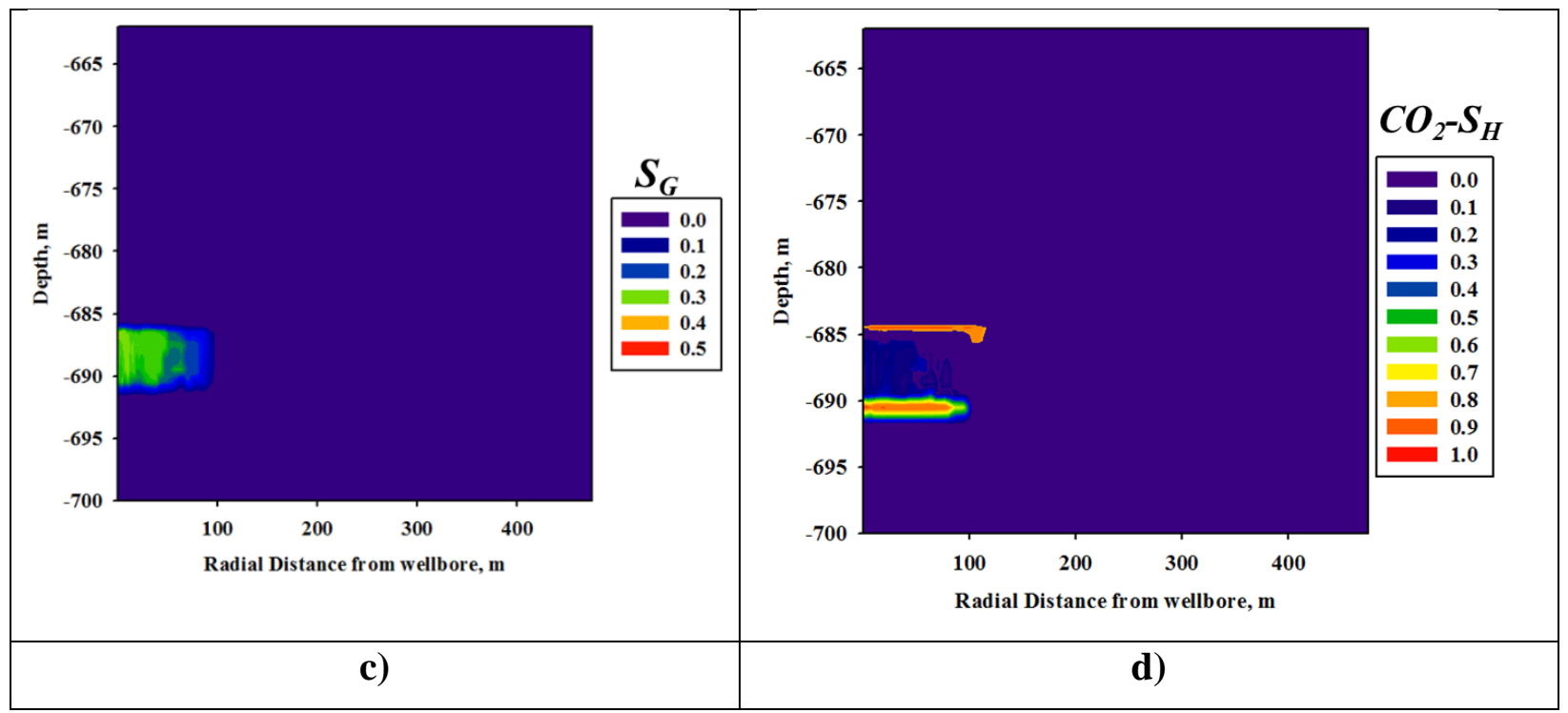

Figure 4-10. Contour plots showing a) pressure distribution $(\mathrm{kPa}), \mathrm{b})$ temperature distribution $\left({ }^{\circ} \mathrm{C}\right)$, c) $\mathrm{CO}_{2}$ gas saturation distribution d) $\mathrm{CO}_{2}$ hydrate saturation distribution after 3.5 years since the commencement of Stage II.

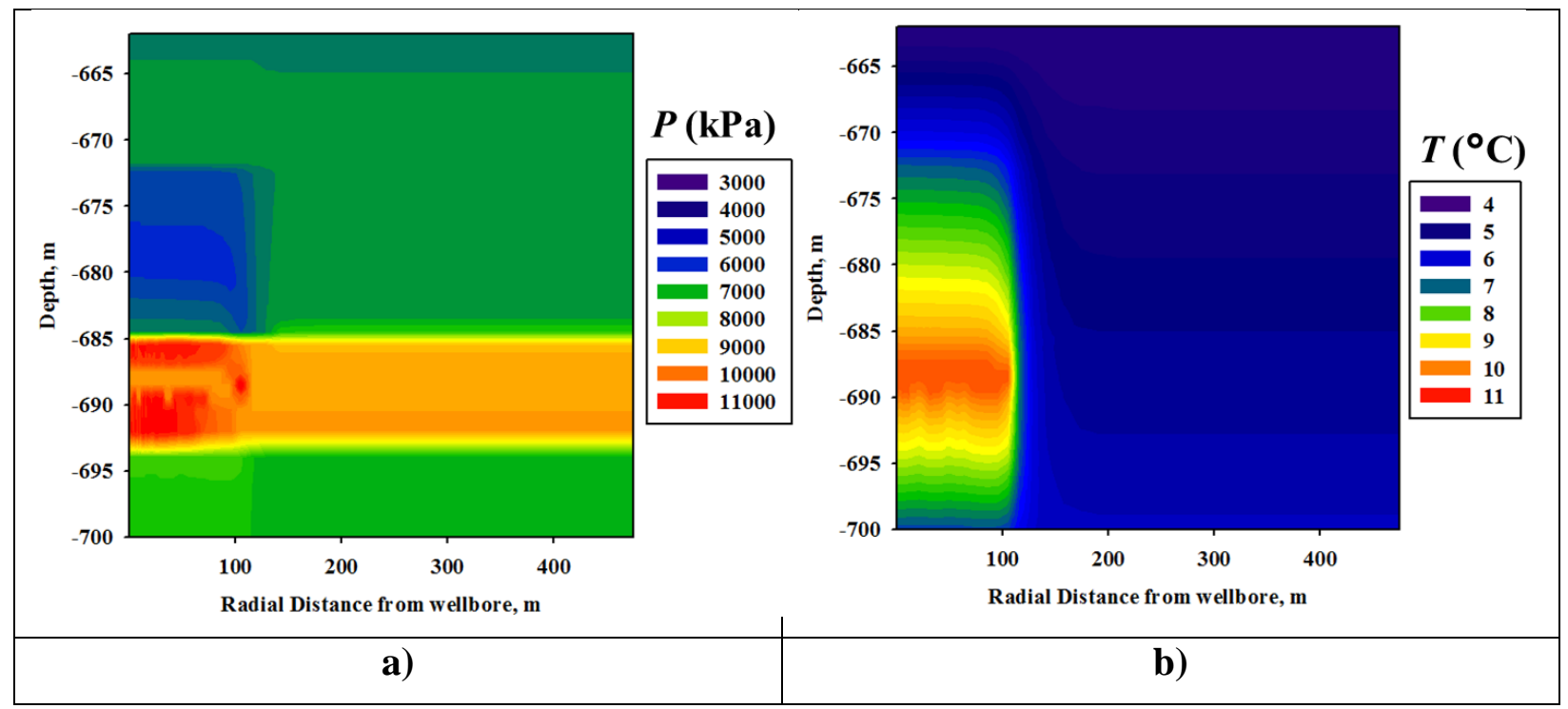




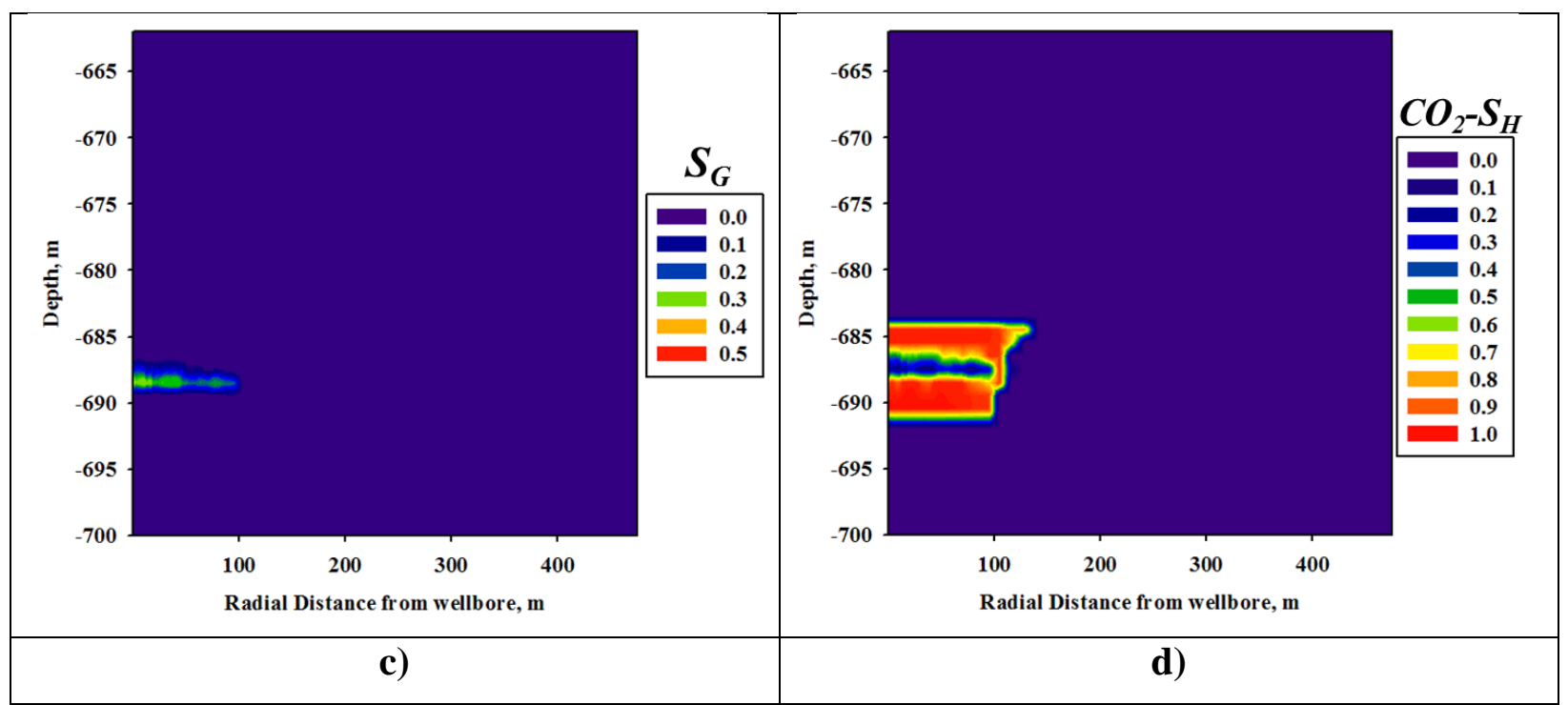

Figure 4-11. Contour plots showing a) pressure distribution $(\mathrm{kPa}), \mathrm{b})$ temperature distribution $\left({ }^{\circ} \mathrm{C}\right)$, c) $\mathrm{CO}_{2}$ gas saturation distribution d) $\mathrm{CO}_{2}$ hydrate saturation distribution after 8 years since the commencement of Stage II.

Before the commencement of Stage III, it's of paramount requirement to ensure adequate formation of an impermeable $\mathrm{CO}_{2}$-hydrate in the reservoir during Stage II. The hydrate formation serves three main purposes. 1)The $\mathrm{CO}_{2}$ dissolved in water (during Stage I) must be converted to hydrate as it is an optimum way to sequestrate the injected $\mathrm{CO}_{2}$ gas, which offsets the risk of its production along with methane gas during Stage III. 2) It also allows in achieving one of the most important goals of this project, which is, lowering of the water production at the onset of depressurization of Zone 1 by drastically reducing the effective permeability of the aquifer. The increase of hydrate saturation in the aquifer (i.e., Zone 2) significantly reduces the effective permeability of water saturated sand zone and assists in lowering the extra water production at the wellbore. One of the major drawbacks of gas recovery from Class 2 accumulations is production of enormous amounts of water especially in the beginning of depressurization which affects the initial gas production rates. Hence, lowering the hydraulic communication between methane hydrate-bearing sand and the underlying aquifer is essential to maintain effective depressurization and steady gas productivity. 
Figure 4-12 displays the effective permeability curve for aqueous phase calculated using the relative permeability function (Brooks-Corey correlation) and irreducible water saturation given in Table 1 and assuming $1000 \mathrm{md}$ of intrinsic permeability of the water-saturated sand formation. The initial hydrate saturation values of the cases corresponding to the $2.5,3.5$ and 8 year time period of the equilibration stage prolongation indicates the initial respective hydrate saturation values as $0.7,0.8$ and 0.9. From the Figure 4.12 it can be noticed that if the initial aqueous saturation is equal to about $0.3,0.2$, and 0.1 (that corresponds to $0.7,0.8$, and 0.9 of initial hydrate saturation, respectively) the effective permeability of the aquifer would be reduced to 10,1 , and $0.001 \mathrm{md}$, respectively, i.e. $10^{2}, 10^{3}$, and $10^{6}$ times smaller the intrinsic permeability. This drastic lowering of the effective permeability lead an efficient pathway in relieving the burden of extra water production from the Class 2 accumulations.

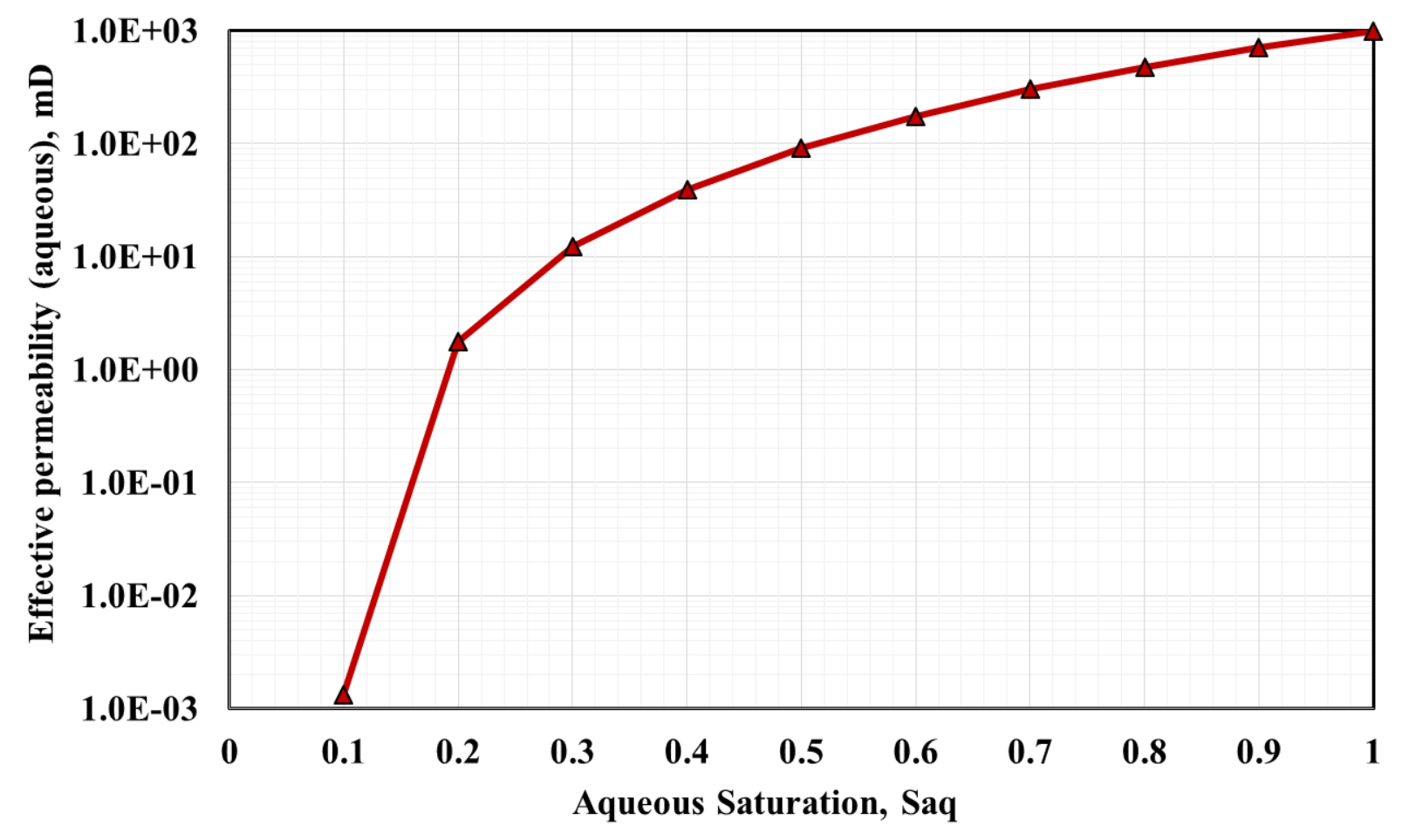

Figure 4-12. Effective permeability (aqueous) curve using power $n$ and $S_{\text {irra }}$ in the Brooks-Corey relative permeability function (Table 4-1). 
3) The heat released from the $\mathrm{CO}_{2}$ hydrate formation reaction (enthalpy of $\mathrm{CO}_{2}$ hydrate formation is from -57.7 to $-63.6 \mathrm{~kJ} / \mathrm{mol}^{[52]}$ ) in the hydrate lattice at the boundary between the methane hydrate-bearing sand and the aquifer can be utilized as an effective asset during the depressurization of the Zone 1 (Stage III), which proliferates the dissociation of $\mathrm{CH}_{4}$-hydrates during Stage III.

The duration of Stage II holds a significant impact on the gas production volumes in the following stage (Stage III). Prolonged Stage II isn't an attractive option even though it results in the highly saturated $\mathrm{CO}_{2}$-hydrate formation in the region where the incipient hydrate formation is seen (Figure 4-13(d)). There are two reasons justifying this fact; 1) the exothermic heat released from the $\mathrm{CO}_{2}$-hydrate formation assists in nurturing the $\mathrm{CH}_{4}$-hydrate dissociation reactions which begins in the following stage. Hence, prolonged Stage II results in most of the heat flux released due to hydrate formation sink into the surrounding formations, thus depriving the heat availability to fuel the hydrate decomposition reaction during the Stage III. 2) Extended Stage II eventually results in formation of $\mathrm{CO}_{2}$-hydrates of saturations going as high as 0.90 , thus significantly reducing the effective permeability of the aquifer.

Hence, to study the impact of duration of the Stage II, three different cases are considered which vary in $\mathrm{CO}_{2}$-hydrate saturation distribution in the Zone 2 (refer to Table 4-5). The three cases considered have a duration of 2.5, 3.5 and 8 years of the Stage II (Cases 1-3 respectively). A base case (Case 4) which is similar to the conventional Class 2 gas hydrate accumulations in which the first two stages are not performed is considered to compare results with Cases 1-3. Besides varied $\mathrm{CO}_{2}$-hydration in the reservoir, each of these cases (Cases 1-3) vary in their initial conditions of the reservoir before the commencement of Stage III due to varied durations of equilibration periods. 
Table 4-5. The duration of stages for the Cases considered. The $\mathrm{CO}_{2}$ hydrate saturation numbers are the saturation at the boundary around $\mathrm{CO}_{2}$ plume in the aquifer after Stage II.

\begin{tabular}{|l|l|l|l|}
\hline $\begin{array}{l}\text { Case number / CO2 } \\
\text { hydrate saturation }\end{array}$ & Stage I Stage II & Stage III \\
\hline & \multicolumn{3}{|c|}{ Time, years } \\
\hline Case 1 / 0.7 & 0.45 & 2.5 & 15.0 \\
\hline Case 2 / 0.8 & 0.45 & 3.5 & 15.0 \\
\hline Case 3 / 0.9 & 0.45 & 8.0 & 15.0 \\
\hline Case 4 0.0 & - & - & 15.0 \\
\hline
\end{tabular}




\subsubsection{Production stage (Stage III)}

The decomposition of methane hydrate region (Zone 1) is induced by depressurizing the region to a constant Bottom-Hole Pressure (BHP) set at $3.5 \mathrm{MPa}$ and temperature of $5^{\circ} \mathrm{C}$. The $\mathrm{BHP}$ of 3.5 MPa was operated so as to maintain the bottom hole conditions at the thermodynamic conditions correspond to $\mathrm{CH}_{4}$ hydrate instability and $\mathrm{CO}_{2}$ hydrate stability zones (Figure 4-13, sectors displayed as $\mathrm{A}$ and $\mathrm{B}$ ). This ensures that the newly formed $\mathrm{CO}_{2}$-hydrates in the underlying aquifer remain intact during the Stage III as the $\mathrm{CH}_{4}$-hydrate lattice begin to break down and release $\mathrm{CH}_{4}$-gas and water.

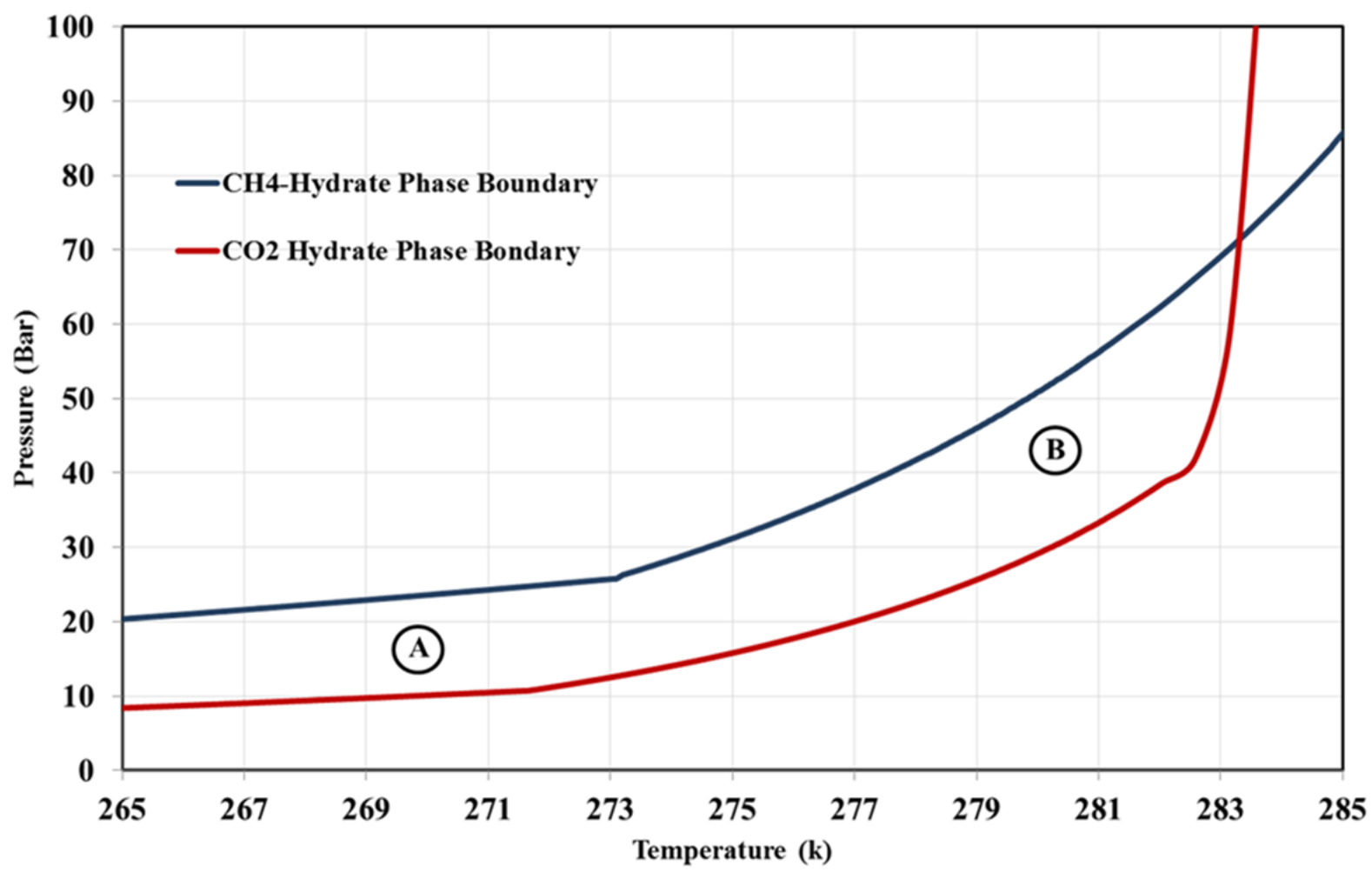

Figure 4-13. Phase equilibrium diagrams for $\mathrm{CO}_{2} /$ water and $\mathrm{CH}_{4} /$ water systems, $\mathrm{A}$ and $\mathrm{B}$ designate the regions of $\mathrm{CO}_{2}$ hydrate stability and $\mathrm{CH} 4$ hydrate instability. 
Figure 4-14 displays the cumulative volumes of produced methane and respective production rates for all the cases for 15 years of the production period. It can be deduced from the Figure 4-14 that first three cases (Cases 1-3) depict higher cumulative gas volume by the end of 15 year depressurization period compared to the base case (Case 4). Moreover, the total volume of $\mathrm{CH}_{4}$ produced in the Case 2 is the highest compared to rest of the three cases and its cumulative gas volume is twice that of the base case (Case 4). Hence, it proves the fact that the additional heat flux brought-in to the Zone 1 during Stage I and II and lowering of aquifer permeability assists in increasing the produced cumulative gas volumes substantially.

We observe that production rates of all the three cases (Cases 1-3) follow a similar trend. Amongst Cases 1-3, it is observed from the Figure 4.14 that Case 3 displays higher initial production rates (in the first 1 year of production period) due to its highest initial temperature (shown in Table 5) of the Zone 1 owing to its longest equilibration period (Stage II) resulting in significant heat transfer to the surrounding strata. However, as the production continues, the production rates of Case 3 plummets (compared to Cases 1 and 2) implying the fact that prolonged Stage II eventually deprives the Stage III (of Case 3) from benefits of additional heat flux in-flow released from Zone 2 methane hydrate bearing-sands. The gas production rates (Figure 4-14) for the Cases 1-3 show a steep increase in the first 3 years (approximately around the same time period for all the three cases) and then there is sharp decline of the rate (around 4-6 years), which again picks up and keep increasing. The reason for such a profile in the first 6 years of the depressurization period is due to lowering of the pressure gradient as the hydrate dissociation front move away from the wellbore. Moreover, as the peak gas production rate is reached this effect starts to negate the effect of increased surface area of hydrate resulting in the decline of net hydrate dissociation rate. It is also observed that the gas rates tend to increase after 6-7 years of production for Cases 1-3 as the heat 
flux form the overburden and underburden starts to kick in and assists in further dissociation of the residual hydrates present. The increase in the gas production rate after a steep decline can be interpreted with the help of heat flux profiles across the top and bottom boundaries of the hydrate zone (refer to Figure 4-15 and 4-16).

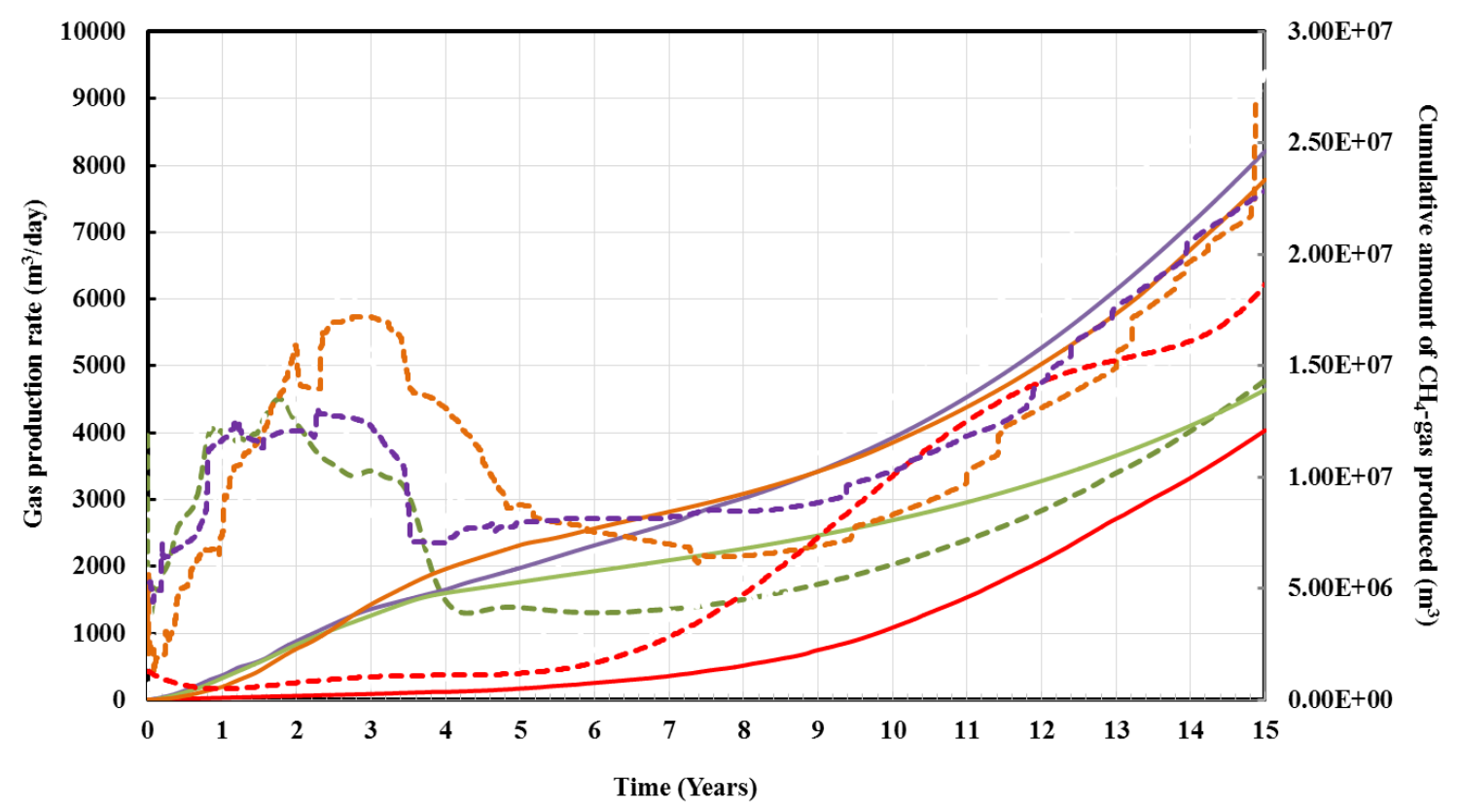

Figure 4-14. Gas production rates (dashed lines) and cumulative volume (solid lines) of gas produced for Cases 1-4. Time zero designates the onset of Stage III. 


\subsection{Discussion}

\subsubsection{Effect of additional heat flux brought-in during Stages I and II to the CH4-hydrate}

\section{formations on gas production}

The Figure 4-15 depicts the heat flux across the top boundary of $\mathrm{CH}_{4}$-hydrate zone (i.e., over burden $-\mathrm{CH}_{4}$ hydrate zone boundary) during Stage III. It shows that after approximately 5 year time period, the flux starts to decrease and eventually goes down to a negative value (implying the reversal of heat transfer direction). Initially, the heat flux value is positive indicating the heat transfer from $\mathrm{CH}_{4}$ hydrate zone to the overburden shale. As the depressurization goes on, the heat flux value decreases due to the endothermic nature of hydrate dissociation, which cools down the $\mathrm{CH}_{4}$ hydrate zone. Eventually, the value reduces below zero, implying the heat transfer direction is reversed (from over-burden shale to $\mathrm{CH}_{4}$-hydrate zone). This heat flow from the over burden shale augments hydrate decomposition, thus increasing the production rate after 6 year time period for the Cases 1-3 (Figure 4-14). 


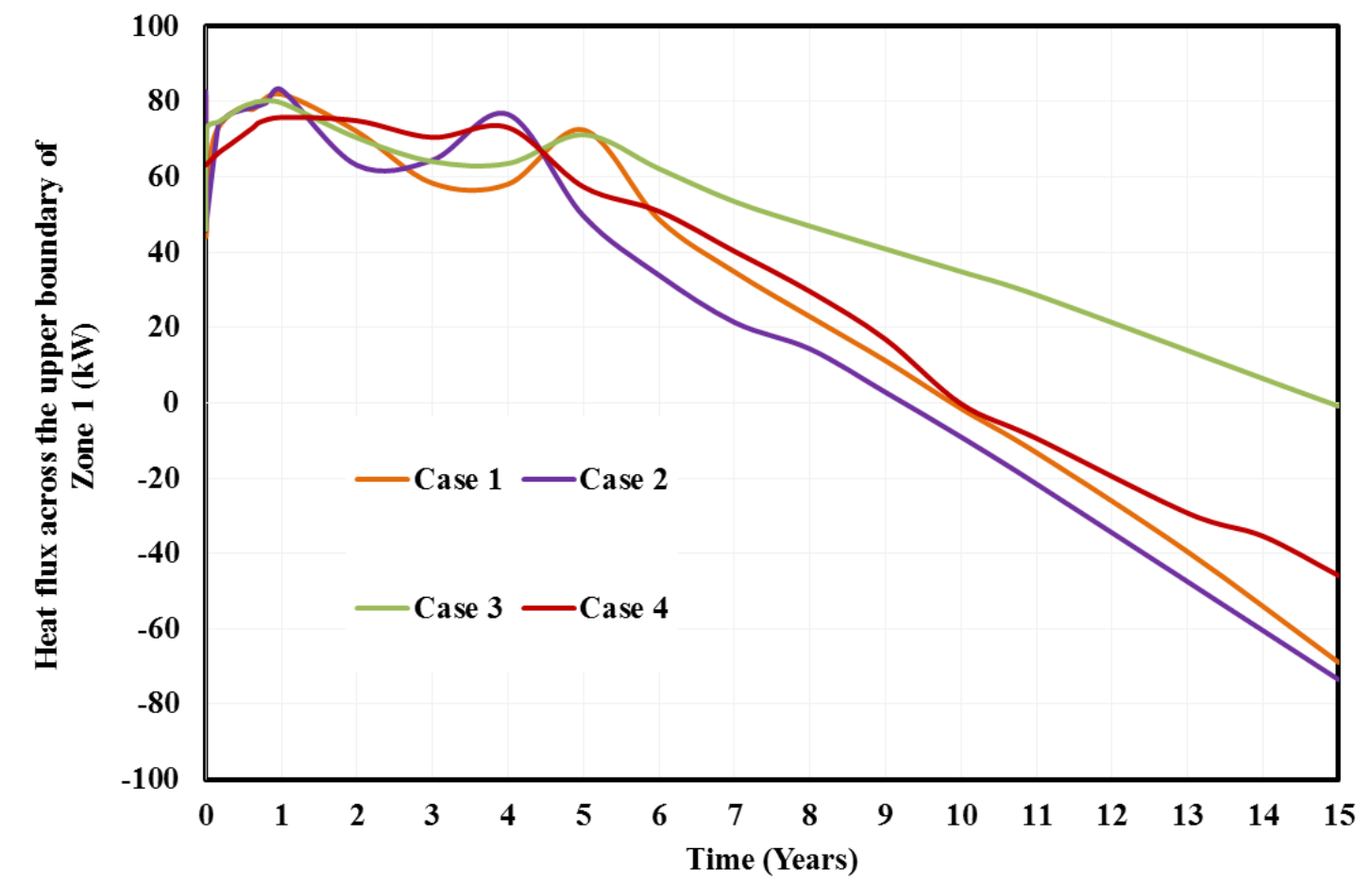

Figure 4-15. Heat flux across the upper boundary of hydrate zone during the Stage III for all the three cases. A positive sign means flow from the methane hydrate-bearing sand to overburden.

One of the primary reasons for the enhanced gas production is the supply of the additional heat flux to the methane-hydrate bearing sediments released from Zone 2 due to many thermodynamic reactions taking place in various stages of the technical approach, the heat flux is attributed to three factors 1) the specific enthalpy of the injected fluid (during Stage I), 2) heat released due to dissolution of $\mathrm{CO}_{2}$ in water (during Stage I) and 3) heat of $\mathrm{CO}_{2}$-hydrate formation (during Stages II and III). The heat flux during all the three stages across the bottom boundary of $\mathrm{CH}_{4}$-hydrate zone (i.e., $\mathrm{CH}_{4}$ hydrate zone boundary- aquifer boundary) is shown in the Figure 4-16. Here, time is set to zero at the beginning of Stage III. The trend of the plot for all the cases is similar which indicates an increase during the Stage I, then declines during the Stage II and eventually there is a sharp rise at the onset of Stage III. During the Stage I, as the gaseous $\mathrm{CO}_{2}$ is injected, heat flux 
increases due to the specific enthalpy of the injected fluid (as fluid is injected at a higher temperature) and heat of dissolution of $\mathrm{CO}_{2}$ in water. During stage II, the wellbore is shutoff for certain period of time (varied for each case, refer Table 4-5) and the reservoir is allowed to cool down to enable the $\mathrm{CO}_{2}$-hydrate formation. As the reservoir is cooling down, it leads to the drop in the heat flux profile during Stage II. The sharp rise in heat flux at the onset of Stage III is due to the heat released from the $\mathrm{CO}_{2}$-hydrate formation reaction.

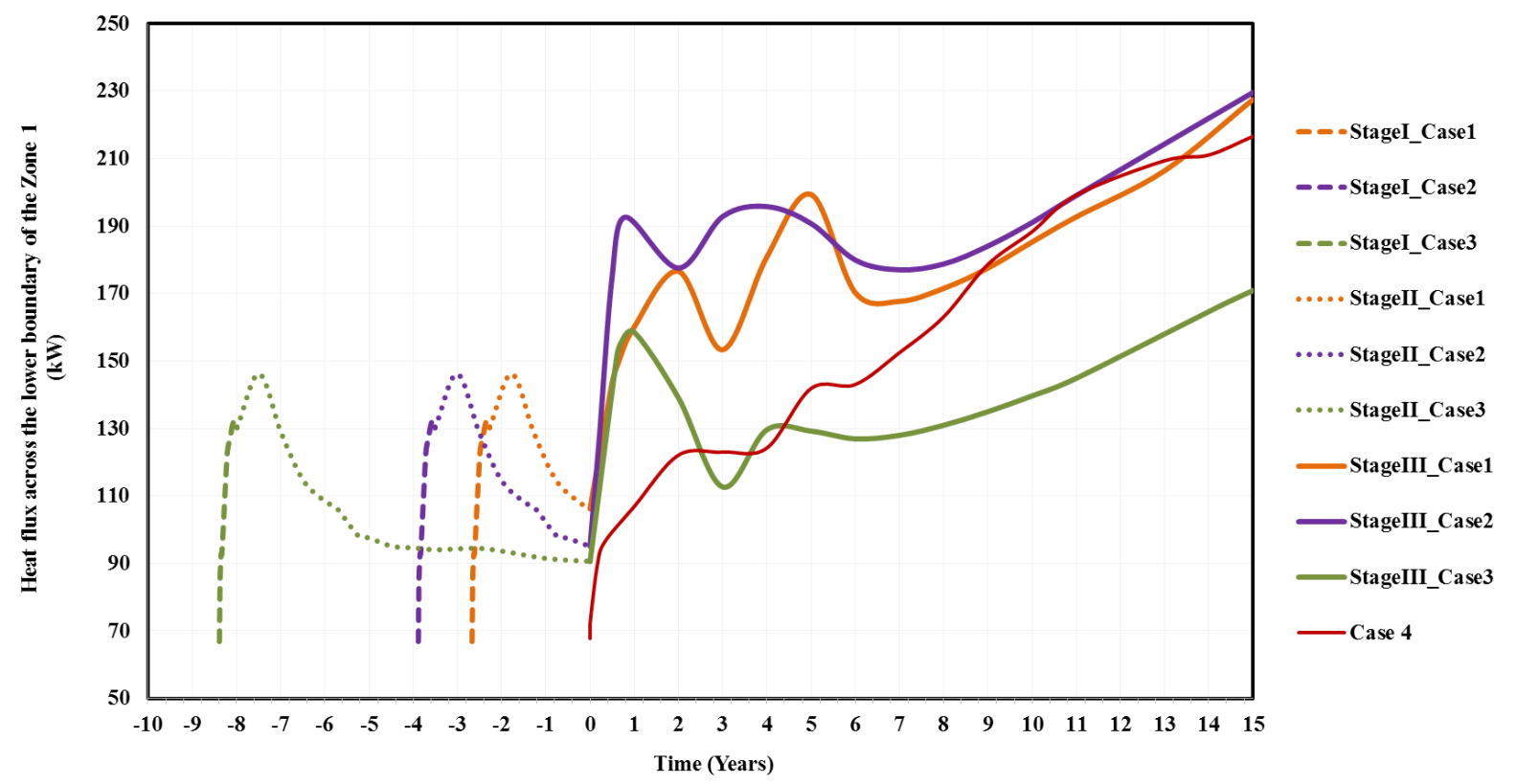

Figure 4-16. Heat flux across the lower boundary of hydrate zone during the Stage I (dashed line), Stage II (dotted line) and Stage III (solid line) for Cases 1-4. A positive sign means flow from the aquifer to methane hydrate-bearing sand.

To comprehend the profile of the heat flux during the Stage III, it's necessary to look into the contributing factors to the total heat flux during this Stage. The contributing factors to the total heat flux across the boundary is attributed to conductive and advective heat transfer mechanisms as displayed in Equation 1 
$F^{h}=\sum_{\beta} h_{\beta} F_{\beta}-K(\nabla T)$

Where

$h_{\beta} \quad$ specific enthalpy of phase $\beta$

$F_{\beta} \quad$ mass flux of phase $\beta$

$\mathrm{K}$ heat conductivity

$\mathrm{T}$ temperature

As the Stage III proceeds on, the increase in $\mathrm{CO}_{2}$-hydrate saturation impacts the effective permeability of the aquifer which significantly impedes the mass flux across the boundary. This eventually lower down the effect of the advective heat flow. This makes the conductive heat transfer the major contributor to the total heat flux across the boundary. As there is a one-to-one correspondence between the temperature gradient and the conductive heat flux ( $q=$ $-K(\nabla T)$, where $q$ is the conductive heat flux), the temperature gradient across the lower boundary of the Zone 2 (temperatures of the bottom sub-layer of the methane hydrate-bearing sand in contact with the top sub-layer of the underlying aquifer) assists in analyzing the trend of conductive heat flux (which eventually led to comprehend the total heat flux profile). Figure 4-17 displays the temperature gradient profiles and its trend is similar to the trend of total heat flux 
(shown in Figure 4-16), thus indicating the effective contribution of conductive heat flux.

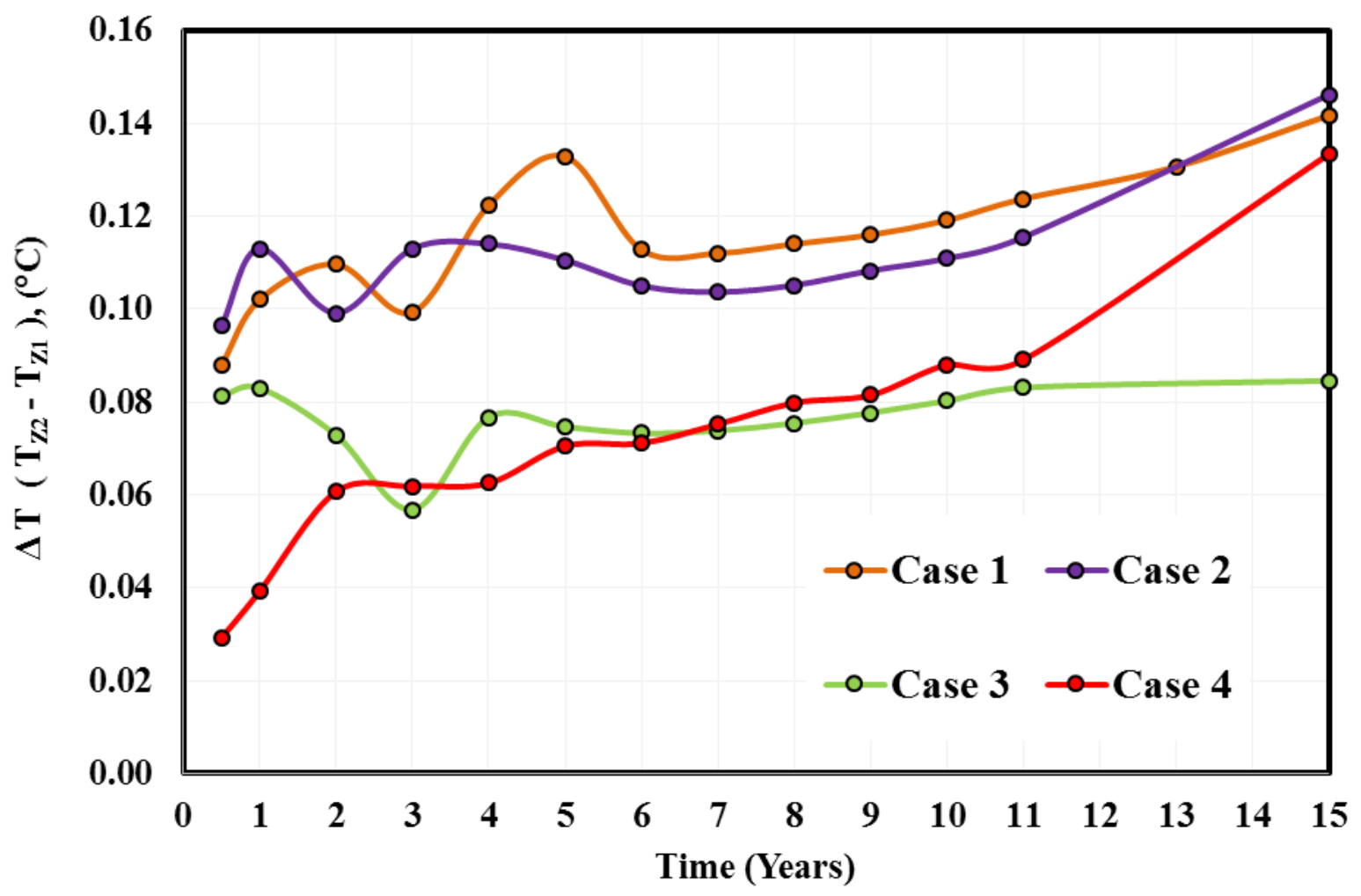

Figure 4-17. Temperature difference between the sub-layers in contact between the methane hydrate-bearing sand and the aquifer during the Stage III for Cases 1-4. Where $\mathrm{T}_{\mathrm{Z} 2}$ and $\mathrm{T}_{\mathrm{Z} 1}$ refers to the temperatures of the bottom sub-layer of the methane hydrate-bearing sand in contact with the top sub-layer of the underlying aquifer, respectively.

Figure 4-18 displays $\mathrm{CO}_{2}$ hydrate evolution process in the sublayers (which are designated as $\mathrm{J}$ to $\mathrm{P}$, sub-layer $\mathrm{J}$ refers to the top one, which is in contact with the methane hydrate-bearing sand, followed by $\mathrm{K}$ to $\mathrm{P}$, with $\mathrm{P}$ being the bottommost layer in contact with underburden shale) present in the aquifer. The temperature gradient profile (Figure 4-17) corresponds to the evolution of $\mathrm{CO}_{2}$ hydrate saturation in the various sub-layers of the aquifer (Figure 4-18) at different time periods. As the Stage III commences, the top and the bottommost sub-layers ( $\mathrm{J}$ and P layers) of the aquifer are the first - where hydrate saturation raises to $>0.9$. The heat of formation generated in the top layer ( $\mathrm{J}$ Layer) is the major contributor for the rise in the heat flux as seen in the Figure 4-16. The first peak value in the heat flux profile (Figure 4-16) is reached when in this top sub-layer and in 
the next $\mathrm{K}$ sub-layer $\mathrm{CO}_{2}$-hydrate saturation is increased up to its maximum values $(\sim 0.95)$ as shown in Figure 4-18. After this time period, the heat of formation generated from rest of the sublayers of the aquifer with forming $\mathrm{CO}_{2}$ hydrate is not sufficient to maintain the same temperature gradient, which starts decreasing as seen in the Figure 4-17 and results in a drop of heat flux as well (Figure 4-16). That can be attributed to a low thermal conductivity of $\mathrm{CO}_{2}$ hydrate-bearing sand that could delay heat flux comparing to surrounding media (shale and water saturated sand, Table 4-2). Later, the temperature gradient starts to increase when the heat of formation of $\mathrm{CO}_{2}$ hydrate (which is proportional to $\mathrm{CO}_{2}$-hydrate saturation) from the rest of the layers comes into effect (Figure 4-17). The total conversion of $\mathrm{CO}_{2}$ into hydrate coincides with the appearance of the second peak of the heat flux profiles (Figure 4-16) that designates the stoppage of heat generation in the aquifer. After approximately 6 years for all the Cases 1-4, the rate of heat transfer across the boundary starts to increase steadily. 


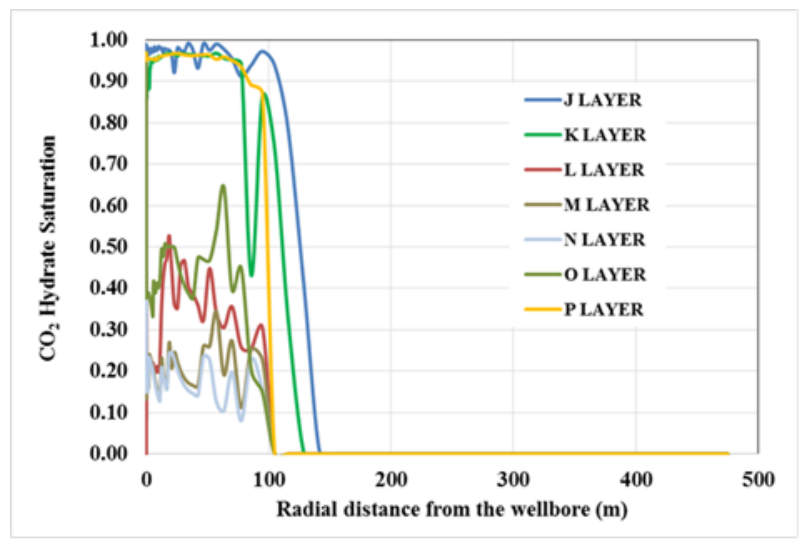

Time $=2$ years

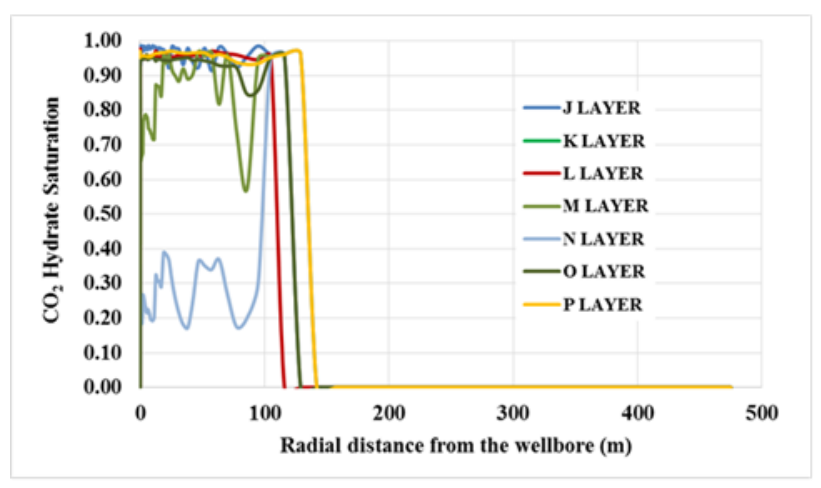

Time $=4$ years

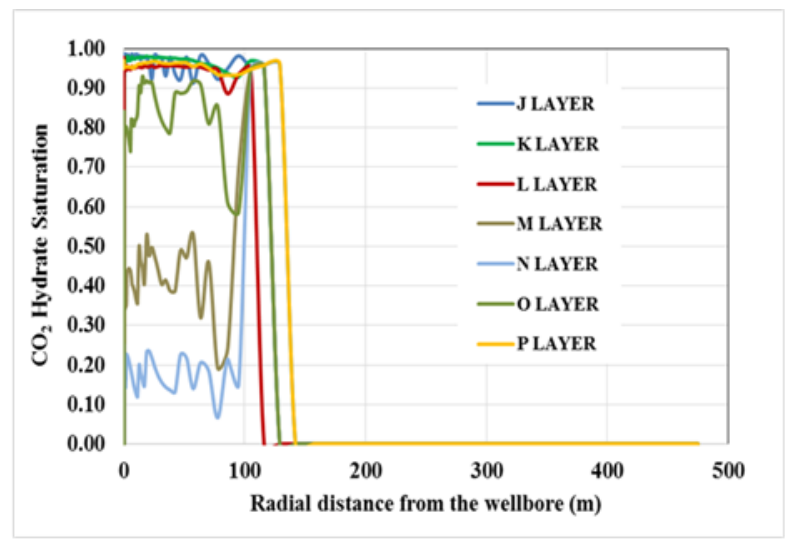

Time $=\mathbf{3}$ years

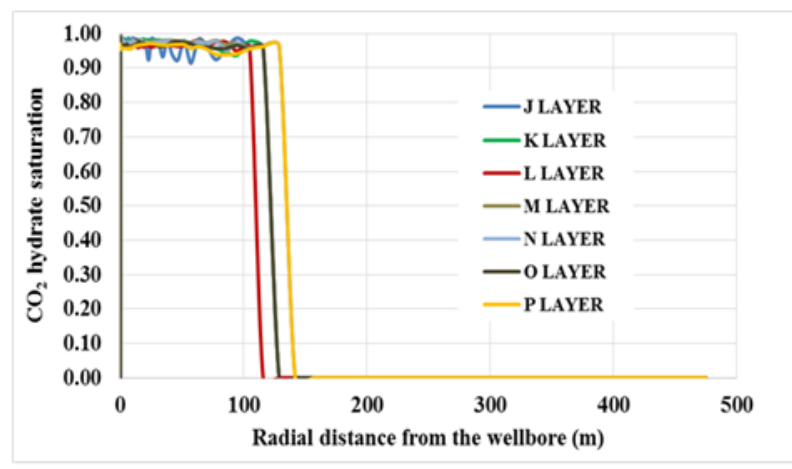

Time $=5$ years

Figure 4-18. Hydrate saturation evolution profiles in the sub-layers present in the aquifer during the Stage III for Cases 2

For the Case 4 due to the presence of high permeable water saturated sand in contact with the methane hydrate formation, the advective heat flux plays a dominant role. This explains the reason for the most intensive increase in the heat flux (Figure 4-16) among all the cases in the later years of production as decomposition of methane hydrate provides effective communication with the aquifer. The other factor contributing for increase in the heat flux is supply from the underburdern as the bottom of the underburden shale is kept at constant boundary conditions mimicking the presence of the underlying strata. 
The evolution of $\mathrm{CO}_{2}$ hydrate saturation and temperature distribution for the most productive case (Case 2) during Stage III at the end of 2, 5, and 15 years of production is shown in Figure 4-19. The distributions show that after 5 years of production the injected $\mathrm{CO}_{2}$ is completely converted into hydrate in the aquifer at hydrate saturation above 0.9 (also seen in Figure 4-19).

\begin{tabular}{|l|l|l|l|l|}
\hline & Hydrate saturation & & Temperature distribution \\
\hline & & & \\
\hline
\end{tabular}




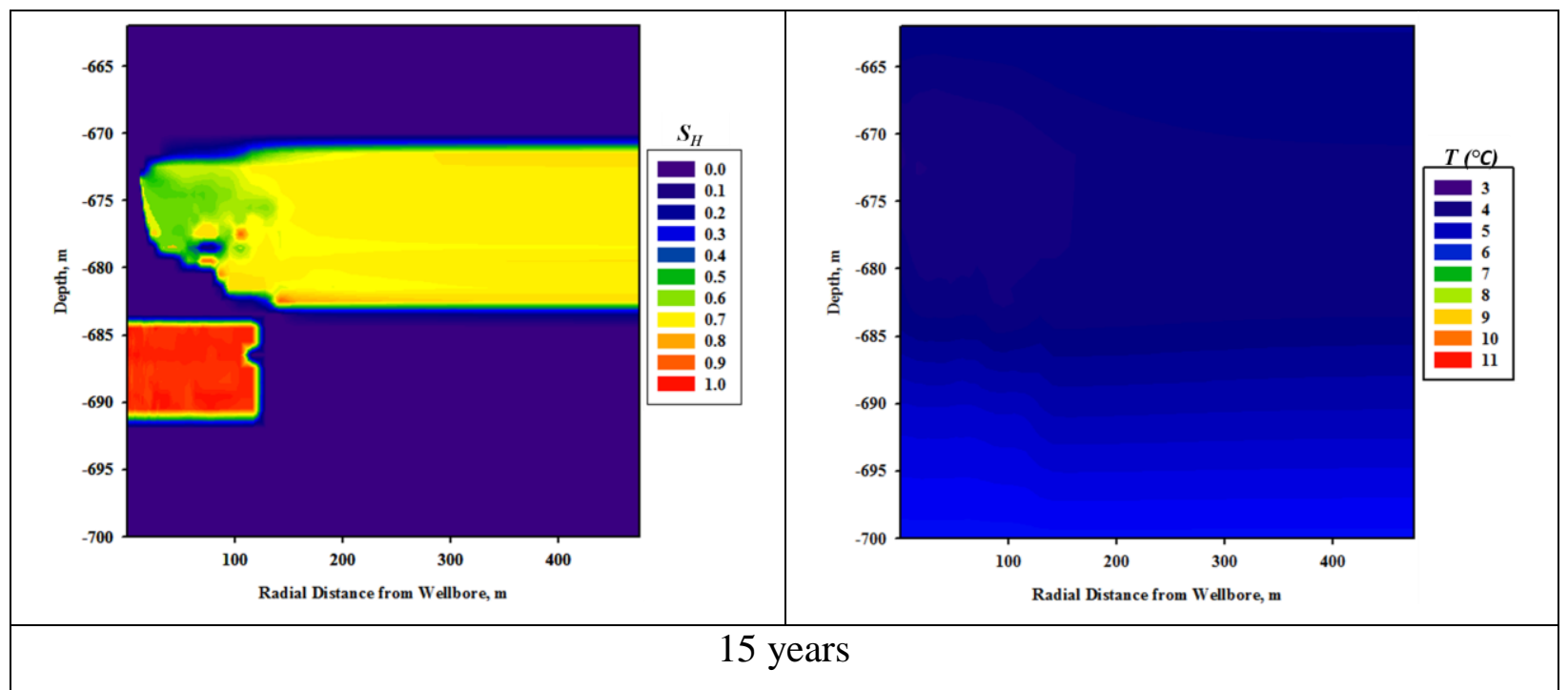

Figure 4-19. Hydrate saturation and temperature distributions in Zones 1 and 2 during Stage III for Case 2.

Figure 4-20 displays cumulative heat flowed from the aquifer into the methane hydrate-bearing sand during Stage III. After 15 years of production the amount of heat transferred across the boundary for Case 2 is higher than that for the base Case 4. Case 4 displays higher cumulative heat flow compared to Case 3 because for Case 3 before the commencement of Stage III the $\mathrm{CO}_{2}$ hydrate-saturation reaches 0.9 leaving lowest concertation of $\mathrm{CO}_{2}$ in the aquifer to maintain the hydrate formation reaction (Table 4-5) during the Stage III (in other words, for the Case 3, since the hydrate saturation is already 0.9 before starting stage III. There is no contribution from hydrate formation heat to the Zone 1$)$ and resulting in very low effective permeability $(<0.001 \mathrm{md})$ for aqueous phase within the first $145 \mathrm{~m}$ form the well bore (the lowest advective heat contribution). 


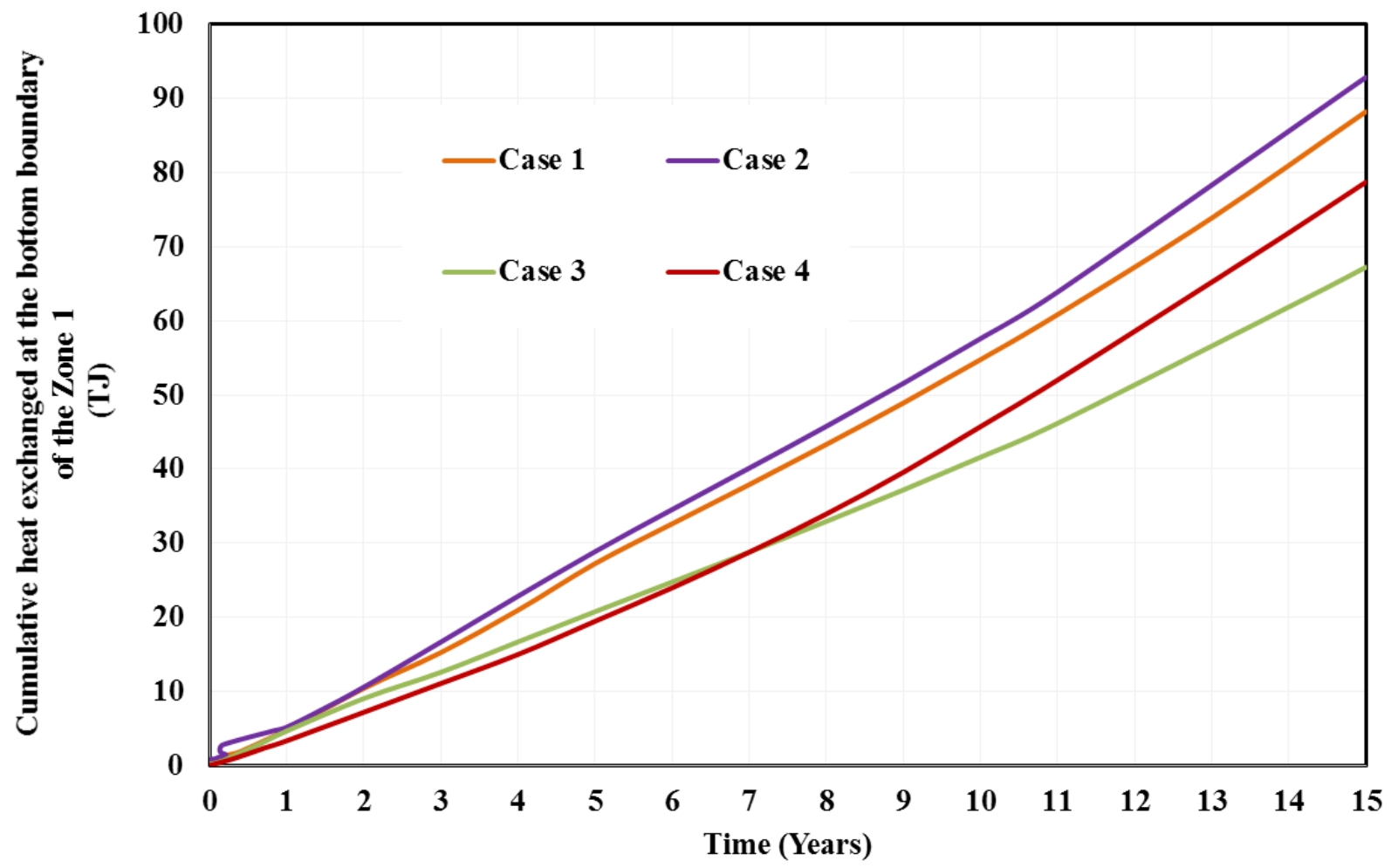

Figure 4-20. Cumulative heat flux across the lower boundary of hydrate zone during the Stage III for Cases 1-4. A positive sign means flow from the aquifer to the methane hydrate-bearing sand

\subsubsection{Effect of reduced water influx from the underlying aquifer to the $\mathrm{CH}_{4}$-hydrate}

\section{formations on gas production}

Apart from the additional heat flux provided to the methane hydrate-bearing sediments, another reason for higher gas production in the Cases 1-3 compared to Case 4 is owed to the lowered water influx from the aquifer underneath the $\mathrm{CH}_{4}$-hydrate formations. As, in the Cases 1-3 the water in the aquifer is trapped in the form of $\mathrm{CO}_{2}$-hydrates and hence increases the relative permeability of gas in the production stream around the wellbore by lowering the competition of water produced from the highly permeable aquifer underlying the methane hydrate deposits and even due to the dissociation of methane hydrates present in the formations. The initial gas production rates (Figure 4-14) for the Cases 1-3 are predominantly higher than the Case 4 which is due to their higher initial temperature of the methane hydrate formations and the significant lowering of water inflow from 
the aquifer present in contact with the $\mathrm{CH}_{4}$-hydrate sediments, which is achieved by reducing the aquifer permeability. Whereas for the Case 4 , in which the $\mathrm{CH}_{4}$-hydrate bearing sands are in contact with highly permeable water-saturated sand sediments resulted in the release of vast volumes of water immediately as the depressurization of the methane hydrate-bearing sands begins (Figure 4-14). Cumulative volumes of water produced throughout the production period and the corresponding water production rates are depicted in Figure 4-21. The gas produced in the Case 2 is twice higher than the Case 4, but the cumulative volume of the produced water for the Case 2 is nearly same as that of the Case 4 owing to the water released due to the effective dissociation of the hydrates. Whereas for the Case 4, the highest water production is attributed to the presence of a permeable aquifer underneath hydrate formations. This can be supported by the Figure 4-22, which displays the water flux across the bottom boundary of Zone 1. The sharp rise in the water flux across lower boundary for the Case 4 shown in Figure 4-22 proves that during the initial 1 1.5 year of production period, the higher water production rates (Figure 4-21) is primarily attributed to the hydraulic communication with aquifer. Evidently, after a long time period of nearly constant water production (about $1.5 \mathrm{~m}^{3} /$ day) water flux across the boundary starts to increase again as seen in Figure 4-22. This behavior can be explained based on Darcy's law, where the phase flux is proportional to the product of relative permeability of the aqueous phase and pressure gradient. As the $\mathrm{CH}_{4}$-hydrate dissociates, the effective permeability of the formation settings escalates, thus increasing the required driving force (product of effective permeability and pressure gradient) beyond a certain threshold value to boost up the water influx. It is also observed that for the Cases 1-3, the water flux comes only from the region of the aquifer where no $\mathrm{CO}_{2-}$ hydrates are formed (Figure 4-23: only Case 2 and Case 4 are displayed). 


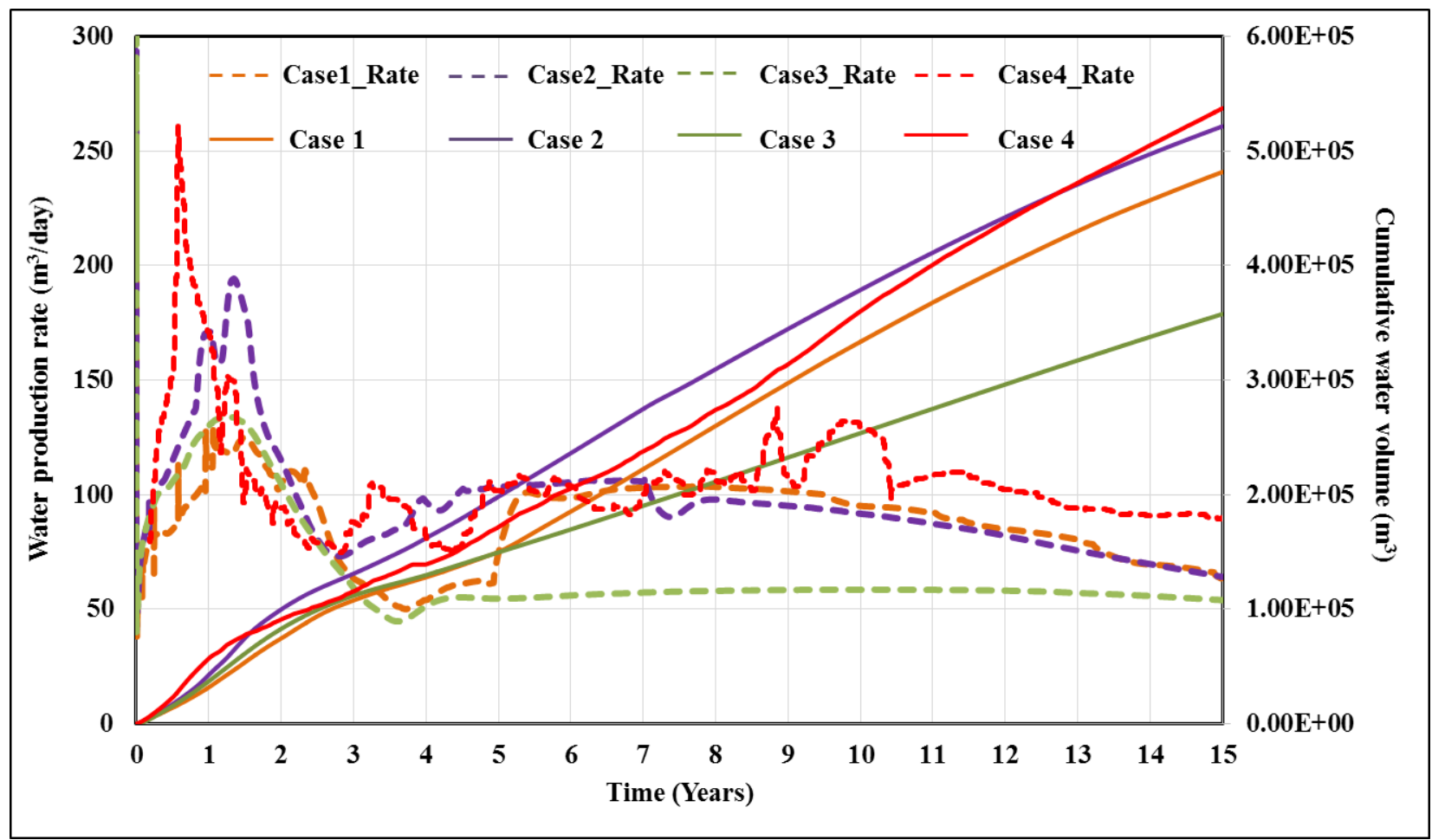

Figure 4-21. Water production rates (dashed lines) and cumulative volume (solid lines) of water produced for Cases 1-4. Time zero designates the onset of Stage III

The ratio of produced water to produced gas is shown in Figure 4-24. It is evident that for the Case 4, the increased water production lowers the volumes of gas produced from the wellbore, thus, leading to very high water-gas ratio in the production stream. Whereas for the rest of the three cases (Cases 1-3), the ratio is very low, implying the increased volume of gas (and significantly lowered volumes of water) in the production stream. 


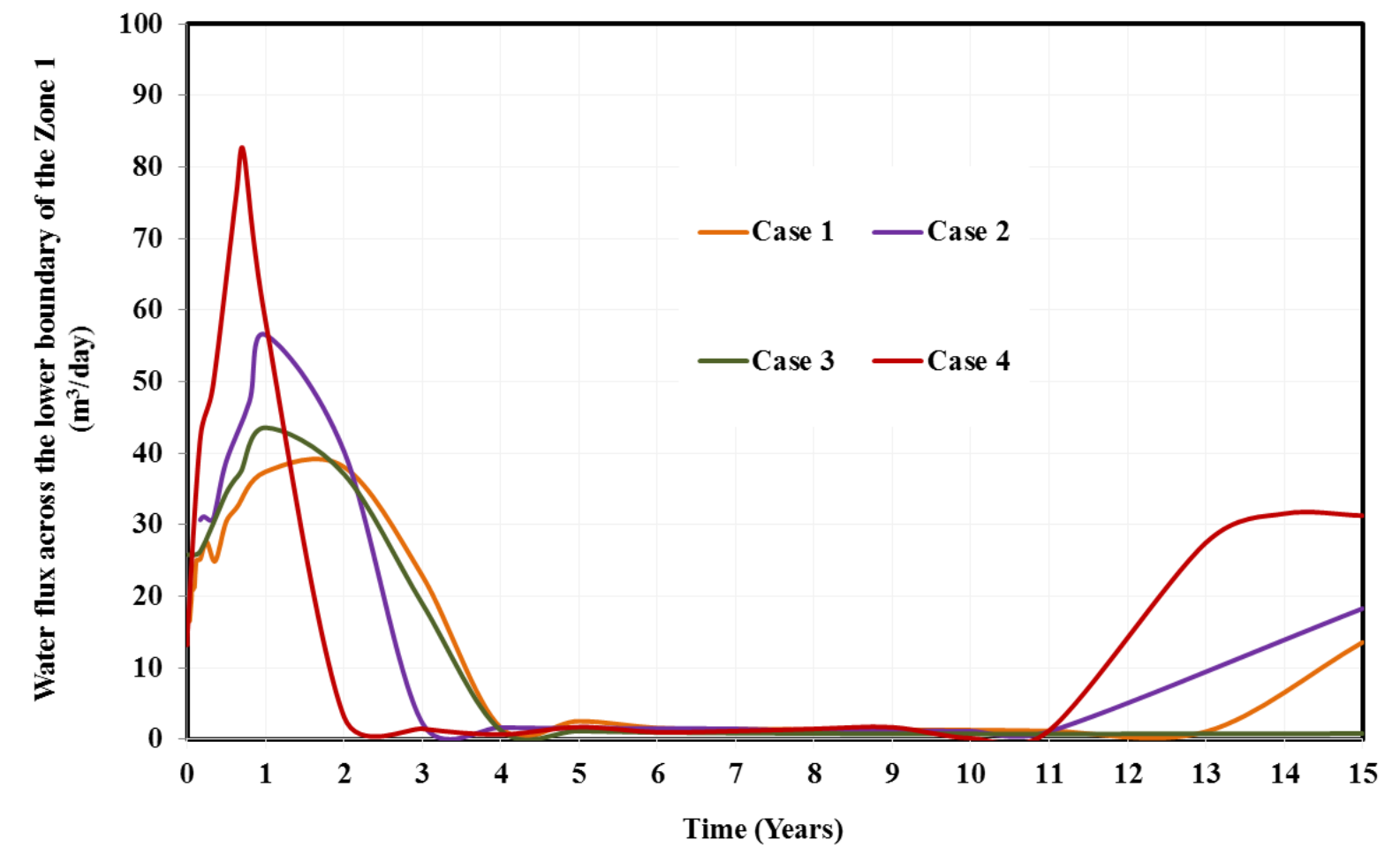

Figure 4-22. Water flux across the lower boundary of hydrate zone during the Stage III for Cases 1-4. A positive sign means flow from the aquifer to methane hydrate-bearing sand.

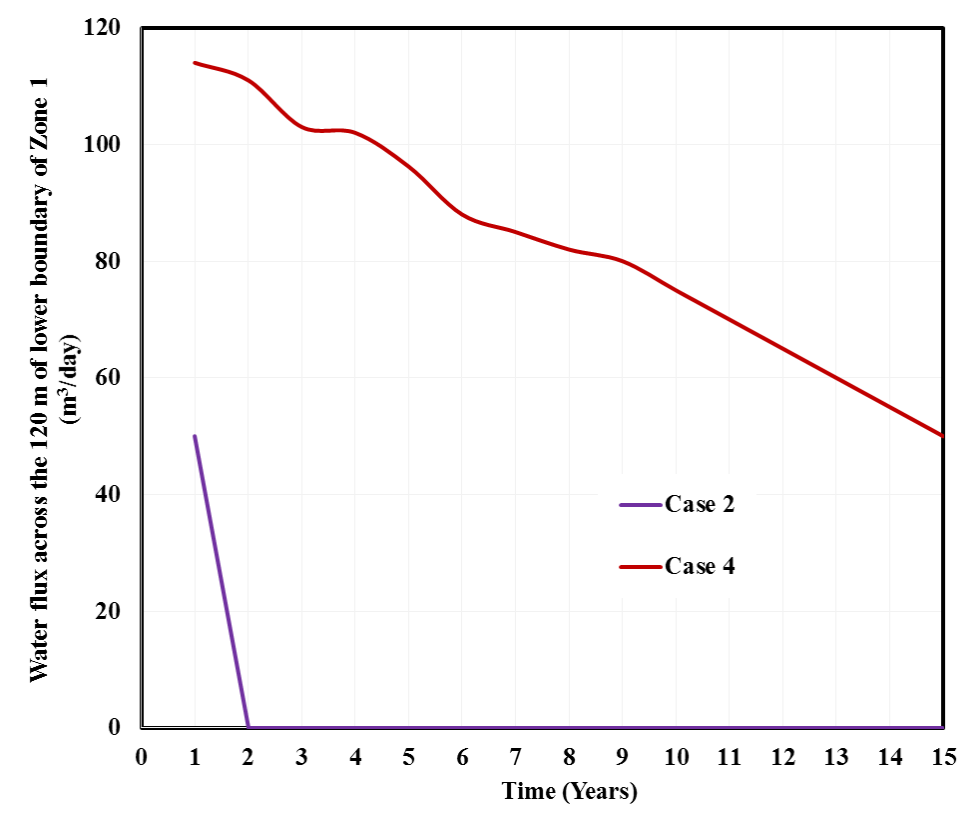

Figure 4-23. Water flux across the first $120 \mathrm{~m}$ of the lower boundary of hydrate zone during the Stage III for Cases 2 and-4. A positive sign means flow from the aquifer to methane hydratebearing sand 


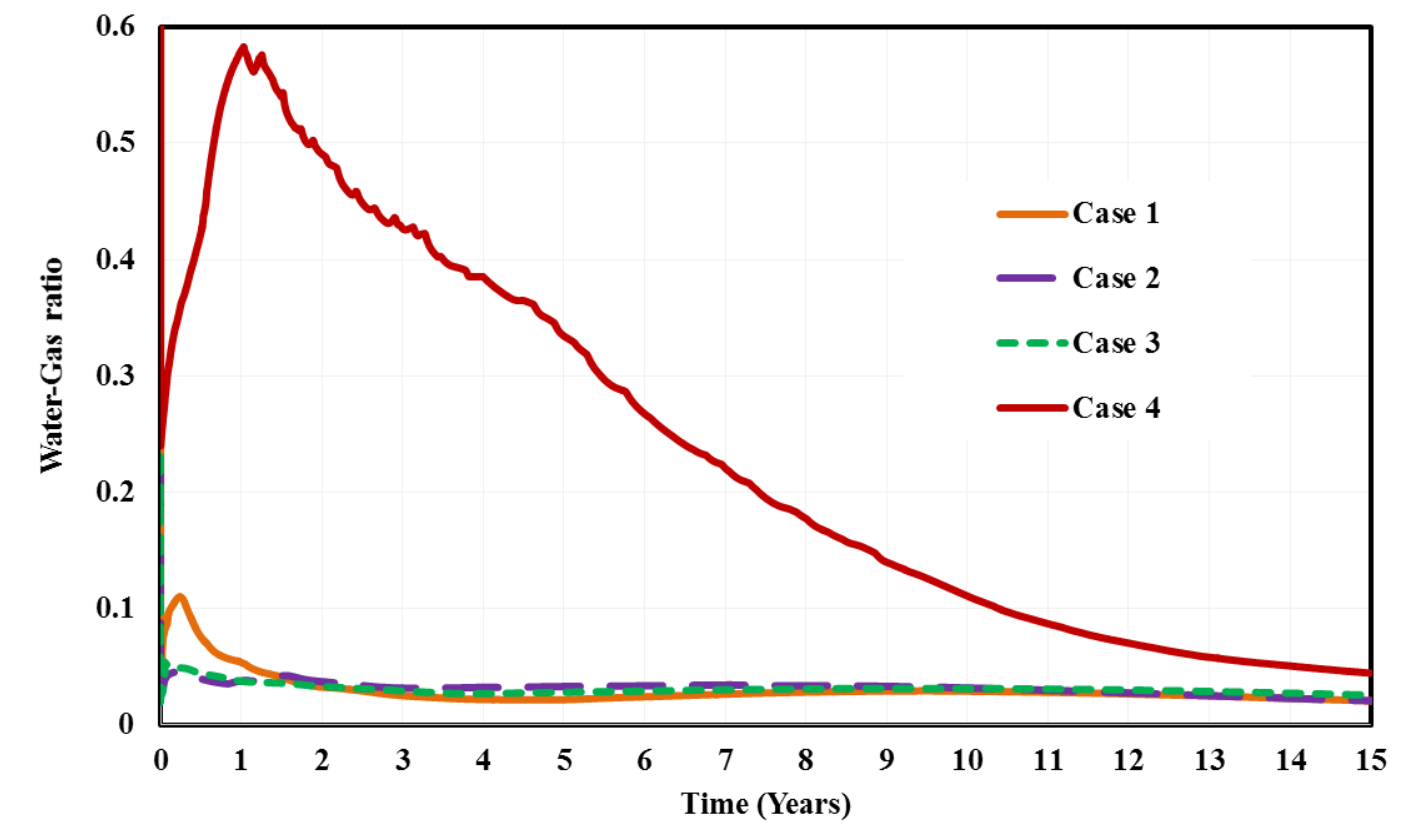

Figure 4-24. Water to gas ratio for all the cases (Cases 1-4)

\subsubsection{Efficient sequestration of injected $\mathrm{CO}_{2}$}

As the contamination of the production stream with $\mathrm{CO}_{2}$ makes the production highly undesirable and raises some serious environmental concerns., the compositions of $\mathrm{CH}_{4}$ and $\mathrm{CO}_{2}$ in the produced gas are constantly supervised all throughout the 15 years of the Stage III (production phase) to ensure the quality of produced methane gas. For the most favorable Cases $(1 \& 2)$, as the $\mathrm{CO}_{2}$ isn't completely converted to $\mathrm{CO}_{2}$-hydrate in the aquifer lying underneath the $\mathrm{CH}_{4}$ hydrate formations, it's possible for $\mathrm{CO}_{2}$ breakthrough in the production stream. Figure 4-25 shows the cumulative amounts of $\mathrm{CO}_{2}$ and $\mathrm{CH}_{4}$ produced during the Stage III. From the Figure 4-25, it's evident that Case 3, characterized by the highest $\mathrm{CO}_{2}$ hydrate saturation of 0.9 in the aquifer at the boundary with the $\mathrm{CH}_{4}$-hydrate formations records the lowest volume of $\mathrm{CO}_{2}$ release in the production stream. Whereas, Case 1 displays the highest cumulative volume of $\mathrm{CO}_{2}$ in the 
production stream, due to it's lowest $\mathrm{CO}_{2}$ hydrate emergence in the aquifer within the spread of $\mathrm{CO}_{2}$ plume. Compared to the total methane volumes the contribution of $\mathrm{CO}_{2}$ in the production stream is negligible. For Cases $1-3$ it is estimated to be $0.02-0.04 \%$ on volume basis. In respect of the total injected $\mathrm{CO}_{2}\left(82 \times 10^{3} \mathrm{ST} \mathrm{m} /\right.$ day $\times 145$ days $\left.=1.189 \times 10^{7} \mathrm{ST} \mathrm{m}^{3}\right)$ the amounts of $\mathrm{CO}_{2}$ leakage into the producing stream are $0.07 \%$ (Case 1), $0.05 \%$ (Case 2), $0.02 \%$ (Case 3) on volume basis.

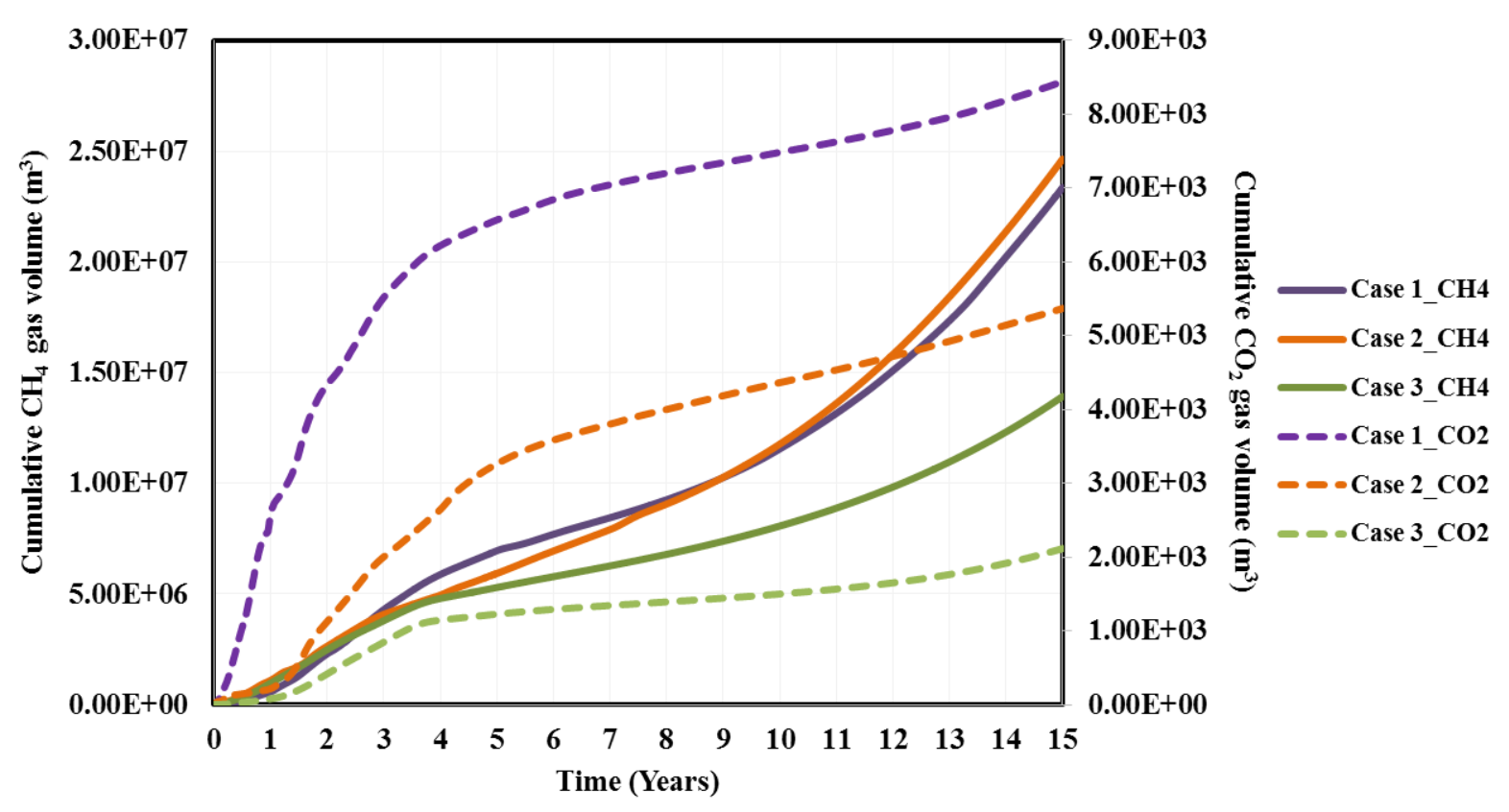

Figure 4-25. Cumulative volumes of $\mathrm{CH}_{4}$ (Solid line) and $\mathrm{CO}_{2}$ (dashed line) for Cases 1-3 in the production stream. 


\subsubsection{Enhanced gas recovery from $\mathrm{CH}_{4}$-hydrate accumulations}

The supply of additional heat flux to the $\mathrm{CH}_{4}$-hydrate accumulations increases the temperature of the methane bearing sand formations. Hence, the warmer formations generate more sensible heat for methane hydrate decomposition. The ratio of sensible heat to heat of methane hydrate decomposition is called as Stefan number (Ste) ${ }^{[42]}$. It is often used to quantify the maximum heat recovered from natural gas hydrate accumulations under adiabatic conditions. Stefan number is calculated based on the Equation 2, where $T_{i}$ is the averaged initial temperatures of the methane hydrate-bearing sand before the commencement of Stage III. Table 4-6 lists out the physical parameters used for the calculation of stefan numbers for all the four cases.

Ste $=\rho C_{\mathrm{p}} \Delta \mathrm{T} / \rho_{\mathrm{H}} \mathrm{S}_{\mathrm{H}} \varphi \Delta \mathrm{H}$ where $\Delta \mathrm{T}=\mathrm{T}_{\mathrm{i}}-\mathrm{T}_{\mathrm{eq}}\left(\mathrm{P}_{0}\right)$

Table 4-6. Physical parameters and initial conditions used in the calculation of Stefan number

\begin{tabular}{|l|l|}
\hline Density of rock $(\rho), \mathrm{kg} / \mathrm{m}^{3}$ & 2600 \\
\hline Density of hydrate $\left(\rho_{H}\right) \mathrm{kg} / \mathrm{m}^{3}$ & 949.6 \\
\hline Specific heat of rock $\left(C_{p}\right) \mathrm{J} / \mathrm{kg}^{\circ} \mathrm{C}$ & 1000 \\
\hline Initial hydrate saturation $\left(S_{H}\right)$ & 0.7 \\
\hline Porosity $(\varphi)$ & 0.35 \\
\hline Heat of decomposition $(\Delta H), \mathrm{J} / \mathrm{kg}$ & 477,000 \\
\hline $\begin{array}{l}\text { Equilibrium temperature when } \\
\text { pressure is set at } 3.5 \mathrm{MPa}, T_{e q}\left(P_{0}\right) \\
\left({ }^{\circ} \mathrm{C}\right)\end{array}$ & 3.06 \\
\hline
\end{tabular}

Table 4-7 tabulates the calculated Stefan numbers using averaged initial temperatures in the methane hydrate-bearing sand before the commencement of Stage III. The increase of the average 
temperature from $\sim 5.0^{\circ} \mathrm{C}$ (Case 4 ) to $7.3-7.5^{\circ} \mathrm{C}$ (Cases 1-3) corresponds to increase in the theoretical recovery from $4.4 \%$ to $\sim 10.0 \%$.

Table 4-7. Stefan numbers for Cases 1-4

\begin{tabular}{|l|l|l|}
\hline Case & $\begin{array}{l}\text { Initial } \\
\text { temperature in } \mathrm{CH}_{4} \\
\text { hydrate-bearing sand } \\
\text { before Stage III }\left(\mathrm{T}_{\mathrm{i}}\right)\end{array}$ & Stefan number (Ste) \\
\hline Case 1 & 7.28 & 0.103 \\
\hline Case 2 & 7.43 & 0.102 \\
\hline Case 3 & 7.47 & 0.099 \\
\hline Case 4 & 4.97 & 0.044 \\
\hline
\end{tabular}

Gas hydrate recovery is the ratio of total volume of methane produced to the total volume of methane stored in a reservoir in a form of hydrate. Gas hydrate recovery is often considered as measure for reservoir performance. Table 4-8 lists out the calculated recovery factors and the best producing Case 2 resulted in a recovery factor 2 times more compared to the base case (Case 4 ).

Table 4-8. Total amount of $\mathrm{CH}_{4}$ stored in the reservoir, cumulative volumes of $\mathrm{CH}_{4}$ produced, and recovery factors for Cases 1-4

\begin{tabular}{|l|l|l|l|}
\hline & $\begin{array}{l}\text { Total amount of } \mathrm{CH}_{4}(\text { as } \\
\text { hydrate) initially present in } \\
\text { the reservoir }\left(\mathrm{m}^{3}\right)\end{array}$ & $\begin{array}{l}\text { Total amount of } \mathrm{CH}_{4} \text { produced at } \\
\text { the end of 15 years of } \\
\text { depressurization }\left(\mathrm{m}^{3}\right)\end{array}$ & $\begin{array}{l}\text { Recovery Factor } \\
(\%)\end{array}$ \\
\hline Case 1 & $4.55 \mathrm{E}+08$ & $2.34 \mathrm{E}+07$ & 5.14 \\
\hline Case 2 & $4.55 \mathrm{E}+08$ & $2.46 \mathrm{E}+07$ & 5.42 \\
\hline Case 3 & $4.55 \mathrm{E}+08$ & $1.39 \mathrm{E}+07$ & 3.06 \\
\hline Case 4 & $4.55 \mathrm{E}+08$ & $1.21 \mathrm{E}+07$ & 2.66 \\
\hline
\end{tabular}




\subsection{Conclusion}

One of the efficient ways to cap down the composition of $\mathrm{CO}_{2}$ in the greenhouse gases present in the atmosphere is Carbon Capture and Sequestration (CCS), which is being widely investigated in the recent times. The gas recovery technique employed in this work utilized pure $\mathrm{CO}_{2}$ as the working fluid and incorporated a novel technique to permanently sequestrate the $\mathrm{CO}_{2}$ underground in one of its most stable forms $\left(\mathrm{CO}_{2}\right.$-hydrates/ $\mathrm{CH}_{4}-\mathrm{CO}_{2}$-hydrates $)$. The approach consisted of three stages which are employed to enhance the decomposition of the clathrated hydrates present in the geological settings of Class 2 natural gas hydrate accumulations.

The Stage I of the technological approach which is injection of pure $\mathrm{CO}_{2}$ into the aquifer of the Class 2 hydrate accumulations at fluid temperatures greater than $\mathrm{CO}_{2}$-hydrate equilibrium temperatures (pertaining to respective reservoir pressure) assisted in extended radial propagation of gas plume by preventing the wellbore plugging. For Stage II, which follows the Stage I, it is evident that the duration of Stage II is necessary in maximizing the cumulative gas production volumes. It's a tradeoff between maximum utilization of the additional heat flux released in the Stages I \& II and successful sequestration of the $\mathrm{CO}_{2}$ as stable hydrate (reaching to a minimal hydrate saturation value), to prevent the contamination of the production stream during the flowback stage (Stage III). From the three different cases considered, it can be inferred that Case 2, for which the average $\mathrm{CO}_{2}$-hydrate saturation is lower than Case 3 (owed to its smaller Stage II duration than Case 3) resulted in higher gas production volumes due to the higher heat retention in the underlying aquifer before the commencement of Stage III. The lowering of aquifer permeability resulted in substantial rise of initial gas production rates in all the Cases 1-3 compared to conventional Class 2 reservoir (Case 4). For Case 4, the highly permeable water-saturated sands 
present underneath the $\mathrm{CH}_{4}$ hydrate formations increased the relative permeability of the water in the production stream at the wellbore, thus lowering the gas production rates.

Commencement of Stage III beholds the advantages of additional heat flux released in the prior two stages and the lowering of aquifer permeability, hence provides a proliferated impact on decomposition of the $\mathrm{CH}_{4}$-hydrates. The gaseous $\mathrm{CO}_{2}$ compositions present in the production stream are monitored throughout the Stage III and from the obtained fractional composition values of $\mathrm{CO}_{2}$ in the production stream, it can be concluded that if the average $\mathrm{CO}_{2}$-hydrate saturation is around 0.7 (Case 1), it suffices the criterion of successful $\mathrm{CO}_{2}$ sequestration, since the production stream observes less than $0.2 \%$ of $\mathrm{CO}_{2}$ composition, which is nearly negligible.

The overall conclusion from this study is that the issue of vast production of water during the exploitation of Class 2 accumulations can be handled efficiently, owing to the virtue of $\mathrm{CO}_{2}$ forming extremely stable hydrates. This technique also ensures in maintaining the geological stability intact during the exploitation of Class 2 hydrate reserves. As this method encompasses the benefits of in-situ thermal stimulation in conjunction with depressurization it ensures the substantial decomposition of the methane hydrates, thus significantly increasing the gas production rates. This study proposed a novel technical approach which utilized an efficient heat transfer mechanisms released by various thermodynamic processes taking place within the reservoir during all the three stages of the production technique. Most of all, the production technique proposed in this work successfully captures and sequesters $\mathrm{CO}_{2}$, thus addressing one of the major environmental concerns. 


\section{Overall conclusions and recommendations}

\subsection{Conclusions}

The overall goal of this work was to enhance the methane gas production from natural gas hydrate accumulations (exclusively Class 2 deposits) by utilizing the $\mathrm{CO}_{2}$ assisted production technique. As a start off, a suite of numerical simulation scenarios featuring the complexities of the mixed hydrate reservoirs were considered to understand the underlying changes in physical, thermodynamic and transport properties with change in pressure and temperature due to the presence of the simple $\mathrm{CO}_{2}$-hydrate and mixed hydrates (mainly $\mathrm{CH}_{4}-\mathrm{CO}_{2}$ hydrate and $\mathrm{CH}_{4}-\mathrm{CO}_{2}-$ $\mathrm{N}_{2}$ hydrate) in the porous geologic media. This suite of simulations encompassed seven different problems with varied complexity. Problems $1 \& 2$ dealt with the $\mathrm{CO}_{2}$-hydrate formation and dissociation respectively. Problem 2 primarily focused on production techniques (depressurization and thermal stimulation) to recover gas from $\mathrm{CO}_{2}$ hydrate reservoir settings. Problem 3 and 4 was modeled to study the dissociation behavior of $\mathrm{CH}_{4}-\mathrm{CO}_{2}$-hydrates present in a reservoir by employing two different production techniques (depressurization and thermal stimulation). Then Problems 5 \& 6 discussed the behavior of $\mathrm{CH}_{4}-\mathrm{CO}_{2}-\mathrm{N}_{2}$ hydrates in the reservoir. Finally, Problem 7 studied the $\mathrm{CO}_{2}$ injection and simultaneous depressurization of a natural gas hydrate reservoir by considering a five-spot well model.

Followed by these problem suite simulations, the subsequent work focused on employing a technological approach which consisted of three stages performed on geological settings of permafrost-associated Class 2 natural gas hydrate accumulations. The approach used one-well design, which serves as an injector in the first stage and as a producer in the third stage. During the Stage I, the $\mathrm{CO}_{2}$ was injected using constant flow rate of 162 metric ton/day $\left(82 \times 10^{3} \mathrm{ST}\right.$ $\mathrm{m}^{3} /$ day) and with the specific enthalpy of $-252.5 \mathrm{~kJ} / \mathrm{kg}$ (appr. $13^{\circ} \mathrm{C}$ ) into the mobile aqueous phase 
and the $\mathrm{CO}_{2}$ plume propagation was allowed till the traces of $\mathrm{CO}_{2}$ hydrate were observed at the advancing front of $\mathrm{CO}_{2}$ propagation. During Stage II, the initiation and evolution of the $\mathrm{CO}_{2}$ hydrate is observed in the reservoir, when the $P$ and $T$ conditions eventually reach a favorable regime of the hydrate equilibrium curve. Here, three different cases were considered based on the duration of their equilibrium stages (Stage II). Hence, prior to the commencement of the Stage III, each case has different initial conditions for Stage III due to their different durations of Stage II. Stage III involves the depressurization of the $\mathrm{CH}_{4}$-hydrate bearing deposits and the gas and water production profiles over the 15 year time-period were monitored. The gas production profiles for all the three cases benefits from the additional heat flux and reduced water influx from aquifer to $\mathrm{CH}_{4}$ hydrate formations. Further, the depressurization of conventional Class 2 hydrate accumulations was considered to compare with enhanced gas production predicted by the $\mathrm{CO}_{2-}$ assisted technique due to better water management (all the three cases).

The following conclusions can be drawn from overall thesis:

- The suite of numerical simulations (Problems 1-6) which focused on studying the behavior of simple $\mathrm{CO}_{2}$-hydrate and mixed hydrates (mainly $\mathrm{CH}_{4}-\mathrm{CO}_{2}$ hydrate and $\mathrm{CH}_{4}-\mathrm{CO}_{2}-\mathrm{N}_{2}$ hydrate) reservoirs concluded that the presence of mixed hydrates in the reservoir significantly affects the effective permeability of the reservoir.

- From the results of Problem 7 which studied the $\mathrm{CH}_{4}-\mathrm{CO}_{2}$ swapping, it can be concluded that the process is feasible without any release of additional concomitant water. But injection of pure $\mathrm{CO}_{2}$ leads to the formation of $\mathrm{CO}_{2}$ hydrate (with free water present in the reservoir) around the wellbore, thus effectively blocking the $\mathrm{CO}_{2}$ pathways and preventing further propagation of $\mathrm{CO}_{2}$ into the reservoir. 
- It can be inferred from the three stage technological approach (for enhanced gas production from Class 2 accumulations by utilizing $\mathrm{CO}_{2}$ sequestration) that the enhanced gas recovery, efficient sequestration of injected $\mathrm{CO}_{2}$, and reduced volumes of produced water observed during Stage III are exclusively owed to the durations of Stages I and II. Stage III also enormously benefits from the amount of heat flux brought in during the first two stages.

- The Stage I which involved injection of pure $\mathrm{CO}_{2}$ into the aquifer of the Class 2 hydrate accumulations at fluid temperatures greater than $\mathrm{CO}_{2}$-hydrate equilibrium temperatures (corresponding to the respective reservoir pressure), assisted in easy migration of $\mathrm{CO}_{2}$ plume in the reservoir without posing any issues of wellbore plugging and blocking of $\mathrm{CO}_{2}$ pathways.

- The lowering of effective permeability of aquifer resulted in substantial rise of initial gas production rates (due to lowered water production) in all the Cases 1-3 compared to conventional Class 2 reservoir (Case 4). For Case 4, presence of highly permeable aquifer present in the proximity of $\mathrm{CH}_{4}$ hydrate formations increased the relative permeability of the water in the production stream at the wellbore, thus lowering the gas production rates.

- Decomposition of $\mathrm{CH}_{4}$ hydrates during Stage III is proliferated due to couple of reasons 1) additional heat flux released during first two stages and 2) the lowering of aquifer permeability by the end of Stage II.

- The overall conclusion from this study is that the issue of vast production of water during the exploitation of Class 2 accumulations can be reduced effectively due to the formation of stable immobile $\mathrm{CO}_{2}$ hydrate. The production technique also assists in maintaining the geological stability intact during the exploitation of Class 2 hydrate reserves. 


\subsection{Recommendations}

It is recommended that the future work focuses on the issues listed out below:

- It is recommended to extend the modeling efforts to 3D heterogeneous reservoir models for Class 2 accumulations by incorporating the available well-log data and geological properties of the known Class 2 gas hydrate deposits (either permafrost-associated or marine settings). This would provide more accurate predictions of the reservoir response to injection and subsequent depressurization.

- During Stage I, the $\mathrm{CO}_{2}$ plume propagation was limited by the $\mathrm{CO}_{2}$ hydrate formation at the advancing front of the $\mathrm{CO}_{2}$ plume propagation. Hence, further study is recommended to formulate various methods to extend the $\mathrm{CO}_{2}$ plume penetration in the reservoir, which eventually assists in greater $\mathrm{CO}_{2}$ sequestration.

- This work proposed implementation of a single well, which serves as an injector and later as a producer. Future study on implementation of multiple well configuration (e.g., five spot well design) might result in extended $\mathrm{CO}_{2}$ plume propagation (implies greater $\mathrm{CO}_{2}$ sequestration) and more pronounced gas recovery from Class 2 accumulations owing to maximized heat-influx.

- The Stage II of the production technique which plays a key role in comprehending the dynamics of $\mathrm{CO}_{2}$ hydrate formation has been predicted by using the equilibrium model, which is the only version that can be handled by Mix3HRS simulator. The knowledge of the kinetics of hydrate formation is highly important to make the proposed technological approach more efficient, thus incorporation of the kinetic model to Mix3HRS is recommended for accurate modeling of the hydrate formation reactions. 
- The current version of Mix3HRS can simulate injection of gaseous $\mathrm{CO}_{2}$ alone, so it is recommended to extend the capabilities of Mix3HRS to simulate injection of liquid $\mathrm{CO}_{2}$. This modification of the code can expand the scope of modeling to handle all possible phases of injected $\mathrm{CO}_{2}$ (gaseous, liquid, and supercritical). 


\section{References}

1. EIA, EIA (U.S. Energy Information Administration), International Energy Outlook 2016, Report: DOE/EIA-0484(2016), , 2016.

2. Boatman, M.C. and J. Peterson, Oceanic gas hydrate research and activities review. 2000.

3. Sloan Jr, E.D. and C. Koh, Clathrate hydrates of natural gases. 2007: CRC press.

4. Villard, P., Compt. Rend. 1888: p. 106.

5. Circone, S., S.H. Kirby, and L.A. Stern, Direct measurement of methane hydrate composition along the hydrate equilibrium boundary. The Journal of Physical Chemistry B, 2005. 109(19): p. 9468-9475.

6. Hammerschmidt, E., Formation of gas hydrates in natural gas transmission lines. Industrial \& Engineering Chemistry, 1934. 26(8): p. 851-855.

7. Natural Gas 1998. Energy Information Adminstration, US Separtment of Energy, 1999.9.

8. Krey, V., et al., Gas hydrates: entrance to a methane age or climate threat? Environmental Research Letters, 2009. 4(3): p. 034007.

9. Subramanian, S., et al., Structural transition studies in methane+ ethane hydrates using Raman and NMR. Annals of the New York Academy of Sciences, 2000. 912(1): p. 873886.

10. Perrin, A., O.M. Musa, and J.W. Steed, The chemistry of low dosage clathrate hydrate inhibitors. Chemical society reviews, 2013. 42(5): p. 1996-2015.

11. Kvenvolden, K.A., Gas hydrates-geological perspective and global change. REVIEWS OF GEOPHYSICS-RICHMOND VIRGINIA THEN WASHINGTON-, 1993. 31: p. 173173. 
12. Ruppel, C., Methane hydrates and the future of natural gas. MITEI natural gas Report, supplementary paper on Methane Hydrates, 2011. 4: p. 25.

13. Henninges, J., et al., Temperature field of the Mallik gas hydrate occurrence-implications on phase changes and thermal properties. BULLETIN-GEOLOGICAL SURVEY OF CANADA, 2005. 585: p. 128.

14. Moridis, G.J. and M. Kowalsky, Gas production from unconfined Class 2 oceanic hydrate accumulations, in Economic Geology of Natural Gas Hydrate. 2006, Springer. p. 249-266.

15. Moridis, G. and T. Collett, Strategies for gas production from hydrate accumulations under various geologic conditions. Lawrence Berkeley National Laboratory, 2003.

16. Osadetz, K., et al., Beaufort-Mackenzie Basin: a review of conventional and nonconventional (gas hydrate) petroleum reserves and undiscovered resources. BULLETIN-GEOLOGICAL SURVEY OF CANADA, 2005. 585: p. 81.

17. Makogon, Y.F., Hydrates of hydrocarbons: Pennwell Pub. Comp. Tulsa, Oklahoma, 1997.

18. Moridis, G.J., et al., Numerical studies of gas production from several CH4-hydrate zones at the Mallik Site, Mackenzie Delta, Canada. Lawrence Berkeley National Laboratory, 2002.

19. Moridis, G.J. and M.T. Reagan, Estimating the upper limit of gas production from Class 2 hydrate accumulations in the permafrost: 1. Concepts, system description, and the production base case. Journal of Petroleum Science and Engineering, 2011. 76(3): p. 194204.

20. Ohgaki, K., et al., Methane exploitation by carbon dioxide from gas hydrates. Phase equilibria for CO2-CH4 mixed hydrate system. Journal of chemical engineering of Japan, 1996. 29(3): p. 478-483. 
21. Nakano, S., K. Yamamoto, and K. Ohgaki, Natural gas exploitation by carbon dioxide from gas hydrate fields-high-pressure phase equilibrium for an ethane hydrate system. Proceedings of the Institution of Mechanical Engineers, Part A: Journal of Power and Energy, 1998. 212(3): p. 159-163.

22. Hirohama, S., et al., Conversion of CH4-hydrate to CO2-hydrate in liquid CO2. Journal of Chemical Engineering of Japan, 1996. 29(6): p. 1014-1020.

23. Smith, D.H., K. Seshadri, and J.W. Wilder. Assessing the thermodynamic feasibility of the conversion of methane hydrate into carbon dioxide hydrate in porous media. in First National Conference on Carbon Sequestration. 2001.

24. Uchida, T., et al. Replacing methane with $\mathrm{CO} 2$ in clathrate hydrate: observations using Raman spectroscopy. in Proceedings of the fifth international conference on greenhouse gas control technologies. 2001. CSIRO Publishing: Collingwood, Australia.

25. McGrail, B., et al., A new method for enhanced production of gas hydrates with CO2. Gas hydrates: energy resource potential and associated geologic hazards, 2004: p. 12-16.

26. Lee, H., et al., Recovering methane from solid methane hydrate with carbon dioxide. Angewandte Chemie International Edition, 2003. 42(41): p. 5048-5051.

27. Park, Y., et al., Sequestering carbon dioxide into complex structures of naturally occurring gas hydrates. Proceedings of the National Academy of Sciences, 2006. 103(34): p. 1269012694.

28. Garapati, N., Reservoir Simulation for Production of CH4 from Gas Hydrate Reservoirs Using CO2/CO2 + N2 by HydrateResSim. 2013: WEST VIRGINIA UNIVERSITY.

29. M.D.White, M.O., STOMP subsurface transport over multiple phases, version 4.0, user's guide. PNNL-15782. June 2006, Pacific Northwest National Laboratory: Richland, WA. 
30. Ors, O. and C. Sinayuc, An experimental study on the CO 2-CH 4 swap process between gaseous $\mathrm{CO} 2$ and $\mathrm{CH} 4$ hydrate in porous media. Journal of Petroleum Science and Engineering, 2014. 119: p. 156-162.

31. Adisasmito, S., R.J. Frank III, and E.D. Sloan Jr, Hydrates of carbon dioxide and methane mixtures. Journal of Chemical and Engineering Data, 1991. 36(1): p. 68-71.

32. Jung, J. and J.C. Santamarina, CH4-CO2 replacement in hydrate-bearing sediments: A pore-scale study. Geochemistry, Geophysics, Geosystems, 2010. 11(12).

33. Kang, S.-P., M.-K. Chun, and H. Lee, Phase equilibria of methane and carbon dioxide hydrates in the aqueous $\mathrm{MgCl} 2$ solutions. Fluid Phase Equilibria, 1998. 147(1): p. 229238.

34. Anderson, B., et al. Review of the Findings of the Ignik Sikumi CO2-CH4 gas Hydrate Exchange Field Trial. in Proceedings of the 8th International Conference on Gas Hydrates (ICGH8-2014), July. 2014.

35. Collett, T.S. and M.W. Lee, Well $\log$ characterization of natural gas-hydrates. Petrophysics, 2012. 53(05): p. 348-367.

36. Dallimore, S., et al., Scientific results from the Mallik 2002 gas hydrate production research well program, Mackenzie Delta, northwest territories, Canada: Preface. Bulletin of the Geological Survey of Canada, 2005(585).

37. Moridis, G.J. and M.T. Reagan. Gas production from class 2 hydrate accumulations in the permafrost. in SPE Annual Technical Conference and Exhibition. 2007. Society of Petroleum Engineers.

38. Moridis, G. Numerical simulation studies of thermally-induced gas production from hydrate accumulations with no free gas zones at the Mallik site, Mackenzie Delta, Canada. 
in SPE Asia Pacific Oil and Gas Conference and Exhibition. 2002. Society of Petroleum Engineers.

39. Ajayi, T., Advanced Reservoir Modeling and Fluid Flow Studies of Natural Gas Production from the Hydrate Reservoirs of the Alaska North Slope. 2016.

40. CMG., Advanced Processes \& Thermal Reservoir Simulator (STARS) User's Guide. 2014

Calgary, Alberta Canada: Computer Modelling Group Ltd.

41. Moridis, G., M. Kowalsky, and K. Pruess, HydrateResSim Users Manual: A Numerical Simulator for Modeling the Behavior of Hydrates in Geologic Media. Contract No. DEAC03-76SF00098. Department of Energy, Lawrence Berkeley National Laboratory, Berkeley, CA, 2005.

42. Kurihara, M., et al., Assessment of gas productivity of natural methane hydrates using MH21 Reservoir Simulator. Natural Gas Hydrates: Energy Resource Potential and Associated Geologic Hazards, Vancouver, BC, Canada, 2004.

43. Moridis, G., M. Kowalsky, and K. Pruess, ToughpHydrate v1. 0 User's Manual: A Code for the Simulation of System Behavior in Hydrate-Bearing Geologic Media. Earth Sciences Division, Lawrence Berkeley National Laboratory. University of California, Berkeley, California, 2008.

44. Anderson, B.J., et al., Application of the cell potential method to predict phase equilibria of multicomponent gas hydrate systems. The Journal of Physical Chemistry B, 2005. 109(16): p. 8153-8163.

45. Gaddipati, M., Code Comparison of Methane Hydrate Reservoir Simulators using CMG STARS, 2008. West Virginia University.

46. laboratory, N.E.T., 2008. 
47. Koide, H., et al., Hydrate formation in sediments in the sub-seabed disposal of CO2. Energy, 1997. 22(2-3): p. 279-283.

48. Van Genuchten, M.T., A closed-form equation for predicting the hydraulic conductivity of unsaturated soils. Soil science society of America journal, 1980. 44(5): p. 892-898.

49. Stone, H.L., Probability model for estimating three-phase relative permeability. Journal of Petroleum Technology, 1970. 22(02): p. 214-218.

50. Mahabadi, N., et al. Water Retention Curve and Relative Permeability for Gas Production from Hydrate-Bearing Sediments. in AGU Fall Meeting Abstracts. 2014.

51. Carroll, J.J., J.D. Slupsky, and A.E. Mather, The solubility of carbon dioxide in water at low pressure. Journal of Physical and Chemical Reference Data, 1991. 20(6): p. 12011209.

52. Anderson, G.K., Enthalpy of dissociation and hydration number of carbon dioxide hydrate from the Clapeyron equation. The Journal of Chemical Thermodynamics, 2003. 35(7): p. 1171-1183.

53. White, M.D. and B.P. McGrail. Numerical simulation of methane hydrate production from geologic formations via carbon dioxide injection. in Offshore Technology Conference. 2008. Offshore Technology Conference.

54. Anderson, G.K., Enthalpy of dissociation and hydration number of methane hydrate from the Clapeyron equation. The Journal of Chemical Thermodynamics, 2004. 36(12): p. 11191127.

55. Join, S., Gridding in reservoir simulation.

56. Anderson, B.J., et al., Regional long-term production modeling from a single well test, Mount Elbert gas hydrate stratigraphic test well, Alaska North slope. Marine and petroleum geology, 2011. 28(2): p. 493-501. 
57. Brooks, R.H. and A.T. Corey, Hydraulic properties of porous media and their relation to drainage design. Transactions of the ASAE, 1964. 7(1): p. 26-0028.

58. Wright, J., S. Dallimore, and F. Nixon, Influences of grain size and salinity on pressuretemperature thresholds for methane hydrate stability in JAPEX/JNOC/GSC Mallik $2 L-38$ gas hydrate research-well sediments. BULLETIN-GEOLOGICAL SURVEY OF CANADA, 1999: p. 229-240.

59. Wiese, B. and S.A. Mathias. Semi-analytical solution for constant pressure injection of CO2 in saline aquifers. in International Conference on Greenhouse Gas Technologies (GHGT), Amsterdam. 2010.

60. Bozzo, A.T., et al., The properties of the hydrates of chlorine and carbon dioxide. Desalination, 1975. 16(3): p. 303-320. 